\title{
Balance hidrológico y flujo de nutrientes asociados al agua en plantaciones de Eucalyptus grandis, en Concordia (Entre Ríos)
}

\section{Ing. Agr. Natalia Tesón}

Trabajo de tesis presentado para optar al grado de Doctor en Ciencias Naturales

Director: Dr. Jorge L. Frangi

Co-Director: Dr. Mario Hernández 


\section{Agradecimientos}

Quiero agradecer mucho a todos quienes colaboraron para que esta tesis pueda llegar a ser. Fundamentalmente a mi Director, el Dr. Jorge Frangi, por ser entusiasta, creativo y colaborador. A la Lic. Mariana Dabadie y al Dr. Víctor Conzonno, por cada análisis químico de aguas. Al Dr. Marcelo Arturi, por su disposición y apoyo en el análisis de los datos.

Al INTA y a los técnicos de INTA, a todos. Especialmente a Diana Díaz por cada gestión. A Darío Kaemena, Diego Moledo, Wilfredo Moledo, Eduardo Almada, Nicolás Alanís y Valentín Eyman quienes me ayudaron con las mediciones, muchas veces poco comunes a su trabajo, como juntar agua después de cada lluvia... y por poner todo su ingenio para armar todo con los caños de PVC, para subir y bajar sensores instalados en lugares insospechados...y por su voluntad para venir cualquier día que se le antojara llover... Gracias!

Al Ing. Agr. Sergio Garrán y a Rubén Garín por los datos meteorológicos, por cada consulta y toda la paciencia, gracias.

Al Ing. Martín Marcó, por permitirme usar sus ensayos y por sus permanentes palabras de aliento.

A la gente del LISEA, Juan Goya, Marcelo Barrera, Corina Graciano, Carolina Pérez y Sara Burns por sus sugerencias, aportes y por el afecto recibido en cada visita.

A María Elena Fernández y Javier Gyenge por su apoyo y generosidad en cada consulta.

A mis hermanos, que adoro. Y a mis padres, por su amor y su ejemplo.

A mi marido Federico y mis hijos, Facundo y Valentina, quienes son el motor de cada día.

Los análisis químicos de suelos utilizados en ésta Tesis fueron realizados en el Laboratorio Químico de Instituto Internacional de Dasonomía Tropical (IITF), en especial por su responsable Mary Jeanne Sánchez, y sus colaboradores Maribelis Santiago y Edwin López, a quienes expreso mi profundo agradecimiento. También al Dr Ariel Lugo Director del IITF (International Institute of Tropical Forestry, USDA-FS, Río Piedras Puerto Rico) quien autorizó esa tarea en el marco del Convenio de Cooperación de largo plazo entre la UNLP, a través del LISEA, y el IITF. 


\section{Resumen}

La conversión de los ecosistemas a sistemas de monocultivo plantea interrogantes vinculados a la pérdida de biodiversidad, la afectación de los ciclos de agua y de nutrientes, cambios en los suelos y otros. En éstos aspectos las plantaciones de eucaliptos han merecido gran atención. El consumo de agua por los eucaliptos es un tema conflictivo en muchos países, particularmente en los lugares donde las precipitaciones son bajas, variables o marcadamente estacionales. Algunos investigadores y ciertos críticos afirman que los eucaliptos producen efectos deletéreos en el balance hidrológico de un área, a través del aumento de las pérdidas gaseosas de agua, el aceleramiento de la erosión superficial, la reducción de la infiltración, la reducción de la capacidad de campo del suelo, y un marcado descenso del nivel de agua del suelo o de los flujos superficiales. Sin embargo, por un lado, pueden existir respuestas no simples para estas afirmaciones y, por otro, en otras situaciones, los eucaliptos favorecen el reclutamiento de especies nativas y su efecto sobre el balance de agua no es notorio. Por ende, las circunstancias de cada plantación serán diferentes y las relaciones entre las plantaciones y su entorno deben ser evaluadas para cada sitio.

En la Provincia de Entre Ríos hay 90048 ha forestadas con eucaliptos, de las cuales el $90 \%$ lo están con Eucalyptus grandis. Estas plantaciones reemplazan comunidades de vegetación natural como los pastizales con isletas de árboles (monte) y el bosque (monte) abierto, como así también a otros usos de la tierra como plantaciones de cítricos, actividades agrícolas y pecuarias. A pesar de la importancia de Eucalyptus grandis, no existen en la zona suficientes estudios hidrológicos y de nutrientes, que permitan una evaluación ecosistémica más o menos integral de lo que ocurre con el balance hídrico, y los ciclos de nutrientes. Investigaciones orientadas al desarrollo de herramientas útiles para el modelado de balances de agua y a la identificación de los aspectos cruciales ligados a las tendencias de cambio en el medio forestado, resultan de interés para evaluar el manejo actual y direccionar la silvicultura de la especie hacia una mayor sustentabilidad ambiental. 
Esta tesis focaliza su interés en aspectos en los que la carencia de información ecológica de interés ecosistémico es mayor (microclima, balance de agua, movimiento de nutrientes con los flujos hídricos, cambios en los suelos debido al cambio en el uso de la tierra) para luego integrarla con información publicada sobre ciclos de nutrientes en la biomasa aérea. El estudio fue realizado en plantaciones de Eucalyptus grandis en la localidad de Concordia, Entre Ríos. Los objetivos del mismo fueron: (1) determinar las características endoclimáticas de una plantación de 11 años y compararlas con los claros circundantes, vincular éstas características con los flujos de agua del rodal; (2) identificar cambios en los suelos como resultado de la conversión de pastizales a plantaciones forestales de Eucalyptus grandis; (3) cuantificar los flujos aéreos del ciclo hidrológico en una plantación de Eucalyptus grandis de edad al turno (11 años) y comparar la trascolación en la plantación de 3 y 11 años; (4) establecer, en base a datos de eventos de lluvia individuales, modelos de regresión entre la precipitación bruta y otras vías de flujo propias del bosque con el fin de evaluar herramientas predictivas de comportamiento hidrológico de la plantación; (5) estimar la demanda evapotranspiratoria en una plantación de Eucalyptus grandis y las consecuencias de las pérdidas gaseosas en el balance de agua bajo el régimen de precipitaciones de la zona; (6) estimar la circulación (aportes, movimientos internos y salidas) de macronutrientes por flujos de agua y ponderar su magnitud en relación a datos disponibles de nutrientes asociados a flujos de la materia seca (biomasa y necromasa); y (7) realizar un modelo de ciclo de nutrientes de la plantación al turno integrando la información obtenida en éste estudio con la existente en la bibliografía para las mismas plantaciones.

Las hipótesis planteadas fueron: (H1) Hipótesis 1: A consecuencia del cambio del tipo de vegetación, en el sitio forestado se produce un endoclima particular y procesos en el suelo que conducen a la pérdida de nutrientes y a la acidificación del mismo. (H2) Las magnitudes de los flujos hídricos en la plantación están directamente relacionados con la magnitud de la precipitación bruta y con la estructura de la plantación; (H3) Como consecuencia de la intercepción de agua por el dosel, del lavado y lixiviado del follaje y del mantillo, la concentración de nutrientes y la abundancia de sustancias orgánicas cromóforas aumenta en la secuencia de eventos de precipitaciones, trascolación, flujo caulinar, escurrimiento. Asimismo la concentración de nutrientes disminuirá con la 
magnitud de los eventos; (H4) Debido a los procesos de descomposición del mantillo hay un aporte de nutrientes en solución que ingresan en el suelo mineral; (H5) La magnitud de la pérdida de nutrientes por escurrimiento es proporcional a la magnitud del evento de Iluvia; (H6) En condiciones ecológicas comparables la eficiencia de uso de agua en la producción de madera de esta especie es similar a la encontrada en otras regiones de cultivo.

Los principales resultados indicaron que al analizar las temperaturas medias mensuales a $1.5 \mathrm{~m}$ se observó que las mismas fueron similares fuera y dentro de la plantación. Cuando la diferencia existe, se producen valores más altos fuera de la plantación. Las mayores diferencias son de hasta $2 \cong \mathrm{C}$. Por otra parte la comparación de la marcha horaria de la temperatura en días despejados y nublados de distintas estaciones del año permitió observar que en los días despejados el calentamiento matutino se inicia antes en el terreno abierto que en el interior de la plantación, lo cual puede deberse al efecto de horizonte que ocasiona la masa forestal. A partir de media mañana las temperaturas interiores y exteriores son muy similares en ambos sitios. No obstante cuando existen diferencias, éstas tienden a manifestarse en las horas de la mañana y cercanas al medio día con valores levemente superiores a favor de los sitios abiertos. En los días con alta nubosidad las temperaturas y la amplitud térmica diaria son más bajas que en días soleados y en general son mayores fuera que dentro de la plantación. Los valores absolutos observados se corresponden con la estación del año. En cuanto a la HR al comparar los valores medios mensuales, a $1.5 \mathrm{~m}$ fuera y dentro de la plantación, se observó la misma tendencia a lo largo del año con valores menores de HR dentro de la plantación (10\% a 15\% menores), las diferencias mayores ocurrieron en el verano. Durante el periodo más lluvioso y húmedo (otoño), la HR de ambos sitios fue similar. Una posible explicación a las diferencias entre la HR del aire en el interior y exterior de la plantación podría ser la diferente cobertura del suelo en los sitios y su efecto sobre las salidas gaseosas de agua desde la superficie del suelo y el estrato inferior.

En cuanto a los suelos comparando los sitios testigos con los lotes forestados se observó una disminución de $\mathrm{pH}$ y de las concentraciones de $\mathrm{C}, \mathrm{N}, \mathrm{Mg}$, Ca y $\mathrm{Mn}$ totales en los sitios forestados. La relación $\mathrm{C} / \mathrm{N}$ aumento en estos últimos y progresó con la edad de la 
plantación. La disminución de Ca en los suelos bajo E. grandis fue notoria en la plantación de mayor edad y en el rango $0-35 \mathrm{~cm}$ de profundidad. Las concentraciones de P y K no variaron entre el pastizal y las plantaciones. Las concentraciones totales de $\mathrm{Fe}$ y $\mathrm{Al}$ tendieron a disminuir en la superficie y a aumentar en profundidad a través del tiempo de reemplazo del pastizal por la plantación. Sin embargo, en las concentraciones como intercambiables los máximos valores se encontraron entre los $5-20 \mathrm{~cm}$ relacionadas a la disminución del pH en los sitios forestados.

Durante los dos periodos del balance hidrológico estudiados (abril 2003-marzo 2004 y abril 2004-marzo 2005) la precipitación anual fue de de $1417 \mathrm{~mm}$ y $1264 \mathrm{~mm}$ respectivamente. Considerando el valor anual promedio de las precipitaciones de la serie histórica 1967-2005, que fue de $1345.3 \pm 287.7 \mathrm{~mm}$, los valores anuales de los dos períodos analizados quedaron comprendidos en el rango del valor medio más/menos un desvío estándar. Las magnitudes de los flujos hídricos aéreos: trascolación, flujo caulinar y escurrimiento superficial representaron el $84 \%$, el $4,5 \%$ y el $6 \%$ de la precipitación bruta (PB) respectivamente. La precipitación neta en los dos períodos evaluados fue de 1265 y $1112 \mathrm{~mm}$ respectivamente. En cuanto a los egresos gaseosos de la plantación (ET), la transpiración fue el principal componente alcanzando el $72 \%$ de la PB, mientras que la intercepción del mantillo y del dosel fueron el 14 y $11 \%$ de la precipitación bruta respectivamente. En síntesis el balance hidrológico fue positivo en los dos años, muy ajustado a las precipitaciones, ya que el cociente ET/PB fue 0.96 y 0.99 para los años evaluados. El agua de percolación que contribuye a las napas subterráneas resulta muy bajo (ca. $2 \%$ de la precipitación bruta).

Para los flujos hídricos aéreos se ajustaron modelos de regresión significativos de cada flujo vs la PB. Para la trascolación vs la PB se encontraron diferencias significativas en las pendientes de las regresiones de la trascolación versus la PB. Las diferencias pueden deberse a cambios en la arquitectura de las copas de los árboles y a la estructura de la plantación.

Para el flujo caulinar se encontró una relación directa de tipo exponencial entre el diámetro de los árboles y el flujo caulinar. Así los árboles más grandes (mayor DAP y área 
basal/individuo) condujeron más agua que los más pequeños, favoreciendo que un mayor volumen de agua llegara al suelo en las inmediaciones de la base de los troncos. Los árboles dominantes y co-dominantes son entonces capaces de captar mayor cantidad y calidad de recursos retroalimentando su posición jerárquica en el rodal.

El año de mediciones del escurrimiento superficial en el pastizal y plantación forestal, permitió ajustar una regresión que vincula los valores del escurrimiento superficial en relación a la precipitación bruta de los eventos de lluvia para cada ecosistema. El volumen de escurrimiento superficial en la plantación resultó un $80 \%$ menor que el registrado para el pastizal.

El aporte de nutrientes desde la atmósfera fue bajo para los nutrientes más críticos como el nitrógeno (3\% de la absorción anual) y el fósforo ( $7 \%$ de la absorción anual). Sin embargo, el menor aporte de la precipitación neta respecto de la precipitación bruta en el balance anual manifiesta que existió absorción de estos nutrientes por el dosel arbóreo. El $C$ (carbono orgánico disuelto $=C O D$ ) fue el nutriente de mayor magnitud disuelto en los flujos hídricos. Los ácidos orgánicos podrían ser en parte responsables de la disminución del $\mathrm{pH}$ en el suelo en los horizontes superiores. Para el potasio y el magnesio existió un aporte importante con la precipitación bruta (17\% y $19 \%$ de la absorción anual). Para el K, Ca y Mg existió un enriquecimiento en los flujos en la secuencia precipitación, trascolación y flujo caulinar. Para estos cationes y para el COD hubo un aporte al suelo mineral con el lixiviado del mantillo, mientras que para el $\mathrm{N}$ y el $\mathrm{P}$, los aportes no fueron muy diferentes que los de la precipitación neta. Debido a la alta relación entre las concentraciones de $\mathrm{C} / \mathrm{N}$ y de $\mathrm{C} / \mathrm{P}$ del mantillo posiblemente parte de los aportes de estos nutrientes con la precipitación neta quedan inmovilizados en el mismo.

El escurrimiento es un flujo de salida de nutrientes pero la tendencia de las relaciones observadas mostró una disminución de las concentraciones con la magnitud del evento, esta tendencia fue significativa para el COD y para el P.

El retorno aéreo de nutrientes representa un porcentaje muy importante en relación a la absorción, pero la mayor parte del mismo tiende a acumularse en el mantillo y algunos de 
los nutrientes a inmovilizarse en él debido a la baja tasa de descomposición por la acción microbiana. Por lo cual, al reducirse el ingreso en solución al suelo mineral de nutrientes críticos como el $\mathrm{N}$ y $\mathrm{P}$, mucho de éstos nutrientes se obtienen de los horizontes minerales a partir del legado de los pastizales y bosques xerófilos preexistentes. La escasez de nutrientes como el $\mathrm{N}$ se manifiesta además en la captura tanto de la copa de los árboles como de los microorganismos ligados al mantillo. Las reducciones de nutrientes y el descenso del pH, observados en los perfiles de suelo, que acompañan el crecimiento de la plantación, muestran como estas plantaciones provocan cambios profundos en el estado nutricional de los suelos arenosos evolucionados bajo pastizales y árboles nativos. Por otra parte, los cambios en la cantidad de nutrientes en el suelo en los sitios forestados no fueron explicados totalmente por la reubicación, en la fracción aérea de la plantación debida a la retención en la biomasa y necromasa forestal que conlleva la conversión de la vegetación natural a plantación forestal. Los datos analizados sugieren que la mayor proporción de los cambios se produciría como consecuencia de la preparación del terreno, a lo que siguen los efectos directos e indirectos de la plantación. Los efectos del manejo actual sobre cada etapa deberían ser evaluados más exhaustivamente para identificar y ponderar con precisión las etapas y procedimientos más críticos que debieran ser optimizados para eliminar o reducir los impactos negativos.

En cuanto a los balances hidrológicos de los dos períodos estudiados si bien presentaron saldo positivo, fueron muy ajustados a los ingresos por la precipitación bruta. Esto haría suponer que años con valores más bajos de precipitación puedan ocasionar balances anuales negativos. Sin embargo en base a datos de períodos anuales posteriores, comparando días con diferente disponibilidad de agua en el suelo y similar demanda atmosférica, se constató una disminución en el flujo de savia a un tercio del valor obtenido con buena disponibilidad hídrica edáfica. Por lo cual, se puede concluir que la transpiración para este sitio está directamente correlacionada con la disponibilidad de agua aportada por las precipitaciones al suelo y subsuelo, sin manifiesta dependencia hídrica de la napa freática.

La eficiencia en el uso de agua está relacionada con la cantidad de agua precipitada para el rango de valores de las precipitaciones locales y fue comparable a la eficiencia encontrada 
en otras regiones. La tendencia al aumento de la eficiencia en el uso de agua con el aumento de la precipitación bruta, se observó en este caso para un mismo sitio en dos años distintos. Una de las consecuencias de este comportamiento de $E$. grandis es que en los años más húmedos es mayor su productividad primaria aérea neta y transpira menos por unidad de materia seca formada, lo que permite concluir que la eficiencia de uso del agua cambia en una misma plantación dependiendo de la disponibilidad de agua.

En relación a las hipótesis ya mencionadas, a las que se refiere en los párrafos siguientes, se concluye que:

H1: La plantación al turno no creó un endoclima térmico muy diferente del externo. La temperatura en el suelo superficial suele ser más alta que la del aire por encima; bajo la plantación los menores valores de humedad relativa a $1.5 \mathrm{~m}$ parecen ser consecuencia de la falta de sotobosque. Las condiciones térmicas y de déficit de saturación de vapor sugieren que las condiciones evaporativas son casi tan elevadas en el piso forestal como en el exterior, lo que puede explicar la elevada intercepción y evaporación desde el mantillo.

Los suelos de los sitios forestados, mostraron incremento de la acidez, y la disminución de las concentraciones totales de $\mathrm{C}, \mathrm{N}, \mathrm{Mg}, \mathrm{Ca}$ y $\mathrm{Mn}$; la disminución de la calidad de la SOM (> $\mathrm{C} / \mathrm{N}$ ) y el aumento de las concentraciones de Fe y Al. Dado que casi todo el Ca se halla en forma intercambiable, el suelo resulta frágil en lo referente a la conservación de ésta base y fácil de acidificarse. El P total se mantiene y el P disponible aumenta hacia el final de la rotación, lo que sugiere el $\mathrm{P}$ es conservado eficazmente dentro del sistema suelovegetación; el $\mathrm{N}$ aparece como un factor que puede llegar a ser limitante debido a sus pérdidas. Los mayores cambios en las concentraciones de nutrientes disponibles e intercambiables en el periodo de preparación del terreno-3 años de crecimiento es un llamado de atención sobre el manejo de la fase de preparación del terreno; las pérdidas durante el crecimiento de la plantación hasta el fin de la rotación resultarían de la acción directa e indirecta de la plantación. Estos resultados plantean la necesidad de investigaciones profundas, atendiendo a procesos bióticos y abióticos, sobre la evolución 
de los suelos bajo plantaciones de Eucalyptus grandis en distintas fases del manejo desde la preparación del terreno, la etapa de crecimiento, la cosecha y la postcosecha. Asimismo, debería incluir, al efecto de otros aspectos involucrados como duración de las rotaciones, los tipos de cosecha, el tratamiento de los residuos, y otros, como han propuesto otros autores.

H2: A través del análisis de regresión se ha constatado que existen relaciones significativas entre distintos flujos hídricos y la precipitación bruta. Esas relaciones significativas entre variables hidrológicas de la plantación de E. grandis, permiten utilizar los modelos de regresión obtenidos para calcular los balances hídricos anuales a partir de datos de precipitaciones obtenidas en estaciones meteorológicas de la zona, tanto para periodos futuros como pasados. Asimismo, se ha demostrado que el flujo caulinar aumenta exponencialmente con el diámetro del árbol, y que la transpiración por individuo varía también su DAP y no está vinculada a aportes de agua freática, por lo cual periodos de sequía marcados pueden afectar notoriamente la producción forestal. Sumado a esto, los cambios en la estructura del rodal a lo largo de la rotación debidos al crecimiento y manejo pueden afectar la distribución de agua y nutrientes y las pérdidas por transpiración. Una elaboración retrospectiva de los balances hídricos de las plantaciones sobre los suelos estudiados, y su ajuste a intervalos temporales adecuados, permitiría la correlación de información hidro-meteorológica con datos de crecimiento y biomasa forestal; y así disponer de herramientas de predicción de la producción en años y periodos plurianuales con diferentes condiciones climáticas. Estos datos asimismo pueden integrarse en modelos a escala de paisaje.

Por último, se ha constatado que el escurrimiento superficial en la plantación es inferior al del pastizal reemplazado, sugiriéndose que esto se debe a las diferencias en la estructura de la biomasa aérea y el mantillo entre ambos ecosistemas.

H3: En general a medida que el agua atravesó el dosel arbóreo aumentó la concentración de nutrientes en solución, en particular de cationes y COD. En cambio, esto no ocurrió con el $\mathrm{P}$ y $\mathrm{N}$, que en parte son absorbidos por el dosel arbóreo. La concentración de nutrientes y COD tuvo un rango de variación mayor en eventos de baja intensidad, sin embargo las 
concentraciones de los elementos químicos y COD disueltos, en su mayoría, no mostraron relación significativa con la intensidad de los eventos. Esto permite junto a los modelos hidrológicos antes mencionados, efectuar estimaciones de circulación de nutrientes en las vías de agua forestal, siempre y cuando no haya cambios en las condiciones químicas atmosféricas actuales.

H4: El aporte de nutrientes en solución al suelo mineral, atribuido a la contribución de los procesos de descomposición del mantillo, pudo constatarse para los cationes $\mathrm{Ca}, \mathrm{K}$ y $\mathrm{Mg}$ y el COD; para el $\mathrm{N}$ y el $\mathrm{P}$, los ingresos son atribuibles mayormente a la precipitación neta. Debido a la alta relación entre las concentraciones de $\mathrm{C} / \mathrm{N}$ y de $\mathrm{C} / \mathrm{P}$ del mantillo posiblemente parte de estos nutrientes quedan inmovilizados en el mantillo.

H5: El escurrimiento es un flujo de salida de nutrientes pero la tendencia de las relaciones observadas mostró una disminución de las concentraciones con la magnitud del evento, o sea una relación inversa entre las variables mencionadas; esta tendencia fue significativa para el COD y para el $P$.

H6: La eficiencia en el uso de agua de Eucalyptus grandis está relacionada con la cantidad de agua precipitada para el rango de valores de las precipitaciones locales y fue comparable a la eficiencia encontrada en otras regiones.

Los resultados de los balances hídricos, y el escaso a nulo excedente de agua, son un llamado de atención sobre la demanda de agua de la zona forestada, la respuesta productiva de la forestación en años de precipitaciones diferentes, particularmente aquellos con precipitaciones por debajo de la media, y el impacto hidrológico a escala de paisaje. La dependencia del agua edáfica por parte de la plantación abre un camino a pensar en el uso del riego, al menos complementario, en años o periodos secos.

En lo referente a los ciclos de nutrientes la tesis ha permitido detectar algunas respuestas adaptativas (ej. absorción foliar, inmovilización en el mantillo) del ecosistema (árboles y microorganismos) para conservar nutrientes críticos como el $\mathrm{N}$ y $\mathrm{P}$; al mismo tiempo reconoció, en los suelos arenosos mestizos, ciertas características que manifiestan su 
fragilidad en relación a algunos elementos nutritivos y su facilidad de acidificación, lo que exige mejorar las distintas etapas del manejo de las plantaciones y sugiere la necesidad de reorientar la búsqueda de ciertas características en las plantas a cultivar sea a través del mejoramiento genético como de la incorporación de nuevas especies. 


\section{Índice}

\section{CAPÍTULO 1: INTRODUCCIÓN}

1.1 Importancia del los ciclos del agua y de nutrientes en las $\begin{array}{ll}\text { plantaciones forestales } & 1\end{array}$

1.2 El ciclo del agua en los ecosistemas forestales 4

$\begin{array}{ll}1.3 \text { Los ciclos de nutrientes en los ecosistemas forestales } & 10\end{array}$

1.4 Relaciones del ciclo del agua con los ciclos de nutrientes 13

1.5 Flujos hídricos en plantaciones de Eucalyptus spp 14

1.6 Circulación de nutrientes en los flujos de agua en plantaciones de Eucalyptus spp

1.7 La importancia de las plantaciones de eucaliptos de rápido crecimiento en el mundo y la Argentina

1.8 Los eucaliptos cultivados en la Mesopotamia argentina con especial referencia al Departamento Concordia

1.8.1. Características del Departamento Concordia

1.9 Eucalyptus grandis Hill ex Maiden: descripción y requerimientos ecológicos

1.10 Estado del conocimiento 31

1.11 Justificación 33

1.12 Objetivos 33

1.13 Hipótesis 34

\section{CAPÍTULO 2: METODOLOGÍA}

2. 1 Área de estudio 36

2. 2 Materiales y métodos 36

2.2.1 Parcelas experimentales 36

2.2.2 Caracterización de las condiciones climáticas y edáficas. 
2.2.3.1 Precipitación bruta

2.2.3.2 Trascolación

2.2.3.3 Flujo caulinar

2.2.3.4 Trascolación del mantillo

2.2.3.5 Escurrimiento superficial

2.2.3.6 Nivel freático

2.2.3.7 Agua del suelo

2.2.3.8 Transpiración

2.2.3.9 Cálculo de otros flujos hídricos.

2.2.4 Nutrientes en los flujos de agua 52

2.2.4.2 Instalaciones para muestreo a campo 52

2.2.4.3 Manipulación y acondicionamiento de muestras y 53 análisis químicos.

2.2.5 Balances de agua y nutrientes 55

2.2.5.1 Balance hídrico

2.2.4.2 Ciclos de nutrientes 56

2.2.6 Crecimiento y producción $\quad 57$

2.2.6.1 Diámetro y altura

2.2.6.2 Caída de detritos finos $\quad 57$

2.2.6.3 Índice de área foliar. $\quad 57$

2.2.6.4 Cálculo de crecimiento y producción 58

2.2.6.5 Producción primaria aérea neta anual 58

2.2.6.6 Eficiencia en el uso del agua y eficiencia en la captura 58 del agua.

\section{CAPÍTULO 3: RESULTADOS Y DISCUSIÓN}

3. 1 Aspectos meteorológicos, microclimáticos y edáficos 61

3.1.1 Temperatura del aire y precipitación 61

3.1.2 Comparación de temperaturas del aire dentro y fuera de la plantación 
3.1.3 Perfil térmico en las plantaciones

3.1.4 Humedad relativa $\quad 72$

3.1.5 Radiación fotosintéticamente activa e índice de área foliar $\quad 74$

3.1.6 Concentración y contenido de nutrientes 75

3.1.6.1 Nutrientes totales. $\mathrm{pH}$ de los suelos.

3.1.6.2 Nutrientes disponibles e intercambiables 87

3.1.7 Densidad aparente de los suelos 93

3.1.8 Agua edáfica $\quad 94$

3.2 Flujos de agua y Balance hidrológico 97

$\begin{array}{ll}\text { 3.2.1 Precipitación bruta } & 97\end{array}$

3.2.2 Trascolación $\quad 99$

$\begin{array}{ll}3.2 .3 \text { Flujo caulinar } & 100\end{array}$

3.2.4 Precipitación Neta e Intercepción 103

$\begin{array}{ll}3.2 .5 \text { Intercepción del mantillo } & 103\end{array}$

$\begin{array}{ll}3.2 .6 \text { Nivel freático } & 105\end{array}$

3.2.7 Escurrimiento superficial en la plantación y en el pastizal 108

$\begin{array}{ll}3.2 .8 \text { Transpiración } & 109\end{array}$

3.2.9 Balance de agua de la plantación forestal 111

$\begin{array}{ll}\text { 3.3 Producción y eficiencia Hídrica } & 117\end{array}$

3.3.1 Crecimiento, producción, eficiencia en el uso y en la 117 captura de agua de la plantación.

\section{4 Ciclos de nutrientes}

3.4.1 Concentración de nutrientes en los flujos hídricos y su relación con la magnitud de los eventos de precipitación bruta

3.4.2 Concentraciones promedio de nutrientes en los flujos de agua

3.4.3 Cocientes de concentraciones de nutrientes entre los flujos hídricos

3.4.4 Otros aspectos relativos al COD: contenido de COD y color de la materia orgánica disuelta en los distintos flujos hídricos y estimación de la concentración de COD en flujos de agua en función del color

3.4.5 Comparación de la concentración de nutrientes en el escurrimiento superficial de la plantación y del pastizal 
3.4.6 Circulación de nutrientes en los flujos hídricos

4.6.1 Nitrógeno

3.4.6.2 Fósforo 146

3.4.6.3 Potasio

3.4.6.4 Calcio

3.4.6.5 Magnesio 150

3.4.6.6 Carbono orgánico disuelto

3.4.7 Ciclo de nutrientes

\section{CAPÍTULO 4: CONCLUSIONES}

4.1 Aspectos micro-climáticos y edáficos

4.2 Flujos hídricos. Balances hidrológicos y eficiencias.

Nutrientes disueltos en los flujos

4.5 Líneas de investigación futura 


\section{Listado de Figuras}

\section{CAPÍTULO 1}

Figura 1.1: Balance hidrológico de una plantación de Eucalyptus grandis.

Figura 1.2: Área de distribución geográfica natural de E. grandis y de las precipitaciones anuales.

Figura 1.3: Climas del mundo: la región subtropical. Fuente: Eldridge, 1994.

\section{CAPÍTULO 2}

Figura 2.1: Ubicación de las plantaciones y perímetro de la EEA Concordia (Línea blanca): plantación de 12 años (Sitio III), plantación de 3 años (Sitio I) y pastizal aledaño.

Figura 2.2: Casillas con sensores de temperatura y humedad relativa ubicados dentro de la plantación.

Figura 2.3: Foto de una parcela del Sitio III con árboles de 12 años de edad donde puede observarse: iárboles con collares de flujo caulinar y su tanque colector al pie; ii- tres colectores rectangulares de trascolación con sus tanques colectores al pie; iii- una canaleta plástica con embudos colectores de agua de trascolación para análisis químicos.

Figura 2.4: Detalle de un anillo colector de flujo caulinar. El anillo está confeccionado con una faja de aluminio corrugado que abraza el árbol en forma oblicua con el lado de unión en la parte más alta.

Figura 2.5. Lisímetro para la medición de la trascolación del mantillo.

Figura 2.6: Parcela para la medición del escurrimiento superficial. En el ángulo inferior derecho, punto más bajo de la parcela, hay un pozo (no evidente en la foto) donde se ubica el recipiente colector.

Figura 2.7: Detalle de los el sistema de sensores para la medición de la densidad de flujo de savia. El sistema se compone de dos termocuplas insertas en dos agujas que se ubican en el xilema activo del árbol, la superior es calefaccionada y la inferior es la termocupla de referencia. Foto superior: vista de las agujas-sonda; foto inferior agujas colocadas en un árbol.

Figura 2.8: Detalle de los colectores de datos (data loggers) instalados en el campo.

Figura 2.9: Dispositivo con solución de safranina para teñir la albura activa $(A)$ y muestra de barreno para la medición de longitud de albura activa puesta en evidencia por el colorante (B).

Figura 2.10: Representación de los flujos medidos $(1,3,4,5,7,8)$ y estimados $(2,6,9)$ del balance hídrico en la plantación de E. grandis.

Figura 2.11: Canasto utilizado para la determinación de la caída anual de detritos finos. 


\section{CAPÍTULO 3}

Figura 3.1.1: Temperatura del aire a $1.5 \mathrm{~m}$ en la plantación y en un claro. En los meses de julio de 2004 y enero de 2005.

Figura 3.1.2: Temperatura media mensual, máxima media mensual y mínima media mensual registradas bajo la forestación y en la Estación meteorológica a 1.5 m de altura. Período de observación: marzo de 2004 - febrero de 2005.

Figura 3.1.3: Regresión entre las temperaturas medias diarias tomadas en casillas meteorológicas a $1.5 \mathrm{~m}$ en la Estación Meteorológica y en la plantación de E. grandis de 12 años de edad. Período de observación: marzo de 2004 - febrero de 2005.

Figura 3.1.4: Regresión entre las temperaturas mínimas diarias tomadas en casillas meteorológicas a $1.5 \mathrm{~m}$ en la Estación Meteorológica y en la plantación de E. grandis de 12 años de edad. Período de observación: marzo de 2004 - febrero de 2005.

Figura 3.1.5: Marcha horaria de las temperaturas a distinta altura sobre el suelo y profundidad bajo su superficie en días del mes de enero de 2004 (días 01 al 20; n= 20).

Figura 3.1.6: Marcha horaria de las temperaturas a distinta altura sobre el suelo y profundidad debajo de él en días del mes de julio de 2004 (días 03 al 23, n=20).

Figura 3.1.7: Marcha horaria de las temperaturas a $1.5 \mathrm{~m}$ bajo la forestación en días con valores contrastantes de heliofanía (H en horas) del mes de enero de 2004, indicados en las referencias.

Figura 3.1.8: Marcha horaria de las temperaturas a $1.5 \mathrm{~m}$ bajo la forestación en días con valores contrastantes de heliofanía (H en horas) del mes de julio de 2004, indicados en las referencias.

Figura 3.1.9: Marcha horaria de las temperaturas a distinta altura sobre el suelo y profundidad debajo de él en un día del mes de enero de 2004 (03/01/2004) con alta heliofanía (H: 12.2).

Figura 3.1.10: Marcha horaria de las temperaturas a distinta altura sobre el suelo y profundidad debajo de él en días del mes de julio de 2004 (04/07/04) con alta heliofanía (H: 8.35).

Figura 3.1.11: Marcha horaria de las temperaturas a distinta altura sobre el suelo y profundidad debajo de él en un día del mes de enero de 2004 (18/01/04) con baja heliofanía (H: 3).

Figura 3.1.12: Marcha horaria de las temperaturas a distinta altura sobre el suelo y profundidad debajo de él en días del mes de julio de 2004 (22/07/04) con baja heliofanía (H: 0).

Figura 3.1.13: Humedad relativa media mensual, máxima media mensual y mínima media mensual registradas bajo la forestación y en la Estación meteorológica a $1.5 \mathrm{~m}$ de altura. Periodo marzo 2004 - febrero 2005.

Figura 3.1.14: Valores de evapotranspiración de referencia (Eto) calculados según la ecuación Penman Montheith FAO, con datos de la Estación Meteorológica de la EEA INTA Concordia. Período: abril de 2003 - abril de 2005. 
Figura 3.1.15: (A) Contenido de nitrógeno total (\%) y (B) carbono orgánico total (\%) en el suelo en los sitios forestados (SI y SIII) y testigos (T1 y T2).

Figura 3.1.16 a: Concentraciones de calcio $(\mathrm{Ca})$, potasio $(\mathrm{K})$, magnesio $(\mathrm{Mg})$ y capacidad de intercambio catiónico efectiva (ECEC) en los Sitios forestados (SI y SIII) y Testigos (T1 y T2).

Figura 3.1.16 b: Concentraciones de fósforo $(\mathrm{P})$ disponible, manganeso $(\mathrm{Mn})$ y hierro $(\mathrm{Fe})$ intercambiables, y Capacidad de Intercambio Catiónico (ECEC) en los Sitios forestados (SI y SIII) y Testigos (T1 y T2).

Figura 3.1.17: Relación entre el pH y el contenido de Al y Fe intercambiables del suelo.

Figura 3.1.18: Perfil de contenido de agua en el Punto de Marchitez Permanente (PMP) convencional, la Capacidad de Campo (CC) y a Saturación (Sat) hasta los $60 \mathrm{~cm}$ de profundidad.

Figura 3.2.1: Precipitaciones mensuales durante los dos períodos estudiados y el promedio para el período $1967-2005$.

Figura 3.2.2: Regresión entre la trascolación y la precipitación bruta a los $3-4$ años de edad $(n=97)$.

Figura 3.2.3: Regresión entre la trascolación y la precipitación bruta a los 11 - 12 años de edad ( $n=97)$.

Figura 3 2.4: Relación entre el flujo caulinar $(\mathrm{mm})$ y la precipitación bruta $(\mathrm{mm})$.

Figura 3.2.5: Relación entre el flujo caulinar (litros de FC/mm de PB) y el diámetro de los árboles (DAP).

Figura 3.2.6: Precipitación Bruta (PB), Trascolación (T), Flujo Caulinar (FC) y Precipitación Neta (PN). Valores mensuales $(\mathrm{mm})$.

Figura 3.2.7: Relación entre la trascolación del mantillo $(\mathrm{mm})$ y la precipitación bruta $(\mathrm{mm})$

Figura 3.2.8: Precipitaciones $(\mathrm{cm})$ y nivel freático $(\mathrm{m})$. Período $1968-2006$

Figura 3.2.9: Nivel freático mensual medidos en pozos encamisados en la Estación meteorológica EEA INTA Concordia (EM), en la plantación estudiada (Eg) y en un claro ubicado a $2000 \mathrm{~m}$ de la plantación.

Figura 3.2.10: Relación entre el escurrimiento superficial en la plantación (Eg) y la precipitación bruta y entre el escurrimiento en el pastizal y la PB.

Figura 3.2.11: Relación entre la albura y el DAP (diámetro del árbol a $1.3 \mathrm{~m}$ )

Figura 3.2.12: Valores de flujo de savia medidos en dos fechas con igual ETP ( $4.1 \mathrm{~mm} /$ día), una con suelo húmedo (h) y, otra, en condiciones de sequía (s) en los clones K, 4 y 2 de Eucalyptus grandis. Corresponde a los días 18/10/2008 y 22/12/2008, respectivamente.

Figura 3.2.13: Hifas y raíces finas de los árboles presentes en condiciones de alta humedad desarrollándose en el mantillo.

Figura 3.2.14: Flujos hídricos período abril 2003 - marzo 2004

Figura 3.2.15: Flujos hídricos período abril 2004 - marzo 2005

Figura 3.2.16: Comparación de fuga profunda de agua (leakage) bajo diferentes tipos de vegetación. Generalmente el leakage es mayor bajo vegetación anual, intermedio bajo vegetación perenne 
y más bajo debajo de los árboles. La diferencia aumenta cuando se incrementan las precipitaciones. Fuente Walker et al. (1999).

Figura 3.3.1: Regresión e intervalos de confianza del 95\% entre la transpiración y la eficiencia en el uso del agua. Realizada con los datos de la tesis doctoral de Stape, 2001 y los resultados de este estudio.

Figura 3.3.2: Crecimiento en área basal $\left(\mathrm{m}^{2} / \mathrm{ha}\right)$ del Sitio III

Figura 3.3.3: Precipitaciones mensuales Estación Meteorológica Concordia (EM).

Figura 3.3.4: Contenido de agua en el suelo hasta $l o s \quad 160 \mathrm{~cm}$ de profundidad

Figura 3.4.1: Concentración de amonio en los flujos hídricos aéreos ( $F C=$ flujo caulinar; $T=$ trascolación; $P B=$ precipitación bruta) en relación a la precipitación bruta $(\mathrm{mm})$.

Figura 3.4.2: Concentración de nitrato en los flujos hídricos aéreos ( $F C=$ flujo caulinar; $T=$ trascolación; PB= precipitación bruta) en relación a la precipitación bruta $(\mathrm{mm})$.

Figura 3.4.3: Concentración de fósforo en los flujos hídricos aéreos ( $F C=$ flujo caulinar; $T=$ trascolación; $P B=$ precipitación bruta) en relación a la precipitación bruta $(\mathrm{mm})$.

Figura 3.4.4: Concentración de potasio en los flujos hídricos aéreos ( $F C=$ flujo caulinar; $T=$ trascolación; $P B=$ precipitación bruta) en relación a la precipitación bruta $(\mathrm{mm})$.

Figura 3.4.5: Concentración de calcio en los flujos hídricos aéreos ( $F C=$ flujo caulinar; $T=$ trascolación; $P B=$ precipitación bruta) en relación a la precipitación bruta $(\mathrm{mm})$.

Figura 3.4.6: Concentración de magnesio en los flujos hídricos aéreos ( $F C=$ flujo caulinar; $T=$ trascolación; $P B=$ precipitación bruta) en relación a la precipitación bruta $(\mathrm{mm})$.

Figura 3.4.7: Concentración de carbono orgánico disuelto en los flujos hídricos aéreos (FC= flujo caulinar; $T=$ trascolación; $\mathrm{PB}=$ precipitación bruta) en relación a I la precipitación bruta $(\mathrm{mm})$.

Figura 3.4.8: Concentraciones de amonio, nitrato y fosfato vs. Precipitación Bruta (PB) en el escurrimiento superficial y en el lixiviado del mantillo.

Figura 3.4.9: Concentraciones de potasio, calcio, magnesio y DOC vs. Precipitación Bruta (PB) en el escurrimiento superficial y en el lixiviado del mantillo.

Figura 3.4.10. Relación entre la concentración de COD y el color por flujo hídrico. Se indican las líneas de regresión por cuadrados mínimos ordinarios.

Figura 3.4.11. Relación entre la concentración de COD y el color para todos los flujos hídricos. Se indica la línea por mínimos cuadrados ordinarios (línea de puntos) y límites de confianza basado en la regresión de cuantiles. $Q 5 \%$ : intercepción $=0.25$, pendiente $=56.56 ; Q 95 \%$ : intercepción= 0.53 , pendiente $=167.01$.

Figura 3.4.12: Nitrógeno disuelto $\left(\mathrm{kg} \mathrm{ha}^{-1} \mathrm{año}^{-1}\right)$ en los flujos hídricos en una plantación de E. grandis. Período abril 2004 - marzo 2005.

Figura 3.4.13: Fósforo disuelto $\left(\mathrm{kg} \mathrm{ha}^{-1} \mathrm{año}^{-1}\right)$ en los flujos hídricos en una plantación de E. grandis. Período abril 2004 - marzo 2005.

Figura 3.4.14: Potasio disuelto $\left(\mathrm{kg} \mathrm{ha}^{-1}\right.$ año ${ }^{-1}$ ) en los flujos hídricos en una plantación de E. grandis. Período abril 2004 - marzo 2005. 
Figura 3.4.15: Calcio disuelto ( $\mathrm{kg} \mathrm{ha}^{-1} \mathrm{año}^{-1}$ ) en los flujos hídricos en una plantación de E. grandis. Período abril 2004 - marzo 2005.

Figura 3.4.16: Magnesio disuelto $\left(\mathrm{kg} \mathrm{ha}^{-1} \mathrm{año}^{-1}\right.$ ) en los flujos hídricos en una plantación de E. grandis. Período abril 2004 - marzo 2005.

Figura 3.4.17: Carbono orgánico disuelto $\left(\mathrm{kg} \mathrm{ha}^{-1}\right.$ año $\left.{ }^{-1}\right)$ en los flujos hídricos en una plantación de $E$. grandis. Período abril 2004 - marzo 2005. 


\section{Listado de Tablas}

\section{CAPÍTULO 1}

Tabla 1.1: Valores de precipitación bruta (PB), precipitación neta (PN), intercepción (I), trascolación (T) y flujo caulinar (FC) en plantaciones de Eucalyptus spp.

Tabla 1.2: Valores de transpiración diaria de plantaciones de Eucalyptus spp. Las abreviaturas en la columna Método corresponden a Penman-Monteith (PM), Flujo de savia (SF), análisis de imágenes satelitales por el Método simplificado (AI).

Tabla 1.3: Antecedentes del aporte de nutrientes de la precipitación bruta (PB), la precipitación neta (PN), la trascolación (T) el flujo caulinar (FC).

Tabla 1.4: Clasificación de las especies de Eucalyptus spp. en base al consumo de agua, las características del crecimiento y la tolerancia a la sequía. Fuente: Florence (1996).

\section{CAPÍTULO 2}

Tabla 2.1: Descripción de la ubicación, tipo y marca de los sensores y registradores utilizados para el monitoreo del microclima.

Tabla 2.2: Ubicación de los pozos donde se registró el nivel freático.

Tabla 2.3: Métodos analíticos utilizados en la determinación de los nutrientes en las muestras de los flujos hídricos.

\section{CAPÍTULO 3}

Tabla 3.1.1: Requerimientos climáticos de E. grandis según Booth \& Prior (1991) y valores de la Estación Meteorológica INTA Concordia (1967- 2006).

Tabla 3.1.2: Valores de la precipitación mensual (media, mediana, máxima y mínima) de la Estación Meteorológica Concordia. Serie 1967 - 2005.

Tabla 3.1.3: Valores de la temperatura mensual (máxima media, mínima media, media, máxima absoluta y mínima absoluta) de la Estación Meteorológica Concordia. Serie 1967 - 2005.

Tabla 3.1.4: Valores de radiación fotosintéticamente activa (PAR) medidos en los plantaciones y en el pastizal aledaño e índice de área foliar (IAF) estimado según el modelo de Norman - Jarvis (1974).

Tabla 3.1.5a: Contenido de nutrientes y pH de los suelos de las parcelas testigo.

Tabla 3.1.5b: Contenido de nutrientes y pH de los suelos de las parcelas forestadas de 3 años (sitio I) y 11 años (sitio III).

Tabla 3.1.6: Cambios en los depósitos de nutrientes en los suelos. Almacenaje de nutrientes inicial (media de dos testigos con pastizal) y bajo la forestación a los 3 y 11 años hasta $65 \mathrm{~cm}$ de profundidad. 
Tabla 3.1.7: Tasa de lixiviación de nutrientes vegetales en suelos de diferentes texturas (Mengel \& Kirby, 2000).

Tabla 3.1.8a: Contenido de nutrientes disponibles e intercambiables y capacidad de intercambio catiónico efectiva (ECEC) de los suelos de las parcelas testigo. Media y desvío estándar (entre paréntesis).

Tabla 3.1.8b: Contenido de nutrientes disponibles e intercambiables y capacidad de intercambio catiónica efectiva de los suelos de las parcelas forestadas de 3 años (sitio I) y 11 años (sitio III). Media y desvío estándar (entre paréntesis).

Tabla 3.1.9: Contenido de nutrientes totales y disponibles en los sitios testigos y en las parcelas forestadas, e índices que los relacionan.

Tabla 3.1.10: Valores de densidad aparente $\left(\mathrm{g} / \mathrm{cm}^{3}\right)$ del suelo en el sitio III.

Tabla 3.1.11: Valores de los índices hídricos del suelo para el Sitio III: Punto de marchitez permanente (PMP a -1,5 MPa), Humedad equivalente (HE) y Saturación (Sat) determinados en laboratorio.

Tabla 3.1.12: Valores del contenido hídrico en el perfil de suelo $(\mathrm{mm})$ a Capacidad de Campo en el Sitio III.

Tabla 3.2.1: Comparación de los parámetros de las dos regresiones entre la Precipitación y la Trascolación (T) en los sitios I y III. Variable indicadora (I), su significancia indica si la ordenada al origen de los modelos de regresión difieren entre si. $\mathrm{T}^{*} \mathrm{I}$, su significancia indica si las pendientes de los modelos de regresión difieren entre sí.

Tabla 3.2.2: Regresión múltiple entre el flujo de savia $(\mu)$ y variables climáticas y edáficas.

Tabla 3.2.3: Valores anuales de los componentes del balance hídrico para los dos años analizados.

Tabla 3.3.1: Valores de Producción Primaria Neta Aérea (ANPP), eficiencia en el uso del agua (WCE) y eficiencia en la captura, medidas y estimados, para los dos períodos estudiados

Tabla 3.4.1a: Comparación entre las concentraciones de nutrientes $(\mathrm{mg} / \mathrm{l})$ y el pH de los flujos hídricos y la napa freática.

Tabla 3.4.1 b: Valores mínimos, promedios y máximos de las determinaciones químicas del agua subterránea en el NE de Entre Ríos (C.E: conductividad eléctrica; R.S: residuos sólidos; Dur: dureza). Fuente: Santi el al., 2009.

Tabla 3.4.2: Relaciones de concentración trascolación/precipitación (T/P), flujo caulinar/precipitación (FC/P), flujo caulinar/trascolación (FC/T), escurrimiento superficial/precipitación neta (ESC/PN) y lixiviación del mantillo /precipitación neta (LM/PN).

Tabla 3.4.3: Valores de COD (ppm) y color en los flujos hídricos de la plantación de $E$. grandis.

Tabla 3.4.4: Concentraciones de nutrientes en escurrimiento superficial de la plantación (ESF) y en el escurrimiento superficial del pastizal aledaño (ESP). Período Junio 2005 - junio 2006. Letras diferentes indican diferencias de concentración significativas $(p<0.01)$ entre sitios.

Tabla 3.4.5: Balance de nutrientes (Barrera et al., 2005) y aportes de nutrientes en los flujos hídricos obtenidos en ésta Tesis. 



\section{INTRODUCCIÓN}

\subsection{Importancia de los ciclos del agua y de nutrientes en plantaciones forestales}

En el mundo la superficie dedicada a las plantaciones forestales de rápido crecimiento ha aumentado en respuesta al incremento en la demanda de madera y de sus productos y a la preservación de los bosques nativos (Hubbard et al., 2004).

La producción forestal depende de la obtención del ambiente de recursos como energía, agua, nutrientes y dióxido de carbono atmosférico que son fijados en la biomasa. Depende también de la partición de la biomasa realizada por los árboles; la asignación a la biomasa leñosa comúnmente es de entre el $10-30 \%$ de la producción total del árbol (Binkley et al., 2004).

Las particularidades de la circulación del agua y los nutrientes asociados con ella en flujos del ciclo geoquímico y biogeoquímico de las plantaciones forestales adquieren entonces gran importancia debido a que la disponibilidad de agua y nutrientes suelen ser las principales limitantes para el crecimiento y producción. Asimismo estas particularidades son de interés ambiental ya que las plantaciones monoespecíficas de especies exóticas, que reemplazan a la vegetación nativa, pueden generar impactos adicionales a la disminución de la diversidad, tales como el descenso de la napa freática (por aumento de la evapotranspiración), cambios en el escurrimiento superficial (debidos a cambios en los suelos y su cubierta), y reducción de la disponibilidad de nutrientes (por consumo y exportación con la cosecha sin reposición mediante fertilización).

Comparado con los pastizales, las forestaciones tienen en general mayor área foliar, mayor rugosidad del dosel arbóreo y acceso a fuentes de agua más profundas (Kelliher et al., 1993; Canadell et al., 1996; Calder, 1998; Jackson, 1999; Schenk et al., 2002). Estos cambios tienen como resultado mayores pérdidas por evaporación (Kelliher et al., 1993; 
Zhang, 2001), menor contenido de humedad en el suelo (Calder et al. 1993, Chen et al 2003), reducida recarga del acuífero (Le Maitre 1999, Jobaggy \& Jackson, 2004a) y descenso de la napa freática (Jobaggy \& Jackson, 2004a).

El comportamiento del agua en bosques y plantaciones de árboles ha merecido la atención de los investigadores desde hace décadas. Por ejemplo, en cuanto a las pérdidas por evaporación, Leonard (1967) y Zinke (1967) han destacado que las plantaciones ocasionan reducciones de la precipitación bruta, debido a la intercepción y pérdida de agua de lluvia por el dosel arbóreo. Dicha intercepción y pérdida evaporativa es dependiente de varios factores entre los que se encuentran el tamaño, área, disposición y configuración foliar del bosque, la viscosidad del agua y la presión externa sobre ella, el régimen de precipitaciones (frecuencia, duración e intensidad de las precipitaciones), el déficit de saturación atmosférico y la acción del viento (Delfs, 1967; Leonard, 1967; Leyton et al., 1967; Frangi \& Richter, 1994).

En general la conversión de ecosistemas a sistemas de monocultivo ha sido motivo de comentarios vinculados a la pérdida de biodiversidad, la afectación de los ciclos de agua y de nutrientes, cambios en los suelos y otros. En éste aspecto las plantaciones de eucaliptos han merecido gran atención. El consumo de agua por los eucaliptos es un tema conflictivo en muchos países, particularmente en los lugares donde las precipitaciones son bajas, variables o marcadamente estacionales. Los críticos afirman que los eucaliptos producen efectos deletéreos en el balance hidrológico de un área, a través del aceleramiento de la erosión superficial, la reducción de la infiltración del agua, la reducción de la capacidad de campo del suelo, y un marcado descenso del nivel de agua del suelo o de los flujos superficiales. Pueden existir respuestas no simples para estas afirmaciones. Las circunstancias de cada plantación serán diferentes y deben ser evaluadas separadamente (Florence, 1996).

Las investigaciones han demostrado que el consumo de agua depende de la región, de la especie, de las condiciones ambientales y de las prácticas de uso del suelo. Las 
poblaciones locales y las ONG reclaman que estas plantaciones secan el suelo. Las empresas productoras de madera y pulpa necesitan mejorar la comprensión del uso del agua por las plantaciones con el objetivo de ajustar las prácticas de manejo para lograr sustentabilidad a largo plazo y responder a los interrogantes planteados. Asimismo, las empresas enfrentan nuevas demandas en los mercados que exigen cada día más garantías de producción con prácticas ambientalmente sustentables, en general asociados a los procesos de certificación forestal (por ejemplo, véase. Kiekens, 1997); en lo concerniente a la hidrología, esto destaca la necesidad de mejorar su conocimiento en las plantaciones forestales de rápido crecimiento (Almeida et al., 2007) para establecer pautas de manejo compatibles con una producción amigable con el ambiente.

A nivel local, a pesar de la superficie forestada y de la alta tasa de plantación, no hay muchos estudios vinculados con el agua y los nutrientes en plantaciones de $E$. grandis. Nosetto et al. (2005) analizaron la evapotranspiración real y concluyen que las plantaciones de $E$ grandis de la zona pierden por esa vía 1.8 veces más agua que los pastizales naturales; asimismo la eficiencia de uso del agua es mayor en suelos de textura media que en los extremos texturales finos y gruesos, en tanto que la evapotranspiración aumenta desde los sitios de textura fina hacia los de textura gruesa, para alcanzar un máximo en suelos costeros (del río) con suministro lateral de agua. Por otra parte Goya et al. (2009) informaron sobre la concentración de nutrientes en la biomasa, como así también de la mineralomasa por compartimentos y total de plantaciones de $E$. grandis en suelos de textura fina (arcillosos), media (mestizos) y gruesa (arenoso) observando mayores concentraciones de nutrientes foliares en los suelos de textura fina y menor en los suelos mestizos en donde $E$. grandis crece más en volumen (Marcó, 1988) y biomasa (Goya et al., 1997). También se ha determinado la extracción total de nutrientes con la cosecha al turno y evaluado las consecuencias de exportación de nutrientes de distintas formas de cosecha y tareas de post-cosecha concluyendo que aquellos tratamientos que dejan mayor cantidad de materia orgánica en el sitio son los que menos afectan la estabilidad ecológica de las plantaciones (Goya et al., 2009). En definitiva, no hay suficientes estudios hidrológicos de plantaciones de Eucalyptus grandis, que expliquen a escala de rodal la magnitud de las vías de flujo del agua en los terrenos forestados, su balance de agua, los ingresos, circulación y egresos de nutrientes en dichas plantaciones, 
y, que evalúen el papel que juegan dichas plantaciones en el ciclo del agua y los principales nutrientes disueltos. Estos aspectos ecológicos resultan de sumo interés tanto para complementar el ciclo de los nutrientes ligado a la materia orgánica, como para establecer una línea de base para ponderar potenciales cambios hídricos y también en los nutrientes que podrían ocurrir a distinta escala (ej. rodal, zonal) a partir del reemplazo de superficies de pastizales y sabanas espontáneas por masas manejadas de $E$. grandis.

\section{2 El ciclo del agua en los ecosistemas forestales}

A nivel de los ecosistemas el agua se moviliza hacia, desde y dentro de los sistemas ecológicos siguiendo vías o flujos característicos conformando los denominados ciclos del agua (Figura 1.1). El balance hidrológico a este nivel esta dado por la diferencia de ingresos y egresos.

Los ingresos de agua a un ecosistema pueden estar dados por la precipitación directa, la precipitación lateral, los ingresos por escurrimiento desde ecosistemas vecinos, y los movimientos de ascenso del agua profunda del suelo; los egresos son la sumatoria de la evapotranspiración, la percolación y los escurrimientos hacia ecosistemas vecinos cuenca abajo.

La precipitación directa, bruta o vertical es aquella que llega a la superficie superior del ecosistema principalmente en forma de lluvia, granizo o nieve según sean las condiciones climáticas del área.

La precipitación lateral ocurre principalmente en sistemas montanos a partir de altitudes donde las temperaturas favorecen la condensación de agua y formación de nubes; en esas condiciones las superficies, en particular aquellas correspondientes a la vegetación de los ecosistemas forestales, como ocurre en el caso de los bosques de niebla, son capaces de sustraer agua de la atmósfera aumentando su disponibilidad en las cuencas. Algunas zonas costeras cercanas a aguas frías oceánicas pueden experimentar precipitaciones laterales o advectivas similares. Este tipo de precipitación es de difícil 
evaluación a nivel de los bosques y no es detectada por los sistemas de medición de la

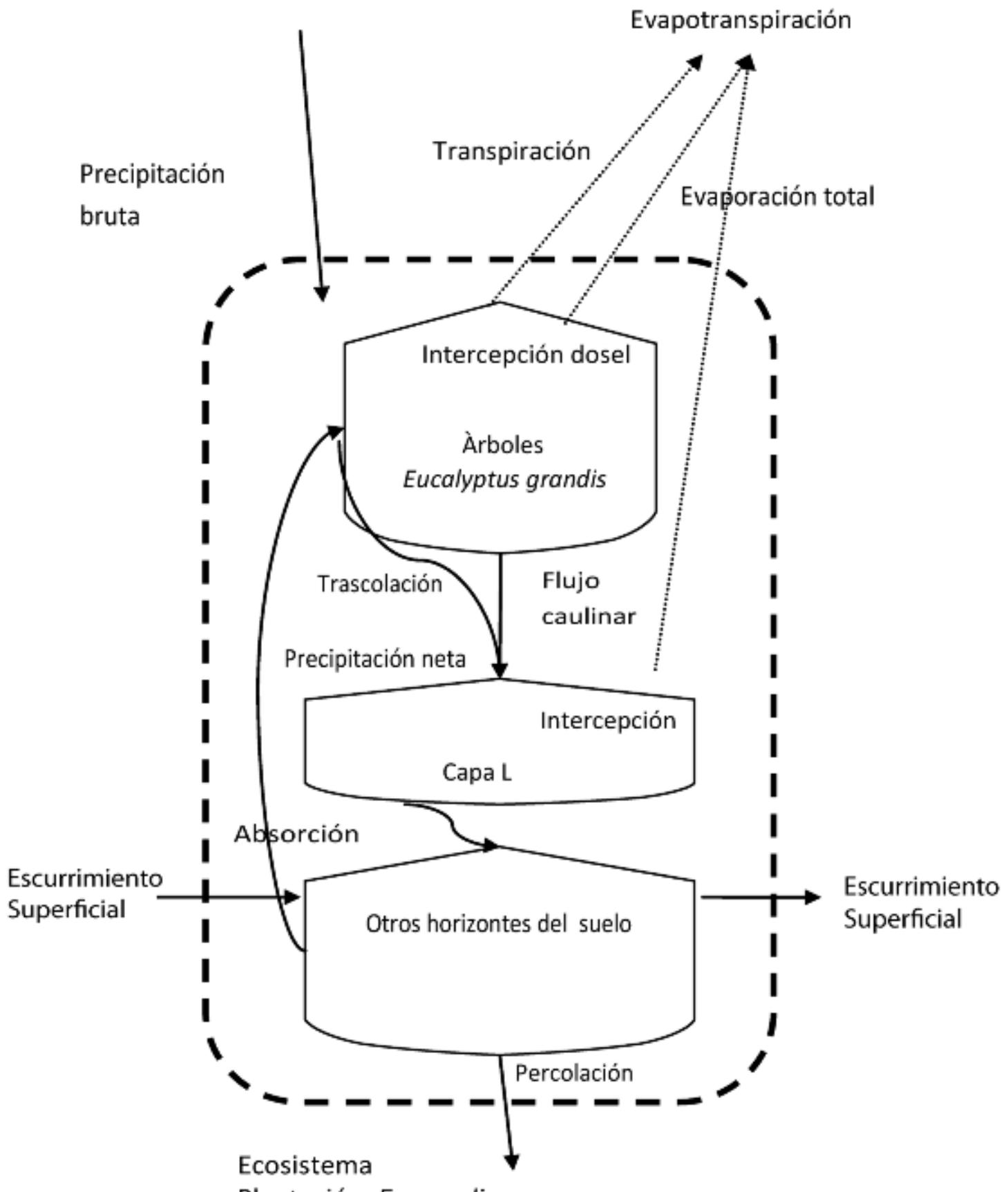

Plantación E. grandis

Figura 1. 1: Balance hidrológico en una plantación de Eucalyptus grandis 
precipitación vertical tradicional. En Concordia es posible tener alguna precipitación lateral en las plantaciones vinculada a los mantos de niebla, que son más frecuentes (promedio de 4 a 6 días con niebla /mes) entre abril y agosto (SMN, 1992); no obstante se estima que los aportes hídricos por esta vía son ínfimos, pues la mayor parte del agua interceptada en horas cercanas al amanecer se evapora en las horas con sol.

El escurrimiento superficial puede constituir una provisión adicional, mantener más o menos constante o significar una exportación de agua de los ecosistemas. El relieve juega un papel importante en la tendencia dominante. En terrenos planos o de muy baja pendiente el escurrimiento superficial puede ser muy escaso y no constituir pérdida o ganancia significativa. En sitios de terrenos cóncavos el escurrimiento desde los ecosistemas vecinos puede ser una ganancia importante de agua. En terrenos convexos, el escurrimiento puede implicar pérdidas. La ganancia de agua desde el subsuelo es evidente allí donde las napas de agua son surgentes o están cercanas a la superficie y pueden ser alcanzadas por las raíces de las plantas. Los árboles en oasis, ciertos humedales boscosos en zonas ribereñas de cuerpos de agua dulce y salada, algunos bosquecillos de árboles freatófitos con raíces profundas en terrazas de ríos, ejemplifican la influencia de ésta fuente.

Las precipitaciones que alcanzan el dosel de un bosque o plantación forestal cambian cualitativa y cuantitativamente al ingresar al ecosistema. La redistribución de las precipitaciones bajo la cubierta arbórea está relacionada con las características de las Iluvias, la estructura del dosel, la topografía, las características climáticas y con el manejo del bosque (Mischterlicht, 1971 en Oyarzún et al., 1985).

Cuando una cierta cantidad de agua se pone en contacto con las copas de los árboles o dosel forestal, una fracción de ella vuelve a la atmósfera mediante evaporación. De la restante, la mayor parte llega al piso forestal directamente, o bien luego de impactar en el follaje y las ramas, constituyendo ambas fracciones la trascolación (T) o throughfall. La parte restante de la fracción interceptada por el follaje escurre por ramas y troncos conformando el flujo caulinar (FC) o stemflow. La suma de T y FC dan lugar a la 
precipitación neta que alcanza la superficie del terreno (Zinke, 1967). Parte del agua que llega al suelo se infiltra en él, parte puede escurrir superficialmente y otra evaporarse desde el suelo. El agua que infiltró en el suelo puede ser retenida hasta cierta cantidad máxima actuando la fuerza de la gravedad (capacidad de campo); el excedente percola eventualmente hasta la napa freática o si encuentra una capa impermeable de material parental drena como flujo lateral o subsuperficial (Bruijnzeel, 1997). El régimen de precipitaciones puede, ante eventos de diferente intensidad, determinar que el agua infiltrada alcance o no los horizontes profundos, la capacidad de campo o excesos de agua que, dependiendo de las características del suelo se movilizará vertical y/o horizontalmente en el perfil.

Las técnicas usuales empleadas por los investigadores para medir la intercepción del dosel comprende la comparación y diferencia entre la precipitación en lugares abiertos o por encima de la vegetación existente, denominada precipitación bruta, con la precipitación neta. Esa forma de medir la intercepción de agua a nivel ecosistémico considera al agua involucrada en dicha diferencia como una pérdida en forma gaseosa, ya que el faltante es explicado como parte de la evaporación de agua desde las superficies del dosel forestal del ecosistema. Asimismo es una manera simple de ponderar un proceso complejo donde intervienen diferentes factores. Por ejemplo la capacidad de almacenar agua de una hoja o cantidad de agua retenida en la superficie de la misma será función del área foliar, la configuración y composición de la hoja, la viscosidad del agua y de la presión externa del líquido así también como de la cantidad de precipitación (Leonard, 1967). La combinación de estos factores produce una superficie de tensión entre la superficie de la hoja y el agua sobre la superficie. Al comenzar una lluvia las gotas son muy retenidas en la superficie foliar y una parte de las gotas salpican desde dicha superficie durante el descenso a través de la atmósfera baja. La humedad retenida sobre la hoja forma una fina película por procesos hidrostáticos, hasta que la capacidad de almacenamiento se completa o las fuerzas de tensión superficial están balanceadas con las fuerzas gravitacionales. A partir de entonces las gotas golpean las hojas formando canales que llevan la humedad hacia las puntas foliares o sus bordes inferiores donde se reúnen nuevamente en gotas. El tamaño de las gotas se incrementa hasta que las fuerzas debidas a la gravedad superan a las fuerzas de tensión superficial. Cuando la relación entre las fuerzas gravitacionales y las 
de tensión supera la unidad la gota se separará del borde de la hoja alcanzando una hoja inferior o pasando a través de las hojas hacia el suelo. La cantidad de agua retenida por la hoja dependerá del área de la hoja y de las fuerzas de tensión superficial. La tensión superficial es en parte función de la configuración de la superficie de la hoja, de la viscosidad del líquido y de la actividad mecánica (Leonard, 1967). La intercepción total es la suma del agua acumulada sobre la vegetación al final del evento de lluvia y la evaporación desde las superficies de las plantas durante el evento.

La proporción de la precipitación bruta que es interceptada y evaporada directamente a la atmósfera depende en gran medida de la intensidad y frecuencia de las precipitaciones (Rutter, 1975 en Evans, 2001). En los trópicos donde gran parte de las precipitaciones se presentan como tormentas cortas e intensas la intercepción no supera el $11 \%$ de la precipitación bruta. En el otro extremo, en climas marítimos donde la precipitación de presenta como lluvias suaves y de larga duración, por lo que la mayor parte del tiempo el dosel está mojado, la intercepción puede llegar al $40 \%$ de la precipitación bruta (Jarvis \& Stewart, 1979; Gash et al., 1980 en Evans, 2001).

La intercepción también depende del dosel, en forestaciones con doseles cerrados, el agua interceptada es una proporción importante de la precipitación bruta siendo el porcentaje de la precipitación bruta interceptado entre el 10 y el 50 \% (Kellinher, 1992 en Waring \& Running, 1998).

Un flujo de suma importancia para las plantas es la transpiración, dada por su magnitud y su función. Debido a que las plantas no tienen membranas que sean a la vez permeables al dióxido de carbono e impermeables al agua, la transpiración es una inevitable consecuencia de la fotosíntesis. Para controlar las pérdidas de agua, las plantas están cubiertas con superficies relativamente impermeables, la mayor parte del dióxido fijado y el agua transpirada pasa a través de estomas. El grado de apertura estomática es modulado por la turgencia de las células oclusivas. La regulación de la apertura determina el compromiso entre incrementar la fijación de dióxido de carbono y reducir la transpiración para prevenir la desecación. Al mismo tiempo la transpiración provee refrigeración a través del enfriamiento evaporativo formando el principal componente del 
balance de energía y de la fuerza conductora para el transporte de agua y nutrientes desde las raíces hacia los brotes (Caemmerer et al., 2007).

La cantidad de agua incorporada a las plantas por la absorción del agua del suelo mediante el sistema radical, luego transportada a través del sistema de conducción y transpirada por el follaje, es esencialmente la misma. En los árboles el volumen de agua usada para el crecimiento es una muy pequeña proporción del agua absorbida por el sistema radicular. Por lo tanto, la medición del movimiento del agua en el tronco puede ser una buena estimación cuantitativa del agua transpirada (Kaufmann \& Kellinher, 1991).

La tasa de transpiración varía con las condiciones del tiempo, el área foliar, la arquitectura de la copa, y la humedad del suelo (Landsberg \& Gower, 1997). La mayor parte del tiempo las condiciones atmosféricas y del suelo determinan que la conductancia estomática sea menor que la máxima y que por lo tanto la transpiración sea también menor. La interpretación y predicción de las respuestas estomáticas al déficit de saturación de vapor son complicadas por el hecho de parecerse más a la de la tasa de transpiración que al déficit de saturación del aire. Los principales componentes ambientales que influyen en la conductancia estomática a nivel del follaje son la luz, el déficit de presión de vapor y el estado hídrico de las hojas. Para un número importante de coníferas y latifoliadas perennes y de hojas caducas el cierre estomático completo se ha observado con déficit de presión de vapor de $35 \mathrm{mb}$. Los estomas de hojas que crecen bajo condiciones de mucho sol en ambientes expuestos generalmente son más sensibles que aquellos de hojas que crecen en ambientes sombreados (Waring \& Schlesinger, 1985). No está demás destacar que el agua disponible en el piso forestal es también esencial para los microorganismos libres y simbióticos, que intervienen en los procesos de descomposición de la matera orgánica, y en la liberación-inmovilización y la incorporación de nutrientes.

Integrando los flujos participantes en el ciclo hidrológicos se puede advertir que los cambios en la cubierta boscosa modificarán sustancialmente al mismo, y que las actividades posibles de manejo deberían tender a buscar prácticas que eviten las pérdidas de recursos y su uso eficiente. 


\subsection{Los ciclos de nutrientes y los ecosistemas forestales}

Otro de los factores que controla la productividad de las comunidades de eucaliptos es el ciclo de nutrientes entre la atmósfera, la biomasa de plantas y animales, y el suelo. Las diferencias en estos procesos cíclicos entre plantas individuales, especies y comunidades influencian su crecimiento relativo potencial y en consecuencia su distribución (Keith, 1997).

Los elementos minerales esenciales para el crecimiento de las plantas pueden ser divididos, de acuerdo a la cantidad requerida, en macronutrientes y micronutrientes. Entre los macronutrientes se encuentran el carbono, hidrógeno, oxígeno, nitrógeno, fósforo, azufre, calcio, magnesio y potasio, y entre los micronutrientes, boro, cloro, cobre, hierro, manganeso, molibdeno, cobalto y zinc. No obstante, esta es una clasificación relativa ya que los organismos pueden manifestar distinta demanda cualitativa y cuantitativa de elementos.

Switzer \& Nelson (1972) propusieron un enfoque para describir los ciclos de nutrientes en los sistemas forestales, identificando tres tipos de ciclo, de acuerdo con las escalas de los ecosistemas, en espacio y tiempo, involucradas. Este ha sido usado por distintos autores en balances de nutrientes de ecosistemas de bosques y plantaciones para estimar los aportes relativos de cada tipo de ciclo, el cual difiere según el nutriente (Kimmins, 1997; Laclau et al., 2009).

Laclau et al. (2009) en este contexto define a los tipos de ciclos de Switzer \& Nelson (1972) como sub-ciclos de los ciclos de nutrientes.

Sub-ciclo bioquímico. Se refiere a los movimientos de minerales, y las sustancias orgánicas en las que se encuentran, entre tejidos de los organismos, en particular para los árboles se destaca la retraslocación o redistribución de ciertos nutrientes desde las hojas senescentes hacia puntos de reserva o en activo crecimiento. Es importante en la recuperación de elementos químicos tales como el $\mathrm{P}$ y $\mathrm{N}$ que pueden migrar integrando 
moléculas orgánicas por vía floemática antes de la abscisión foliar, reduciendo la necesidad de absorción de nutrientes para satisfacer los requerimientos de la planta.

Sub-ciclo geoquímico. Abarca las relaciones de importación y exportación de nutrientes (ej. transporte por organismos, deposiciones atmosféricas, mineralización y pérdidas por drenaje) entre ecosistemas vecinos en el paisaje. Los ingresos atmosféricos durante periodos secos y lluviosos son una vía importante de aporte geoquímico en ciertos ecosistemas. A través del agua de lluvia, elementos minerales existentes en la atmósfera entran en ecosistemas terrestres en forma de iones disueltos y núcleos de condensación o, por el arrastre de partículas suspendidas en el aire, en la forma elemental. Estos ingresos varían en función de la localización geográfica, estación del año y de la cantidad de partículas existentes en el aire (Andrade et al., 1995).

Los nutrientes pueden ingresar a los ecosistemas como formas disueltas con la precipitación incidente (precipitación húmeda) y como seca particulada (precipitación seca) o como la combinación de ambas (bulk precipitation). La precipitación húmeda disuelve el nitrógeno y precipita el polvo y los contaminantes directamente desde la atmósfera. Aproximadamente $5 \mathrm{~kg}$ de nitrógeno por hectárea son adicionados anualmente en las zonas templadas, sin embargo el rango es típicamente entre 1 y $10 \mathrm{~kg}$ por ha (Spurr \& Barnes, 1980).

Subciclo- biogeoquímico. Comprende las relaciones suelo - planta - heterótrofos involucrados en las cadenas tróficas y las relaciones de extracción y restitución a los suelos en el seno de un ecosistema. La biogeoquímica en un ecosistema forestal es compleja y la disponibilidad de nutrientes depende de las interrelaciones entre el aporte, por las deposiciones atmosféricas, el intercambio catiónico, la meteorización mineral o mineral weathering (el aporte por el desgaste mineral) y la mineralización de la materia orgánica, y las pérdidas por la lixiviación y la inmovilización en la vegetación forestal.

Los cambios químicos ocurridos en el agua de lluvia se deben fundamentalmente a dos procesos: al lavado de elementos depositados sobre el follaje y a los cambios que se 
producen en el dosel arbóreo (a través de la lixiviación de nutrientes desde el follaje y/o la absorción directa de la copa).

La intercepción de la lluvia por las copas de los árboles tiene gran relevancia en el ciclo biogeoquímico de nutrientes en los suelos de baja fertilidad de los bosques nativos y de las plantaciones forestales.

Diversos estudios demuestran que las concentraciones de nutrientes en las vías de agua se incrementan en la secuencia precipitación - trascolación - flujo caulinar y escurrimiento superficial para luego frecuentemente descender en las aguas por debajo de la profundidad de mayor concentración de raíces (Kimmins, 1997; Laclau et al., 2005).

Las particularidades de la circulación del agua y los nutrientes asociados con ella en los flujos de los sub-ciclos geoquímico y biogeoquímico de las plantaciones forestales adquieren gran importancia debido a que la disponibilidad de agua y nutrientes suele ser la principal limitante para su crecimiento y producción. Asimismo, y en consonancia con el desarrollo de una actividad forestal amigable con el ambiente resulta importante comprender los balances de agua de las plantaciones con la finalidad de conocer el impacto ambiental, en el aspecto hidrológico, derivado del reemplazo de ecosistemas naturales o de cultivos de otras características.

El presente estudio abarca parte de los dos últimos sub-ciclos si bien, la lixiviación de nutrientes del follaje está relacionada con la ocurrencia de las retraslocaciones internas. La incorporación de información procedente de los trabajos publicados por otros autores permitirá asimismo ponderar la participación de los flujos hídricos y sus contenidos de nutrientes en la totalidad del ciclo de nutrientes de la plantación. 


\subsection{Relaciones del ciclo del agua con el ciclo de los nutrientes}

Las precipitaciones son una fuente de nutrientes al ecosistema ya que permiten deposiciones húmedas de sustancias presentes en el aire; si se trata de zonas con intensa actividad humana (urbana e industrial principalmente) los aportes pueden ser significativamente altos y hasta tóxicos o nocivos (por ejemplo lluvias ácidas). Sin embargo, muchos de los nutrientes se obtienen en solución gracias a la circulación del agua desde el suelo hacia las raíces y desde allí hacia el follaje y la atmósfera. La mayoría de los nutrientes que se absorben desde el suelo deben estar en estado iónico antes de ser absorbidos y esto requiere la presencia del agua. En resumen, la columna de agua extendida desde las raíces hasta las hojas lleva los nutrientes en solución y provee el medio de transporte dentro del árbol. La transpiración desde la superficie de las hojas hace posible el movimiento de agua hasta la cima de los árboles a la vez que juega un importante rol en la recarga de humedad de la atmósfera. Finalmente, cerrando el ciclo, la precipitación desde la atmósfera es directa o indirectamente responsable de la recarga de humedad del suelo (Spurr \& Barnes, 1980). Si bien los ciclos muchas veces son estudiados de manera aislada, los mismos constituyen una unidad.

Otro variable de importancia que caracteriza y vincula el ciclo de agua y nutrientes es el pH de los flujos hídricos. El pH del agua de lluvia, principal fuente de agua en las plantaciones estudiadas, puede dar indicio de las condiciones de la atmósfera de la zona de estudio y afectar distintos procesos vinculados con la circulación de nutrientes. Por ejemplo, valores de $\mathrm{pH}$ bajos pueden estar vinculados con una fuerte contaminación atmosférica en la cual los óxidos de nitrógeno y azufre pueden combinarse con el agua para formar ácidos fuertes que dan lugar a bajos pH. Asimismo, la lixiviación como mecanismo de retorno de nutrientes al suelo forestal se efectúa exclusivamente en solución acuosa. Los minerales pueden asimismo depositarse sobre las superficies vegetales y ser arrastrados por el agua de lluvia. Diferentes minerales se lavan y lixivian con distinta facilidad. La lixiviación es un proceso importante, principalmente para los elementos con alta solubilidad, pudiendo con el aumento del nivel de acidez de las lluvias aumentar la solubilización mineral, principalmente de cationes (McCune \& Boyce, 1992). De este modo, el lavado y la lixiviación de los nutrientes minerales desde las copas pueden 
intensificar el ciclo biogeoquímico, en la medida que el agua de lluvia que llega al suelo bajo el dosel arbóreo contenga nutrientes en las formas prontamente asimilables, siendo rápidamente absorbidos por las raíces y los microorganismos (Andrade et al., 1995).

\subsection{Flujos hídricos en plantaciones de Eucalyptus spp}

Las magnitudes de los flujos hídricos en las plantaciones de Eucalyptus spp y su impacto dependen de la densidad de plantación, las características del follaje, del tronco y de la corteza. Como así también, de las características climáticas y edáficas del lugar.

Antecedentes sobre valores de Precipitación Bruta (PB), Precipitación Neta (PN) e Intercepción (I) en plantaciones de Eucalyptus spp. se presentan en la Tabla 1. 1.

El consumo de agua de los eucaliptos se ha estimado con distintos métodos, en numerosos lugares del mundo bajo diferentes condiciones ambientales y edades. Valores diarios de consumo se presentan en la Tabla 1. 2 (Olbrich, 1990; Stape et al., 2002; Dye, 1996; Kallarackal, 1997; Benyon, 1999).

Las plantaciones de eucaliptos tienen un alto consumo de agua, pero a su vez una gran eficiencia en su uso. En los sitios más productivos de Brasil se han medido eficiencias de uso del agua (WUE) de hasta $311 \mathrm{Kg}$ agua / kg MS de producción primaria aérea neta (Stape, 2004a).

En cuencas del SE de Australia donde dominan bosques nativos de Eucalyptus spp. la napa freática se mantiene a mayor profundidad que en las cuencas convertidas a la agricultura. Allison \& Hughes (1983) observaron que la recarga debajo del bosque nativo era menor a

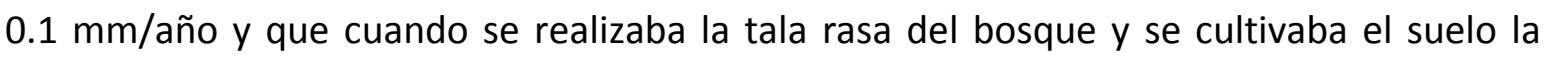
recarga se incrementaba a valores de entre 5-30 mm/año. 


\begin{tabular}{|c|c|c|c|c|c|c|c|}
\hline Especie & $\begin{array}{l}\text { Edad } \\
\text { (año) }\end{array}$ & $\begin{array}{l}\mathrm{PB} \\
(\mathrm{mm})\end{array}$ & $\begin{array}{l}\text { PN } \\
(\%)\end{array}$ & $\begin{array}{l}\text { I } \\
(\%)\end{array}$ & $\begin{array}{l}T \\
(\%) \\
\end{array}$ & $\begin{array}{l}\mathrm{FC} \\
(\%)\end{array}$ & Referencia \\
\hline E. camaldulenis & 1 & & & 5.3 & & & Karschon, 1971(*) \\
\hline E. camaldulenis & 3 & & & 7.1 & & & Karschon, $1971\left(^{*}\right)$ \\
\hline E. tereticornis & 6 & & & 11.7 & & & George, $1978\left(^{*}\right)$ \\
\hline E. tereticornis & 6 & & & 11.5 & & & Ghosh et al., $1979\left(^{*}\right)$ \\
\hline E.saligna & 6 & 1400 & 83.6 & 12.2 & & & Lima, $1976\left(^{*}\right)$ \\
\hline E. camaldulenis & 7 & & & 14.3 & & & Karschon, $1967\left(^{*}\right)$ \\
\hline E. saligna & 6 & 1280 & 88 & 12 & 84 & 4 & $\begin{array}{l}\text { Lima, } 1976 \text { en Bruijnzeel, } \\
1997\end{array}$ \\
\hline E.tereticornis & 6 & 1670 & 89 & 11 & 81 & 8 & $\begin{array}{l}\text { George, } 1978 \text { en Bruijnzeel, } \\
1997\end{array}$ \\
\hline E. grandis & 9 & 1396 & 88 & 10.8 & & & Soares et al., 2001 \\
\hline E. globulus & & & & 16.8 & & & Almeida et al.,1990 (*) \\
\hline E. melanophoia & & & & 11 & & & Prebble et al., 1980 \\
\hline E. dunni & & & & 12 & & & Rebori et al., 2004 \\
\hline
\end{tabular}

Tabla 1.1: Valores de precipitación bruta (PB), precipitación neta (PN), intercepción (I), trascolación (T) y flujo caulinar (FC) en plantaciones de Eucalyptus spp.

(*) Fuente: Teixeira Dias, 2004

\begin{tabular}{lccll}
\hline Especie & $\begin{array}{c}\text { Edad } \\
\text { (años) }\end{array}$ & $\begin{array}{c}\text { Transpiración } \\
\text { (mm/día) }\end{array}$ & Método & Referencia \\
\hline Eucalyptus spp & s/d & $1.5-6.0$ & & Poore et al.,1987 \\
E. camaldulensis & 1 & $1.5-3.5$ & PM & Roberts et al,1993 \\
E tereticornis & 4 & $3.5-7.7$ & PM & Kallarackal et al., 1997 \\
E. grandis & 4 & $2.5-6.5$ & PM & Kallarackal et al., 1997 \\
E. grandis & 9 & $1.1-5.8$ & PM & Soares \& Almeida, 2001 \\
E. grandis & 9 & $2.0-4.0$ & SF & Dye, 1996 \\
E. grandis & 5 & 4.3 & SF & Myers et al., 1998 \\
E. grandis & 3 & 8 & SF & Myers et al.,1996 \\
E. grandis & s/d & $3.02-3.50$ & Al & Nosetto et al., 2005 \\
E. grandis & 6 & $4.7(2.4-4.7)$ & PM & Dye, 1987
\end{tabular}

Tabla 1.2: Valores de transpiración diaria de plantaciones de Eucaliptos. Las abreviaciones en Método corresponden a Penman-Monteith (PM), Flujo de savia (SF) y a análisis de imágenes satelitales por el Método simplificado (AI). 
Por otra parte O’Laughlin \& Nambiar (2001) observaron que bajo la vegetación natural, las sales eran retenidas debajo de la zona radicular y relativamente inmovilizadas; pero el cambio hacia la agricultura resultó en recargas superiores, causando el acercamiento de la napa a la superficie y la movilización de la sal presente en el perfil. Según los autores la reforestación con árboles es vista como la herramienta más importante para restaurar el balance hidrológico en esta zona.

Según Stoneman (1994 en Bell \& Williams, 1997) para resistir la sequía los eucaliptos han desarrollado dos mecanismos principales que retardan la deshidratación, manteniendo la turgencia y el volumen celular. Algunas especies sobreviven la sequía mediante el control estomático, y otras, mediante el crecimiento de las raíces lo suficientemente profundo como para alcanzar el agua no disponible para otras plantas (Eldridge et al., 1994). Las especies que realizan control estomático tienden a desarrollar un potencial hídrico foliar pre-alba bajo (Ej. E. beheriana: -4.7 MPa; E. marginata: -2.4 MPa) que les permite sobrevivir potenciales hídricos edáficos moderadamente bajos (Bell \& Williams, 1997). Los valores más bajos indicarían una mayor habilidad para retener contenidos relativos de agua más altos en los tejidos durante los períodos de sequía. Por otra parte, las especies que, como E. camaldulensis (árbol freatófito), tienen la habilidad de desarrollar rápidamente sistemas de raíces profundos (Gibson et al., 1994; Awe et al. 1976 ambos en Bell \& Williams, 1997), y adquirir agua en profundidad, tienen elevados potenciales hídricos pre - alba aún durante períodos de sequía.

Para E. grandis en Concordia se han medido valores de potencial agua mínimos, en condiciones de marcada sequía, de $-3.3 \pm 0.3 \mathrm{MPa}(n=6)$, con conservación del contenido hídrico del agua foliar; en dichas condiciones se observó una notoria caída de hojas posiblemente producto de la cavitación en el xilema peciolar (Tesón et al., 2010). Este comportamiento correspondería al de las especies del primer grupo.

En un ensayo realizado en Wagga Wagga, Australia, en el que se reutilizaron los efluentes secundarios provenientes de una planta de tratamiento municipal se concluyó que el control estomático en Eucalyptus grandis limitaba el crecimiento y el uso de agua. En el 
ensayo se irrigó una plantación con distintas cantidades de efluentes, y también se realizó un tratamiento con agua natural, sin embargo el déficit de saturación de vapor del aire era tan elevado que los árboles cerraban los estomas y no transpiraban (Myers et al., 1996). La fuerte respuesta estomática en especies subtropicales, como es ésta, limitó su crecimiento y el uso del agua en climas con excesiva demanda atmosférica, aún cuando el agua del suelo y los nutrientes no son limitantes. Por lo tanto para este caso es una falacia calcular el consumo de agua en base a coeficientes de cultivo de la evaporación del tanque A. En el caso del ensayo mencionado la sobreestimación podría haber sido del $28 \%$. Sin embargo, un modelo como la ecuación de Penman - Monteith, la cual incorpora una función que describe la respuesta estomática a la VPD produce una ajustada estimación del uso del agua (Myers et al., 1996).

Posteriormente en un trabajo publicado por Korol et al.(2000), en el que se analiza la discriminación de los isótopos de C y la concentración intercelular de CO2, en cuatro sitios de Australia, con diferentes demandas evaporativas, se concluye que la disminución del crecimiento no se puede atribuir sólo a la respuesta estomática sino a la disminución de la capacidad fotosintética de las hojas, fundamentando que los valores más bajos de discriminación isotópica ocurrían en los sitios con mayor demanda atmosférica.

En un estudio sobre el efecto de las plantaciones sobre el rendimiento hídrico, Farley et al. (2005) analizaron 26 cuencas, con una cobertura forestal entre el $20 \%$ y el $100 \%$. Allí evaluaron distintos factores que afectaban el escurrimiento superficial: vegetación original, especie forestal, edad de la plantación, y precipitaciones medias anuales (MAP). Entre los resultados encontraron reducciones promedio del escurrimiento superficial entre el $44 \%$ y el $31 \%$ según si los sitios provenían de pastizales o áreas arbustivas respectivamente. Las cuencas forestadas con especies de Eucalyptus mostraron una mayor reducción del escurrimiento comparadas con las forestadas con especies de Pinus; la reducción del escurrimiento por Eucalyptus respecto de los pastizales fue del $75 \%$. Respecto a la edad esta afectó fuertemente el escurrimiento disminuyendo el mismo con el incremento de la edad de la plantación siendo mayor la reducción en los sitios provenientes de pastizales. Al relacionar el escurrimiento con la precipitación media anual 
(PMA), la reducción absoluta del escurrimiento fue mayor con valores mayores de PMA, pero en proporción resultaban menores sugiriendo que el efecto es más severo en zonas secas.

\section{6 Circulación de nutrientes en los flujos de agua en plantaciones de Eucalyptus spp}

A nivel internacional existen numerosos estudios sobre la circulación de nutrientes en los flujos de agua en plantaciones de Eucalyptus.

En Victoria, Australia, Baker \& Attiwill (1987) analizaron el contenido químico de los flujos de agua en forestaciones y bosques nativos de eucaliptos encontrando que la concentración de todos los elementos era mayor en el agua de trascolación que en el de la precipitación y que generalmente la concentración era aún mayor cuando se comparaba el flujo caulinar con la trascolación.

En África, Laclau et al. (2005) analizaron el agua de lluvia, trascolación y flujo caulinar en plantaciones de eucaliptos encontrando la tendencia mencionada en las concentraciones de nutrientes entre los flujos. Los principales cationes presentes en los flujos hídricos fueron sodio, amonio e hidrogeniones mientras que los aniones correspondían a cloruros, sulfatos y nitratos. Es importante destacar que la química de las precipitaciones analizadas por Laclau estaba fuertemente influenciada por la cercanía al mar.

En Brasil, Carvalho Balieiro et al. (2007) encontraron que el dosel arbóreo de distintas especies forestales evaluadas entre ellas la de E. grandis incrementaba la concentración en el agua de trascolación y de flujo caulinar respecto al agua de lluvia en la mayoría de los nutrientes estudiados ( $\mathrm{N}-\mathrm{NH} 4, \mathrm{~K}, \mathrm{Ca}, \mathrm{Mg}$ y $\mathrm{Na}$ ).

En otro estudio realizado en Brasil en plantaciones de 2 - 3 años de edad de $E$. grandis con distintos tratamientos de fertilización, Andrade et al. (1995) encontraron que el agua de lluvia que había pasado por la copa y troncos de los árboles (precipitación neta), se enriquecía en calcio, magnesio y sulfatos. Asimismo observaron disminución de la concentración de nitrógeno y fósforo. Lo que indicaba una posible absorción de estos 
nutrientes en el dosel arbóreo. El potasio se comportó de manera diferente según el tratamiento analizado siendo absorbido desde la copa en el tratamiento con menor aporte de fertilizante químico.

Un resumen sobre los antecedentes del aporte anual de nutrientes con los flujos hídricos en plantaciones de Eucalyptus grandis se presenta en la Tabla 1.3.

\subsection{La importancia de las plantaciones de eucaliptos de rápido crecimiento en el mundo y la Argentina}

El género Eucalyptus presenta un amplio espectro de especies, de árboles en relación a su adaptación a sitios, a sistemas de manejo y variedad de usos, tanto provenientes de bosques naturales como de plantaciones (Eldridge et al., 1994).

A pesar de ser casi exclusivo de Australia los eucaliptos pueden crecer en la mayoría de las regiones tropicales y templadas entre los $45^{\circ}$ latitud sur y los $40^{\circ}$ latitud norte.

La distribución y desarrollo de los distintos subgéneros, especies e individuos, en su área de origen, ha sido atribuido a las distintas respuestas a la disponibilidad de agua.

Los eucaliptos creciendo bajo diferentes condiciones ambientales, exhiben considerables variaciones morfológicas y fisiológicas. La complejidad de las respuestas ecofisiológicas a los estímulos ambientales ha sido estudiada para un número pequeño de especies (Williams \& Woinarski, 1997).

En el mundo es uno de los principales géneros elegidos para realizar plantaciones de rápido crecimiento ya que tiene una gran adaptación a distintas condiciones ecológicas y ha experimentado en los últimos años un importante incremento en su productividad debido a los avances en el mejoramiento genético y en el manejo intensivo de las plantaciones (Stape et al., 2001). Se ha estimado para el año 2008 una superficie mundial cubierta con especies del género Eucalyptus de 19.8 millones de hectáreas, siendo los 
principales países productores India, Brasil y China, que concentran el $56 \%$ de la superficie

\begin{tabular}{|c|c|c|c|c|c|c|c|c|c|}
\hline \multirow{2}{*}{ Especie } & \multirow{2}{*}{ Ubicación } & \multirow{2}{*}{ Flujo } & \multicolumn{6}{|c|}{ Nutrientes (kg/ha/año) } & \multirow{2}{*}{ Referencia } \\
\hline & & & $\mathbf{N}$ & $\mathbf{P}$ & K & $\mathrm{Ca}$ & Mg & $\mathrm{Na}$ & \\
\hline \multirow[t]{2}{*}{ E. grandis } & Australia & PB & & 0.1 & 6.1 & 3.5 & 3.1 & & Turner y \\
\hline & & PN & & 0.2 & 27.2 & 7.3 & 8.3 & & $\begin{array}{l}\text { Lambert, } \\
1983\left(^{*}\right)\end{array}$ \\
\hline \multirow[t]{3}{*}{ E. grandis } & Brasil & PB & 5.02 & 0.6 & 11.4 & 4 & 2.8 & 5.2 & \\
\hline & & PN & 7.15 & 1.2 & 37.8 & 4.5 & 3.4 & 14 & Carvalho \\
\hline & & $\mathrm{FC}$ & 0.04 & 0.4 & 13.5 & 2.8 & 2.1 & 3.8 & $\begin{array}{l}\text { Balieiro,1999 } \\
(*)\end{array}$ \\
\hline \multirow[t]{4}{*}{ E. grandis } & Brasil & PB & $8.42(* *)$ & 0.95 & 19.04 & 6.74 & 4.72 & 8.71 & Carvalho \\
\hline & & $T$ & $12(* *)$ & 1.99 & 63.36 & 7.62 & 5.68 & 23.47 & Balieiro, \\
\hline & & FC & $0.07(* *)$ & 0.66 & 22.64 & 4.63 & 3.56 & 6.34 & 2007 \\
\hline & & PN & 0.8 & 0.2 & 6.1 & 3.5 & 3.1 & & Andrade et \\
\hline E. grandis & Brasil & PB & 3.3 & 0.8 & 21.1 & 3.8 & 5.2 & & al., $1995\left(^{*}\right)$ \\
\hline Eucalyptus & Camerún & $\mathrm{PB}$ & 3.6 & 0.1 & 8.6 & 5.5 & 1.1 & & Harmand, \\
\hline$s p$. & & PN & 4.9 & 0.5 & 15.7 & 6 & 1.8 & & 1997 \\
\hline \multirow[t]{2}{*}{ E. grandis } & Brasil & $\mathrm{PB}$ & 5.3 & 1.2 & 13.3 & 5.1 & 1.7 & & Andrade et \\
\hline & & PN & 1.5 & 4.7 & 15.9 & 3.39 & 3.5 & & al., $1995\left(^{*}\right)$ \\
\hline Eucalyptus sp & Portugal & $\mathrm{PB}$ & 5.2 & 0.1 & 1.2 & 4 & 1.7 & 13.3 & $\begin{array}{lr}\text { Cortez en } \\
\text { Laclau, } 2001\end{array}$ \\
\hline
\end{tabular}

cultivada (Iglesias-Trabado \& Wilstermann, 2008).

Tabla 1.3: Antecedentes del aporte de nutrientes de la precipitación bruta (PB), la precipitación neta (PN), la trascolación (T) el flujo caulinar (FC). $\left(^{*}\right)$ Fuente: Teixeira Dias, H. C., 2004; $\left(^{* *}\right)$ Solo análizado $\mathrm{N}-\mathrm{NH}_{4}$

Según sus características ecológicas Florence (1996) distingue 5 categorías de especies del género Eucalyptus basadas en el consumo de agua, características del crecimiento y tolerancia a la sequía (Tabla 1.4). El autor citado considera que estas categorías pueden ser utilizadas para interpretar el comportamiento de las especies de eucaliptos como exóticas. 
La clasificación de Florence permite apreciar la amplitud de condiciones ambientales en donde pueden desarrollarse las distintas especies del género y los diversos mecanismos de adaptación desarrollados.

\subsection{Los eucaliptos cultivados en la Mesopotamia argentina con especial referencia al Departamento Concordia.}

Los eucaliptos en la Argentina habrían sido introducido en el año 1857 por Domingo F. Sarmiento quién hizo sembrar Eucalyptus globulus en estancias y campos de la Provincia de Buenos aires. Al principio las forestaciones de eucalipto acompañaron el desarrollo de los establecimientos agrícolas donde se los utilizó como cortinas protectoras, como sombra para el ganado y para la ornamentación de jardines y plazas (Carpinetti et al, 1995).

La introducción del eucalipto para plantaciones forestales en la Región Mesopotámica reconoce dos vías: desde Brasil en Misiones y desde Australia en Entre Ríos (Carpinetti et al., 1995).

En la Provincia de Entre Ríos las forestaciones reemplazan comunidades de vegetación natural como los pastizales con isletas de árboles (monte) y el bosque (monte) abierto, como así también a otros usos de la tierra como plantaciones de árboles, actividades agrícolas y pecuarias.

En el NE de Entre Ríos la superficie forestada con Eucalyptus spp es de 90048 ha (Braier, 2004) siendo la especie dominante Eucalyptus grandis (90\%).

En los Departamentos de Concordia y Colón se han forestado unas 6000 ha con Eucalyptus globulus subsp. globulus, con serios problemas sanitarios, de crecimiento y de forma por 
falta de adaptabilidad de la especie a las condiciones templado cálidas de la región. Esta especie provee la mejor pasta pulpable a nivel mundial.

Eucalyptus dunnii, es una especie con muy buenas condiciones para producir pulpa de papel y regulares condiciones para el aserrado. De muestra una muy buena adaptación a las condiciones ecológicas de la zona y resulta muy interesante por su tolerancia al frío, mayor que la del Eucalyptus grandis. Pero su comportamiento para el aserrado y la falta de experiencia en el secado limitan su actual expansión (Marcó \& Shield, 2005). 


\begin{tabular}{|c|c|c|}
\hline Categoría & Especies & Características \\
\hline I & $\begin{array}{l}\text { E. regnans } \\
\text { E. delegatensis } \\
\text { E. diversicolor }\end{array}$ & $\begin{array}{l}\text { Incluye especies de alta productividad. Ninguna de las especies está ampliamente } \\
\text { cultivada como exótica. Limitadas capacidades para tolerar condiciones } \\
\text { ambientales adversas. }\end{array}$ \\
\hline II & $\begin{array}{l}\text { E. grandis } \\
\text { E. urophylla } \\
\text { E. robusta } \\
\text { E. globulus } \\
\text { E. viminalis } \\
\text { E. saligna }\end{array}$ & $\begin{array}{l}\text { Especies de alta productividad. Crecimiento inicial rápido. Difieren de las anteriores } \\
\text { por su amplia tolerancia ambiental. Pueden tener alta tasa de crecimiento y de } \\
\text { consumo de agua y adaptarse a condiciones más severas que en su distribución } \\
\text { natural. }\end{array}$ \\
\hline III & $\begin{array}{l}\text { E. camaldulensis } \\
\text { E. tereticornis }\end{array}$ & $\begin{array}{l}\text { Crecimiento inicial rápido. Altas tasas de consumo de agua cuando está disponible. } \\
\text { Mayor tolerancia a largos períodos de sequía. Pico de crecimiento a los } 4 \text { - } 5 \\
\text { años. Desarrollo radicular profundo. Control estomático. }\end{array}$ \\
\hline IV & E. pilularis & $\begin{array}{l}\text { Adaptadas a suelos con poco desarrollo, con impedimentos y por lo tanto, con } \\
\text { limitado almacenamiento de humedad. Sitios expuestos a fuerte estrés } \\
\text { evapotranspiracional. Especies poco usadas como exóticas. Con posibilidades } \\
\text { dadas las características de su madera para sitios secos en áreas con alta a } \\
\text { moderada precipitación. }\end{array}$ \\
\hline V & $\begin{array}{l}\text { E. sideroxylon } \\
\text { E. mycrocarpa } \\
\text { E. wollsiana } \\
\text { E. melliodora }\end{array}$ & $\begin{array}{l}\text { Especies de las zonas más secas del continente. Presencia de lignotuber, sistema } \\
\text { radicular muy extensivo, amplio espacio entre los árboles maduros, conservación } \\
\text { del agua del suelo mediante una moderada conductancia estomática en } \\
\text { condiciones favorables. }\end{array}$ \\
\hline
\end{tabular}

Tabla 1.4: Clasificación de las especies de Eucalyptus spp. según el consumo de agua, las características del crecimiento y la tolerancia a la sequía. Fuente: Florence (1996). 
A nivel experimental se están evaluando, híbridos interespecíficos de $E$. grandis $x E$. camaldulensis y de E. grandis $x$ E. tereticornis y la expectativa recae en combinar características de crecimiento, adaptación ecológica y calidad de madera de las especies progenitoras. Otra especie promisoria para la zona es $E$. saligna que demuestra tener muy buenas aptitudes maderables con posibilidades ciertas de encontrar orígenes geográficos de semilla en Australia tolerantes a las bajas temperaturas (Marcó \& Shield, 2005).

\section{8.1 Características del Departamento Concordia}

Ubicación. El Departamento Concordia (DC) posee una extensión territorial de $3508 \mathrm{~km}^{2}$ se encuentra ubicado en el extremo noreste de la provincia de Entre Ríos entre los $57^{\circ} \mathrm{y}$ $58^{\circ}$ de longitud oeste y entre los $30^{\circ}$ y $31^{\circ} 50^{\prime}$ de latitud sur. Está limitado al norte por el Departamento Federación, al oeste por los Departamentos Federal, Villaguay y San Salvador, al sur por el Departamento Colón y al este por el Río Uruguay. Políticamente, está dividido en 5 distritos: de norte a sur, Moreira $\left(753 \mathrm{~km}^{2}\right)$, Suburbios $\left(615 \mathrm{~km}^{2}\right)$, Ejido de Concordia $\left(184 \mathrm{~km}^{2}\right)$, Yuquerí $\left(1173 \mathrm{~km}^{2}\right)$ y Yeruá $\left(682 \mathrm{~km}^{2}\right)$.

Clima. La región de Concordia puede caracterizarse climáticamente como templado cálida sin estación seca, con una temperatura media anual de $18.7^{\circ} \mathrm{C}$, temperaturas media y máxima media de $25.2^{\circ} \mathrm{C}$ y $32.2^{\circ} \mathrm{C}$, respectivamente, para el mes más cálido enero- y temperaturas media y mínima media de $12.6^{\circ} \mathrm{C}$ y $7.1^{\circ} \mathrm{C}$, respectivamente, para el mes más frío, julio.

El período medio libre de heladas es de 10 meses, con una frecuencia media de 7 heladas meteorológicas en los últimos 15 años y con valores promedio de las máximas y mínimas extremas anuales de $38.1^{\circ} \mathrm{C}$ y $-1.7^{\circ} \mathrm{C}$ y de $41.4^{\circ} \mathrm{C}$ y $-5.1^{\circ} \mathrm{C}$ para las máximas y mínimas absolutas registradas hasta la fecha, respectivamente (Garrán, 2007). El número de días con heladas se incrementa de este a oeste, siendo el período de ocurrencia de heladas de mayo a septiembre.

Los valores de humedad relativa son altos durante todo el año mayores al $70 \%$, entre abril y agosto la humedad relativa supera el $80 \%$. 
El promedio anual de las precipitaciones y el valor de su mediana son $1345.3+/-287.7 \mathrm{~mm}$ y $1261 \mathrm{~mm}$ con valores anuales máximos y mínimos de $2193.2 \mathrm{~mm}$ y $868.1 \mathrm{~mm}$, respectivamente. Aunque el balance hidrológico registra ligeros déficits en diciembre, febrero y algo mayores en enero, la mayoría de los índices climáticos indican ausencia de estación seca o de meses secos (Garrán, 2007). No obstante, el amplio rango de lluvias anuales muestra que hay años extremadamente lluviosos y otros muy poco lluviosos. En estos últimos, se observa en las plantaciones de Eucalyptus grandis manifestaciones de estrés hídrico, como reducción del área foliar y del crecimiento fustal.

El trimestre con menores lluvias corresponde al invernal, en el que se registra el $15 \%$ del total anual, correspondiéndole a las tres estaciones restantes porcentajes similares del orden del $28 \%$. A pesar de ello, el trimestre invernal es el que suele tener los mayores excesos hídricos, en parte por un almacenaje de humedad edáfica proveniente de las lluvias abundantes de otoño, y en parte también por la menor evapotranspiración estacional debido a las temperaturas invernales relativamente bajas (Garrán, 2007).

El promedio de días con lluvias (período 1950 -1990) fue de 88.2 días/año.

La evaporación potencial anual (Tanque A) es de 1420 mm alcanzando valores máximos en diciembre y enero de 207 y $204 \mathrm{~mm}$ respectivamente.

En cuanto a los vientos predominan los procedentes del este, ya como aire cálido y húmedo cuando provienen del NE o como aire frío y húmedo cuando provienen del SE.

La información geológica, geomorfológica y edáfica que se incluye a continuación se obtuvo de Tasi (1993).

Geología. Las rocas más antiguas que afloran en el Departamento Concordia corresponden a basaltos de la formación "Serra Geral". Por encima de la formación "Serra Geral" se depositaron, en el Cretácico Superior, las areniscas rojas bien silicíficadas de la formación "Puerto Yeruá". Al igual que los basaltos no originan suelos excepto en 
ciertos puntos, aunque sí es importante su influencia sobre las geoformas locales. Durante la era Terciaria se depositaron varias formaciones que no afloran en el Departamento, Formación "Pay Ubre" y Formación "Fray Bento". Al final de esta era y comienzo de la era Cuaternaria se depositó la Formación "Ituzaingó" (Plioceno Superior Plioceno Inferior conformadas por arenas ocráceas y delgados bancos arcillosos verde azulados).

Durante la era Cuaternaria se depositaron los sedimentos a partir de los cuales se desarrollaron los principales suelos del departamento. La más antigua de estas formaciones (Pleistoceno inferior o medio) la constituyen los sedimentos fluviales de la Formación "Salto Chico" conformada por una composición heterogénea de arcillas arenosas de tonalidades muy rojas y a veces amarillentas, intercalándose lentes de canto rodados. También durante el Pleistoceno medio se depositaron los sedimentos de la formación más importante de la provincia por su gran área de distribución y porque es el material parental que generó a los suelos de los órdenes Vertisoles, Alfisoles y algunos Molisoles. Se trata de la Formación "Hernandarias", constituida por sedimentos de origen lacustre o palustre con un alto contenido de arcillas expansibles, fundamentalmente montmorillonita e illita en una proporción del $75 \%$ al $95 \%$ de la primera y un $25 \%$ al $10 \%$ de la segunda. El $56 \%$ de los suelos del departamento fueron originados en esta formación.

Geomorfología. Realizando un corte Este - Oeste se encuentran las antiguas terrazas del Río Uruguay las cuales debido a los procesos de erosión geológica a los que han sido sometidas han ido perdiendo las formas aplanadas para transformarse con el tiempo en un paisaje ondulado con pendientes entre $4-6 \%$ y en algunos puntos cercanos al río de hasta $8-9 \%$ y aún superiores. Hacia el oeste y en una posición más alta del paisaje se encuentra una franja de ancho irregular de 2 a $15 \mathrm{~km}$, con suelos arenosos pardos localmente llamados "mestizos". Su relieve es ondulado a suavemente ondulado, con pendientes largas que rara vez superan el $3 \%$ y presenta una red de drenaje bien definida. Esta unidad constituye una zona intermedia entre las arenas rojizas de las terrazas fluviales del río y el dominio de los suelos negros arcillosos, del orden Vertisol, en la zona occidental. Más hacia el oeste y ubicadas en las alturas máximas del 


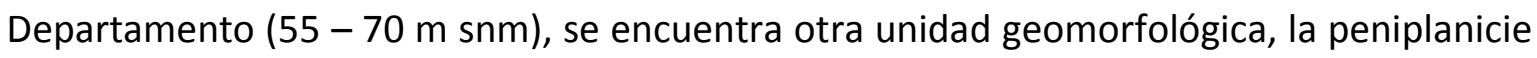
ondulada caracterizada por pendientes entre el $2.5-3 \%$ de intensidad con longitudes que oscilan entre los $500-700 \mathrm{~m}$. Constituye un paisaje muy homogéneo característico para el centro del Departamento. Continúa hacia el oeste el paisaje de las altillanuras relativamente similar al anterior pero donde el rasgo geomorfológico característico es la suavidad de las ondulaciones, con pendientes que rara vez superan el $1.5 \%$ que normalmente superan los 1500 m de longitud, por lo cual la definición de la red de drenaje no es clara. En el extremo noroeste del Departamento aparecen las unidades que fisiográficamente han sido denominada "altillanuras junto a aquellas otras que localmente se conocen como "bañados de altura". Estas son áreas planas sin red de drenaje definida y con charcos y lagunas que en algunos puntos cubren hasta el $60 \%$ de la unidad. Se trata de una antigua superficie que durante el Holoceno tardío sufrió una intensa acción eólica.

Suelos. Los suelos del Departamento Concordia pertenecen a los Órdenes Vertisoles, Molisoles, Entisoles, Inceptisoles y Alfisoles (Plan Mapa de Suelos, 1993). Los suelos destinados a la producción forestal son principalmente los llamados localmente arenosos y mestizos que corresponden a suelos de los Órdenes Entisoles, Inceptisoles y Molisoles.

Los suelos más productivos son los mestizos, correspondientes a los órdenes Inceptisoles y Molisoles, con incrementos medios anuales a los 10 años (IMA) cercanos a los $50 \mathrm{m3} / \mathrm{ha}$ año.

Comparado con los suelos arenosos (Orden Entisol) los suelos mestizos tienen un desarrollo pedogenético mayor, presentando uno o más horizontes diagnóstico. Tienen un epipedón oscuro debido al mayor contenido de materia orgánica y mayor retención de humedad, y no presentan problemas potenciales con el exceso de agua o el déficit hídrico propio de los suelos arcillosos (Vertisoles).

Los suelos vertisoles tienen un desarrollo pedogenético relativamente mayor que el de los Entisoles, por lo cual presentan uno o más horizontes diagnóstico. Sin embargo son el resultado de procesos de evolución incipientes. Tienen un epipedón oscuro por el alto 
contenido de materia orgánica que puede ser confundido con un epipedón mólico sin embargo la relación $\mathrm{C} / \mathrm{N}$ es muy alta (más de 17) y la saturación de bases es menor al 50\%. No obstante el perfil típico descripto en la fuente bibliográfica no presenta una relación $\mathrm{C} / \mathrm{N}$ superior al límite mencionado.

Actividades. Las principales actividades agropecuarias que coexisten con la actividad forestal en el Departamento Concordia son la producción cítrica, ganadera, arrocera y en los últimos años ha comenzado a desarrollarse la producción de arándanos destinado a la exportación para consumo como fruta fresca.

\subsection{Eucalyptus grandis Hill ex Maiden: descripción y requerimientos ecológicos}

La especie Eucalyptus grandis es nativa de la costa este de Australia (Figura 3). Su nombre común es "rose gum" (eucalipto rosado) o "flooded gum". A pesar de su nombre común, la especie no tolera períodos de anegamiento (Burguess, 1983 citado por Eldridgeet al., 1994).

Eucalyptus grandis es una de las principales especies forestales en los estados australianos de Queensland y New South Wales, en donde alcanza una altura de 43 a $55 \mathrm{~m}$ y un diámetro de 122 a $183 \mathrm{~cm}$. Su forma es cilíndrica, con fuste claro, recto y alto de hasta dos tercios de la altura total. La corteza es delgada y caduca, se desprende en fajas, lo que deja ver una superficie lisa, marcada con patrones ondulados, de color blanco-plateado, gris pizarra, terracota o verde claro. En ocasiones persiste un forro cortical gris claro, en forma de planchas o con fisuras, sobre los primeros 1-2 $\mathrm{m}$ de la base del tronco.

Eucalyptus grandis crece en forma continua en la costa de New South Wales y Queensland desde los $32^{\circ} 52^{\prime} \mathrm{S}$ hasta los 26오 (Eldridge et al., 1994). En esa área de su distribución crece en las margas aluviales o volcánicas, en valles y planicies a una distancia máxima de la costa de $160 \mathrm{~km}$ (Meskimen \& Francis, 2000) (Figura 1.2). Más al N la especie está ausente hasta ca. 18ㅇ S y en forma de parches alcanza el extremo $\mathrm{N}$ de su rango a los 16응 S (Burgess, 1983 citado por Eldridge et al., 1994) 
E. grandis crece en un rango de tipos de suelos pero generalmente ocupa los moderadamente fértiles, en valles de baja pendiente a menudo adyacentes a la selva tropical (rain forests) (Eldridge et al., 1994).

El clima en la distribución natural australiana de la especie es subtropical húmedo, con temperaturas mínimas promedio durante los meses más fríos entre 2 y $10{ }^{\circ} \mathrm{C}$ y temperaturas máximas promedio de cerca de $29{ }^{\circ} \mathrm{C}$ durante los meses más calientes. La precipitación promedia entre 1020 y 1780 mm anuales; se encuentra concentrada durante el verano y la precipitación mensual durante la temporada seca es de por lo menos 20 $\mathrm{mm}$. Las áreas costeras se ven por lo general libres de las heladas, pero las áreas a una mayor altitud y más alejadas de la costa sufren heladas ocasionales (Meskimen \& Francis, 2000).

Los nichos climáticos para las especies, derivados de su distribución natural (nativa) y/o de su buen comportamiento en sitios exóticos, pueden ser usados para determinar áreas climáticamente adecuadas para su introducción (Eldridge et al., 1994). Teniendo en cuenta que la distribución continua y principal de E. grandis se encuentra principalmente en clima subtropical húmedo puede notarse que homoclimas de su área de distribución nativa se encuentran en África, Asia y América, incluyendo la zona de plantación en nuestro país (Figura 1.3). Criterios de zonas aptas de plantación basados en las condiciones climáticas han sido desarrollados en Natal, Sudáfrica. Esta experiencia indicó que la temperatura media del mes más frío no debería ser menor a 11 ㄷ $\mathrm{C}$ y que la temperatura media diaria mínima no debería ser menor a 4 으 para el crecimiento óptimo de la especie E. grandis (Eldridge et al., 1994). Booth \& Prior (1991), considerando las áreas de crecimiento óptimo, estimaron los requerimientos de 21 especies de Eucalyptus. Para E. grandis fueron: precipitación media anual entre 700 y 2500 mm, régimen de precipitaciones uniformes o estivales, período seco entre 0 y 7 meses, temperatura media máxima del mes más cálido entre 25 y $34^{\circ} \mathrm{C}$, temperatura media mínima del mes más frío entre 3 y $18^{\circ} \mathrm{C}$, temperatura media anual entre 14 y $25^{\circ} \mathrm{C}$ y temperatura mínima absoluta mayor a $-8^{\circ} \mathrm{C}$. 


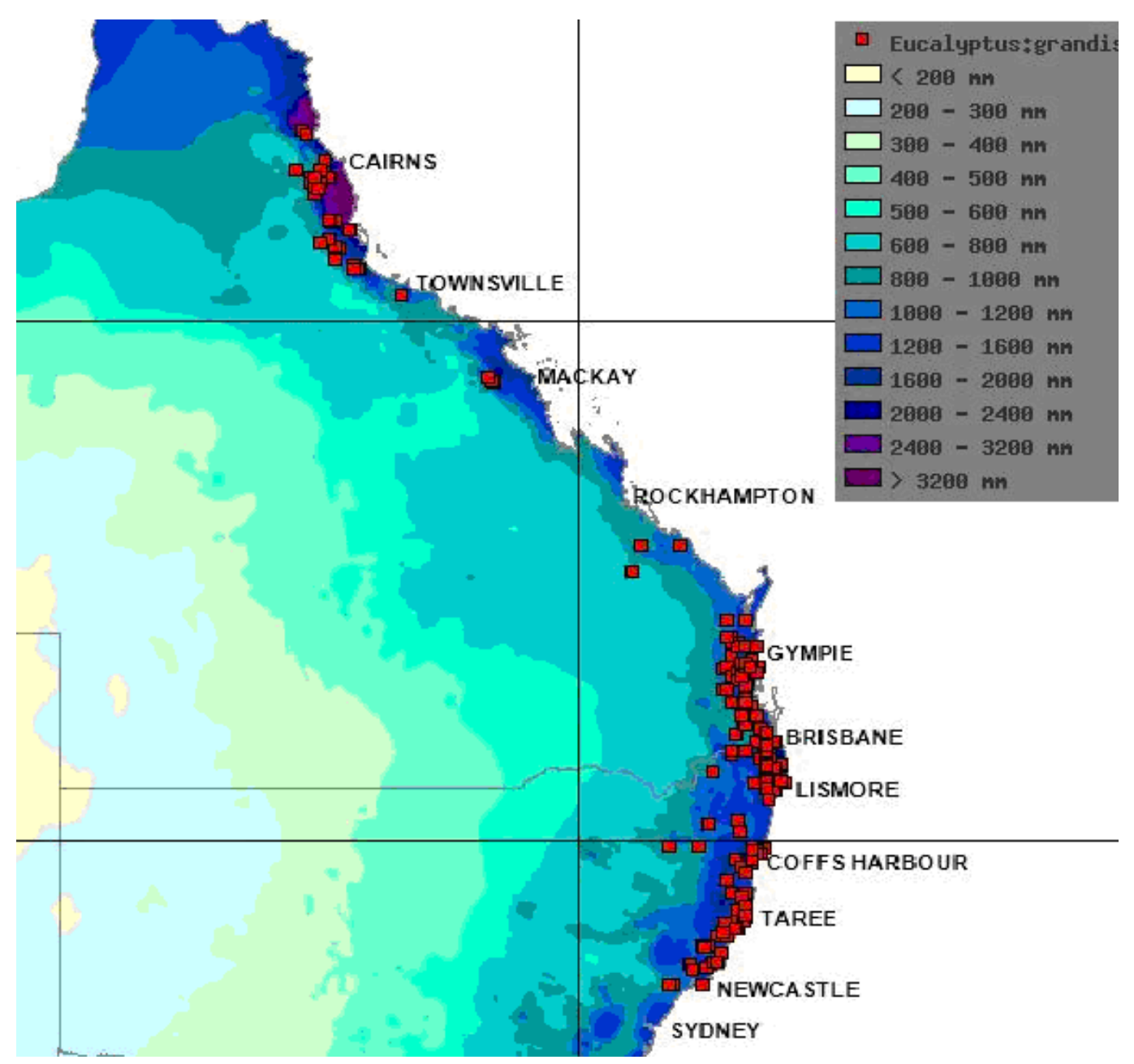

Figura 1.2: Área de distribución geográfica natural de E. grandis y de las precipitaciones anuales. Fuente: Australian's virtual herbarium. Royal Botanic Gardens, Melbourne.

Eucalyptus grandis pertenece al subgénero Shymphyomyrtus. Las especies de éste subgénero, han sido consideradas más tolerantes al frío, especialmente bajo condiciones de anegamiento, que las del subgénero Monocalyptus (Noble, 1989 en Bell \& Williams, 1997). Sin embargo, la helada es considerada uno de los factores que limita los rangos latitudinal y altitudinal de distribución de las plantaciones de E. grandis. Existen registros de severos daños por heladas en África, Sudamérica y sudeste de EE UU (Eldridge et al., 1994). En la zona de Concordia las heladas suelen afectar negativamente (matan y deforman las plantas) a ejemplares de las plantaciones jóvenes de E. grandis, principalmente las implantadas durante el otoño. 


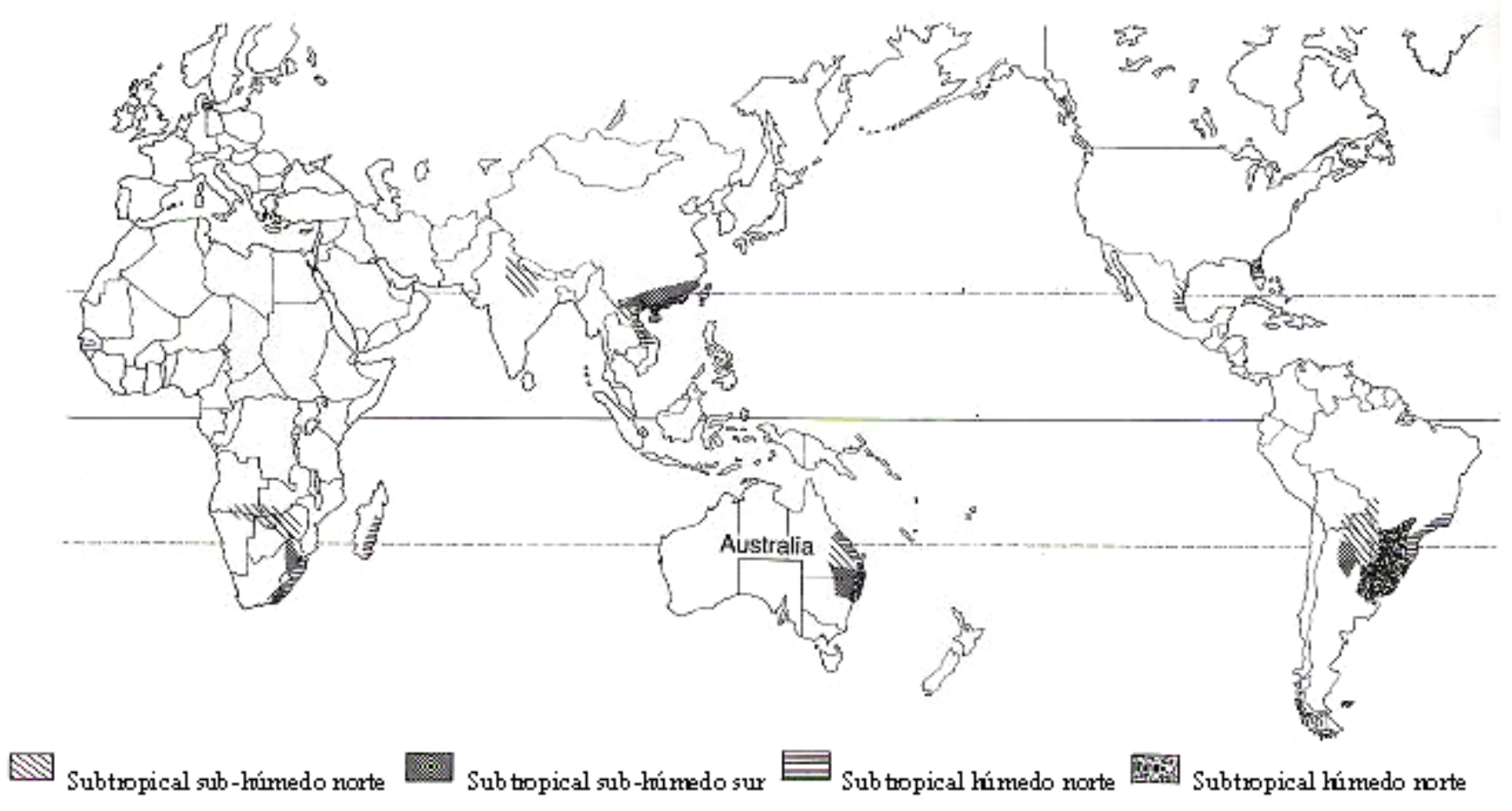

Figura 1.3: Climas del mundo: la región subtropical. Fuente: Eldridge et al., 1994.

\section{10 Estado del conocimiento}

Referido al balance de agua en ecosistemas forestales los antecedentes nacionales no son muchos. Existe un estudio en Argentina en bosques nativos de Nothofagus en Tierra del Fuego realizado por Frangi \& Richter (1994). En este estudio se evaluó el ciclo hidrológico en bosques de $N$. pumilio, $N$. antartica y $N$. betuloides concluyendo que el agua no es una limitante para el desarrollo de estos bosques basales y que las magnitudes de los componentes del ciclo hidrológico están asociados con numerosas variables como el régimen de precipitaciones, el relieve, el tipo de suelo, la biomasa y la estructura forestal, la duración de las fenofases foliares, el índice de área foliar y la arquitectura de las plantas, entre otras.

En plantaciones los antecedentes principalmente se refieren a la Patagonia sobre el uso de agua de plantaciones de Pinus ponderosa en los que se lo compara con el de los pastizales 
nativos o con especies forestales nativas. En estos estudios se evalúa el consumo de agua, la eficiencia en el uso del agua y numerosos parámetros fisiológicos (Gyenge et al., 2008; Licata et al., 2008, 2011). En los mismos se concluye que $P$. ponderosa tiene mayor consumo de agua que los pastizales y que Austrocedrus chilensis, aunque menores pérdidas por intercepción cuando se lo compara con este último. Estos estudios alertan sobre la importancia de evaluar los efectos de este tipo de plantaciones sobre los recursos hídricos de esa zona.

Dentro del género Eucalyptus existe un estudio en una plantación de Eucalyptus camaldulensis sobre el uso del agua subterránea en la Provincia de Buenos Aires en el cual se observó que las plantaciones con esta especie ocasionaban la salinización de los suelos debido a la interrupción de la recarga y por lo tanto del lavado de sales, y al mayor consumo de agua en relación al pastizal. Se demostró además cómo el cambio de vegetación altera la distribución vertical y la biodisponibilidad de elementos minerales al estudiar la reducción del contenido de Mn en profundidad $(20-60 \mathrm{~cm}$ ) en plantaciones de 50 años y su mayor concentración en superficie, entre 12 y 25 veces mayor a la de la de los pastizales naturales (Jobbagy et al., 2004).

Para la zona de Concordia existe un estudio realizado por Nosetto et al. (2005), citado en la introducción, en el que se estima la evapotranspiración de plantaciones de Eucalyptus grandis y de pastizales usando información radiométrica de imágenes satelitales, en un gradiente textural de suelos, concluyendo que esta especie utiliza más agua que los pastizales nativos.

Sin embargo dada la importancia del Eucalyptus grandis entre las especies utilizadas en las plantaciones comerciales y la cantidad de superficie forestada en Argentina y particularmente en la Mesopotamia, como se alerta en los antecedentes, son necesarios estudios hidrológicos y de nutrientes en los flujos hídricos a nivel de ecosistemas, particularmente en plantaciones de Eucalyptus grandis, que permitan disponer de más información científica para evaluar y mitigar, si es necesario, los cambios que se producen por el cambio en el uso de los recursos. 


\section{11 Justificación}

Se estima que conocer las particularidades y magnitudes de los flujos hídricos, y del movimiento de ingreso y egreso de nutrientes asociados a las vías de agua de las plantaciones, contribuirá a tener elementos de juicio relevantes para quienes tomen decisiones acerca de la planificación del uso de la tierra. En un marco sustentable esa información aportará elementos vinculados a la necesidad de compatibilizar los beneficios económicos de corto plazo con el sostenimiento de la producción, la calidad ambiental y la calidad de vida en el futuro previsible para la región de referencia.

\subsection{Objetivos}

Los objetivos principales de esta tesis son:

- Determinar las características endoclimáticas de la plantación y compararlas con los claros circundantes. Vincular éstas características con los flujos de agua del rodal.

- Identificar cambios en los suelos como resultado de la conversión de pastizales a plantaciones forestales de Eucalyptus grandis.

- Cuantificar los flujos aéreos del ciclo hidrológico en una plantación de Eucalyptus grandis de edad al turno (11 años). Comparar la trascolación en plantaciones de 3 y 11 años.

- Establecer, en base a datos de eventos de lluvia individuales, modelos de regresión entre la precipitación bruta y otras vías de flujo propias del bosque con el fin de evaluar herramientas predictivas de comportamiento hidrológico de la plantación.

- Estimar la demanda evapotranspiratoria en una plantación de Eucalyptus grandis y las consecuencias de las pérdidas gaseosas en el balance de agua bajo el régimen de precipitaciones de la zona. 
- Estimar la circulación (aportes, movimientos internos y salidas) de macronutrientes por flujos de agua y ponderar su magnitud en relación a datos disponibles de nutrientes asociados a flujos de la materia seca (biomasa y necromasa).

- Realizar un modelo de ciclo de nutrientes de la plantación al turno integrando la información obtenida en éste estudio con la existente en la bibliografía para las mismas plantaciones.

\subsection{Hipótesis}

Las hipótesis planteadas son las siguientes:

Hipótesis 1: A consecuencia del cambio del tipo de vegetación, en el sitio forestado se producen un endoclima particular y procesos en el suelo que conducen a la pérdida de nutrientes y a la acidificación del mismo.

Hipótesis 2. Las magnitudes de los flujos hídricos en la plantación están directamente relacionadas con la magnitud de la precipitación bruta y con la estructura de la plantación.

Hipótesis 3. Como consecuencia de la intercepción de agua por el dosel, del lavado y lixiviado del follaje y del mantillo, la concentración de nutrientes y la abundancia de sustancias orgánicas cromóforas aumenta en la secuencia de eventos de precipitaciones, trascolación, flujo caulinar, escurrimiento.

Hipótesis 4. Debido a los procesos de descomposición del mantillo forestal hay un aporte de nutrientes en solución que ingresan en el suelo mineral.

Hipótesis 5. La magnitud de la pérdida de nutrientes por escurrimiento es proporcional a la magnitud del evento de lluvia.

Hipótesis 6. En condiciones ecológicas comparables la eficiencia de uso de agua en la producción de madera de esta especie es similar a la encontrada en otras regiones de cultivo de eucaliptos. 


\section{Capítulo II}

Metodología 


\section{METODOLOGÍA}

\section{1 Área de Estudio}

Ubicación. El estudio se realizó en la Estación Experimental Agropecuaria Concordia del Instituto Nacional de Tecnología Agropecuaria ubicada en el Distrito Yuquerí del Departamento Concordia, a $12 \mathrm{~km}$ de la Ciudad de Concordia.

Clima. El clima en el área de estudio es templado cálido sin estación seca. Véanse detalles en 1.9.

Suelos. El suelo sobre el que se desarrolló este estudio se clasificó como Haplumbrepte fluvéntico (Orden Inceptisol), localmente denominado "suelo mestizo". Este suelo está representado en el Departamento Concordia por la Serie Puerto Yeruá.

\subsection{Materiales y métodos}

\subsubsection{Parcelas experimentales}

Dentro de la EEA Concordia fueron seleccionadas dos forestaciones de Eucalyptus grandis de 3 años (sitio I) y 12 años (sitio III) de edad, considerando situaciones similares de suelos y técnicas de manejo, y dos parcelas de pastizal testigo cercana a las forestaciones (Figura 2.1).

El manejo de las plantaciones elegidas para el estudio fue el tradicional de la zona. El suelo fue preparado mediante labores mecánicas (con rastras de disco y de dientes) y la plantación fue realizada de manera manual. No se realizaron podas ni raleos.

Los lotes forestados así como el pastizal testigo eran, con anterioridad a 1966, terrenos de pastizales naturales bajo uso ganadero. Los lotes y el pastizal testigo 1 son muy cercanos, aproximadamente los tres sitios se encuentran dentro de un radio de $150 \mathrm{~m}$. La EEA Concordia, se establece en el predio de Estación Yuquerí en el año 1966, anteriormente el predio era un campo privado. 


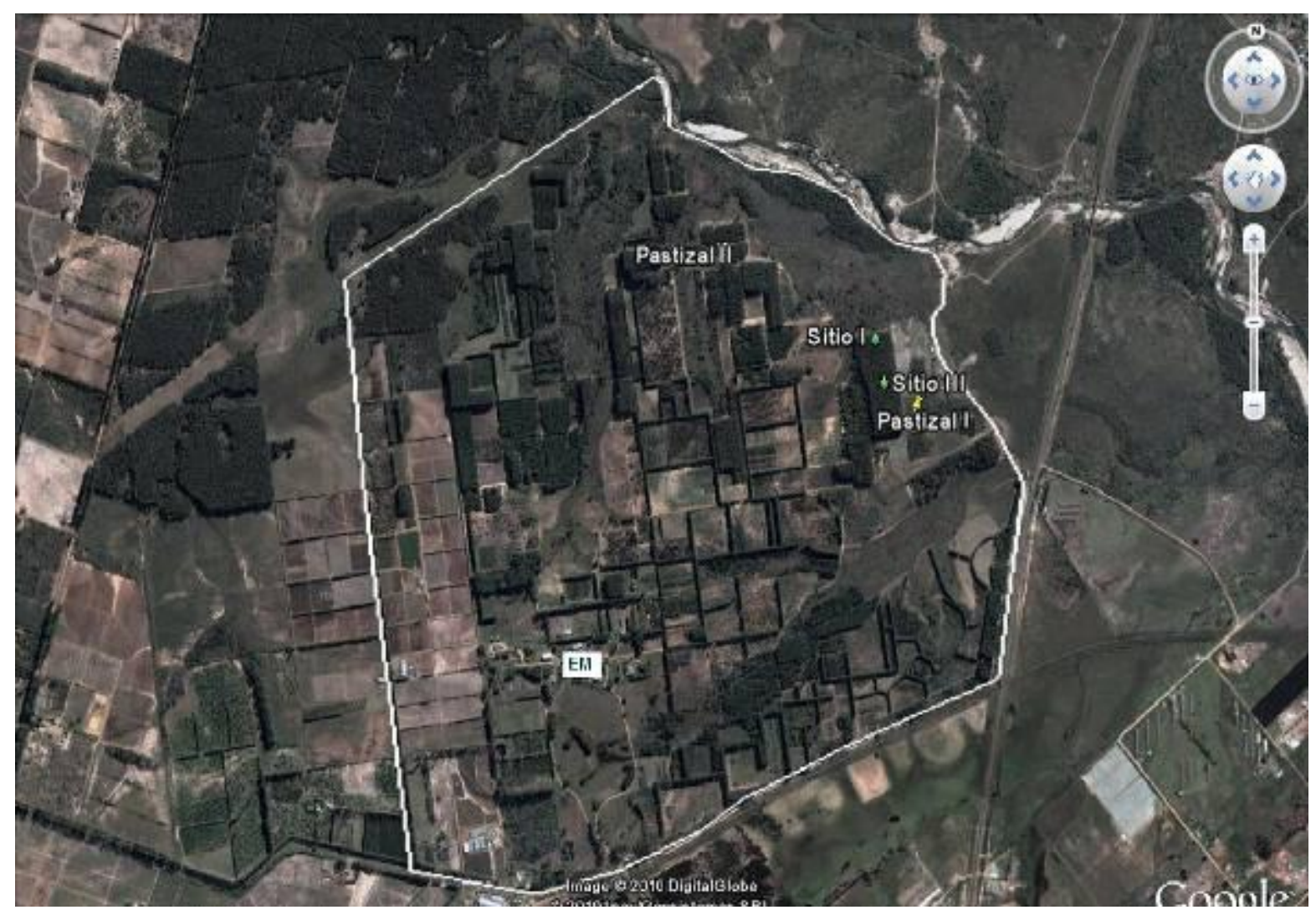

Figura 2.1: Ubicación de las plantaciones y perímetro de la EEA Concordia (Línea blanca): plantación de 11 años (Sitio III), plantación de 3 años (Sitio I), pastizales aledaños y Estación Meteorológica (EM).

En cada forestación se ubicaron tres parcelas de $100 \mathrm{~m}^{2}$ cada una.

Las características de las plantaciones en cada uno los sitios fueron:

\section{Sitio III:}

Fecha de plantación: 16/09/1992

Superficie de la plantación: 2.20 ha

Edad al inicio del estudio: 11 años

Altura media al inicio: $28 \mathrm{~m}$

Área Basal al inicio del estudio: $28.20 \mathrm{~m}^{2}$

Densidad de plantación: 1111 pl/ha 
Sitio l:

Fecha de plantación: 14/04/2000

Superficie de la plantación: 1.6 ha

Edad al inicio del estudio: 3 años

Altura media al inicio: $16 \mathrm{~m}$

Área Basal al inicio del estudio: $18.3 \mathrm{~m}^{2}$

Densidad de plantación: $1000 \mathrm{pl} / \mathrm{ha}$

\subsubsection{Caracterización de las condiciones climáticas y edáficas}

Mediciones climáticas locales en Estación Agrometeorológica EEA INTA Concordia. Se utilizó información aportada por la Estación Agrometeorológica de la EEA INTA Concordia. La misma está ubicada a $31^{\circ} 22^{\prime} \mathrm{S}, 58^{\circ} 07^{\prime} \mathrm{O}, 47.5 \mathrm{~m}$ snm a $1600 \mathrm{~m}$ de distancia de los sitios bajo estudio.

Se utilizaron datos de:

- temperaturas máximas y mínimas a 1.50 m

- velocidad y dirección del viento a 2 m

- humedad a $1.5 \mathrm{~m}$

- precipitación

- heliofanía

Mediciones microclimáticas de la plantación. Se instalaron sensores de temperatura y humedad del aire a distintas alturas y profundidades respecto del nivel del terreno (Tabla 2.1; Figura 2.1) con la finalidad de analizar las variables climáticas a cada nivel y realizar perfiles de ellas para distintas condiciones. 


\begin{tabular}{|c|c|c|}
\hline $\begin{array}{l}\text { Altura en relación } \\
\text { al nivel del terreno }(\mathrm{m})\end{array}$ & Variables medidas & Registradores \\
\hline-0.25 & Temperatura del suelo & $\begin{array}{l}\text { Conectados con los registradores a } 0.10 \\
\mathrm{~m}\end{array}$ \\
\hline-0.10 & Temperatura del suelo & Conectados con los registradores a $1.5 \mathrm{~m}$ \\
\hline 0.10 & $\begin{array}{l}\text { Temperatura y humedad } \\
\text { relativa del aire }\end{array}$ & $\begin{array}{l}\text { Dos Hobo H8, Onset Computer } \\
\text { Corporation y un WatchDog 425, } \\
\text { Spectrum Technologies, Inc. }\end{array}$ \\
\hline 1.5 & $\begin{array}{l}\text { Temperatura y humedad } \\
\text { relativa del aire }\end{array}$ & $\begin{array}{l}\text { Tres Hobo H8, Onset Computer } \\
\text { Corporation }\end{array}$ \\
\hline 30 & $\begin{array}{l}\text { Temperatura y humedad } \\
\text { relativa del aire }\end{array}$ & $\begin{array}{l}\text { Dos Hobo H8, Onset Computer } \\
\text { Corporation y un WatchDog } 425 \text {, } \\
\text { Spectrum Technologies, Inc }\end{array}$ \\
\hline
\end{tabular}

Tabla 2.1: Descripción de la ubicación, tipo y marca de los sensores y registradores utilizados para el monitoreo del microclima.

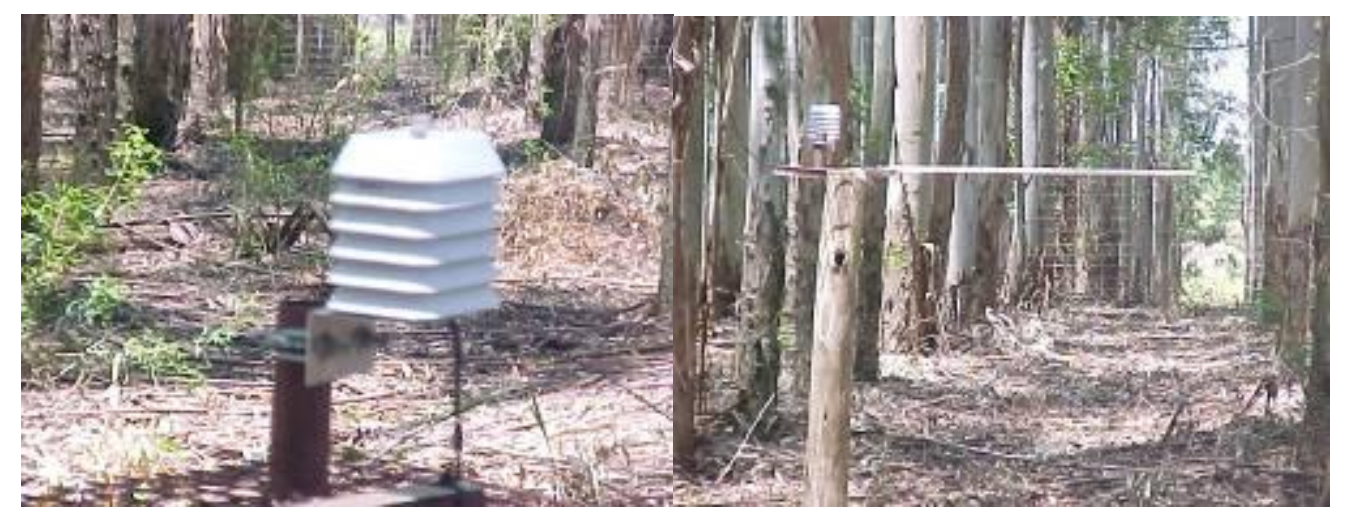

Figura 2.2: Casillas con sensores de temperatura y humedad relativa ubicados dentro de la plantación.

Análisis de suelos. Se realizaron tres perfiles dentro de las plantaciones (SI y SIII) y en dos pastizales aledaños y se tomaron muestras para su análisis químico a las siguientes profundidades: $0 \mathrm{~cm}-5 \mathrm{~cm}, 5 \mathrm{~cm}-20 \mathrm{~cm}, 20 \mathrm{~cm}-35 \mathrm{~cm}, 35 \mathrm{~cm}-50 \mathrm{~cm}$ y $50 \mathrm{~cm}-65 \mathrm{~cm}$. 
Las muestras fueron secadas al aire y tamizadas con malla de $2 \mathrm{~mm}$. Posteriormente se secaron en un horno-estufa de ventilación forzada (Preiser Científica) a $40{ }^{\circ} \mathrm{C}$ y nuevamente se tamizaron con una malla 20.

Alícuotas de las muestras fueron digeridas en medio ácido con $\mathrm{HNO}_{3}$ concentrado, $\mathrm{H}_{2} \mathrm{O}_{2}$ y $\mathrm{HCl}$ concentrado; esta combinación es una modificación del método de digestión de Luh Huang \& Schulte (1985). Las extracciones ácidas fueron utilizadas para la posterior determinación de las concentraciones totales de P, K, Ca, Mg, Mn, Fe y Al.

El Carbono total y Nitrógeno total se determinaron mediante combustión seca (Tabatabai \& Bremner, 1991) utilizando un LECO TruSpec CN Analyzer (Leco Corporation, 2005).

Los cationes intercambiables $\mathrm{Ca}, \mathrm{Mg}$ se extrajeron mediante $\mathrm{KCl} 1 \mathrm{~N}$. Para extraer Fe, $\mathrm{Mn}$, $\mathrm{K}$ y $\mathrm{P}$ se empleó el procedimiento Olsen-EDTA $\left(\mathrm{NH}_{4}\right.$-EDTA - $\left.\mathrm{NaHCO}_{3}\right)($ Anderson \& Ingram, 1993).

El análisis elemental y la determinación de la concentración, en los extractos de nutrientes totales e intercambiables- disponibles, se realizó utilizando espectrometría de plasma con un Espectrómetro Spectro Ciros CCD ICP.

Los materiales de referencia certificados, utilizados como patrones de calibración y muestras de control de calidad durante todo el procedimiento de análisis, fueron adquiridos a Leco Corp. (St. Joseph, MI) y Microanálisis Elemental Ltd. El suelo certificado de referencia fue Montana (NIST-2711); muestras de éste suelo fueron analizadas para verificar la recuperación de elementos.

Lacorrección del factor de humedada $105{ }^{\circ} \mathrm{C}$ se realizó utilizando un analizador termogravimétrico Leco modelo TGA 701 (Leco Corporation, 2009). 
Para medir el pH del suelo, en agua y en $\mathrm{KCl} 1 \mathrm{~N}$, se empleó un medidor de $\mathrm{pH}$, TermoOrion Modelo 350, con un electrodo de combinación epoxi. La relación de suelo / líquido empleada fue 1:1 (McLean, 1982).

Densidad aparente de los suelos. La densidad aparente fue medida con un muestreador Meridian. Tomándose tres muestras por horizonte y por perfil. Las muestras se secaron en estufa a $105^{\circ} \mathrm{C}$ hasta peso constante. Luego se calculó la densidad aparente.

Contenido de nutrientes en los suelos. El mismo se determinó como la sumatoria del producto entre la concentración del elemento químico, la densidad aparente y el volumen de cada horizonte muestreado. La sumatoria se calculó hasta los $65 \mathrm{~cm}$ de profundidad en todos los sitios muestreados.

A los efectos de deslindar el impacto del manejo ligado a la preparación del sitio de los cambios anuales en los contenidos de nutrientes se estimó la diferencia anual del contenido de nutrientes/ha entre los testigos y la plantación de tres años de edad (modificaciones por la preparación del suelo y primeros tres años de la plantación). Por otra parte, las diferencias anuales entre el sitio de tres y once años se utilizaron como un estimador de los efectos de las plantaciones.

Este estudio de carácter intensivo y oneroso dificulta tener verdaderas repeticiones pues ello incrementa aún más los costos de instalación y operativos, y la realización de una tesis. Por ello se han realizado tres seudorépilicas para cada edad. A pesar de esa característica que puede en principio considerarse una limitación para la extrapolación de sus resultados, podrá observarse posteriormente que la comparación con estudios similares realizados por otros autores, muestran tendencias similares y coincidencias significativas, como asimismo aportan novedades que solo pueden detectarse en estudios de mucho detalle como el presente. En todo caso, también ponen en evidencia puntos críticos que pueden ser objetivos particulares de investigaciones futuras. 


\subsubsection{Flujos de agua}

Los equipos de medición a campo fueron instalados en el último trimestre de 2002 y se esperó un periodo de estabilización a campo de unos 6 meses durante el cual además se ajustaron técnicas de laboratorio. Muestras de los flujos hídricos fueron tomadas entre fines de 2002 y el año 2006. Más adelante se indican los periodos cuyos datos fueron efectivamente utilizados.

2.2.3.1 Precipitación bruta. Teniendo en cuenta las características del clima, el suelo y la topografía local en el que se ubican las plantaciones se han considerado las lluvias como la principal fuente de agua. Si bien es posible algún ingreso lateral debido a intercepción de niebla durante algunos días de invierno, este es considerado de escasa importancia.

Para la medición de la precipitación bruta se instalaron 2 parcelas testigos sin cubierta forestal, aledañas a las forestaciones. En ellas, a una altura de $1 \mathrm{~m}$ sobre el terreno, se colocó un pluviómetro de $1900 \mathrm{~cm}^{2}$ de superficie, 1 pluviógrafo (Tipping Bucket Rain Gauge) y un colector plástico en forma de embudo con botella colectora para muestras de agua de lluvia. Adicionalmente se dispuso de los registros obtenidos por la Estación Meteorológica de la EEA Concordia.

2.2.3.2 Trascolación. Para medir la trascolación se colocaron, a $1 \mathrm{~m}$ sobre el suelo, 3 trascoladores de forma rectangular de $1900 \mathrm{~cm}^{2}$ por parcela, distribuidos de manera de captar agua en toda la distancia entre árboles con el fin de reducir la varianza, generalmente alta, que resulta de usar formas circulares de colectores de pequeña superficie (Figura 2.3). La trascolación fue determinada como la lámina de agua, calculada a partir de la relación entre el volumen de agua colectada y la superficie del colector. El porcentaje se determinó en relación a la de la precipitación bruta colectada fuera de la plantación en los pluviómetros. 


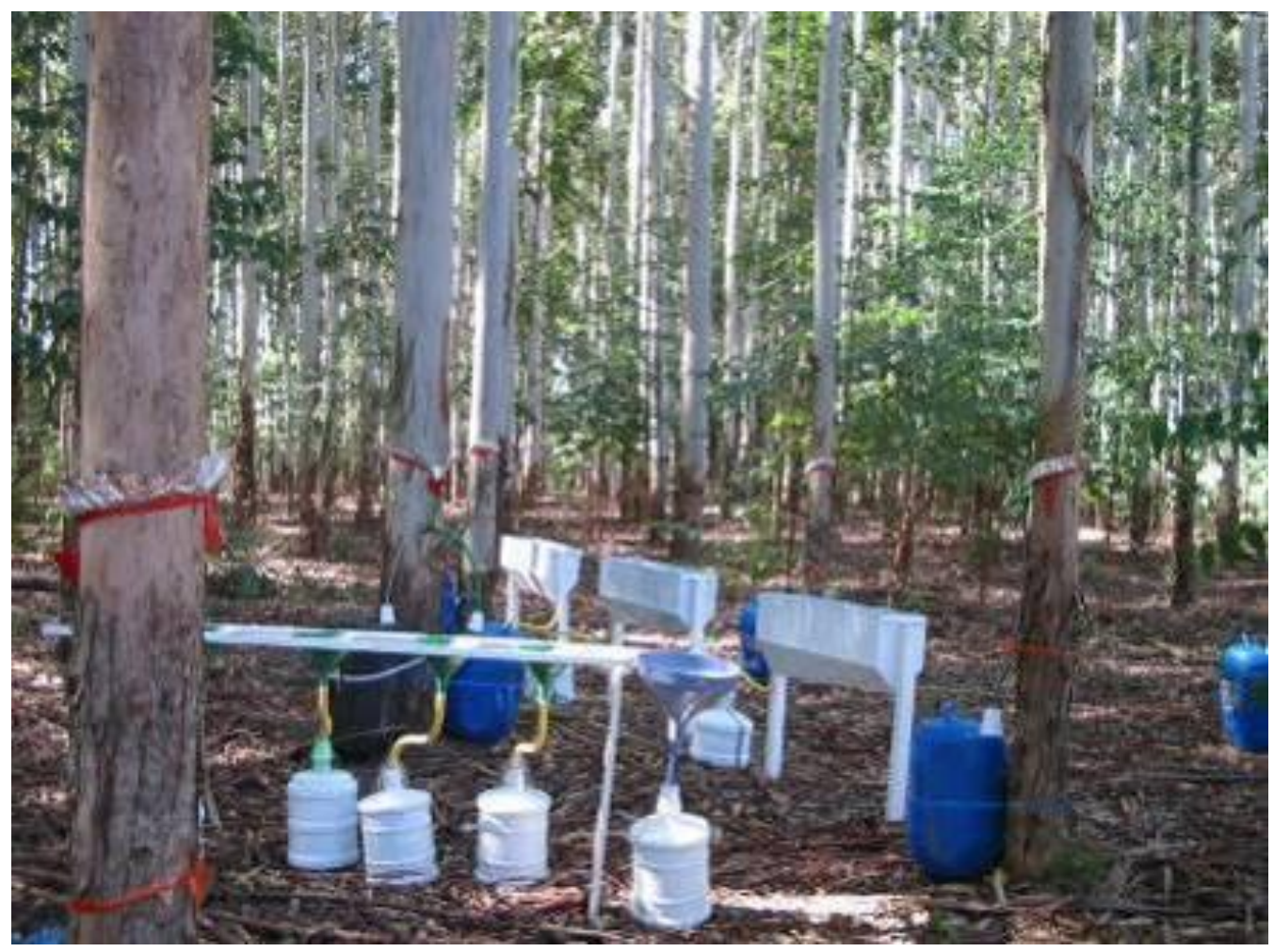

Figura 2.3: Foto de una parcela del Sitio III con árboles de 12 años de edad donde puede observarse: i- árboles con collares de flujo caulinar y su tanque colector al pie; ii- tres colectores rectangulares de translocación con sus tanques colectores al pie; iii- una canaleta plástica con embudos colectores de agua de trascolación para análisis químicos.

2.2.3.3 Flujo Caulinar. A cada uno de los 11 árboles ubicados dentro de cada una de 3 parcelas de $100 \mathrm{~m}^{2}$ se les colocó un anillo (collar) conductor del flujo caulinar, ubicado a $1.30 \mathrm{~m}$ sobre el suelo, realizado en lámina de aluminio, adherido al tronco con goma siliconada, que vierte el agua sobre un embudo conectado a un recipiente colector mediante una manguera plástica ubicado en el suelo (Figura 2.4). Los recipientes receptores variaban en su capacidad entre los 35 y 200 I en función del diámetro de los árboles. El flujo caulinar se determinó como la relación entre el volumen colectado en la parcela (sumatoria de las colecciones de agua de todos los árboles en ella) y la superficie de la misma. 


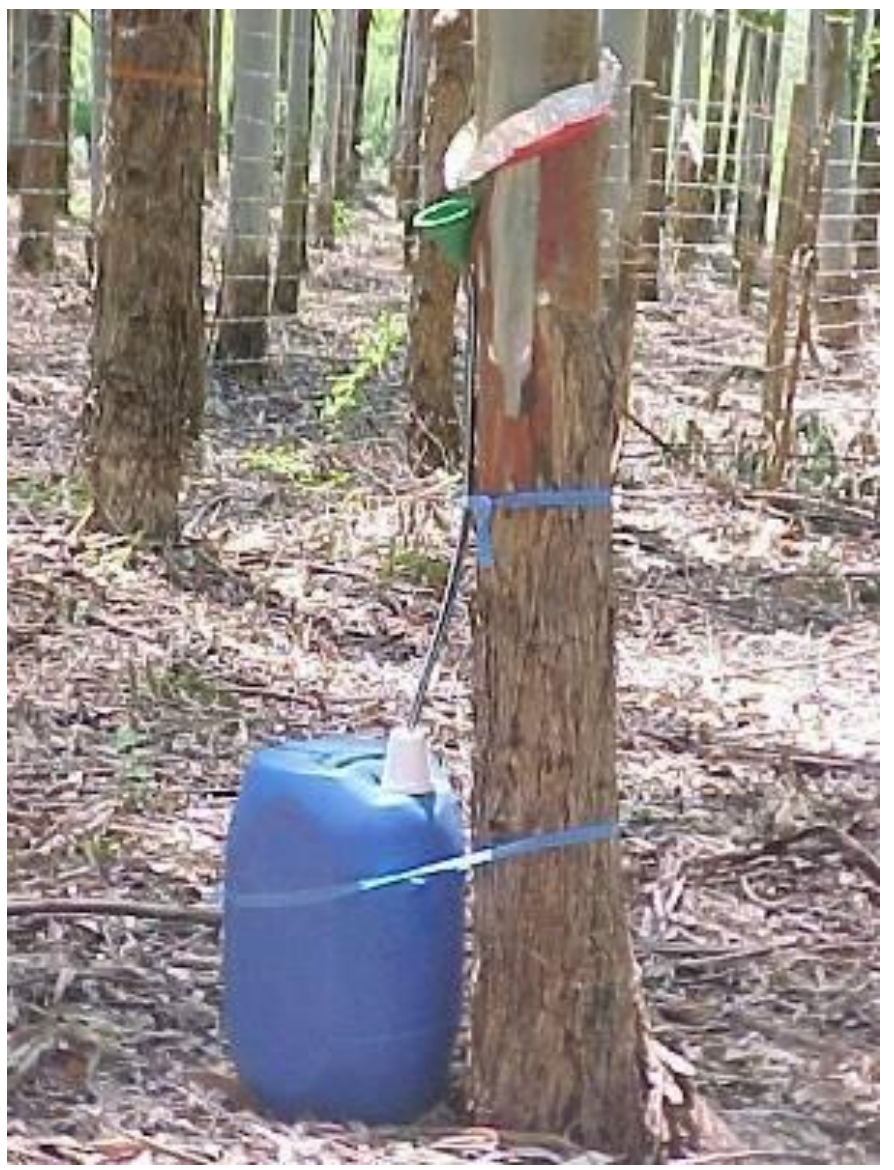

Figura 2.4: Detalle de un anillo colector de flujo caulinar. El anillo está confeccionado con una faja de aluminio corrugado que abraza el árbol en forma oblicua con el lado de unión en la parte más alta.

2.2.3.4 Trascolación del mantillo. Para medir el agua que logra atravesar el mantillo se colocaron tres lisímetros de tensión cero de $4050 \mathrm{~cm}^{2}$ de superficie $(81 \mathrm{~cm} \times 50 \mathrm{~cm})$, con malla de $1.5 \mathrm{~mm}$ debajo de aquella capa y se colectó el agua en recipientes plásticos (Figura 2.5). La intercepción desde el mantillo se calculó como la diferencia entre la precipitación neta y el agua colectada en los lisímetros bajo el mantillo, ambas expresadas en mm. A los fines del cálculo de la evapotranspiración se asumió que el agua retenida en el mantillo, si bien en parte puede ser utilizada por microorganismos y absorbida por raíces, constituye mayormente una perdida por evaporación desde el suelo. 


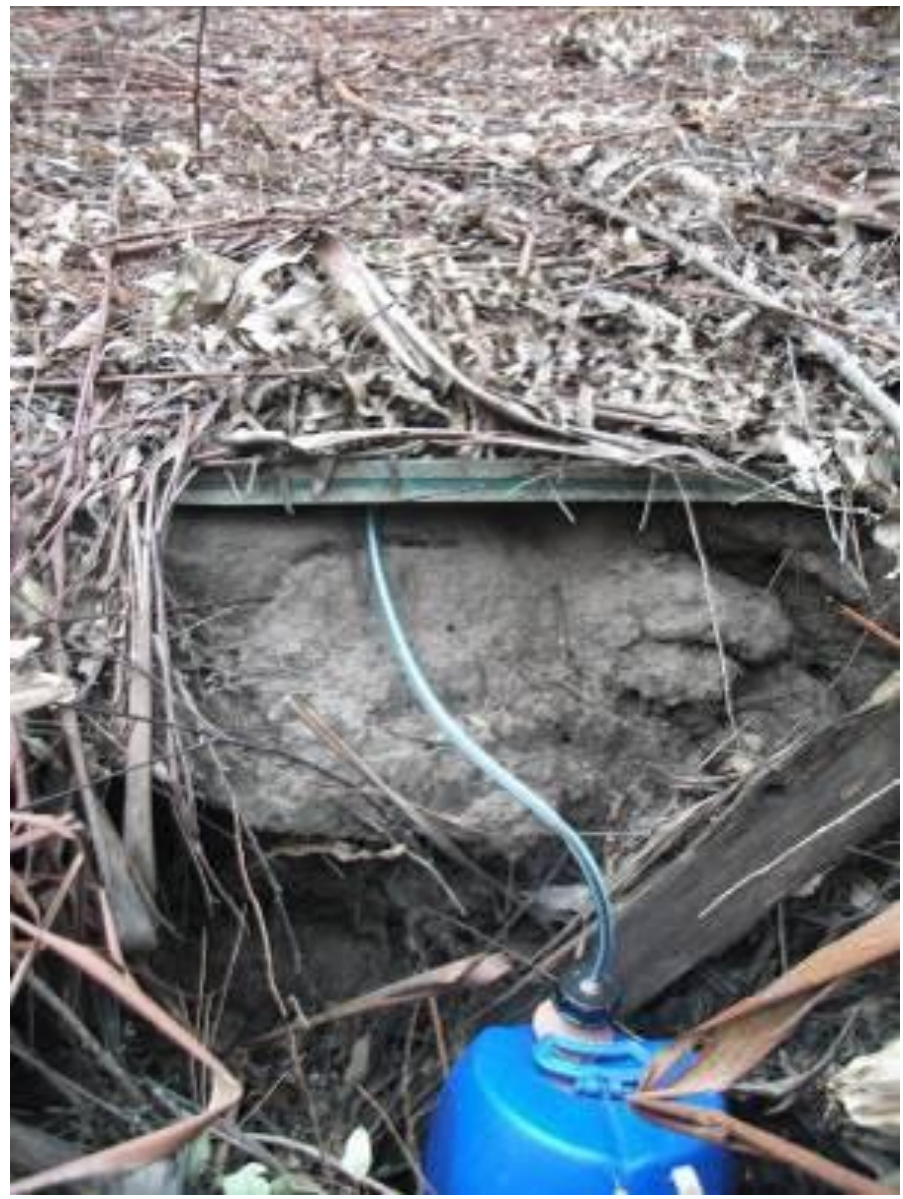

Figura 2.5. Lisímetro para la medición de la trascolación del mantillo.

2.2.3.5 Escurrimiento Superficial. Fue medida en la plantación y el pastizal vecino. En la plantación se instalaron tres parcelas colectoras del escurrimiento superficial, de $3 \mathrm{~m} \times 3$ m. Cada parcela tenía un ejemplar arbóreo en su interior. En tres lados, excepto el superior, del perímetro de las parcelas, se colocaron caños de PVC de 4 pulgadas, con una abertura lateral de 30 ㅇ que daba hacia el interior de la parcela con su lado inferior a unos $3 \mathrm{~cm}$ bajo el nivel de la cara superior del horizonte mineral superior del suelo. En el interior de los caños se dispuso una faja de polietileno de 250 micrones de espesor y 15 $\mathrm{cm}$ de ancho que sobresale lateralmente por la abertura del caño, la cual fue inserta en el suelo en una ranura de unos 2 - $4 \mathrm{~cm}$ realizada en la periferia de los tres lados a unos 2 $\mathrm{cm}$ de profundidad. Esa especie de babeta se dispuso para evitar la pérdida de agua en el lugar de contacto entre el caño y el suelo. Los caños condujeron el agua del escurrimiento a un recipiente colector ubicado en una fosa a unos $50 \mathrm{~cm}$ de la parcela. En el lado más 
alto de la parcela, se realizó una zanja de $20 \mathrm{~cm}$ de alto por $20 \mathrm{~cm}$ de profundidad para derivar fuera de la parcela el flujo proveniente de las partes más altas.

En el pastizal aledaño a la forestación se instalaron tres parcelas colectoras del escurrimiento superficial de $9 \mathrm{~m}^{2}$ similares a las instaladas bajo la forestación.

Durante 12 meses, entre junio de 2005 y junio de 2006, se midió el escurrimiento superficial en un pastizal aledaño y dentro de la forestación de manera simultánea.

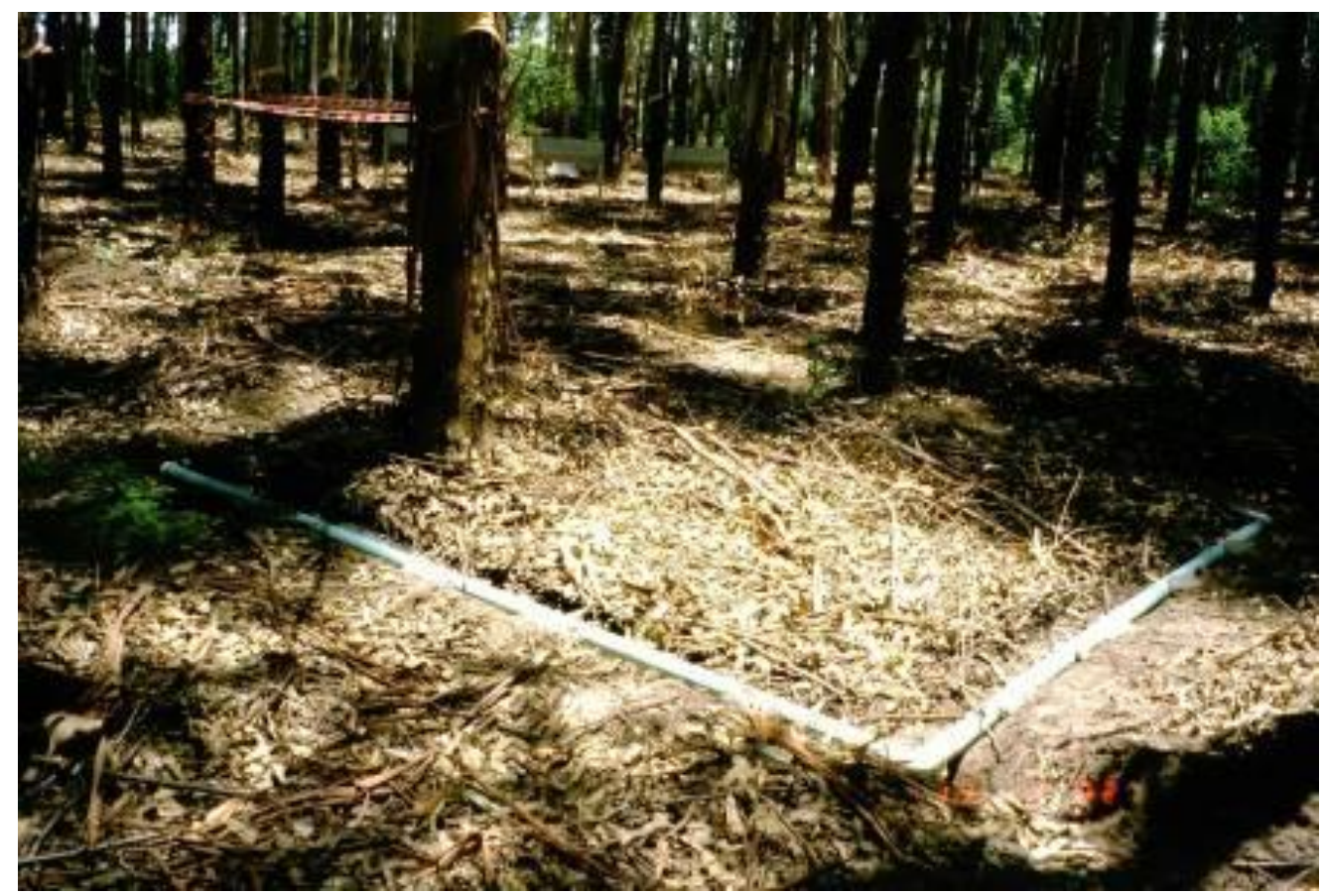

Figura 2.6: Parcela para la medición del escurrimiento superficial. Obsérvese la canaleta colectora dispuesta a lo largo de 3 de los 4 lados de la parcela. El recipiente colector (no visible) se encuentra en el ángulo inferior derecho de la foto.

2.2.3.6 Profundidad del nivel freático. El nivel freático se midió durante un año con una frecuencia de quince días mediante con un freatímetro del tipo silbato, dentro de la forestación y en dos sitios no forestados, uno de ellos corresponde al pozo ubicado en las inmediaciones de la Estación Meteorológica INTA Concordia. 
2.2.3.7 Agua del suelo. Los valores de los Índices Hídricos, Contenido de Agua a Saturación, Humedad Equivalente y Punto de Marchitez Permanente, para el Sitio III fueron determinados en el Laboratorio de Edafología de la Facultad de Ciencias agrarias y Forestales de la UNLP.

\begin{tabular}{llll}
\hline Pozo & Latitud Sur & Longitud Oeste & Altitud (m) \\
\hline $\begin{array}{l}\text { Estación } \\
\text { meteorológica }\end{array}$ & $31^{\circ} 22^{\prime}$ & $58^{\circ} 07^{\prime}$ & 47 \\
$\begin{array}{l}\text { Plantación E grandis } \\
\text { Claro }\end{array}$ & $31^{\circ} 21^{\prime} 47.9^{\prime \prime}$ & $58^{\circ} 06^{\prime} 14.9^{\prime \prime}$ & 37 \\
\hline & $31^{\circ} 21^{\prime} 45.4^{\prime \prime}$ & $58^{\circ} 07^{\prime} 19.9^{\prime \prime}$ & 41 \\
\hline
\end{tabular}

Tabla 2.2: Ubicación de los pozos donde se registró el nivel freático

La Capacidad de Campo fue determinada en el Sitio III mediante la saturación de 3 perfiles y la toma a las 24 hs de muestras mediante un muestreador de densidad aparente (Marca comercial: Meridian).

Se comparó la capacidad de campo con la humedad equivalente determinada en laboratorio, en tres perfiles de suelo en el Sitio III.

El valor de humedad equivalente fue utilizado para ajustar el modelo de humedad antecedente PIP-APIP. El modelo PIP-APIP es un modelo indirecto de representación de la evolución del contenido de humedad en el suelo con el objetivo de estimar escurrimientos superficiales de origen pluvial. Se basa en la combinación de un índice de humedad antecedente el API (Antecedent Precipitation Index), y un eje de referencia variable a lo largo del año, el PIP Pérdida Inicial Potencial que rectifica el límite de saturación del suelo (Romanazzi, P, comunicación personal).

Las expresiones analíticas son:

$$
A P I_{t+1}=0,9(A P I-P I P)_{t}+P I P t_{t+1}+P_{t+1}
$$

El valor de API fue una de las variables evaluadas en la regresión múltiple utilizada para la estimación de la transpiración diaria. El índice se utilizó para incorporar en el análisis una estimación del contenido de agua del suelo. 
2.2.3.8 Transpiración. Una vez que el agua ha sido absorbida por las raíces de los árboles, asciende por el interior de los vasos conductores del xilema. Este ascenso se explica según la teoría de la tensión-cohesión: en las hojas la evaporación de agua genera una tensión que se transmite hacia abajo, hasta los ápices de las raíces, a través de todo el sistema conductor de la planta, haciendo disminuir la presión xilemática y el potencial hídrico del xilema. Esto origina la absorción de agua por el xilema. El xilema activo transportará tanta más agua a las partes aéreas de la planta cuanto mayor sea el flujo de la transpiración. La velocidad máxima posible de este flujo depende de las particularidades estructurales del sistema de conducción. El flujo de agua se adapta de un modo extraordinariamente rápido a la intensidad de la transpiración de modo que refleja las oscilaciones en la evaporación aunque sean esporádicas y pueden extraerse conclusiones del registro de la velocidad del flujo que son válidas para la copa del árbol en su totalidad.

La transpiración se calculó a partir del método de disipación de calor constante desarrollado por Granier (1987). El método consiste en un sistema de sensores que permiten medir el flujo de savia en un eje radial en la albura del tronco. El sistema se compone de dos sondas cilíndricas de aproximadamente $2 \mathrm{~mm}$ de diámetro y de $20 \mathrm{~mm}$ de largo, insertas radialmente en la albura del tronco separadas a una distancia vertical de $10 \mathrm{~cm}$ aproximadamente (Figura 2.7). Una de las sondas es calentada por medio de un cable de constantan enrollado alrededor de una aguja hipodérmica alimentado mediante una tensión controlada. Una termocupla de cobre-constantan se dispone a mitad del largo en el interior de la aguja hipodérmica a la cual, cubierta con una grasa siliconada, se la introduce en una vaina de aluminio inserta previamente en el árbol, logrando un conjunto cuya finalidad es proteger el sensor y asegurar la conducción uniforme del calor. La segunda sonda, no calefaccionada, situada en el tronco por debajo de la anterior, encierra una termocupla idéntica.

El sistema permite medir eléctricamente la diferencia de temperaturas entre las dos sondas, la cual es mayor cuando menor es el flujo de agua en la albura.

A partir de las diferencias registradas en milivoltios se estima el índice de flujo de savia (K) (Fórmula (1)), que es un número adimensional. Y en base a la calibración realizada por 
Granier, entre K y la densidad del flujo de savia $(\mu)$, que es independiente de la especie, se estima $\mu$ (Fórmula (2)).

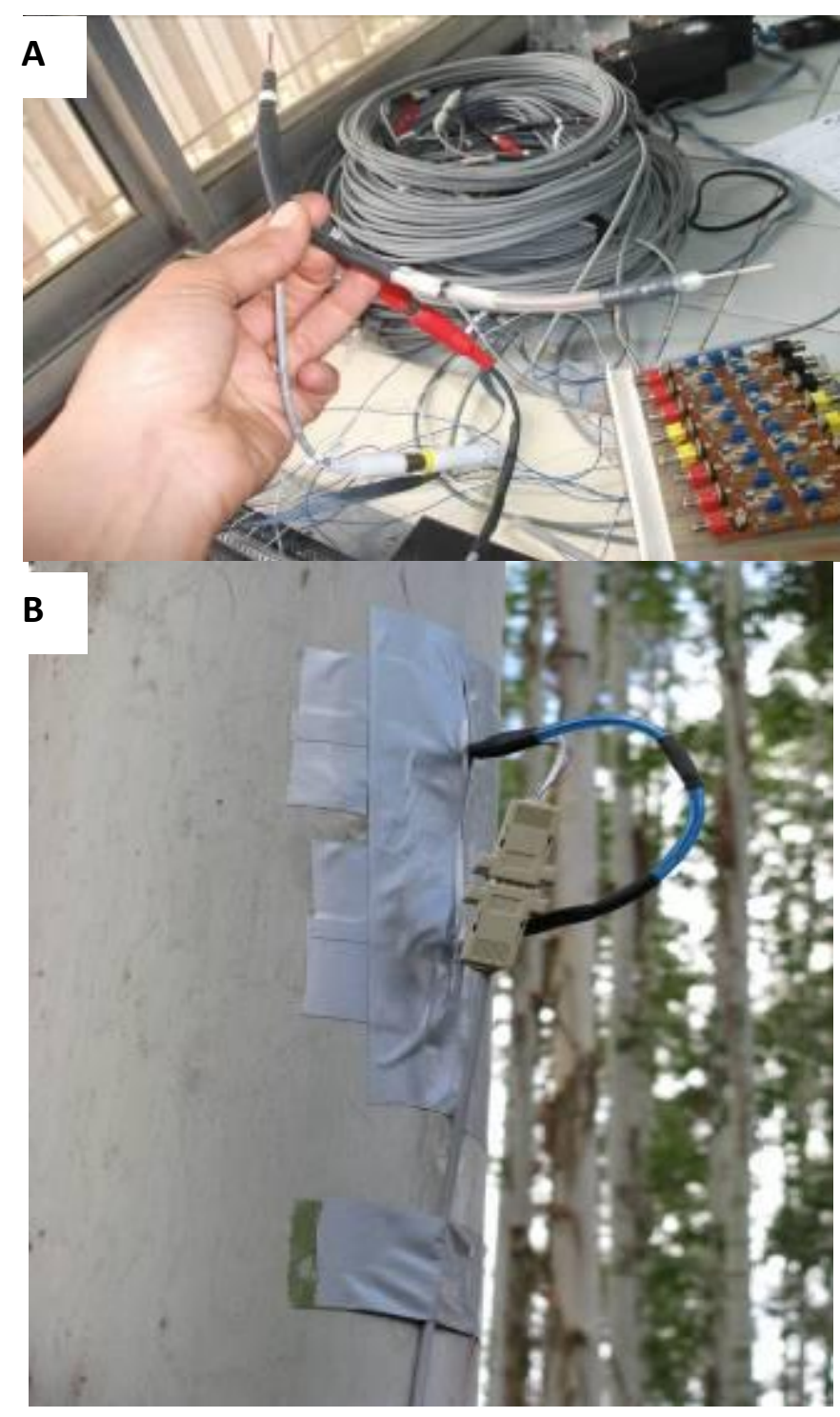

Figura 2.7: Detalle de los el sistema de sensores para la medición de la densidad de flujo de savia. El sistema se compone de dos termocuplas insertas en dos agujas que se ubican en el xilema activo del árbol, la superior es calefaccionada y la inferior es la termocupla de referencia. Foto A: vista de las agujas-sonda; foto B: agujas colocadas en un árbol.

$$
\begin{aligned}
& \mathrm{K}=(\Delta \mathrm{T} \text { máx }-\Delta \mathrm{T}) / \Delta \mathrm{T})(1) \\
& \left.\mu=0.119 *\left(\left(\Delta \mathrm{T}_{\text {máx }}-\Delta \mathrm{T}\right) / \Delta \mathrm{T}\right)^{1.23}\right)(2)
\end{aligned}
$$


$\Delta T_{\text {máx: }}$ diferencia máxima de temperaturas registrada en condiciones de no flujo (predawn).

$\Delta T$ : diferencia de temperaturas registradas en condiciones de flujo positivo

La transpiración diaria ( $\mathrm{mm} /$ día) fue obtenida a partir de la densidad del flujo de savia $\left(\mathrm{m}^{3} \mathrm{~m}^{-2}\right.$ día $\left.{ }^{-1}\right)$ y la superficie de albura de la plantación $\left(\mathrm{m}^{2}\right.$ ha $\left.{ }^{-1}\right)$.

Las diferencias de temperaturas entre las termocuplas de entre 6 y 12 árboles por día, se registraron cada 15 min en un almacenador de datos (data logger) Modelo CR21X o CR10 de Campbell Scientific Inc. (Figura 2.8).

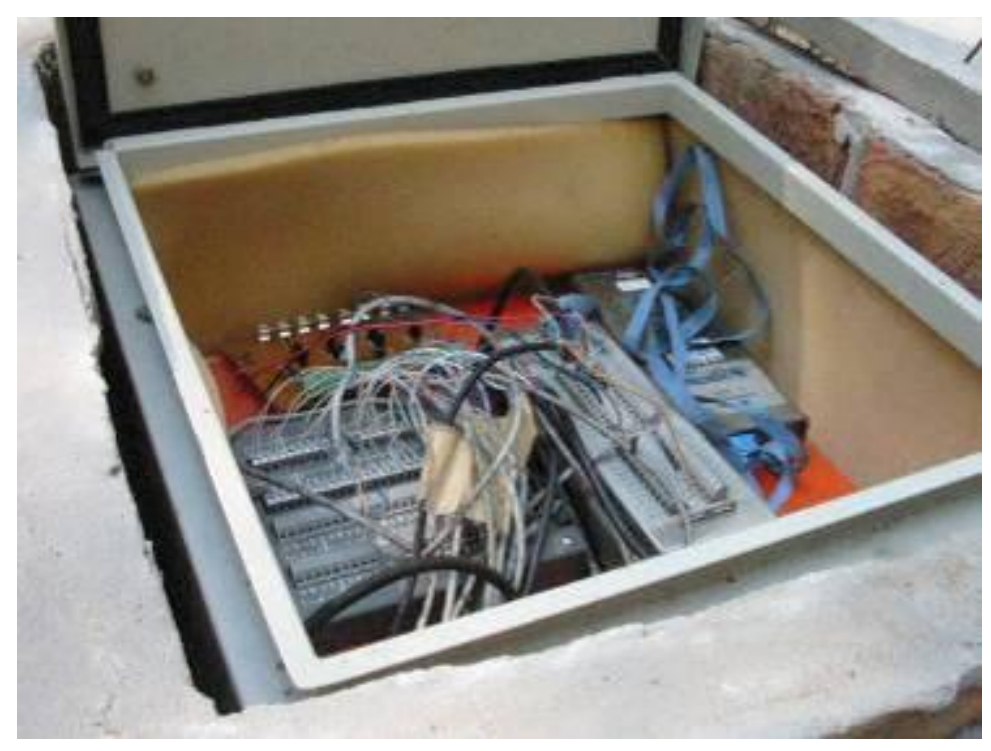

Figura 2.8: Detalle de los colectores de datos (data loggers) instalados en el campo.

El valor de $\mu$ promedio se determinó para 99 días, luego se ajustó una regresión múltiple entre la densidad de flujo diario promedio y las variables climáticas (heliofanía, déficit de saturación de vapor y velocidad del viento) (Jiménez, 2007) y una variable edáfica, el índice de humedad antecedente (API) para obtener los valores de la densidad del flujo de savia diarios durante todo el período. 
Para determinar la superficie de albura activa se barrenaron los árboles de las tres parcelas, mediante un barreno de Pressler de $4 \mathrm{~mm}$ y se les colocó una solución acuosa de safranina al $1 \%$ (Figura 2.9 A). A las 24 hs se procedió a barrenar nuevamente el árbol a $10 \mathrm{~cm}$ por encima de la barrenada anterior y se midió la longitud del tarugo coloreado (Figura 2.9 B). Luego se determinó la superficie de albura de cada individuo y se calculó la superficie de albura de la parcela (Figura 2.9).

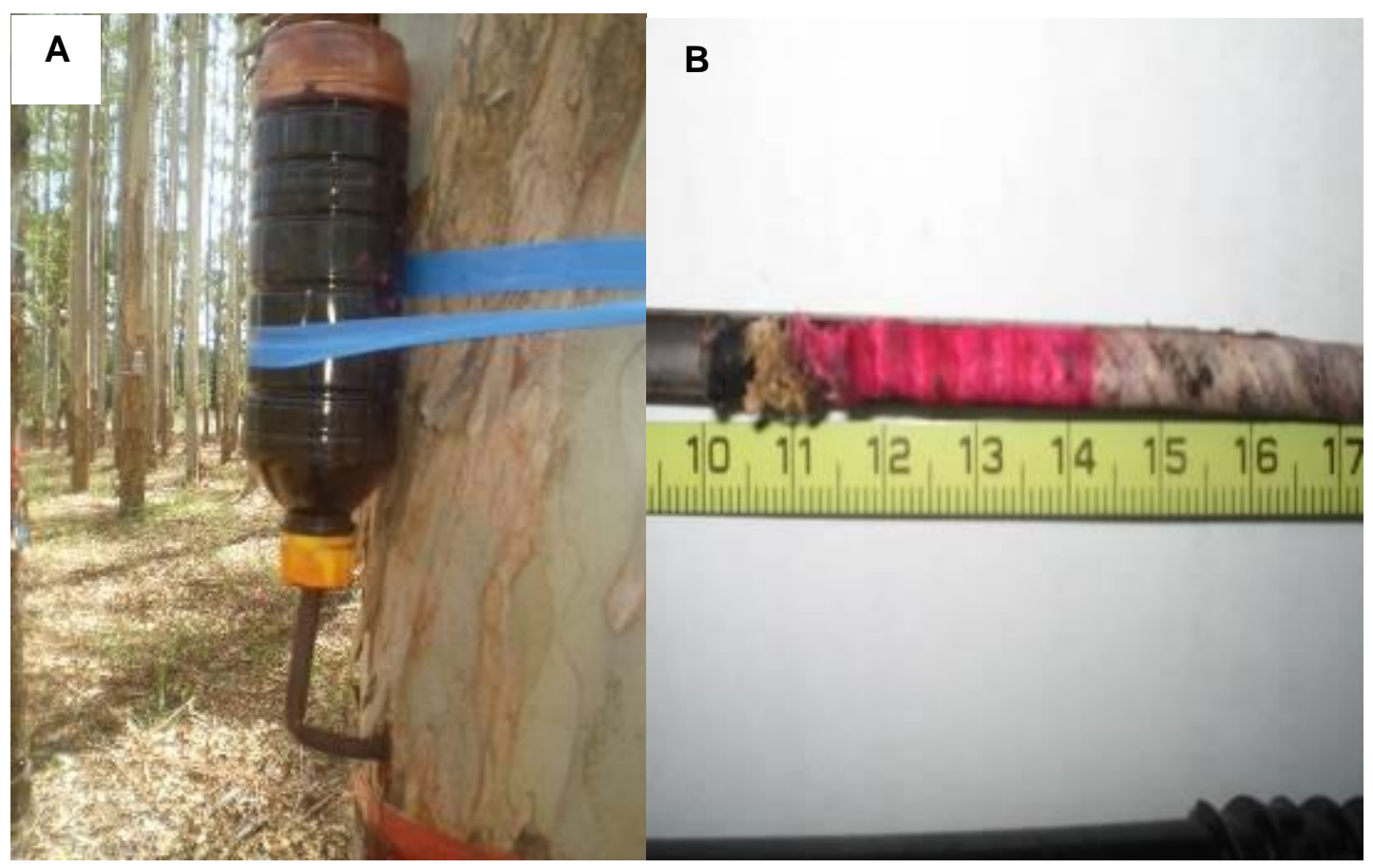

Figura 2.9: Dispositivo con solución de safranina para teñir la albura activa $(A)$ y muestra de barreno para la medición de longitud de albura activa puesta en evidencia por el colorante (B).

2.2.3.9 Cálculo de otros flujos hídricos. Los siguientes flujos hídricos fueron obtenidos mediante cálculos. A continuación se indican los mismos y las fórmulas empleadas.

\footnotetext{
Intercepción del dosel $(\mathrm{Id})=$ Precipitación bruta $(\mathrm{PB})$ - Precipitación neta (PN)

Precipitación neta $=$ Trascolación dosel $(\mathrm{Td})+$ Flujo caulinar $(\mathrm{FC})$

Intercepción del mantillo $(\mathrm{Im})$ = Trascolación dosel - Trascolación del mantillo (LM)
} 
Evapotranspiración total $(\mathrm{EVT})=$ Int dosel + Intercepción mantillo + Transpiración (T)

Percolación $(\mathrm{P})$ = Trascolación de mantillo - Transpiración

\subsubsection{Nutrientes en los flujos de agua}

2.2.4.1 Muestras de agua para análisis químicos. Durante el segundo período anual, entre abril de 2004 y marzo de 2005, se analizaron las concentraciones de fósforo, potasio, calcio, magnesio, amonio, nitrato y nitritos de los flujos del bosque (trascolación, flujo caulinar, escurrimiento superficial, lavado del mantillo) y de la precipitación bruta. Con la excepción del nivel freático el muestreo fue realizado por triplicado en las plantaciones y sus inmediaciones: 3 sitios abiertos para la precipitación, 3 parcelas para flujo caulinar y trascolación, 3 parcelas para escurrimiento superficial, 3 lisímetros para trascolación de la hojarasca. Los dispositivos de medición de precipitación y trascolación contaron con mallas plásticas cercanos al desagote para impedir la contaminación de restos de plantas e insectos; se los revisó periódicamente extrayéndose hojas y partes gruesas en ellos. Las muestras de agua fueron colectadas, de artefactos dedicados específicamente al análisis de nutrientes, 2 horas después de los eventos de precipitación diurna, y a las 9 am posterior a los eventos de precipitación nocturna. En algunos casos la toma de muestras correspondió a intervalos que contenían varios eventos cercanos de precipitación intermitente. En cada muestreo se registró el volumen de agua obtenido y se colectaron 500 a $1000 \mathrm{~cm}^{3}$ de muestra por cada compartimiento. Estos muestreos colectaron nutrientes de la deposición húmeda y seca de los intervalos, o bien solo húmeda si el intervalo era breve. En algunos intervalos superiores a una semana sin lluvia, los colectores plásticos de precipitación y trascolación se lavaron con cantidades de agua destilada conocida con la finalidad de estimar la deposición seca que llega al dosel del bosque y al suelo; éstos datos permitieron corregir y obtener la precipitación húmeda de los intervalos mixtos con lluvias.

2.2.4.2 Instalaciones para muestreo a campo. En cada parcela, el agua de precipitación fue muestreada en baterías de 5 pluviómetros plásticos de 20 y $30 \mathrm{~cm}$ de diámetro, 
dispuestos a $1 \mathrm{~m}$ sobre el piso. La trascolación y el flujo caulinar fueron medidos en parcelas de $100 \mathrm{~m}^{2}$. Para el muestreo de la trascolación, en cada parcela se utilizó un colector rectangular, de $10 \mathrm{~cm} \times 150 \mathrm{~cm}$, realizado con un caño plástico de $10 \mathrm{~cm}$ de diámetro conectado mediante una manguera con trampa de vapor a un bidón plástico colocado sobre el suelo. Para el flujo caulinar se colectó una muestra compuesta extraída de los once árboles en los que se medía el volumen de flujo caulinar. Las muestras del agua trascolada desde el mantillo fueron obtenidas de lisímetros rectangulares de tensión cero, de $81 \mathrm{~cm} \times 50 \mathrm{~cm}$, colocados debajo de la capa L del mantillo, y conectados mediante una manguera con trampa de vapor a un recipiente ubicado en una fosa. Las muestras de flujo superficial fueron obtenidas de los recipientes utilizados para cuantificar el volumen, ubicados en una fosa en el extremo más bajo de la parcela. El agua subterránea, de la napa freática fue muestreada en un pozo realizado en la parcela B del ensayo.

2.2.4.3 Manipulación y acondicionamiento de muestras y análisis químicos. El mismo día de obtenidas las muestras, en el laboratorio del Área forestal de la EEA INTA Concordia se midió el pH con un peachímetro Orion modelo 520 A, se las colocó en conservadoras de poliuretano expandido, con materiales refrigerantes, y se las envió al laboratorio del LISEA en La Plata, en transporte nocturno, donde se las mantuvo en heladera hasta su análisis. Las muestras fueron procesadas dentro de las $48 \mathrm{~h}$ de obtenidas en el campo. Las muestras fueron filtradas usando equipos de filtración de policarbonato, con filtros de membrana Millipore de 0,45 $\mu \mathrm{m}$, y bombas de vacío. El análisis químico de nitratos, nitrito, amonio, fosfatos, magnesio, calcio y potasio y la medición de color fue realizado en el LISEA. Alícuotas de $125 \mathrm{~cm}^{3}$ de las muestras filtradas fueron enviadas mediante correo_internacional al IITF-USDA Forest Service, Rio Piedras, Puerto Rico para medir la concentración de COD.

Los métodos utilizados se indican en la Tabla 2.3.

Cuando las concentraciones detectadas estuvieron por debajo del límite de detección del método se estimó una concentración mínima equivalente a 1/3 del límite de detección del elemento en cuestión. 
Nitritos Determinación espectrofotométrica del colorante azoico obtenido por reacción con sulfanilamida y naftiletilendiamina (Hilton y Rigg, 1983). Límite de detección: 5ug/l

Nitrato Determinación en forma indirecta, como nitrito, por reducción previa con sulfato de hidracina (Hilton y Rigg, 1983). Límite de detección: 20 ug/l

Amonio Determinación por espectrofotometría del azul de indofenol formado por reacción con fenol e hipoclorito (Mackereth et al, 1978). Límite de detección: 10 ug/l

Fosfato Determinación por espectrofotometría del azul de molibdeno obtenido por reacción con molibdato de amonio y posterior reducción del ácido fosfomolíbdico formado con ácido ascórbico (Murphy y Riley, 1962). Límite de detección: 10 ug/l

Potasio Determinación por fotometría de llama utilizando un equipo marca Enige y efectuando la determinación de acuerdo al manual del fabricante. Límite de detección: $0,1 \mathrm{mg} / \mathrm{l}$.

Calcio y Determinación por titulación volumétrica con EDTA y murexida y negro de Magnesio eriocromo T como indicadores respectivamente (APHA, 1985). Límite de detección: 0,1 $\mathrm{mg} / \mathrm{l}$.

COD Lachat Instruments Model IL550 TOC-TN Analysis System.

Color La absorbancia fue medida con espectrofotómetro Metrolab 325, a $365 \mathrm{~nm}$ empleando cubetas de vidrio de $1 \mathrm{~cm}$ de paso.

Tabla 2.3: Métodos analíticos utilizados en la determinación de los nutrientes en las muestras de los flujos hídricos analizadas. 


\subsubsection{Balance de agua y nutrientes}

2.2.5.1 Balance hídrico. El balance hídrico de un bosque se ha considerado desde dos aspectos. Un aspecto gráfico, en base a modelos gráficos utilizando elementos de los modelos de emergía de Odum (1971) en el que se disponen el conjunto de vías de circulación del agua hacia, desde y dentro del bosque y sus valores. Como cálculo, en base a una ecuación de balance de masas, como se indica a continuación:

$$
B H=P B-(I+I m+T+\Delta S+/-E S)
$$

Donde:

$\mathrm{BH}=$ balance hídrico

PB = Precipitación Bruta

I = Intercepción del dosel

Im = Intercepción del mantillo

$\mathrm{T}=$ Transpiración

$\Delta \mathrm{S}=$ Variación del almacenaje de agua en el suelo

ES = Escurrimiento superficial

Si bien el escurrimiento superficial puede considerarse una pérdida neta de agua y nutrientes que contiene, la posición del rodal en una media loma, permite asumir que existe un ingreso de agua, no medido, desde la parte superior de la pendiente. Por ello se asumió que el escurrimiento superficial es similar entre entrada y salida y que el cambio en el contenido de agua del suelo por esa vía es nulo.

Asimismo, la variación del almacenaje de agua en el suelo se ha considerado igual a cero debido a que las mediciones iniciales y finales de los balances se hicieron en la misma época del año y en ambos casos después de un periodo sin precipitaciones similar. Por ende, el balance hídrico aplicado resulta de una simplificación de la (Ec. 1) a saber:

$$
B H=P B-(I+I m+T)
$$


Una representación gráfica de los flujos de agua considerados en ésta tesis se indica en la Figura 2.10 El balance fue calculado para dos períodos de un año. Entre abril del 2003 y marzo del 2004 y entre abril de 2004 y marzo de 2005.

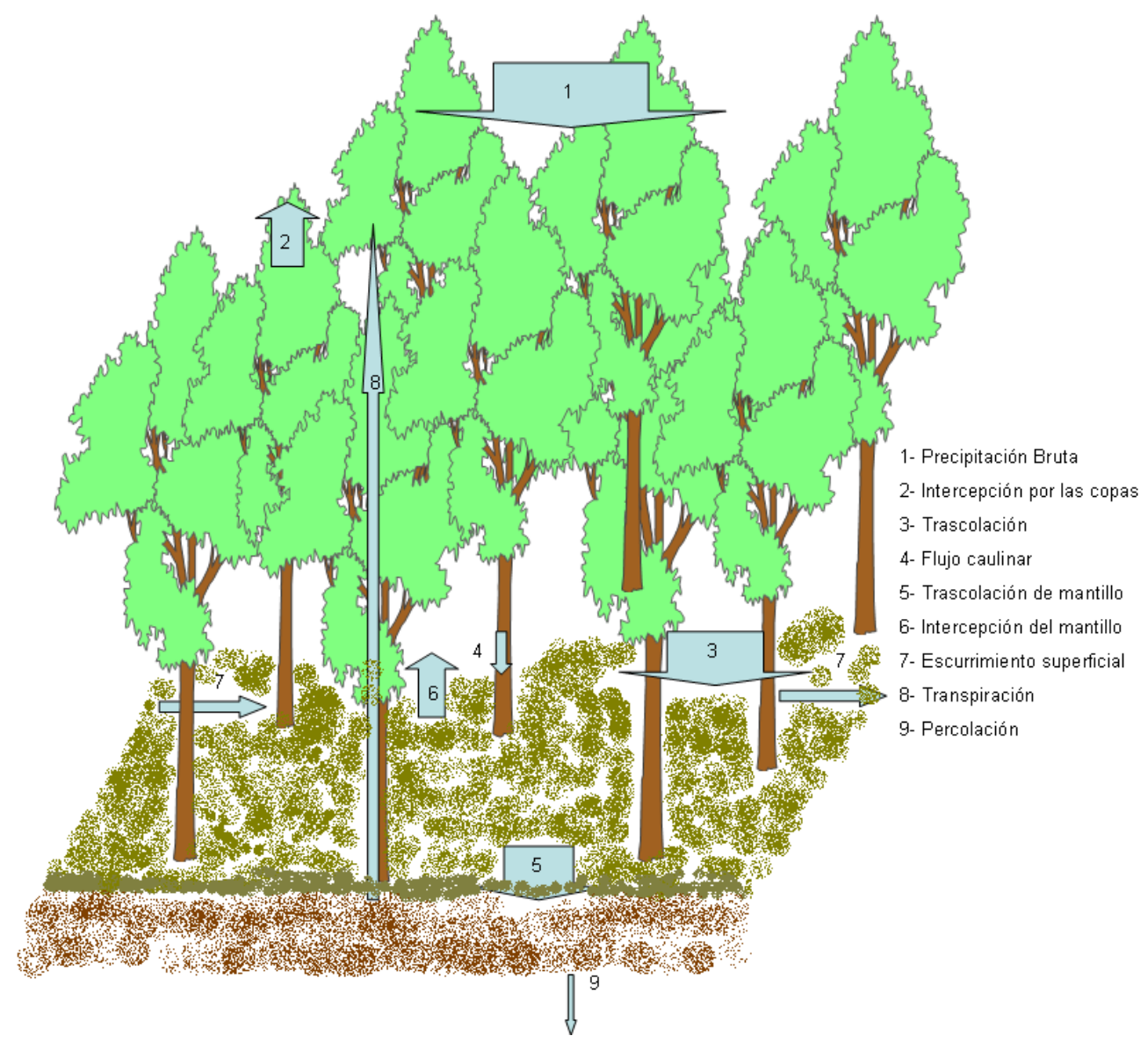

Figura 2.10: Representación de los flujos medidos $(1,3,4,5,7,8)$ y estimados $(2,6,9)$ del balance hídrico en la plantación de E. grandis

2.2.5.2 Ciclos de nutrientes. Se calcularon las concentraciones de carbono orgánico disuelto, nitrógeno, fósforo, potasio, magnesio y calcio en los distintos flujos, el cociente de estos nutrientes entre los flujos y los ingresos y egresos en masa ( $\left.\mathrm{kg} \mathrm{ha}^{-1} \mathrm{año}^{-1}\right)$. Luego se integraron estos valores con los de los ciclos de nutrientes en la biomasa y la necromasa calculados por Barrera (2005). 


\subsubsection{Crecimiento y producción}

2.2.6.1 Diámetro y altura. Anualmente se midió altura total y diámetro (DAP) de los árboles de los dos sitios. Para realizar las mediciones se utilizaron hipsómetros y cintas diamétricas.

2.2.6.2 Caída de detritos finos. La caída de detritos finos se estimó mediante tres canastas trampa por parcela, de $0.25 \mathrm{~m}^{2}$ cada una (Figura 2.11). Mensualmente, durante 24 meses, se colectó el material y se seco en estufa a $70^{\circ} \mathrm{C}$ hasta peso constante. El material colectado se clasifico en hojas, ramas pequeñas, corteza y frutos.

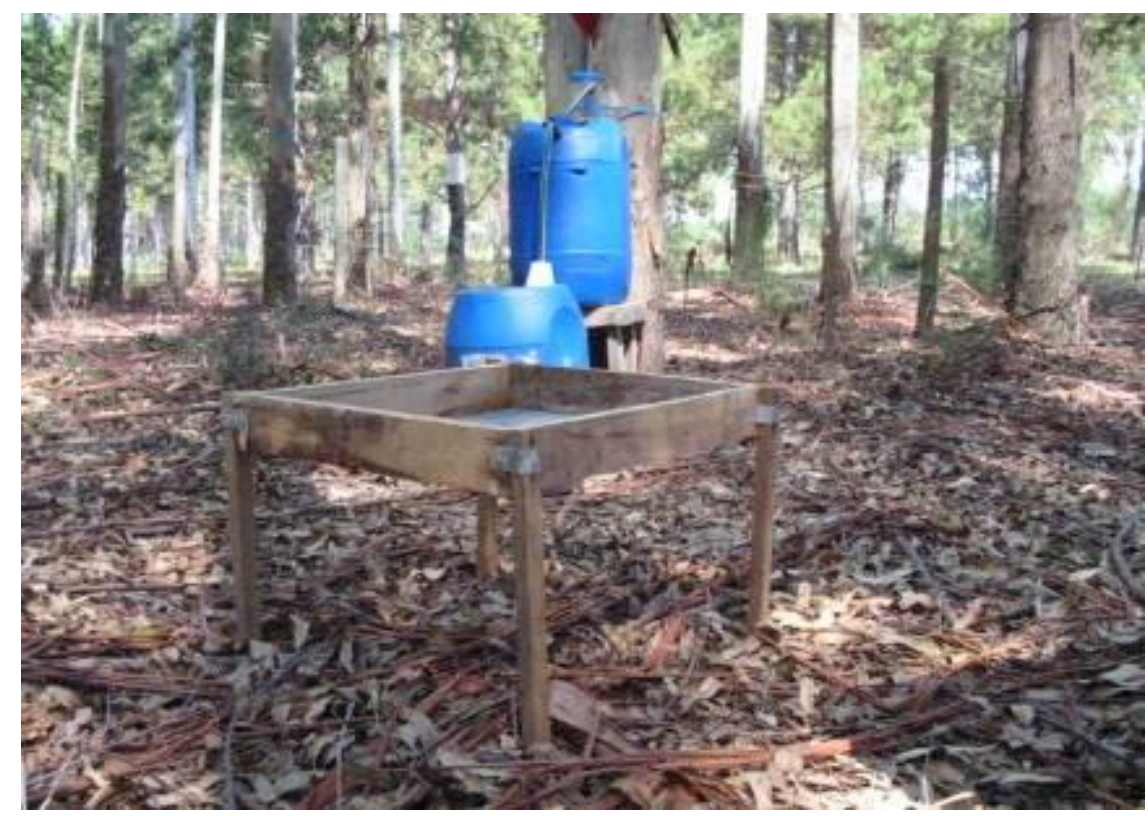

Figura 2.11: Canasto utilizado para la determinación de la caída anual de detritos finos.

2.2.6.3 Índice de área foliar. El índice de área foliar (IAF) se estimó mediante un ceptómetro Sunfleck PAR Ceptometer, Decagon, USA con medición de la Radiación Fotosintéticamente Activa (PAR) dentro y fuera de las plantaciones en días totalmente cubiertos, de manera de poder estimar el IAF sin considerar la estructura de la vegetación ni el ángulo de elevación del sol. Se utilizó la ecuación de Norman J, provista como metodología en el manual de operación del usuario: 


$$
L=\frac{\left[\left(1-\frac{1}{2 K}\right) f_{b}-1\right] \ln \tau}{A\left(1-0.47 f_{b}\right)}
$$

Donde:

L: índice de área foliar

K: coeficiente de extinción

T: proporción de PAR medido por debajo de la cubierta arbórea en relación con la medida por encima.

A: absortividad de la hoja

fb: fracción de PAR incidente (días nublados fb:0)

2.2.6.4 Cálculo de crecimiento y producción. Para el cálculo del volumen por hectárea se utilizó la ecuación de volumen ajustada por Glade y Friedl (1988) para Eucalyptus grandis en el noreste de Entre Ríos. En la misma las variables independientes para el cálculo del volumen total con corteza (Vol c/c) son el diámetro a la altura del pecho (DAP) y la altura total $(\mathrm{Ht})$.

El DAP y la Ht se midieron en todos los individuos de cada parcela de manera anual. A partir de estas mediciones se calcularon los volúmenes individuales de los árboles de cada parcela, se determinó el volumen promedio de las parcelas y se lo refirió a hectárea. La ecuación utilizada fue:

$$
\operatorname{Ln} \mathrm{Vol} c / c=10.038684+1.8362776 \operatorname{Ln}(\mathrm{DAP})+1.0814966 \operatorname{Ln}(\mathrm{Ht})
$$

2.2.6.5 Producción primaria aérea neta anual. La producción primaria aérea neta se obtuvo como la sumatoria el crecimiento anual de madera más la caída fina anual considerando una vida media de las hojas de un año (Stape et al., 2004). 
2.2.6.6 Eficiencia en el uso del agua y Eficiencia en la captura del agua. La eficiencia en el uso del agua se obtuvo como el cociente entre la producción primaria neta anual (ANPP) y la transpiración (Stape et al., 2004). La eficiencia en la captura del agua se obtuvo como el cociente entre la transpiración y la precipitación (Stape et al., 2004)

\subsection{Estadística}

Dada la falta de antecedentes de estudios sobre balances hidrológicos a nivel de plantación en la zona, esta investigación es un estudio de caso, exploratorio, en el que se analiza una plantación de once años (para la trascolación se incluyó además una plantación de tres años) y un claro adyacente con vegetación espontánea.

En la plantación se instalaron tres parcelas, de $100 \mathrm{~m}^{2}$ intentando cubrir la variabilidad de la misma. En cada parcela se midieron los distintos flujos de agua mencionados anteriormente y se ajustaron regresiones lineales entre los flujos y la precipitación bruta. Se compararon estas regresiones para saber si existían o no diferencias entre las mismas.

Para analizar la concentración de los nutrientes en los distintos flujos se realizaron análisis de varianza de los promedios ponderados y comparación de medias mediante la prueba de Tukey $(p<0.05)$. Para la estimación de la transpiración se realizó una regresión múltiple entre el flujo de savia y variables climáticas y el índice de humedad del suelo API.

Los análisis estadísticos se realizaron mediante el programa Statistica versión 7, Statsoft, Inc. 


\section{Capítulo III}

Resultados y discusión 


\section{RESULTADOS Y DISCUSIÓN}

\section{1. Aspectos meteorológicos, microclimáticos y edáficos}

\subsubsection{Temperatura del aire y precipitación}

La temperatura máxima media del mes más cálido, la temperatura mínima media del mes más frío, la temperatura media anual, la temperatura mínima absoluta, junto con la precipitación media anual, el régimen de precipitación y la duración de la estación seca fueron los requerimientos climáticos considerados por Booth \& Prior (1991) para evaluar los sitios con posible aptitud climática para 21 especies de Eucalyptus entre ellas E. grandis.

Comparando los requerimientos climáticos con la información de la EEA Concordia (Tabla 3.1.1), se observa que las condiciones climáticas de Concordia, como es de esperar, son adecuadas para la especie $E$. grandis, ya que sus valores se encuentran en el rango establecido por los autores, y las temperaturas mínimas absolutas son más altas.

\begin{tabular}{|c|c|c|c|c|c|c|c|}
\hline & $\begin{array}{l}\text { Precipitación } \\
\text { anual media }\end{array}$ & $\begin{array}{c}\text { Regimen de } \\
\text { precipitaciones }\end{array}$ & $\begin{array}{l}\text { Estación } \\
\text { seca } \\
\text { (meses) }\end{array}$ & $\begin{array}{l}\text { Temp. máx. } \\
\text { media del mes } \\
\text { más cálido (으) }\end{array}$ & $\begin{array}{l}\text { Temp. mín } \\
\text { media del mes } \\
\text { más frío (oC) }\end{array}$ & $\begin{array}{c}\text { Temp media } \\
\text { anual } \\
\text { (ㅇ) }\end{array}$ & $\begin{array}{c}\text { Temp mín } \\
\text { absoluta (ㅇ) }\end{array}$ \\
\hline Requerimientos & $700-2500$ & Estivales & $0-7$ & $25-34$ & $3-18$ & $14-25$ & $>-8$ \\
\hline E grandis & & $\begin{array}{l}\text { Uniformes } \\
\text { Bimodales }\end{array}$ & & & & & \\
\hline Concordia, ER & 1345 & Uniformes & 0 & 31.7 & 7.2 & 18.7 & -5.1 \\
\hline
\end{tabular}

Tabla 3.1.1: Requerimientos climáticos de E. grandis según Booth \& Prior (1991) y valores de la Estación Meteorológica INTA Concordia (1967- 2006).

Según la información de Booth \& Prior (1991) se observa que E. grandis puede tolerar períodos de hasta 7 meses de duración de la estación seca (Tabla 3.1.1), considerando la duración de la estación seca como el número de meses consecutivos con precipitaciones 
menores a los $40 \mathrm{~mm}$. Si se observan los valores medios en la Tabla 3.1.2, en Concordia no se registran meses con precipitaciones que correspondan a los valores mínimos para ser considerados secos. Sin embargo pueden ocurrir períodos con valores correspondientes a estaciones secas, como lo ocurrido en el año 2008, con un valor anual de precipitaciones de $809.4 \mathrm{~mm}$ y precipitaciones en los meses de noviembre y diciembre de $11.7 \mathrm{~mm}$ y 18.4 $\mathrm{mm}$ respectivamente.

Respecto a las temperaturas, a pesar de que los valores (Tabla 3.1.3) se corresponden a los requerimientos de la especie (Tabla 3.1.1), las heladas limitan el cultivo del E. grandis (Marco, 2007), produciendo severos daños.

\begin{tabular}{lrrrrrrrrrrrrr}
\hline Precipitación (mm) & ENE & FEB & MAR & ABR & MAY & JUN & JUL & AGO & SET & OCT & NOV & DIC & Total Anual \\
& & & & & & & & & & & & & \\
\hline Promedio & 133.1 & 126.3 & 145.3 & 145.0 & 106.8 & 88.7 & 62.7 & 59.5 & 95.0 & 126.4 & 136.1 & 120.5 & 1345.3 \\
& & & & & & & & & & & & \\
Mediana & 112.4 & 91.6 & 118.1 & 136.9 & 89.7 & 56.4 & 47.0 & 53.0 & 72.7 & 96.9 & 129.3 & 109.8 & 1261.2 \\
Máxima & 583.7 & 477.0 & 347.6 & 361.0 & 304.2 & 397.6 & 237.7 & 154.4 & 297.0 & 296.6 & 318.1 & 459.9 & 2193.2 \\
Mínima & 9.6 & 10.7 & 14.6 & 14.7 & 1.5 & 4.9 & 7.3 & 6.3 & 7.1 & 25.0 & 4.7 & 21.2 & 868.1 \\
Desv. Stand. & 103.5 & 101.1 & 88.3 & 93.3 & 76.9 & 85.6 & 49.4 & 33.2 & 64.5 & 73.9 & 74.0 & 83.2 & 287.7 \\
CV (\%) & 77.7 & 80.1 & 60.8 & 64.4 & 72.0 & 96.5 & 78.8 & 55.9 & 68.0 & 58.5 & 54.4 & 69.1 & 21.4 \\
\hline
\end{tabular}

Fuente: Estación Meteorológica EEA Concordia. Serie 1967 - 2005. Ing. Sergio Garrán.

Tabla 3.1.2: Valores de la precipitación mensual (media, mediana, máxima y mínima) de la Estación Meteorológica Concordia. Serie $1967-2005$.

\begin{tabular}{lcccccccccccc}
\hline Temperatura (oC) & ENE & FEB & MAR & ABR & MAY & JUN & JUL & AGO & SET & OCT & NOV & DIC \\
\hline Temp. máx. media & 31.7 & 30.1 & 28.3 & 24.2 & 20.9 & 17.8 & 17.9 & 19.9 & 21.7 & 24.6 & 27.2 & 30.3 \\
Temp. mín. media & 18.6 & 18.1 & 16.3 & 12.9 & 10.2 & 7.7 & 7.2 & 8.1 & 9.5 & 12.4 & 14.6 & 17.1 \\
Temp. media & 25.1 & 24.1 & 22.3 & 18.6 & 15.6 & 12.7 & 12.5 & 14.0 & 15.6 & 18.6 & 20.9 & 23.7 \\
Temp. máx. abs. & 40.8 & 41.3 & 40.2 & 35.1 & 32.6 & 30.0 & 31.9 & 35.7 & 37.6 & 37.2 & 39.2 & 40.5 \\
Temp. mín. abs. & 8.4 & 6.8 & 6.4 & 1.1 & -2.2 & -5.1 & -4.6 & -4.2 & -2.4 & -0.4 & 2.4 & 6.5 \\
\hline Fuente. Estación Meteorológica EEA Concordia Serie 1967-2005. Ing Sergio Garrán. & & & & &
\end{tabular}

Tabla 3.1.3: Valores de la temperatura mensual (máxima media, mínima media, media, máxima absoluta y mínima absoluta) de la Estación Meteorológica Concordia. Serie 1967 - 2005.

Garrán (2007) analizó las tendencias de las principales variables térmicas e hídricas registradas en la EEA Concordia del INTA durante la serie 1967-2006, abarcando 40 años 
de observaciones. Observó para este período aumentos de las temperaturas medias, máximas y mínimas en todos los meses excepto en mayo y julio. Respecto a las precipitaciones también encontró que se incrementaron excepto para el trimestre invernal. Indicó, además, que los aumentos de temperaturas de marzo, abril y especialmente junio, puede tener importantes efectos fenológicos en las forestaciones de E. grandis, pudiendo extenderse el ciclo vegetativo, retrasando los procesos de rustificación y descanso invernal, de modo que cuando se alcancen temperaturas más bajas en julio, tal como lo marca la tendencia observada para este mes, estos cultivos se encuentren menos aclimatados para resistir esas bajas temperaturas (Garrán, 2007).

Lo observado por Garrán (2007) puede atribuirse a que los eucaliptos no tienen la dormancia invernal ni la rustificación o endurecimiento (hardening) determinadas por el fotoperiodo; su nivel de aclimatación al frío está determinado por el régimen de temperaturas mínimas de los días y semanas anteriores al potencial daño por frío (Eldridge et al., 1994). Los eucaliptos son entonces muy susceptibles a los daños por frío en climas donde, a continuación de un tiempo templado con noches con mínimas superiores a $\operatorname{los} 5^{\circ} \mathrm{C}$, se producen heladas advectivas, prolongadas y severas, como en el sudeste de EEUU y sur de Francia (Eldridge et al., 1994). En Concordia se ha observado que los daños en Eucalyptus grandis son mayores cuando las heladas son precedidas por varias noches con temperaturas elevadas. Esta situación se dio en el invierno de 2006 cuando las heladas de fines de julio, principio de agosto, fueron precedidas por elevadas temperaturas (la mínima media de julio fue de $10,7^{\circ} \mathrm{C}$ ) lo que provocó daños notables en plantaciones y rebrotes de hasta dos años de edad (Garrán, 2007). En el presente estudio se observó una situación similar para el año 2004, cuando en el mes de julio, precedieron a las heladas, días con temperaturas muy altas, con temperaturas nocturnas mayores a los $15^{\circ} \mathrm{C}$ (Figura 3.1.1). En cambio, cuando los descensos térmicos y las heladas aumentan su severidad gradualmente, como ocurre en el otoño y en el invierno temprano de Australia, se produce una rustificación progresiva de las plantas de Eucalyptus (Turnbull \& Eldridge, 1984, en Eldridge et al., 1994). Esta característica climática que ocurre en la zona de origen de la especie y que no se produce regularmente en la zona de Concordia es la que estaría determinando el daño ocasionado por el frío en las plantaciones de la zona. 


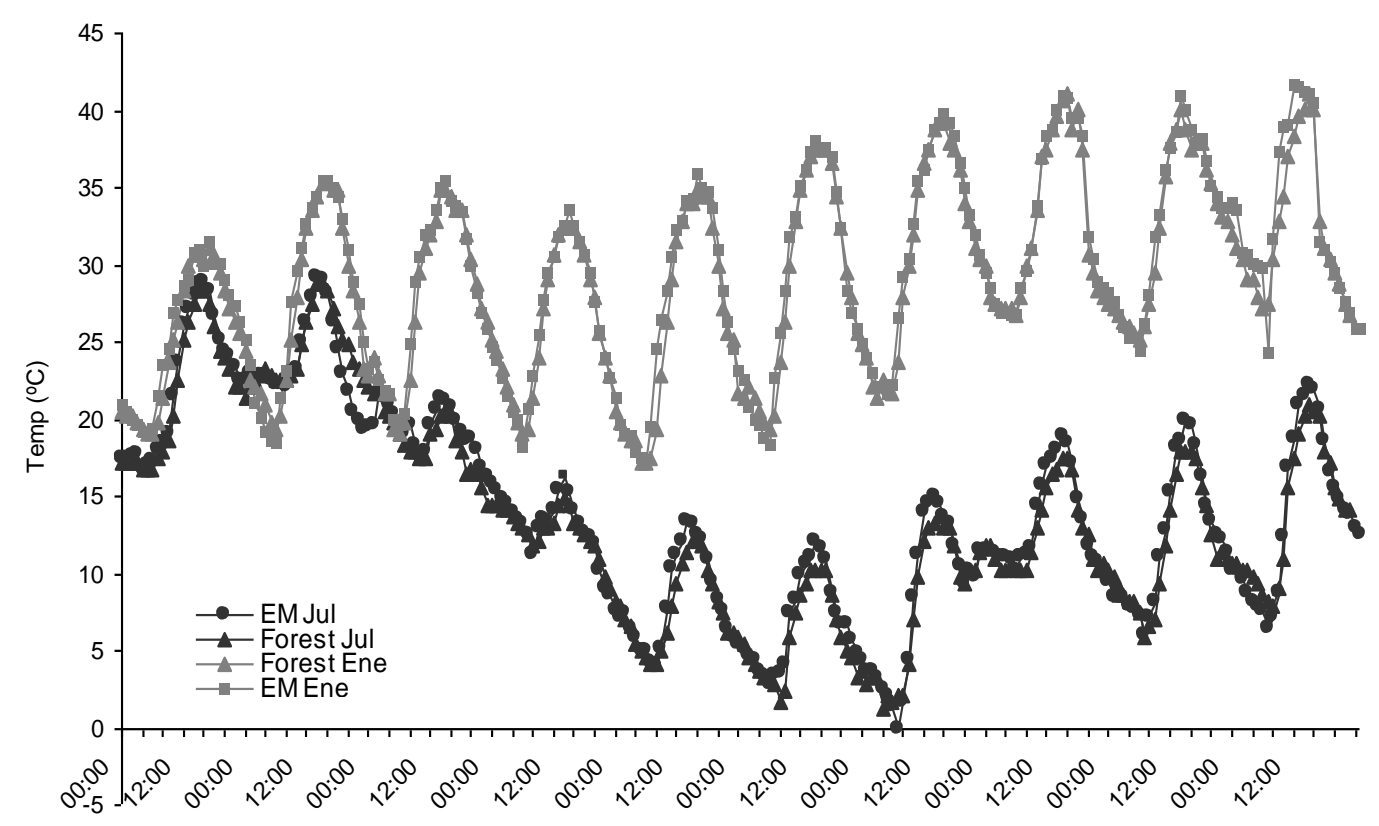

Figura 3.1.1: Temperatura del aire a 1.5 m en la plantación y en un claro. En los meses de julio de 2004 y enero de 2005.

\subsubsection{Comparación de temperaturas del aire dentro y fuera de la plantación}

Analizando el microclima de la plantación, al considerar las temperaturas medias mensuales a $1.5 \mathrm{~m}$ se observa que las mismas fueron similares fuera y dentro de la plantación. Cuando la diferencia existe, es a favor de valores más altos fuera de la plantación. Las mayores diferencias son de hasta $2 \stackrel{\circ}{ }$, se observaron principalmente en los meses de mayo a setiembre (otoño- invierno) y fueron más notorias en las temperaturas medias y máximas medias. Las temperaturas mínimas medias fueron muy similares dentro y fuera de la plantación. Esto manifiesta que en el período frío hay una limitada pero detectable capacidad de reducir la entrada de energía solar al piso forestal durante las horas diurnas, y una pérdida nocturna de energía tal que permite prácticamente igualar el balance térmico que ocurre en el exterior de la forestación (Figura 3.1.2). Durante la época cálida, desde mediados de primavera a fines del verano la capacidad de la plantación de regular la temperatura es prácticamente nula. 


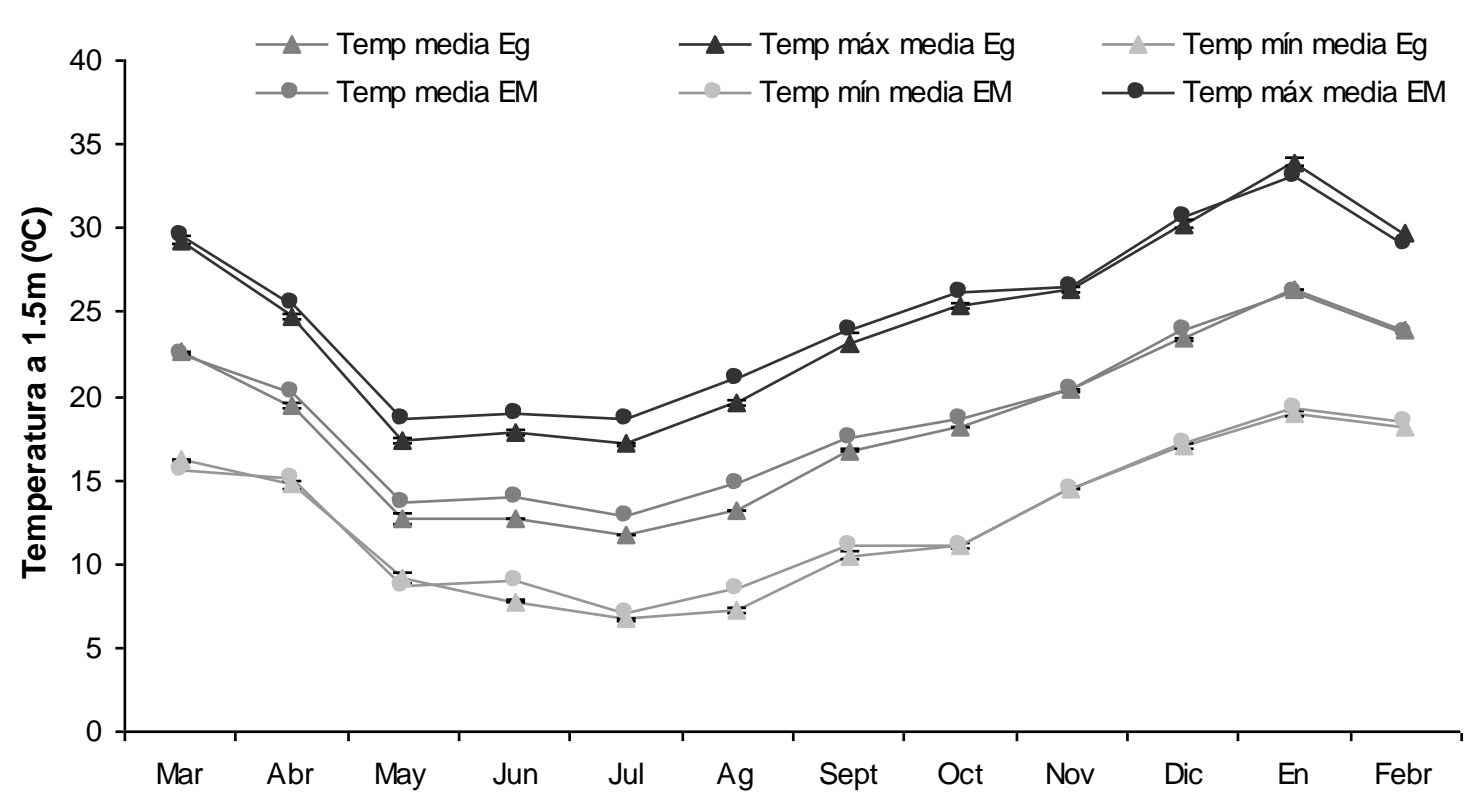

Figura 3.1.2: Temperatura media mensual, máxima media mensual y mínima media mensual registradas bajo la forestación y en la Estación meteorológica a 1.5 m de altura. Período de observación: marzo de 2004 - febrero de 2005.

La ecuación de regresión entre las temperaturas medias diarias en casilla meteorológica a 1.5 m, en la estación meteorológica INTA Concordia y en la plantación confirma que las diferencias entre dichas temperaturas medias son inferiores a $1 \stackrel{\circ}{\circ}$, y que esa relación es significativa, lo cual permite hacer adecuadas estimaciones de temperaturas medias diarias dentro de las plantaciones con los valores de estaciones climáticas de las inmediaciones (Figura 3.1.3). Esto puede servir, por ejemplo, a estudios que intenten identificar las temperaturas críticas que en las plantaciones puedan asociarse con niveles de daño a la misma. 


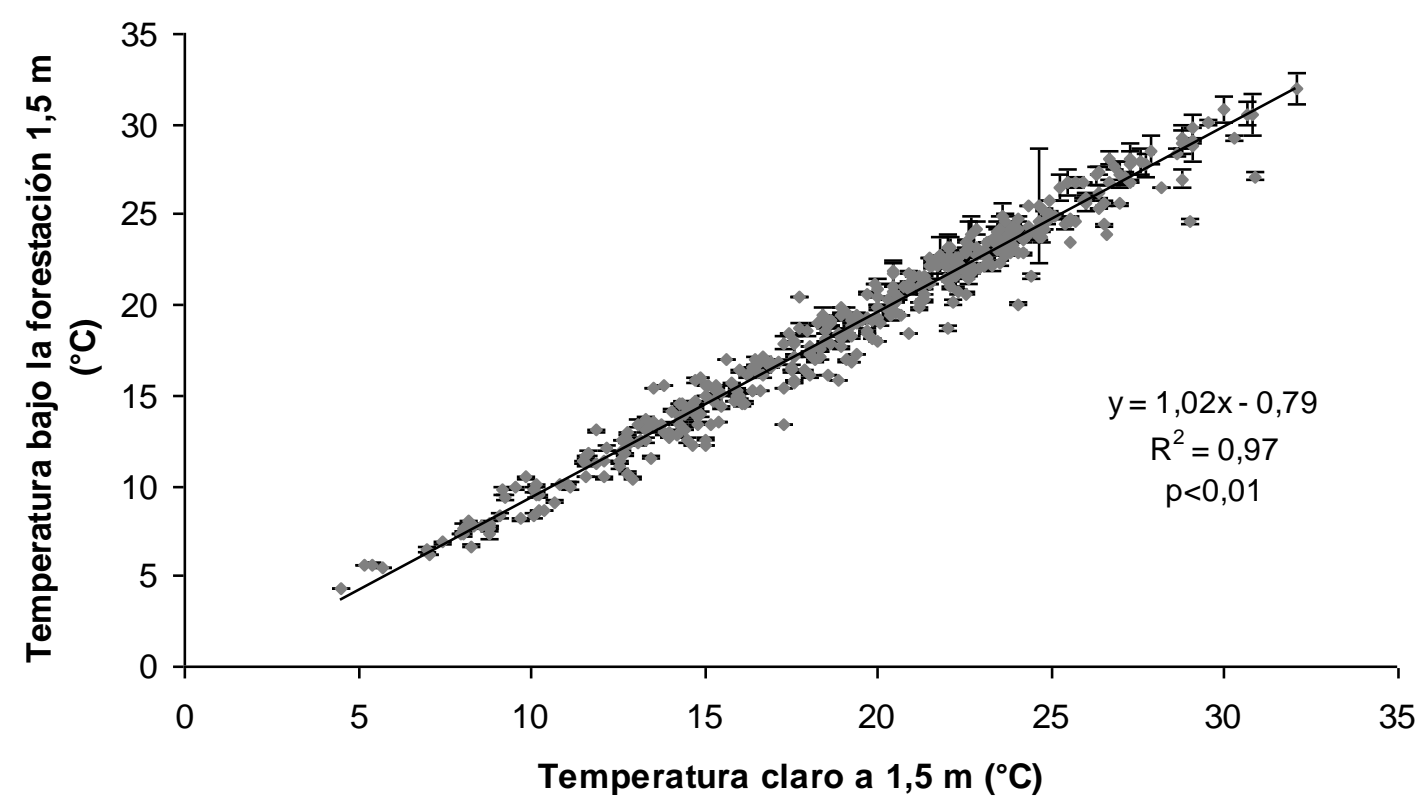

Figura 3.1.3: Regresión entre las temperaturas medias diarias tomadas en casillas meteorológicas a 1.5 m en la Estación Meteorológica y en la plantación de E. grandis de 12 años de edad. Período de observación: marzo de 2004 - febrero de 2005.

Por otra parte la comparación de la marcha horaria de la temperatura en días despejados y nublados de distintas estaciones del año permitió observar que en los días despejados el calentamiento matutino se inicia más tempranamente en el terreno abierto que en el interior de la plantación, lo cual puede deberse al efecto de horizonte que ocasiona la masa forestal (Figura 3.1.1). A partir de media mañana las temperaturas interiores y exteriores son muy similares en ambos sitios. No obstante cuando existen diferencias, éstas tienden a manifestarse en las horas de la mañana y cercanas al medio día con valores levemente superiores a favor de los sitios abiertos. En los días con alta nubosidad las temperaturas y la amplitud térmica diaria son más bajas que en días asoleados y en general son mayores fuera que dentro de la plantación. Los valores absolutos observados se corresponden con la estación del año.

Las temperaturas mínimas diarias del aire dentro y fuera de la plantación mostraron también una fuerte correlación; la temperatura mínima es muy similar en ambos sitios aunque cerca de medio grado centígrado inferior en el interior de la forestación (Figura 3.1.4). 


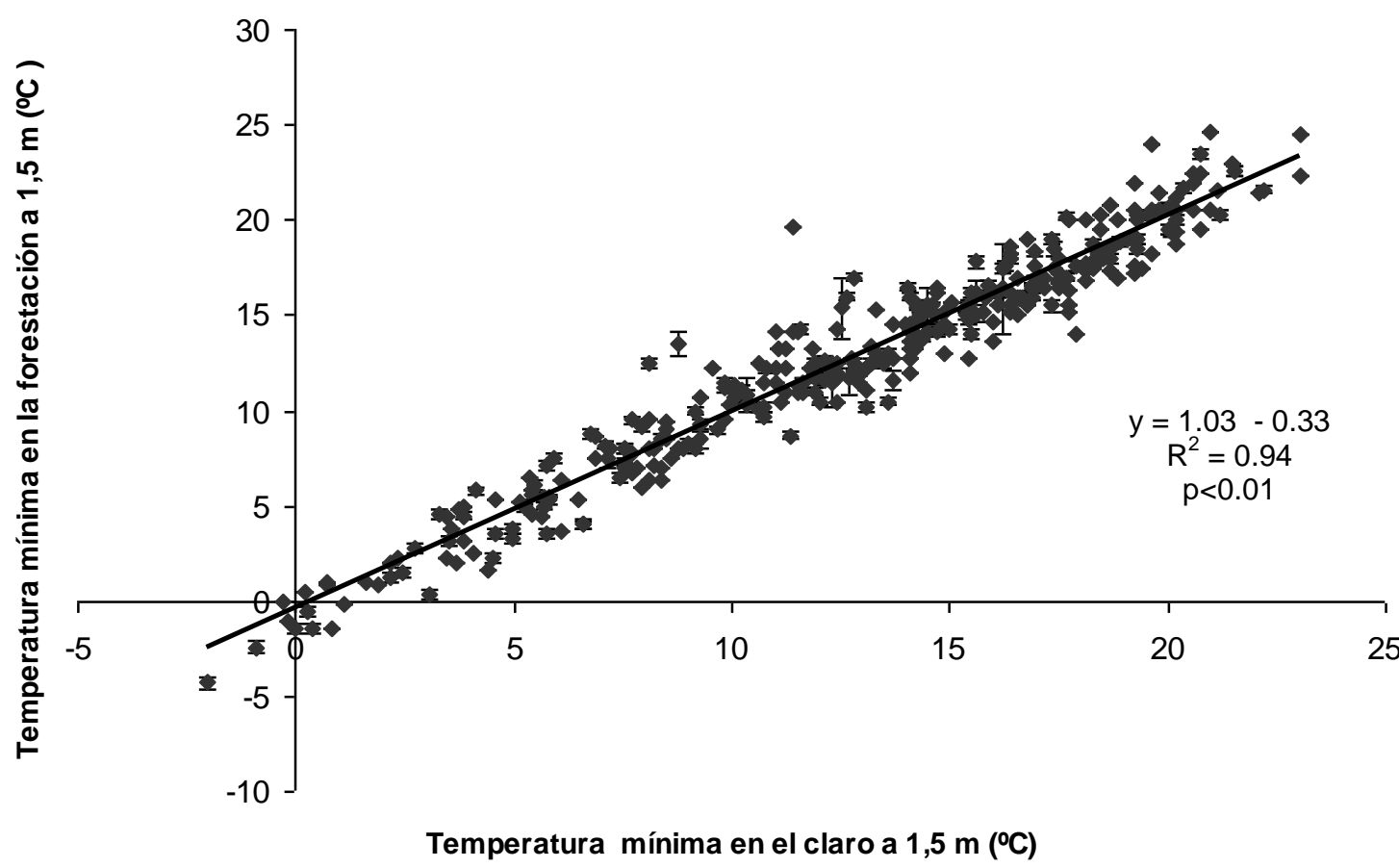

Figura 3.1.4: Regresión entre las temperaturas mínimas diarias tomadas en casillas meteorológicas a $1.5 \mathrm{~m}$ en la Estación Meteorológica y en la plantación de E. grandis de 12 años de edad. Período de observación: marzo de 2004 febrero de 2005.

\subsubsection{Perfil térmico en las plantaciones}

En las Figuras 3.1 .5 y 3.1.6 se observan los valores de las temperaturas a distintas alturas en el interior de la plantación en días de enero y julio.

En enero las temperaturas del aire, con excepción mayormente de las mínimas diarias, estuvieron en general por encima de las del suelo. En cambio, durante el mes de julio, las temperaturas del suelo fueron, en general, mayores que en el aire, con la excepción de las temperaturas de horas cercanas al mediodía; en pleno invierno las temperaturas edáficas a menor profundidad resultaron más bajas que a mayor profundidad, en forma inversa a lo observado en verano.

Comparando días con mayor y menor número de horas de sol, tanto en el verano como el invierno se observó una menor amplitud térmica en los días con menor heliofanía, debido a que la radiación terrestre de onda larga queda retenida entre la superficie terrestre y las capas de nubes, reduciéndose así la pérdida de calor (Figuras 3.1.7 y 3.1.8). 
Las diferencias de temperatura del aire en el rango de 30 metros sobre el suelo fueron bajas, en especial en días soleados cuando las temperaturas máximas ocurren cuando el sol está en el cenit. En el suelo mineral, como era de esperar, la amplitud descendió rápidamente en profundidad dentro de los $25 \mathrm{~cm}$ medidos.

En el día despejado, se observó un desplazamiento horario, hacia la media tarde, del pico de mayor temperatura desde el aire al suelo. Las mínimas temperaturas del aire se registraron al amanecer. Comparando ambos días, como era de esperar, las amplitudes térmicas del aire fueron menores en el día nublado (Figuras 3.1.8 a 3.1.12).

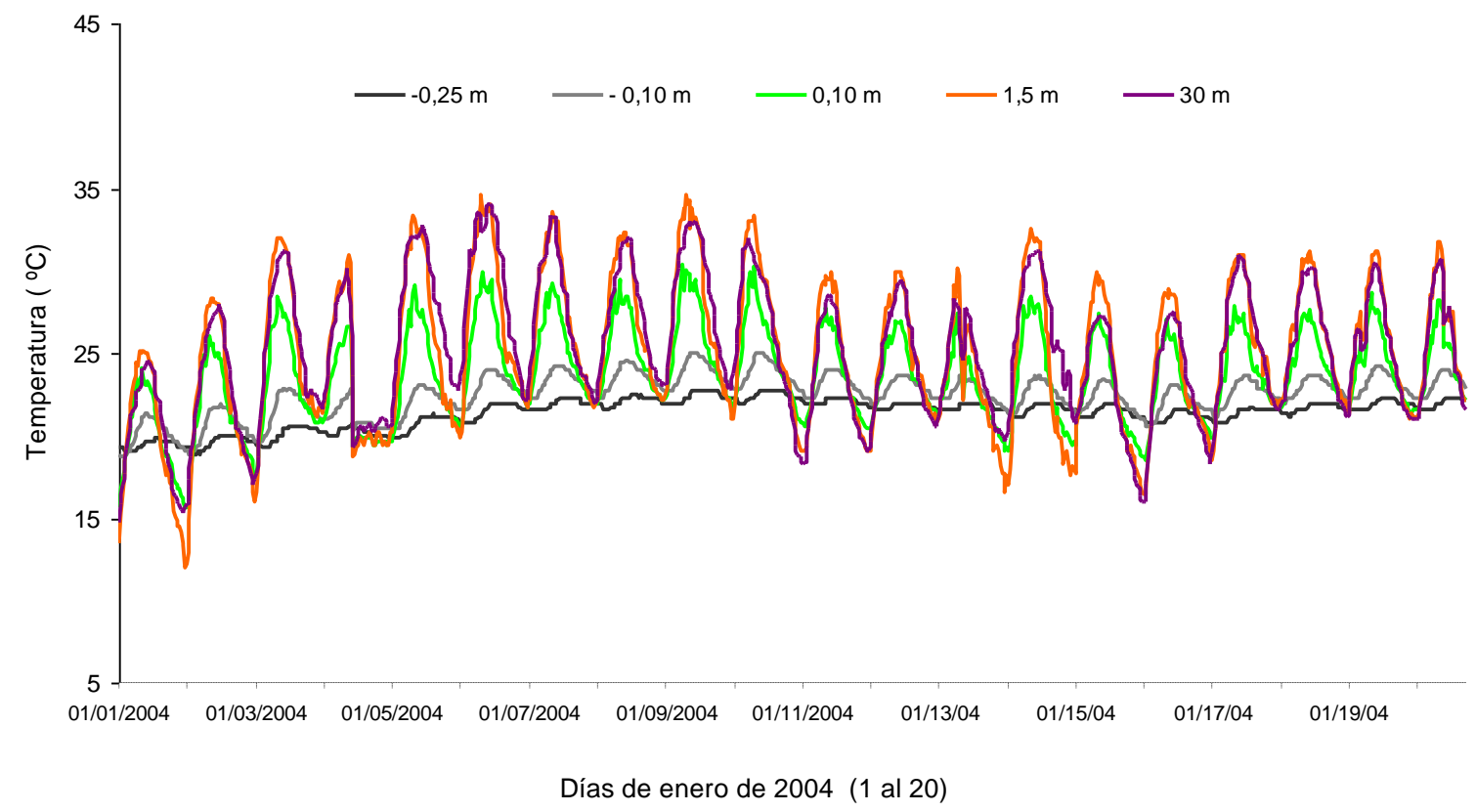

Figura 3.1.5: Marcha horaria de las temperaturas a distinta altura sobre el suelo y profundidad bajo su superficie en días del mes de enero de 2004 (días 01 al 20; n= 20). 


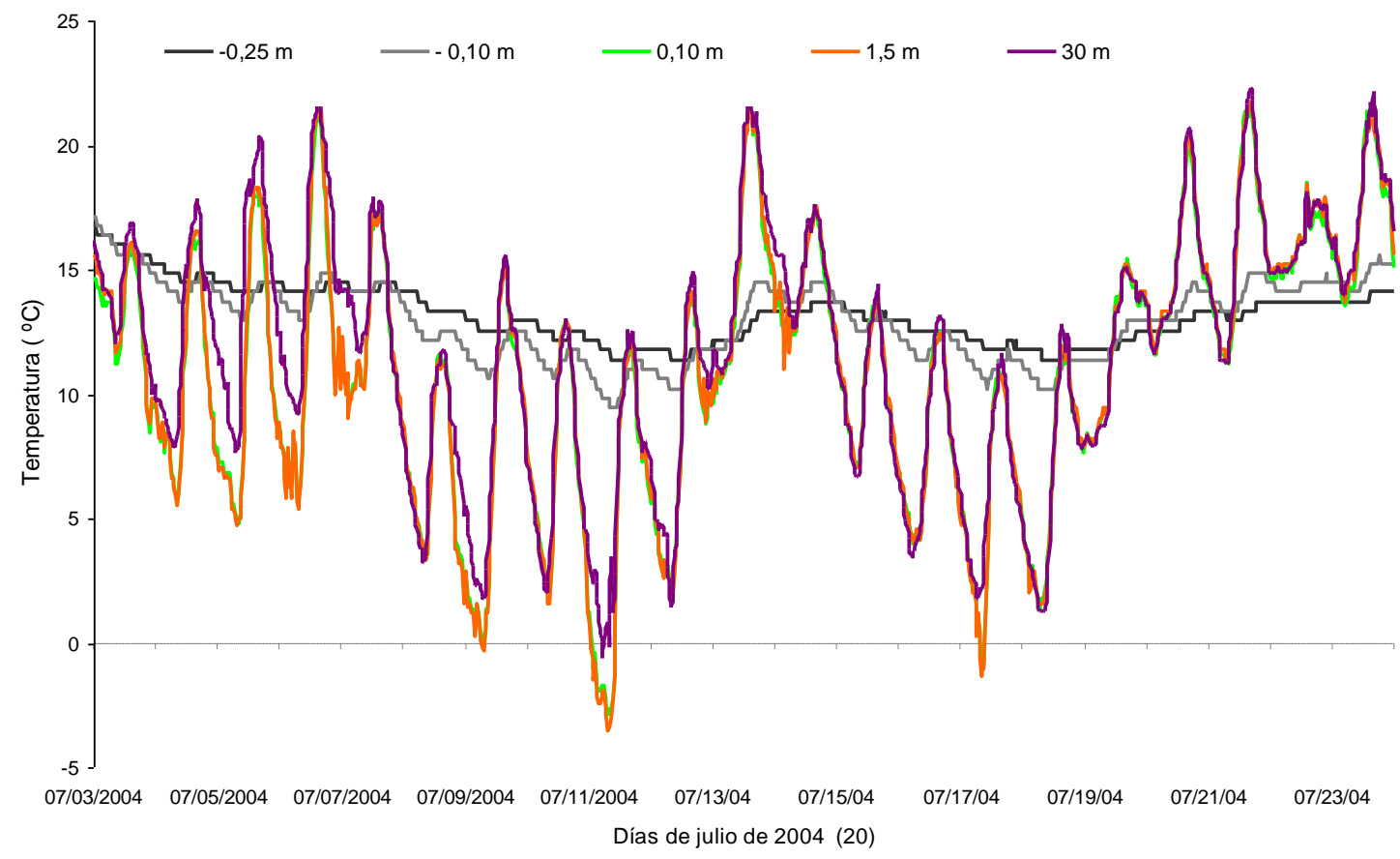

Figura 3.1.6: Marcha horaria de las temperaturas a distinta altura sobre el suelo y profundidad debajo de él en días del mes de julio de 2004 (días 03 al 23, n=20).

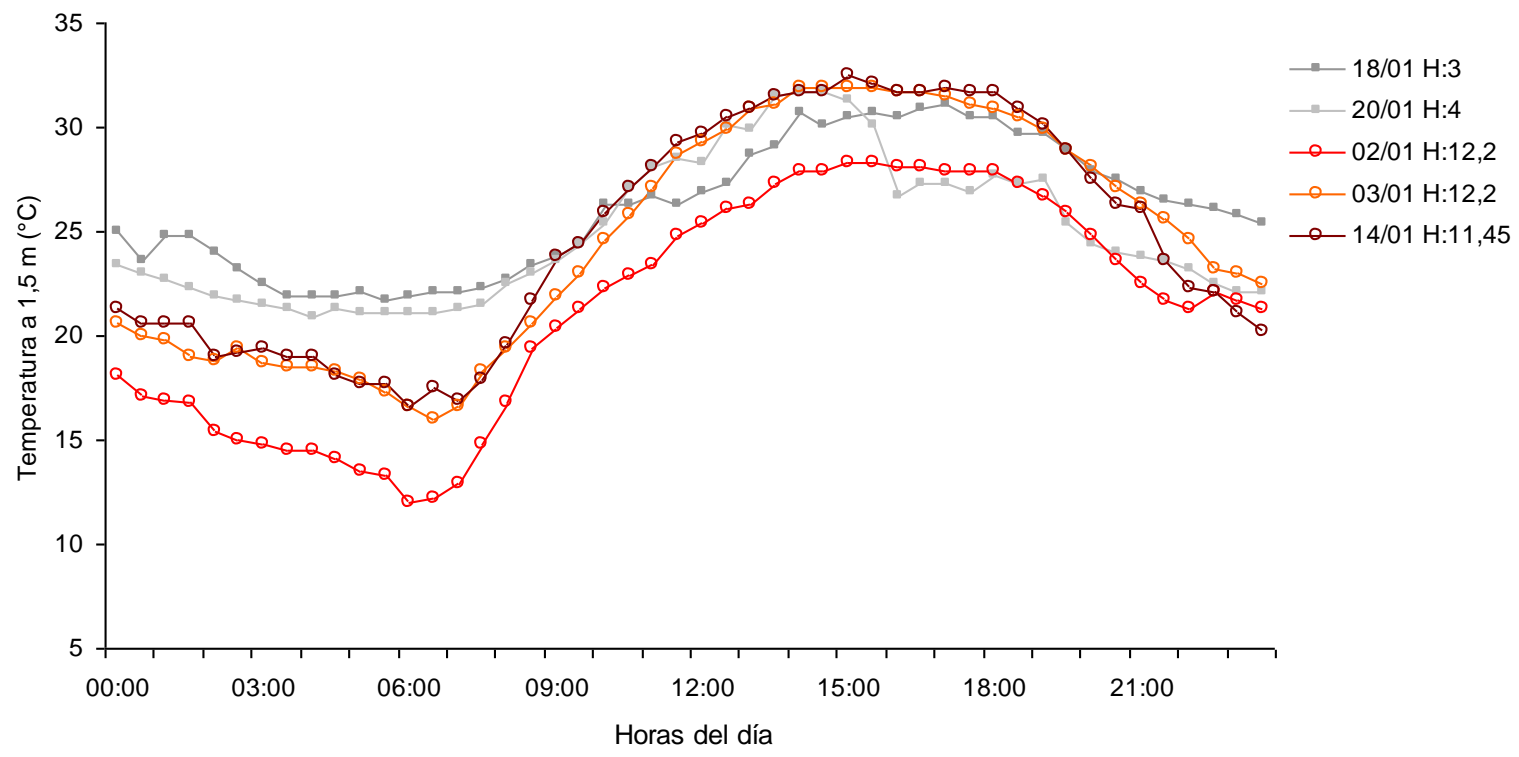

Figura 3.1.7: Marcha horaria de las temperaturas a $1.5 \mathrm{~m}$ bajo la forestación en días con valores contrastantes de heliofanía (H en horas) del mes de enero de 2004, indicados en las referencias. 


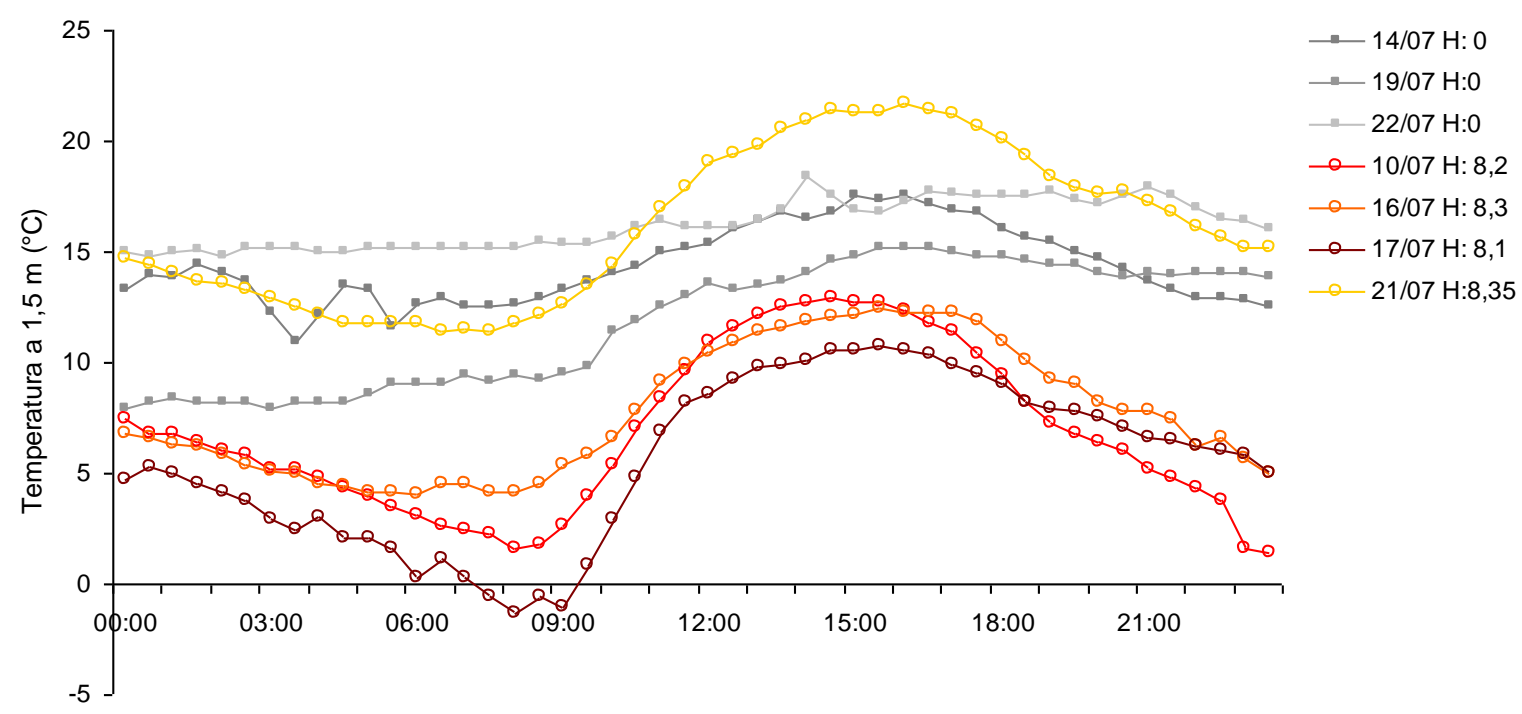

Horas del día

Figura 3.1.8: Marcha horaria de las temperaturas a 1,5 $\mathrm{m}$ bajo la forestación en días con valores contrastantes de heliofanía ( $\mathrm{H}$ en horas) del mes de julio de 2004, indicados en las referencias.

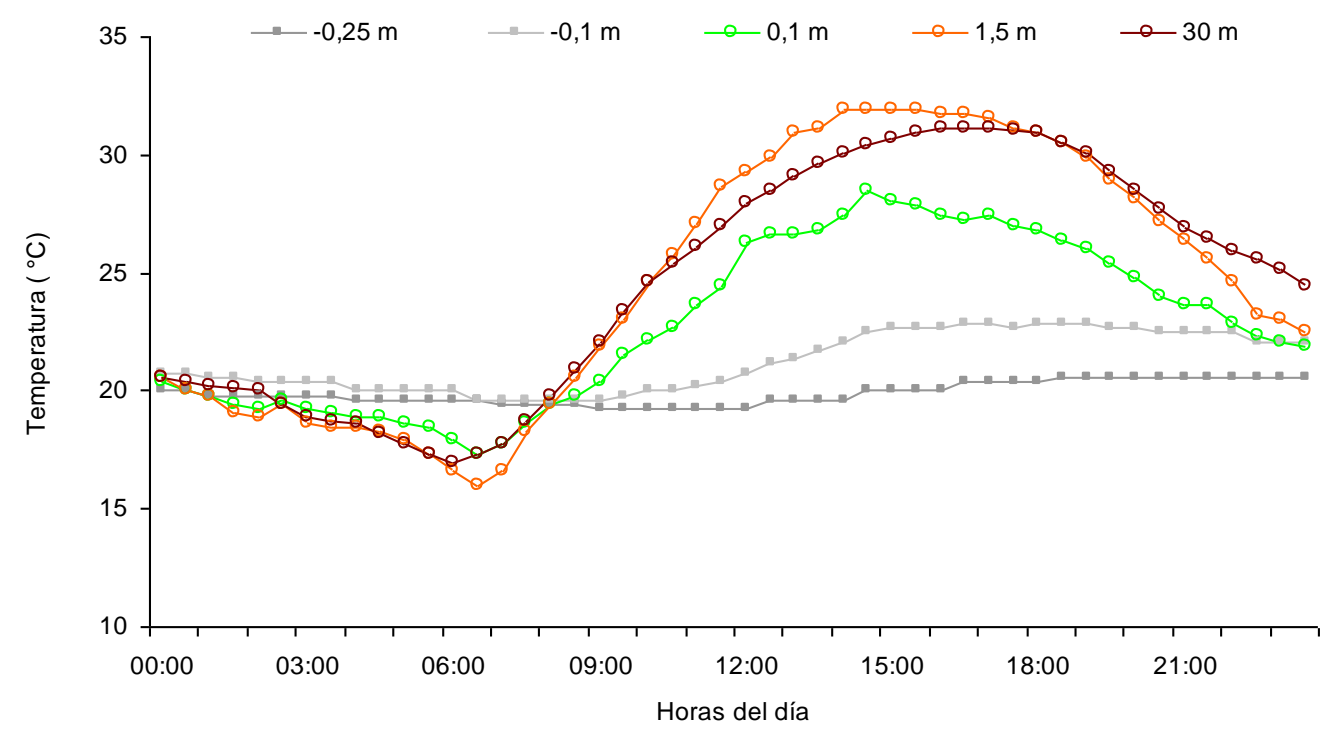

Figura 3.1.9: Marcha horaria de las temperaturas a distinta altura sobre el suelo y profundidad debajo de él en un día del mes de enero de 2004 (03/01/2004) con alta heliofanía (H: 12.2 hs). 


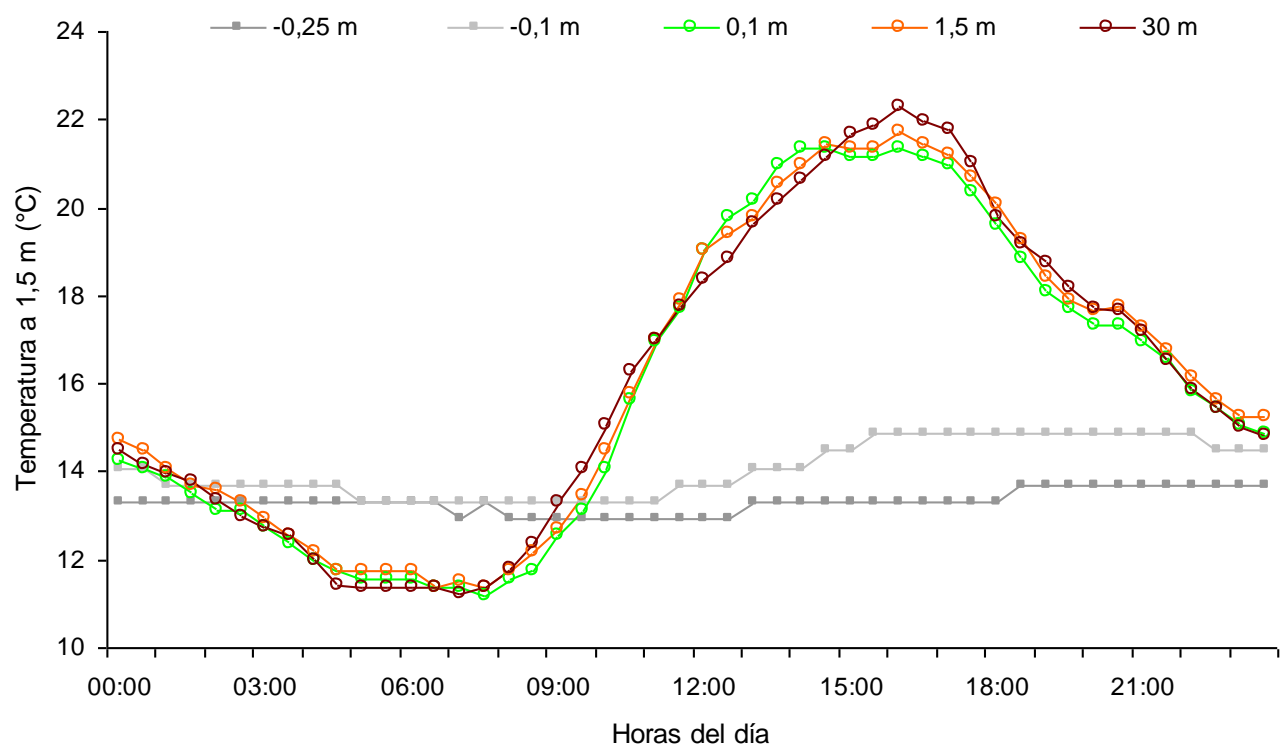

Figura 3.1.10: Marcha horaria de las temperaturas a distinta altura sobre el suelo y profundidad debajo de él en días del mes de julio de 2004 (04/07/04) con alta heliofanía (H: 8.35 hs).

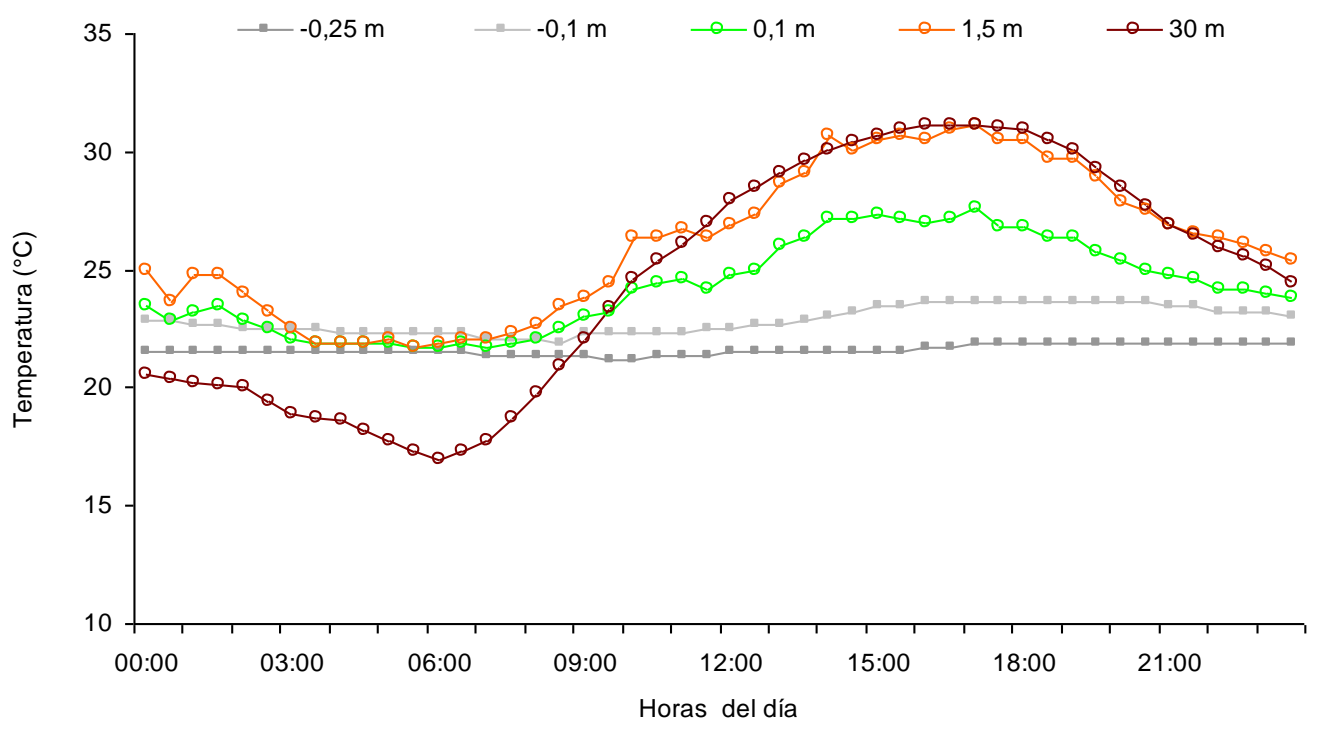

Figura 3.1.11: Marcha horaria de las temperaturas a distinta altura sobre el suelo y profundidad debajo de él en un día del mes de enero de 2004 (18/01/04) con baja heliofanía (H:3). 


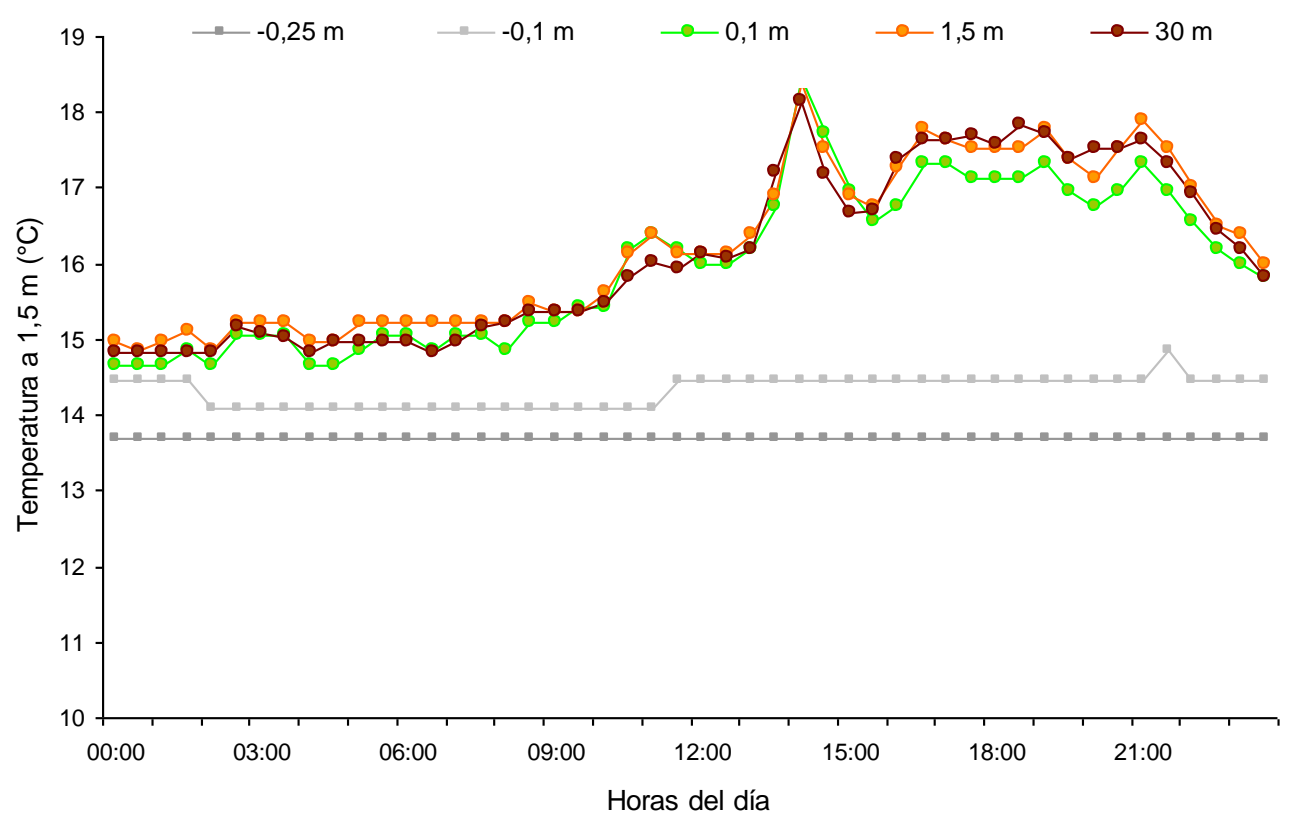

Figura 3.1.12: Marcha horaria de las temperaturas a distinta altura sobre el suelo y profundidad debajo de él en días del mes de julio de 2004 (22/07/04) con baja heliofanía (H: 0 hs).

\subsubsection{Humedad relativa}

La humedad relativa (HR) media mensual bajo la plantación varió en el transcurso del año (Figura 3.1.13). El otoño fue la estación con mayor humedad relativa media, y máxima y mínima media mensual, coincidiendo con el descenso térmico estacional y un periodo de lluvias abundantes. Durante el invierno poco lluvioso la HR decreció, para volver a aumentar hacia la primavera. Las lluvias de primavera, estación frecuentemente lluviosa como el otoño, se prolongaron durante el estío con valores mensuales comparables. Sin embargo, los aumentos térmicos parecieron tener gran influencia sobre la HR que alcanzó sus menores valores en el verano. 


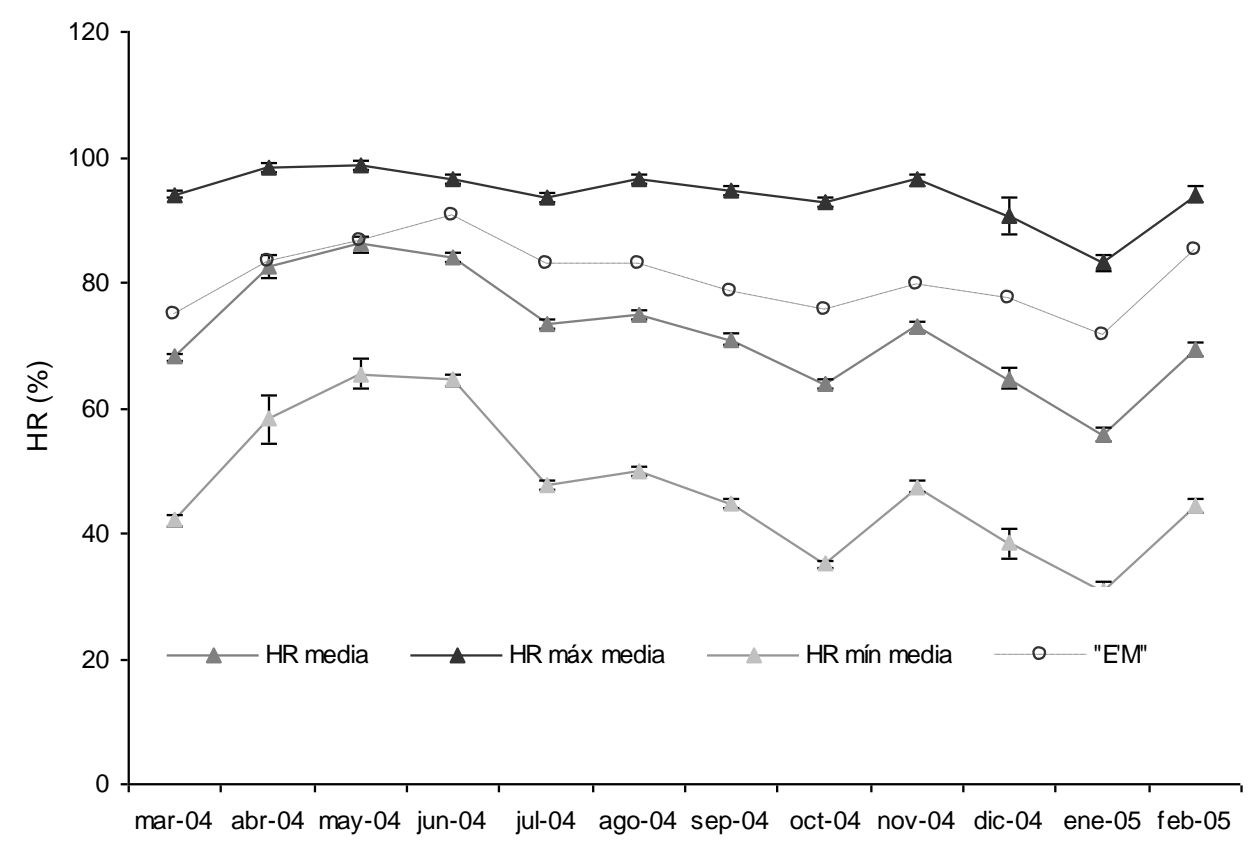

Figura 3.1.13: Humedad relativa media mensual, máxima media mensual y mínima media mensual registradas bajo la forestación y en la Estación meteorológica a 1.5 m de altura. Periodo marzo 2004 - febrero 2005.

Al comparar los valores medios mensuales de humedad relativa a $1.5 \mathrm{~m}$, fuera y dentro de la plantación se observó la misma tendencia a lo largo del año pero con valores menores de HR dentro de la plantación (10\% a 15\% menores) que fueron mayores en el verano. La excepción ocurrió durante el periodo más lluvioso y húmedo (otoño), cuando la HR de ambos sitios fue similar. Una posible explicación a las diferencias entre la HR del aire en el interior y exterior de la plantación podría estar en la diferente cobertura del suelo en los sitios y su efecto sobre las salidas gaseosas de agua desde la superficie del suelo y el estrato inferior. Mientras que en el claro hubo una cubierta dominante de pastos, en la plantación la cubierta es de hojas, ramas y corteza siendo insignificante la cubierta de

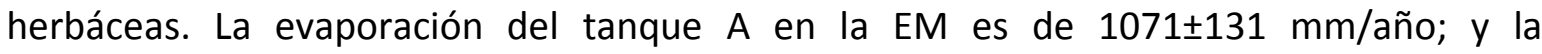
evapotranspiración de referencia (Eto; Figura 3.1.14), según la ecuación de FAO Penman Monteith (FAO, 2006), fue de $1169 \mathrm{~mm}$. Por otra parte Nosetto et al. (2005) ha estimado la evapotranspiración real de los pastizales en $639 \mathrm{~mm} / \mathrm{año}$ y, como se verá más adelante, la evaporación del mantillo forestal en éste estudio se ha estimado en 192 mm promedio para los dos períodos evaluados. De esos datos, y de la mínima diferencia de temperatura entre interior y exterior (Figuras 3.1 .2 y 3.1.3) puede suponerse que los 
mayores aportes de agua desde los pastizales explicarían el incremento de la HR a $1.5 \mathrm{~m}$ en lugares abiertos o no forestados.

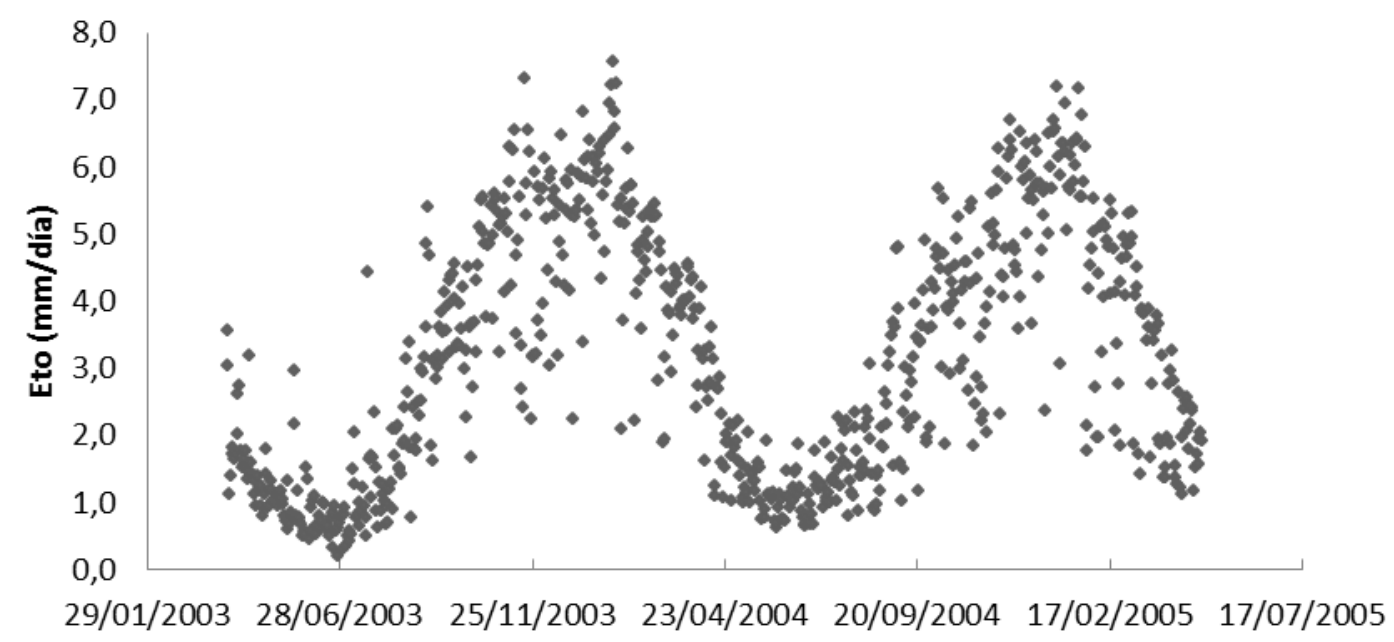

Figura 3.1.14: Valores de evapotranspiración de referencia (Eto) calculados según la ecuación Penman - Montheith FAO, con datos de la Estación Meteorológica de la EEA INTA Concordia. Período: abril de 2003 - abril de 2005

\subsubsection{Radiación fotosintéticamente activa e índice de área foliar}

La radiación medida a $1.5 \mathrm{~m}$ en las plantaciones y en el pastizal aledaño se presenta en la Tabla 3.1.4. Los resultados sugieren que el IAF alcanzado por la plantación más joven es similar a la de edad más adulta.

\begin{tabular}{lccc}
\hline Variable & Pastizal & Plantación Sitio I & Plantación Sitio III \\
\hline PAR $\left(\mu \mathrm{mol} \mathrm{m} \mathrm{m}^{-2} \mathrm{~s}^{-1}\right)$ & & & \\
Promedio & 533.25 & 74.75 & 72.13 \\
Desví & 12.80 & 2.76 & 6.22 \\
IAF & & 2.3 & 2.3 \\
\hline
\end{tabular}

Tabla 3.1.4: Valores de radiación fotosintéticamente activa (PAR) medidos en los plantaciones y en el pastizal aledaño e índice de área foliar (IAF) estimado según el modelo de Norman - Jarvis (1974).

Las dos plantaciones evaluadas tenían similar área foliar, posiblemente la más joven aún no había alcanzado el pico máximo y la más adulta estaba en fase de reducción del área foliar. La evolución del área foliar fue descripta en Almeida et al. (2007) para una rotación completa de plantaciones híbridas con Eucalyptus grandis alcanzando a la edad de 
rotación valores similares a los de este estudio, mientras que para los tres años de edad, en la localidad estudiada de Brasil, las plantaciones habían alcanzado el máximo, luego del cual existe un fuerte efecto de la edad que reduce el IAF.

\subsubsection{Concentración y contenido de nutrientes}

\subsubsection{Nutrientes totales. $\mathrm{pH}$ de los suelos.}

Los resultados de los análisis del contenido total de nutrientes en el suelo de los perfiles realizados en dos sitios aledaños con pastizal y en las plantaciones se presentan en las Tablas 3.1.5 a, b.

Comparando los sitios testigos con los lotes forestados se observó una disminución de pH en los últimos perfiles, principalmente en el horizonte de $5-20 \mathrm{~cm}$ y en los horizontes 35 - $50 \mathrm{~cm}$ y $50-65 \mathrm{~cm}$. Esta disminución del pH en los suelos plantados con Eucalyptus también fue mencionada por diversos autores (García-Préchac et al., 2001; Loubelo, 1990 y Bandzouzi, 1993 en Carrasco - Letelier et al., 2004; Carrasco - Letelier et al., 2004; Jobbagy et al., 2006; Delgado et al., 2006). El pH en ClK fue inferior en los suelos forestales, lo que indica mayor proporción de iones hidrógeno y aluminio en la $\mathrm{CIC}$, resultando en un potencial de acidificación mayor.

Hasta los $50 \mathrm{~cm}$ de profundidad, los suelos resultaron ser medianamente (pastizal y plantación) a fuertemente (plantación) ácidos. En el pastizal, los horizontes ubicados entre los $50-65 \mathrm{~cm}$ tuvieron un pH ligeramente ácido a ligeramente alcalino (según la escala de Scheffer \& Schachtschabel fide Gonzalez et al., en Conti, 2000). 


\begin{tabular}{|c|c|c|c|c|c|c|c|c|c|c|c|c|c|}
\hline Sitio & $\begin{array}{l}\text { Prof } \\
(\mathrm{cm})\end{array}$ & $\begin{array}{c}\mathrm{pH} \\
\mathrm{H} 2 \mathrm{O}\end{array}$ & $\begin{array}{l}\mathrm{pH} \\
\mathrm{KCl}\end{array}$ & $\begin{array}{l}\mathrm{C} \\
\text { (\%) }\end{array}$ & $\begin{array}{l}\mathrm{N} \\
(\%)\end{array}$ & $\begin{array}{c}P \\
(\mathrm{mg} / \mathrm{g})\end{array}$ & $\begin{array}{c}\mathrm{K} \\
(\mathrm{mg} / \mathrm{g})\end{array}$ & $\begin{array}{c}\mathrm{Mg} \\
(\mathrm{mg} / \mathrm{g})\end{array}$ & $\begin{array}{c}\mathrm{Ca} \\
(\mathrm{mg} / \mathrm{g})\end{array}$ & $\begin{array}{c}\mathrm{Mn} \\
(\mathrm{mg} / \mathrm{g})\end{array}$ & $\begin{array}{c}\mathrm{Fe} \\
(\mathrm{mg} / \mathrm{g})\end{array}$ & $\begin{array}{c}\text { Al } \\
(\mathrm{mg} / \mathrm{g})\end{array}$ & $\mathrm{C} / \mathrm{N}$ \\
\hline
\end{tabular}

Testigo 1

$\begin{array}{ccccccccccccc}0-5 & 5.6 & 4.7 & 2.58 & 0.23 & 0.15 & 0.26 & 0.52 & 2.17 & 0.31 & 3.15 & 3.85 & 11 \\ & (0.2) & (0.0) & (0.14) & (0.01) & (0.02) & (0.03) & (0.03) & (0.10) & (0.07) & (0.20) & (0.28) & \\ 5--20 & 5.5 & 4.6 & 1.53 & 0.13 & 0.10 & 0.24 & 0.56 & 2.39 & 0.31 & 4.20 & 5.43 & 12 \\ & (0.0) & (0.0) & (0.10) & (0.02) & (0.01) & (0.01) & (0.03) & (0.25) & (0.07) & (0.31) & (0.43) & \\ 20-35 & 5.7 & 4.6 & 1.19 & 0.10 & 0.06 & 0.33 & 0.72 & 3.67 & 0.30 & 5.57 & 8.08 & 12 \\ & (0.1) & (0.0) & (0.06) & (0.01) & (0.01) & (0.07) & (0.15) & (0.70) & (0.05) & (1.15) & (1.81) & \\ 35-50 & 6.2 & 5.0 & 0.55 & 0.05 & 0.04 & 0.58 & 1.23 & 4.40 & 0.50 & 6.81 & 9.56 & 11 \\ & (0.2) & (0.0) & (0.17) & (0.02) & (0.01) & (0.12) & (0.26) & (0.58) & (0.05) & (0.77) & (0.90) & \\ 50-65 & 7.1 & \mathrm{~s} / \mathrm{d} & 0.68 & 0.07 & 0.08 & 0.64 & 1.49 & 5.12 & 0.37 & 6.69 & 9.64 & 10\end{array}$

Testigo 2

$\begin{array}{ccccccccccccc}0-5 & 5.5 & 4.8 & 3.31 & 0.29 & 0.20 & 0.32 & 0.62 & 3.29 & 0.32 & 3.42 & 4.52 & 11 \\ & (0.0) & (0.0) & (0.25) & (0.02) & (0.01) & (0.02) & (0.04) & (0.49) & (0.00) & (0.03) & (0.13) & \\ 5--20 & 5.4 & 4.5 & 1.75 & 0.14 & 0.12 & 0.29 & 0.61 & 3.05 & 0.27 & 4.36 & 6.04 & 12 \\ & (0.0) & (0.0) & (0.05) & (0.00) & (0.01) & (0.05) & (0.05) & (0.23) & (0.03) & (0.29) & (0.47) & \\ 20-35 & 5.7 & 4.7 & 1.20 & 0.07 & 0.05 & 0.36 & 0.71 & 3.86 & 0.18 & 5.46 & 8.41 & 16 \\ & (0.0) & (0.0) & (0.03) & (0.01) & (0.01) & (0.04) & (0.05) & (0.23) & (0.01) & (0.08) & (0.43) & \\ 35-50 & 5.8 & 4.8 & 0.69 & 0.04 & 0.02 & 0.50 & 1.03 & 4.80 & 0.25 & 6.35 & 10.01 & 17 \\ & (0.0) & (0.0) & (0.01) & (0.01) & (0.02) & (0.07) & (0.08) & (0.58) & (0.01) & (0.41) & (0.75) & \\ 50-65 & 7.6 & 6.7 & 0.35 & 0.03 & 0.08 & 0.62 & 1.43 & 6.75 & 0.37 & 5.38 & 7.84 & 13 \\ & (0.0) & (0.0) & (0.01) & (0.02) & (0.04) & (0.06) & (0.10) & (0.18) & (0.03) & (0.44) & (0.56) & \end{array}$

Tabla 3.1.5 a: Contenido de nutrientes totales y pH de los suelos de las parcelas testigo. Media y desvío estándar (entre paréntesis). 


\begin{tabular}{|c|c|c|c|c|c|c|c|c|c|c|c|c|c|}
\hline Sitio & $\begin{array}{l}\text { Prof } \\
(\mathrm{cm})\end{array}$ & $\begin{array}{c}\mathrm{pH} \\
\mathrm{H}_{2} \mathrm{O}\end{array}$ & $\begin{array}{l}\mathrm{pH} \\
\mathrm{KCl}\end{array}$ & $\begin{array}{l}\mathrm{C} \\
\text { (\%) }\end{array}$ & $\begin{array}{l}N \\
(\%)\end{array}$ & $\begin{array}{c}P \\
(\mathrm{mg} / \mathrm{g})\end{array}$ & $\begin{array}{c}\mathrm{K} \\
(\mathrm{mg} / \mathrm{g})\end{array}$ & $\begin{array}{c}\mathrm{Mg} \\
(\mathrm{mg} / \mathrm{g})\end{array}$ & $\begin{array}{c}\mathrm{Ca} \\
(\mathrm{mg} / \mathrm{g})\end{array}$ & $\begin{array}{c}\mathrm{Mn} \\
(\mathrm{mg} / \mathrm{g})\end{array}$ & $\begin{array}{c}\mathrm{Fe} \\
(\mathrm{mg} / \mathrm{g})\end{array}$ & $\begin{array}{c}\text { Al } \\
(\mathrm{mg} / \mathrm{g})\end{array}$ & $\mathrm{C} / \mathrm{N}$ \\
\hline
\end{tabular}

Sitio I

$\begin{array}{ccccccccccccc}0-5 & 5.4 & 4.6 & 1.07 & 0.08 & 0.11 & 0.29 & 0.33 & 2.34 & 0.33 & 3.59 & 3.07 & 13 \\ & (0.1) & (0.1) & (0.06) & (0.01) & (0.03) & (0.06) & (0.05) & (2.37) & (0.05) & (0.16) & (0.37) & \\ 5-20 & 4.4 & 3.5 & 0.68 & 0.04 & 0.09 & 0.23 & 0.27 & 0.21 & 0.22 & 3.72 & 3.24 & 16 \\ & (0.0) & (0.0) & (0.04) & (0.01) & (0.02) & (0.03) & (0.03) & (0.08) & (0.03) & (0.33) & (0.19) & \\ 20-35 & 4.8 & 3.8 & 0.69 & 0.05 & 0.07 & 0.31 & 0.44 & 1.12 & 0.10 & 5.61 & 5.42 & 13\end{array}$

$\begin{array}{lllllllllll}(0.0) & (0.0) & (0.01) & (0.02) & (0.01) & (0.02) & (0.02) & (0.10) & (0.01) & (0.23) & (0.06)\end{array}$

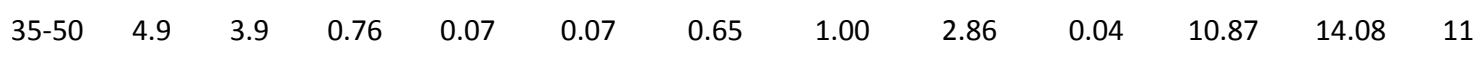

$\begin{array}{llllllllllll}(\mathrm{I} / \mathrm{S}) & (\mathrm{I} / \mathrm{S}) & (0.05) & (0.01) & (0.01) & (0.08) & (0.08) & (0.09) & (0.00) & (0.54) & (1.43)\end{array}$

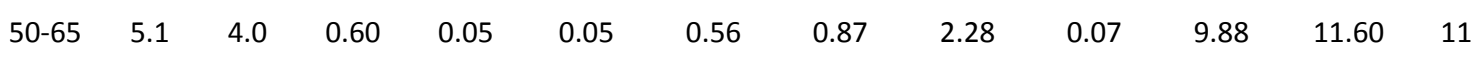

$\begin{array}{llllllllllll}(0.0) & (0.0) & (0.06) & (0.00) & (0.01) & (0.24) & (0.44) & (1.21) & (0.02) & (4.26) & (5.92)\end{array}$

Sitio III

$\begin{array}{ccccccccccccc}0-5 & 5.3 & 4.5 & 0.91 & 0.06 & 0.12 & 0.23 & 0.24 & 0.63 & 0.34 & 3.17 & 2.57 & 16 \\ & (0.0) & (0.0) & (0.05) & (0.01) & (0.00) & (0.02) & (0.02) & (0.04) & (0.01) & (0.10) & (0.23) & \\ 5-20 & 4.3 & 3.5 & 0.56 & 0.04 & 0.08 & 0.18 & 0.22 & 0.12 & 0.15 & 3.48 & 2.85 & 13 \\ & (0.0) & (0.0) & (0.01) & (0.01) & (0.02) & (0.02) & (0.02) & (0.04) & (0.01) & (0.19) & (0.26) & \\ 20-35 & 5.0 & 3.9 & 0.51 & 0.02 & 0.06 & 0.21 & 0.28 & 0.66 & 0.11 & 4.35 & 3.49 & 22 \\ & (0.0) & (0.0) & (0.05) & (0.00) & (0.02) & (0.04) & (0.07) & (0.17) & (0.03) & (0.91) & (0.68) & \\ 35-50 & 5.1 & 4.0 & 0.73 & 0.05 & 0.06 & 0.49 & 0.75 & 2.09 & 0.02 & 10.97 & 11.72 & 15 \\ & (0.0) & (0.0) & (0.10) & (0.01) & (0.01) & (0.10) & (0.15) & (0.37) & (0.00) & (2.06) & (2.89) & \\ 50-65 & 5.2 & 4.1 & 0.67 & 0.05 & 0.05 & 0.66 & 1.05 & 2.79 & 0.02 & 14.27 & 16.71 & 15 \\ & (0.0) & (0.0) & (0.06) & (0.01) & (0.00) & (0.07) & (0.10) & (0.34) & (0.00) & (1.33) & (2.10) & \end{array}$

Tabla 3.1.5 b: Contenido de nutrientes totales y pH de los suelos de las parcelas forestadas de 3 años (sitio I) y 11 años (sitio III). Media y desvío estándar (entre paréntesis). 
Los sitios forestados de distintas edades no manifestaron diferencias notorias de $\mathrm{pH}$ entre los mismos. En cambio, hubo una disminución respecto de los pastizales en las concentraciones de $\mathrm{N}$ y C, principalmente en los dos horizontes superiores (Figuras 3.1.15 y 3.1.16 a, b). De los datos y edades comparadas pudo deducirse que la tasa de disminución de las concentraciones de $\mathrm{C}$ y $\mathrm{N}$ resultó ser más rápida al comienzo del crecimiento de la plantación. Asimismo el suelo del pastizal tiene una relación $\mathrm{C} / \mathrm{N}$ más baja que los suelos de las plantaciones; en éstos, ese cociente se incrementó y progresó en profundidad con la edad de la plantación (Tabla 3.1.5b). La concentración de Mg y Mn también descendió en las plantaciones. La disminución de Ca en los suelos bajo E. grandis fue notoria en la plantación de mayor edad y en el rango $0-35 \mathrm{~cm}$ de profundidad. Las concentraciones de $\mathrm{P}$ y $\mathrm{K}$ no variaron entre el pastizal y las plantaciones. El Fe y $\mathrm{Al}$ tendieron a disminuir en la superficie y a aumentar en profundidad a través del tiempo de reemplazo del pastizal por la plantación.

Algunos de los cambios sugieren que los suelos donde se instalaron las plantaciones se vieron expuestos a varios procesos simultáneos. Por un lado, cuando se preparó el suelo para la instalación de la plantación, se interrumpió el flujo de materia orgánica al mismo provista principalmente por las herbáceas. Asimismo, en el período pre-plantación, los trabajos realizados parecen haber facilitado procesos que favorecieron las pérdidas de materia orgánica y nutrientes, como lo reportado por García-Préchac (2001), ya que las tareas de preparación del suelo remueven el mismo, aumentan la aireación, eliminan la cubierta vegetal haciéndolos más susceptibles a la erosión y lixiviación, y finalmente, a aproximadamente un año de instalada la plantación, la cubierta herbácea es casi nula (la importancia de las masas pérdidas, posiblemente debidas en gran medida al manejo preparatorio del suelo previo a la plantación, se tratan con posterioridad en la sección 3.1.7). Es de esperar que el proceso de descomposición de la materia orgánica en los horizontes minerales, legada del pastizal previo, continúe y se haga más lenta a medida que avanza el turno (como han observado en Uruguay Sicardi et al., 2004) en parte debido a la incorporación de materia orgánica producto de la descomposición del mantillo forestal; inicialmente, la descomposición de la MO heredada del pastizal cumpliría un papel destacado en el aporte de $\mathrm{N}$ disponible para satisfacer los requerimientos de los árboles en crecimiento que, en su primera etapa demandan importantes cantidades de $\mathrm{N}$ 
para sus hojas donde se lo encuentra principalmente en una de las principales proteínas foliares, la RUBISCO (ribulosa difosfato carboxilasa oxidasa), y en la clorofila que intervienen en la fotosíntesis (Salisbury \& Ross, 1992). Asimismo, el Mg es también requerido como integrante de la molécula de clorofila (Salisbury \& Ross, 1992). Simultáneamente con el crecimiento de los árboles comienza la caída de tejidos de $E$. grandis, en especial el foliar, cuyas hojas viven aproximadamente un año. La baja tasa anual de descomposición de las hojas caídas de E. grandis, ( $k=0.30$ según Goya et al, 2008), determina la acumulación de mantillo, la incorporación lenta de MO de distinta calidad que la del pastizal - verificada en un mayor cociente $\mathrm{C} / \mathrm{N}$ - y la inmovilización y baja tasa de ingreso de nutrientes al suelo mineral. Asimismo a medida que los árboles crecen aumenta la proporción de madera en la biomasa aérea producida y la demanda de Ca, y aumenta la masa de raíces que, en profundidad, encuentran limitaciones a su crecimiento debidas a los horizontes inferiores endurecidos; esto aumenta los requerimientos de nutrientes (Goya, 2004), la explotación de los horizontes por sobre las capas endurecidas y probablemente la lixiviación de bases debido al menor pH del suelo. Ese menor $\mathrm{pH}$ se vería favorecido en la zona más arenosa superior del suelo debido a condiciones más aeróbicas y a la menor cantidad de agua, mientras que la tendencia a un mayor $\mathrm{pH}$ en profundidad puede a su vez verse favorecido en el horizonte con mayor proporción de partículas finas con mayor humedad y más anaeróbicos (González et al. en Conti, 2000). El resultado de éstos procesos es que el pastizal preexistente subsidia con nutrientes al crecimiento y desarrollo de la plantación al menos durante la primera rotación, y los cambios debidos a la preparación del terreno y a los efectos directos e indirectos inducidos en el suelo por la plantación, empobrece los horizontes minerales superiores en nutrientes y MO, reducen la calidad química de la MOS lo que da lugar a bajas tasas de descomposición y a la inmovilización de nutrientes en el mantillo (Goya et al., 2008) lo que retarda el reingreso de $\mathrm{MO}$ y nutrientes al suelo, y afectan la acidez en la parte superior del perfil provocando el aumento de la solubilidad del Al y Fe que se traslada acumulándose en horizontes inferiores. La textura arenosa de los horizontes superiores determina una escasa capacidad de retención de cationes por coloides inorgánicos y asimismo la escasez de cargas positivas dificulta la retención de aniones como los nitratos y fosfatos. Por ello resulta de gran importancia lo que sucede con el 
contenido y tipo de materia orgánica del suelo para explicar la abundancia y reducción de $\mathrm{N}$ en el suelo con la plantación.
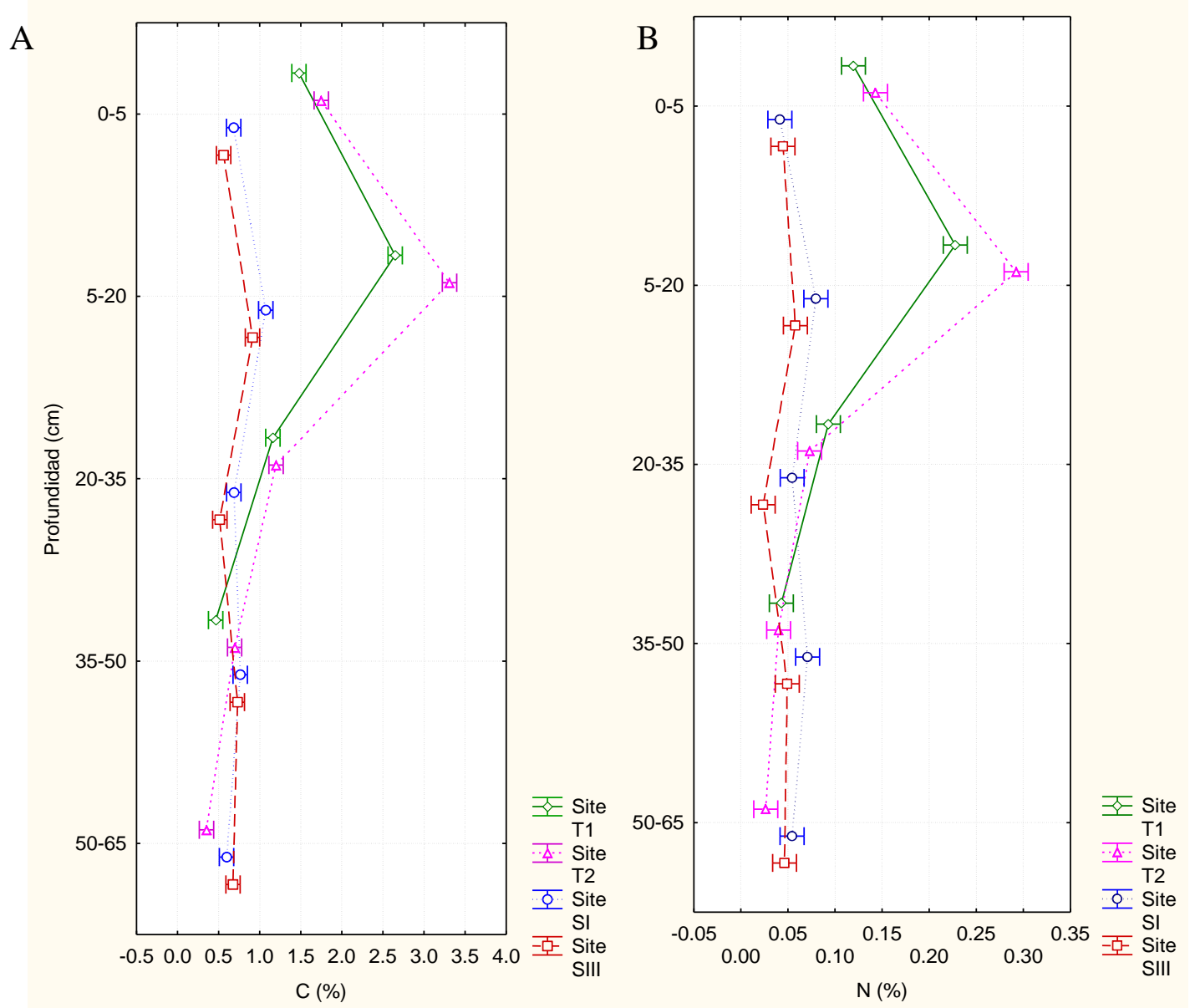

Figura 3.1.15: (A) Contenido de carbono orgánico total (\%) y (B) nitrógeno total (\%) en el suelo en los sitios forestados (SI y SIII) y testigos (T1 y T2).

Los cambios en los contenidos de elementos químicos en el suelo resultan de interés a fin de analizar las consecuencias químicas sobre los suelos de la conversión de los pastizales a plantaciones de E. grandis de primera rotación en suelos mestizos (Tabla 3.1.6). La magnitud de las pérdidas depende de varios factores entre los que se encuentran el nutriente, el tipo de suelo, las características climáticas, incluida la calidad química de las lluvias, la especie cultivada, la duración de la rotación, el tipo de cosecha, la preparación del sitio para la regeneración o plantación e, incluso, la forma de estimarlas. Por ende, los resultados que se indican a continuación son solo un primer indicio en la zona de Concordia del impacto sobre los suelos del cultivo de E. grandis. 


\begin{tabular}{|c|c|c|c|c|c|c|c|c|c|}
\hline Nutrientes en el suelo & C & $\mathbf{N}$ & $\mathbf{P}$ & K & Mg & $\mathrm{Ca}$ & $\mathrm{Mn}$ & $\mathrm{Fe}$ & Al \\
\hline \multicolumn{10}{|l|}{ - Almacenajes } \\
\hline Testigos (kg/ha) & 112916 & 9088 & 767 & 4516 & 9808 & 42989 & 3277 & 56282 & 81344 \\
\hline Plantación 3 años (kg/ha) & 74373 & 5960 & 765 & 4438 & 6451 & 17214 & 1286 & 75011 & 84451 \\
\hline Plantación 11 años (kg/ha) & 66721 & 4368 & 731 & 3828 & 5637 & 13892 & 985 & 81211 & 84379 \\
\hline \multicolumn{10}{|l|}{ - Cambio anual absoluto } \\
\hline Periodo inicial (kg/ha. año) $\left({ }^{*}\right)$ & 12848 & 1042 & 1 & 26 & 1119 & 8591 & 664 & -6243 & -1036 \\
\hline Periodo plantación (kg/ha. año) $\left({ }^{* *}\right)$ & 956 & 199 & 4 & 76 & 102 & 415 & 38 & -775 & 9 \\
\hline \multicolumn{10}{|l|}{ - Cambio anual relativo } \\
\hline Periodo inicial (\% de stock inicial). & 11 & 11 & 0 & 1 & 11 & 20 & 20 & -11 & -1 \\
\hline Periodo plantación (\% de stock inicial) & 1 & 2 & 1 & 2 & 1 & 1 & 1 & -1 & 0 \\
\hline \multicolumn{10}{|l|}{ - Destino de pérdidas anuales (\%) } \\
\hline Absorción & & 17 & 103 & 23 & 9 & 21 & - & & \\
\hline Retención en biomasa & & 12 & 90 & 17 & 6 & 16 & - & & \\
\hline Retorno al mantillo & & 5 & 13 & 6 & 3 & 5 & - & & \\
\hline Otras vías & & 83 & -3 & 77 & 91 & 79 & - & & \\
\hline
\end{tabular}

Tabla 3.1.6: Cambios en los depósitos de nutrientes totales en los suelos. Almacenaje de nutrientes inicial (media de dos testigos con pastizal) y bajo la forestación a los 3 y 11 años hasta $65 \mathrm{~cm}$ de profundidad. Cambio anual absoluto de nutrientes en el suelo (valores positivos= pérdidas; valores negativos= ganancias) para el periodo inicial $(*)$, que incluye los cambios ocurridos durante el laboreo previo a la plantación más aquellos bajo la forestación hasta los 3 años de edad; y para un periodo solo bajo plantación $\left({ }^{* *}\right)$, calculado con los datos de suelos de las plantaciones de 3 y 11 años de edad. Asimismo esos cambios anuales se expresan en (\%) relativo al almacenaje al inicio del periodo respectivo. Se indica también el destino de las pérdidas anuales netas de nutrientes del suelo que es explicado por la absorción y retención neta en tejidos vegetales (biomasa y necromasa).

Se destacan las enormes pérdidas de nutrientes totales ocurridas durante el periodo inicial, lo cual parece indicar que la preparación del terreno arenoso frágil para su forestación resulta la fase más crítica para la silvicultura de primera rotación en éstos sitios. Por otra parte, los cambios bajo la plantación significaron reducciones anuales del almacenaje de $199 \mathrm{~kg} \mathrm{~N} / \mathrm{ha}, 4 \mathrm{~kg}$ P/ha, 76g Kg K/ha, $956 \mathrm{~kg} \mathrm{C} / \mathrm{ha}, 102 \mathrm{Kg} \mathrm{Mg} / \mathrm{ha}, 415$ $\mathrm{Ca} / \mathrm{ha}, 38 \mathrm{~kg} \mathrm{Mn} / \mathrm{ha}$. Estos valores, comparados con las pérdidas por lixiviación de suelos arenosos (Mengel \& Kirby, 2000; Tabla 3.1.7.) resultan 1,5 veces mayores para Ca, 3 veces para Mg y cuatro para $\mathrm{N}$ y K. Esto destaca que en estos suelos las magnitudes de las pérdidas siguen siendo importantes bajo especies de crecimiento rápido y en rotaciones cortas. 


\begin{tabular}{lcccccc}
\hline Textura & $\begin{array}{c}\text { Arcilla } \% \\
(\%)\end{array}$ & $\mathrm{N}$ & $\begin{array}{c}\mathrm{K} \\
\left(\mathrm{Kg} \mathrm{ha}^{-1} \mathrm{año}^{-1}\right)\end{array}$ & $\mathrm{Na}$ & $\mathrm{Ca}$ & $\mathrm{Mg}$ \\
\hline Arenosa & 3 & $12-52$ & $7-17$ & $9-52$ & $110-300$ & $17-34$ \\
Fr. Arenosa & 16 & $0-27$ & $0-14$ & $1-69$ & $0-242$ & $0-37$ \\
Franca & 28 & $9-44$ & $3-8$ & $9-42$ & $72-341$ & $10-54$ \\
Arcillosa & 39 & $5-44$ & $3-8$ & $9-42$ & $72-341$ & $10-54$ \\
\hline
\end{tabular}

Tabla 3.1.7: Tasa de lixiviación de nutrientes vegetales en suelos de diferentes texturas (Mengel \& Kirby, 2000).

El cambio en el contenido de aluminio, teniendo en cuenta la magnitud del stock, puede considerarse irrelevante, no obstante ya se ha destacado en la sección previa la relocalización más profunda de Al y Fe en el perfil. Por otra parte los cambios más importantes de ganancia de Al ocurrirían desde la preparación del sitio hasta los tres años de edad. En cuanto al Fe hubo un incremento anual de $775 \mathrm{~kg} / \mathrm{ha}$.

La reducción de nutrientes en los suelos se ha asignado frecuentemente a la relocalización mineral en la biomasa de las plantaciones teniendo en cuenta que los organismos arbóreos tienen una mayor biomasa y tienen mayor concentración de algunos nutrientes como por ej. Ca. Sin embargo, al relacionar la absorción anual neta de nutrientes necesarios para el crecimiento aéreo (estimado a partir de la mineralomasa aérea dividido la edad de la planta) y aquellos retenidos en la necromasa del mantillo puede observarse que entre ambos compartimentos contienen solo entre el 9 y el $23 \%$ de lo perdido por el suelo. Con la excepción del fósforo en el que la totalidad del elemento se puede explicar por la absorción arbórea y por ende sus pérdidas pueden considerarse nulas. Otras vías de pérdida como la descomposición y la lixiviación podrán ser causa de otra parte de las reducciones, pero ésta tesis no tiene como objetivo ahondar en la explicación causal de las pérdidas. Los diversos procesos de origen natural y antrópico que ocurren en el suelo durante distintas etapas de la conversión en el uso de la tierra y que desencadenan pérdidas de nutrientes y materia orgánica, cambios en la calidad de ésta última, acidificación, cambios en procesos microbiológicos de interés para la producción, y otros, muchos de los cuales interaccionan entre sí, son de características complejas y han sido considerados por diversos autores (Hopmans et al., 1993 en Evans, 2001; Jobbágy \& Jackson, 2003; Vázquez, 2007, 2010; Delgado et al., 2006) 
En cuanto al impacto sobre los suelos, la fracción porcentual del contenido de nutrientes del suelo que es perdida anualmente, refleja nuevamente que un manejo inadecuado en la preparación del suelo y las etapas iniciales del crecimiento de $E$. grandis pueden ocasionar reducciones por año cercanas al $10 \%$ del contenido de nutrientes (el doble para el calcio). En la fase de plantación ya instalada estas pérdidas se reducen a cerca del 1-2\% anual, lo que da un tiempo de recambio de los nutrientes en el suelo de solo 50 a 100 años. Estas tasas pueden considerarse elevadas. El impacto de las forestaciones sobre los suelos se ha medido también en base al cálculo de la mineralomasa aérea como indicadora de cosecha de árbol completo (Attiwill \& Lepper, 1987; Federer et al.,1989; Judd, 1996; Goya et al. 2009). Federer et al. (1989) calcularon las extracciones de nutrientes en cosechas de árbol completo al turno (no anuales) para un conjunto de bosques maduros del NE de EEUU e informaron $250 \mathrm{~kg} \mathrm{~N} / \mathrm{ha}, 20 \mathrm{~kg} \mathrm{P} / \mathrm{ha}, 150 \mathrm{~kg} \mathrm{~K} / \mathrm{ha}$, 350-600 kg Ca/ha, $40 \mathrm{~kg} \mathrm{Mg} / \mathrm{ha}$. Las pérdidas de $\mathrm{P}, \mathrm{K}$ y $\mathrm{Mg}$ en una cosecha fueron del orden del 3\% de los depósitos totales (biomasa aérea +mantillo + suelo mineral); y las de $\mathrm{N}$ y Ca fueron inferiores al $8 \%$, con excepción de algunos bosques de roble-nogal en que la pérdida de Ca fue de 13-19\%. Para bosques nativos de eucaliptos muy productivos del E de Australia (Attiwill \& Lepper, 1987) los datos son similares (Attiwill \& Weston, 2001) y las pérdidas en 100 años, por cosecha forestal, de $\mathrm{N}$ y $\mathrm{P}$ fueron de de cerca de $2 \%$ cuando se extraían solo tallos, a 4.3\% (N) a 4.8\% (P) del depósito total (donde cerca del 95\% de ese stock procedía del suelo mineral hasta $30 \mathrm{~cm}$ de profundidad) en cosecha de árbol completo. Judd (1996) mostró que, en 80 años bajo plantación de eucaliptos de corteza lisa como las de $E$. grandis, las rotaciones cortas (10 años) y la extracción de árboles con corteza producían mayores pérdidas, $776 \mathrm{~kg} \mathrm{~N} / \mathrm{ha}, 96 \mathrm{~kg} \mathrm{P} / \mathrm{ha}, 2168 \mathrm{~kg} \mathrm{Ca} / \mathrm{ha}$, $512 \mathrm{~kg} \mathrm{Mg} / \mathrm{ha}$, y $720 \mathrm{~kg} \mathrm{~K} / \mathrm{ha}$, que las de rotaciones de 20 años con cosecha similar donde se perdieron $716 \mathrm{~kg} \mathrm{~N} / \mathrm{ha}, 76 \mathrm{~kg} \mathrm{P} / \mathrm{ha}, 1756 \mathrm{~kg} \mathrm{Ca} / \mathrm{ha}, 64 \mathrm{~kg} \mathrm{Mg} / \mathrm{ha}$, y $644 \mathrm{~kg} \mathrm{~K} / \mathrm{ha}$.

En Concordia, Goya et al. (2009) analizaron tres escenarios de cosecha y post-cosecha, para dos turnos 8 años (T1) y 11 años (T2) en plantaciones de Eucalyptus grandis de sitios arenosos: cosecha de productos comerciales (fustes hasta $5 \mathrm{~cm}$ con corteza) y posterior conservación de los residuos de la cosecha, (2) cosecha de los árboles completos, comercialización de los productos maderables y retirada de los residuos producidos por la cosecha y, (3) cosecha de productos comerciales (fustes hasta $5 \mathrm{~cm}$ con corteza) y quema 
in situ de los residuos de la cosecha. De los resultados puede estimarse que, en una rotación, las mayores extracciones de nutrientes por cosecha se produjeron, salvo $\mathrm{N}$ y K, en el turno más largo (11 años). Sin embargo, calculando un periodo con rotaciones de 100 años, la rotación corta muestra que en cosecha de árbol completo se extraerían 1075 Mg C/ha, y, para los nutrientes (en paréntesis) los siguientes kg/ha: $6175(\mathrm{~N}), 525(\mathrm{P})$, 3225 (K), 8200 (Ca) y 1050 (Mg). En tanto que para la rotación más larga comparada los valores serían $955 \mathrm{Mg} \mathrm{C/ha,} \mathrm{y,} \mathrm{para} \mathrm{los} \mathrm{nutrientes} \mathrm{los} \mathrm{siguientes} \mathrm{kg/ha:} 3382(\mathrm{~N}), 500(\mathrm{P})$, 1709 (K), 8782 (Ca) y 927 (Mg). De ello se deduce que en cosecha de árbol completo la rotación corta (8 años) da lugar, en términos relativos respecto de los valores de la rotación larga, a una productividad aérea neta (en C) un 13\% inferior, acompañada de una extracción adicional (aumento en las pérdidas de nutrientes del suelo respecto de la rotación larga) del $83 \%$ de N, 5\% de P y $89 \%$ de K, y una menor extracción de $\mathrm{Ca}(7 \%)$ y $\mathrm{Mg}$ (13\%). Además de las diferencias entre rotaciones, estos autores observaron diferencias significativas entre distintos escenarios de tipos de cosecha y manejo de los residuos de post-cosecha; por ej., en la rotación de 11 años, la cosecha del fuste con corteza y la quema de residuos en el campo, prácticas habituales en la zona, dan lugar a las mayores pérdidas de nutrientes (kg/ha): $368.9(\mathrm{~N}), 46.2(\mathrm{P}), 175.4(\mathrm{~K}), 911.8$ (Ca) y $97.2(\mathrm{Mg})$, aunque las pérdidas de P no registraron diferencias significativas con otros escenarios. Los escenarios de cosecha que dejaron la mayor cantidad de materia orgánica y nutrientes en el sitio son los que menos afectaron la estabilidad ecológica de las plantaciones (según el Índice de Estabilidad de las Plantaciones de Fölster \& Khanna, 1997 en Goya, et al. 2009); el escenario de cosecha del fuste sin corteza y abandono de los residuos en el sitio representó la técnica más conservadora en términos de nutrientes para el aprovechamiento de las plantaciones de Eucalyptus grandis. Los indicadores de rentabilidad comúnmente usados en la administración de estas plantaciones se vieron reducidos significativamente con la consideración de la compensación de nutrientes al suelo; esta reducción puede afectar la decisión de desarrollo del proyecto de una plantación comercial lo que debería alertar y estimular a técnicos y productores a mejorar el manejo de la necromasa residual en las etapas de cosecha y postcosecha (Goya et al., 2009). 
Estos trabajos, muestran que las pérdidas ligadas al manejo de la plantación varían ampliamente con la duración de la rotación, las fracciones cosechadas, el manejo de los residuos de cosecha; como asimismo influye el hecho de tratarse de bosques nativos bajo manejo o de plantaciones de crecimiento rápido. Estas últimas habitualmente implican extracciones mayores de elementos químicos. Asimismo algunos indicadores económicos hacen dudar sobre la factibilidad económica de reponer nutrientes perdidos. También es de destacar que, las pérdidas estimadas en base a los contenidos nutritivos en la biomasa y necromasa aéreas, solo consideran la extracción con diferentes regímenes de cosecha, que no es la fracción mayor pérdida y por ende representan una subestimación de las pérdidas totales del suelo tal como se han estimado en ésta tesis con datos de suelos.

En Uruguay, la conversión de pasturas a plantaciones de E. grandis, luego de 10 años, produjo mayor acidez del suelo, aumento del contenido de Al intercambiable, disminución del contenido total de C orgánico y disminución de la capacidad de retención de agua del suelo a un potencial mátrico de -10 kPa (Durán et al., 2001 y Pérez Bidegain et al., 2001a, en Sicardi et al., 2004).

Delgado et al. (2006) plantean que los cambios mencionados, detectados en un corto período siguiente a la plantación, tienen como principal explicación el cambio en los procesos de formación de suelos que se generan por el cambio de vegetación. Dado que los árboles realizan un aporte importante a través de las hojas muertas sobre el suelo mientras que la vegetación de pastos hacen un aporte de biomasa dentro del suelo a través de los restos de su sistema radical. Por las características diferenciales de ambos tipos de residuos, y su sitio de deposición y descomposición, la materia orgánica resultante y su dinámica son diferentes (Goya et al., 1997). En el caso de especies forestales se trata de compuestos orgánicos muy móviles, de cadena corta, ricos en grupos funcionales capaces de ionizar $\mathrm{H}^{+}$, y ser fuente de acidez en el suelo. Su movilidad les permite infiltrar con el agua en el suelo y acumularse a la profundidad en que el movimiento descendente de agua libre es restringido por la aparición del horizonte B. La riqueza en $\mathrm{H}^{+}$que se genera en el suelo sustituye cationes de las posiciones de intercambio y ataca estructuras cristalinas de los minerales, principalmente secundarios, liberando $\mathrm{Al}^{+3}$, parte del cual pasa a ser intercambiable. Complementariamente, existe 
una alta extracción de bases de intercambio, las cuales en parte son exportadas por la cosecha forestal, mientras que otra parte es reciclada a través de los restos de cosecha dejados en superficie. En la medida de considerar sucesivos turnos de plantación, la reducción de las mismas en el suelo se irá acentuando, pudiendo llegar a limitar la producción de futuras replantaciones, situación en la cual según Delgado et al. (2006) haría necesaria su reposición al suelo vía encalado con dolomitas (aportando Ca y Mg) y fertilización con $\mathrm{K}$.

Sicardi et al. (2004) analizan diferentes indicadores microbiológicos en suelos bajo pastizal y bajo plantación. No encuentra diferencias significativas en el número de microorganismos en el suelo bajo la pastura y en aquel bajo la plantación forestal, por lo cual el efecto de la conversión sobre los suelos no pudo ser detectado mediante esta variable. Pero si encuentra diferencias significativas cuando analiza la respiración del suelo y el coeficiente de mineralización de C-orgánico. La respiración edáfica fue siempre mayor bajo la pastura que bajo eucaliptos, lo que sugiere una mayor actividad en la rizosfera del sistema de raíces de los pastos que en los árboles adultos de $E$. grandis. Además, los coeficientes de mineralización de C, principalmente en primavera, fueron el doble en la pastura que en la forestación. Ambas variables indican una mayor actividad microbiana en la pastura. Sicardi et al. (2004) señalan además que la actividad de varias enzimas edáficas, directamente involucradas en la transformación de la MO del suelo, es sensible al cambio en el uso de la tierra de pastura a forestación. Ellos observaron la reducción de la actividad de la dehidrogenasa del suelo, la hidrólisis FDA, y las fosfatasas ácida y alcalina, con la conversión de pastura a forestación con E. grandis Aparentemente, las comunidades microbianas responden a los disturbios, primero con cambios en la actividad enzimática y subsecuentemente con cambios en la biomasa. Cambios prolongados en biomasa y función microbiana pueden eventualmente afectar aquellos procesos y conducir a la acumulación o reducción de la materia orgánica del suelo (Caldwell et al., 1999 en Siccardi, 2004 ). 


\subsubsection{Nutrientes disponibles e intercambiables}

Los resultados de los análisis de los nutrientes disponibles e intercambiables en el suelo de los perfiles realizados en dos sitios aledaños con pastizal y en las plantaciones se presentan en las Tablas 3.1.8 a, b.

\begin{tabular}{|c|c|c|c|c|c|c|c|c|c|}
\hline Sitio & $\begin{array}{l}\text { Prof. } \\
\text { (cm) }\end{array}$ & $P$ & K & $\mathrm{Ca}$ & $\begin{array}{c}\mathrm{Mg} \\
(\mathrm{mg} / \mathrm{g})-\end{array}$ & $\mathrm{Fe}$ & $\mathrm{Mn}$ & Al & $\begin{array}{c}\text { ECEC } \\
(\mathrm{me} / 100 \mathrm{~g})\end{array}$ \\
\hline \multirow[t]{7}{*}{$\begin{array}{c}\text { Testigo } \\
1\end{array}$} & $0-5$ & $\begin{array}{c}0.04 \\
(0.01)\end{array}$ & $\begin{array}{c}0.10 \\
(0.02)\end{array}$ & $\begin{array}{c}1.96 \\
(0.03)\end{array}$ & $\begin{array}{c}0.28 \\
(0.03)\end{array}$ & $\begin{array}{c}0.23 \\
(0.02)\end{array}$ & $\begin{array}{c}0.21 \\
(0.00)\end{array}$ & $\begin{array}{c}0.00 \\
(0.00)\end{array}$ & $\begin{array}{l}12.99 \\
(0.33)\end{array}$ \\
\hline & $5--20$ & 0.02 & 0.07 & 2.42 & 0.24 & 0.18 & 0.12 & 0.00 & 14.85 \\
\hline & & $(0.00)$ & $(0.00)$ & $(0.22)$ & $(0.01)$ & $(0.01)$ & $(0.00)$ & $(0.00)$ & (1.16) \\
\hline & $20-35$ & 0.01 & 0.09 & 3.85 & 0.25 & 0.08 & 0.07 & 0.00 & 22.28 \\
\hline & & $(0.00)$ & $(0.00)$ & (0.09) & $(0.01)$ & $(0.01)$ & $(0.00)$ & $(0.00)$ & $(0.51)$ \\
\hline & $35-50$ & 0.01 & 0.08 & 4.84 & 0.29 & 0.03 & 0.11 & 0.00 & 27.96 \\
\hline & & $(0.00)$ & $(0.00)$ & (0.09) & $(0.01)$ & $(0.00)$ & $(0.00)$ & $(0.00)$ & $(0.56)$ \\
\hline \multirow{10}{*}{$\begin{array}{c}\text { Testigo } \\
\mathbf{2}\end{array}$} & $0-5$ & 0.05 & 0.11 & 2.59 & 0.31 & 0.14 & 0.18 & 0.01 & 16.18 \\
\hline & & $(0.00)$ & $(0.00)$ & (0.17) & $(0.02)$ & $(0.00)$ & $(0.00)$ & $(0.00)$ & (1.04) \\
\hline & $5--20$ & 0.03 & 0.09 & 2.78 & 0.26 & 0.16 & 0.14 & 0.00 & 16.61 \\
\hline & & $(0.00)$ & $(0.00)$ & $(0.02)$ & $(0.00)$ & $(0.02)$ & $(0.00)$ & $(0.00)$ & $(0.14)$ \\
\hline & $20-35$ & 0.01 & 0.08 & 3.63 & 0.20 & 0.07 & 0.05 & 0.00 & 20.28 \\
\hline & & $(0.00)$ & $(0.00)$ & $(0.10)$ & $(0.00)$ & $(0.00)$ & $(0.00)$ & $(0.00)$ & $(0.54)$ \\
\hline & $35-50$ & 0.01 & 0.08 & 4.64 & 0.21 & 0.04 & 0.06 & 0.00 & 25.42 \\
\hline & & $(0.00)$ & $(0.00)$ & $(0.02)$ & $(0.00)$ & $(0.00)$ & $(0.00)$ & $(0.00)$ & $(0.14)$ \\
\hline & $50-65$ & 0.01 & 0.08 & 5.41 & 0.19 & 0.01 & 0.06 & 0.00 & 29.16 \\
\hline & & $(0.00)$ & $(0.00)$ & $(0.20)$ & $(0.01)$ & $(0.00)$ & $(0.00)$ & $(0.00)$ & $(0.99)$ \\
\hline
\end{tabular}

Tabla 3.1.8 a: Contenido de nutrientes disponibles e intercambiables y capacidad de intercambio catiónico efectiva (ECEC) de los suelos de las parcelas testigo. Media y desvío estándar (entre paréntesis).

Al comparar las concentraciones en los distintos horizontes y sitios (Fig. 3.1.16 a, b) se observa que ocurrieron importantes reducciones en las concentraciones de Ca en todo el perfil y en consecuencia de la ECEC, lo que es comprensible debido a que el Ca representa la principal base del complejo de intercambio; según Conti (2000) el 50 -60 \% de la CIC es Ca cuando el $\mathrm{pH}$ es 6 - 7.5. El $\mathrm{K}$ y el $\mathrm{Mg}$ disminuyen en los primeros horizontes y aumentan en los más profundos. El Al y el Fe aumentan en los sitios forestados con concentraciones máximas en el horizonte de $5-20 \mathrm{~cm}$ relacionado con la disminución del pH en los sitiios forestados. La concentración de Mn disminuye en los horizontes más profundos y el P con valores siempre muy bajos aumenta en el sitio forestado. 


\begin{tabular}{|c|c|c|c|c|c|c|c|c|c|}
\hline \multicolumn{2}{|l|}{ Sitio } & $\mathbf{P}$ & $K$ & $\mathrm{Ca}$ & $\mathrm{Mg}$ & $\mathrm{Fe}$ & $\mathrm{Mn}$ & Al & $\begin{array}{c}\text { ECEC } \\
\text { (me/100g) }\end{array}$ \\
\hline \multirow{10}{*}{$\begin{array}{c}\text { Sitio } \\
1\end{array}$} & $0-5$ & 0.05 & 0.09 & 0.81 & 0.14 & 0.28 & 0.21 & 0.00 & 6.05 \\
\hline & & $(0.00)$ & $(0.00)$ & $(0.03)$ & $(0.00)$ & $(0.00)$ & $(0.00)$ & $(0.00)$ & $(0.19)$ \\
\hline & 5- 20 & 0.04 & 0.05 & 0.26 & 0.11 & 0.47 & 0.15 & 0.16 & 4.70 \\
\hline & & $(0.00)$ & $(0.00)$ & $(0.00)$ & $(0.00)$ & $(0.02)$ & $(0.01)$ & $(0.02)$ & $(0.25)$ \\
\hline & $20-35$ & 0.02 & 0.07 & 1.12 & 0.18 & 0.30 & 0.05 & 0.05 & 8.50 \\
\hline & & $(0.00)$ & $(0.00)$ & $(0.02)$ & $(0.00)$ & $(0.00)$ & $(0.00)$ & $(0.00)$ & $(0.08)$ \\
\hline & $35-50$ & 0.01 & 0.11 & 2.90 & 0.44 & 0.16 & 0.01 & 0.05 & 19.66 \\
\hline & & $(0.00)$ & $(0.00)$ & $(0.01)$ & $(0.00)$ & $(0.01)$ & $(0.00)$ & $(0.00)$ & $(0.07)$ \\
\hline & $50-65$ & 0.01 & 0.10 & 3.07 & 0.46 & 0.14 & 0.02 & 0.05 & 13.90 \\
\hline & & $(0.01)$ & $(0.03)$ & $(0.16)$ & $(0.01)$ & $(0.10)$ & $(0.02)$ & $(0.00)$ & (11.91) \\
\hline \multirow{10}{*}{$\begin{array}{c}\text { Sitio } \\
3\end{array}$} & $0-5$ & 0.06 & 0.09 & 0.67 & 0.10 & 0.33 & 0.22 & 0.07 & 4.94 \\
\hline & & $(0.00)$ & $(0.00)$ & $(0.05)$ & $(0.01)$ & $(0.01)$ & $(0.01)$ & $(0.01)$ & $(0.32)$ \\
\hline & $5--20$ & 0.05 & 0.05 & 0.14 & 0.06 & 0.59 & 0.11 & 0.13 & 3.69 \\
\hline & & $(0.00)$ & $(0.00)$ & $(0.00)$ & $(0.01)$ & $(0.02)$ & $(0.00)$ & $(0.02)$ & $(0.20)$ \\
\hline & $20-35$ & 0.02 & 0.06 & 0.59 & 0.09 & 0.31 & 0.07 & 0.06 & 4.61 \\
\hline & & $(0.00)$ & $(0.00)$ & $(0.05)$ & $(0.01)$ & $(0.02)$ & $(0.01)$ & $(0.00)$ & $(0.36)$ \\
\hline & $35-50$ & 0.01 & 0.10 & 2.15 & 0.35 & 0.19 & 0.01 & 0.11 & 9.88 \\
\hline & & $(0.00)$ & $(0.00)$ & $(0.22)$ & $(0.03)$ & $(0.02)$ & $(0.00)$ & $(0.00)$ & $(8.40)$ \\
\hline & $50-65$ & 0.01 & 0.10 & 2.92 & 0.49 & 0.10 & 0.00 & 0.02 & 13.17 \\
\hline & & $(0.00)$ & $(0.00)$ & $(0.17)$ & $(0.04)$ & $(0.00)$ & $(0.00)$ & $(0.01)$ & $(11.22)$ \\
\hline
\end{tabular}

Tabla 3.1.8 b: Contenido de nutrientes disponibles e intercambiables y capacidad de intercambio catiónica efectiva de los suelos de las parcelas forestadas de 3 años (sitio I) y 11 años (sitio III). Media y desvío estándar (entre paréntesis). 

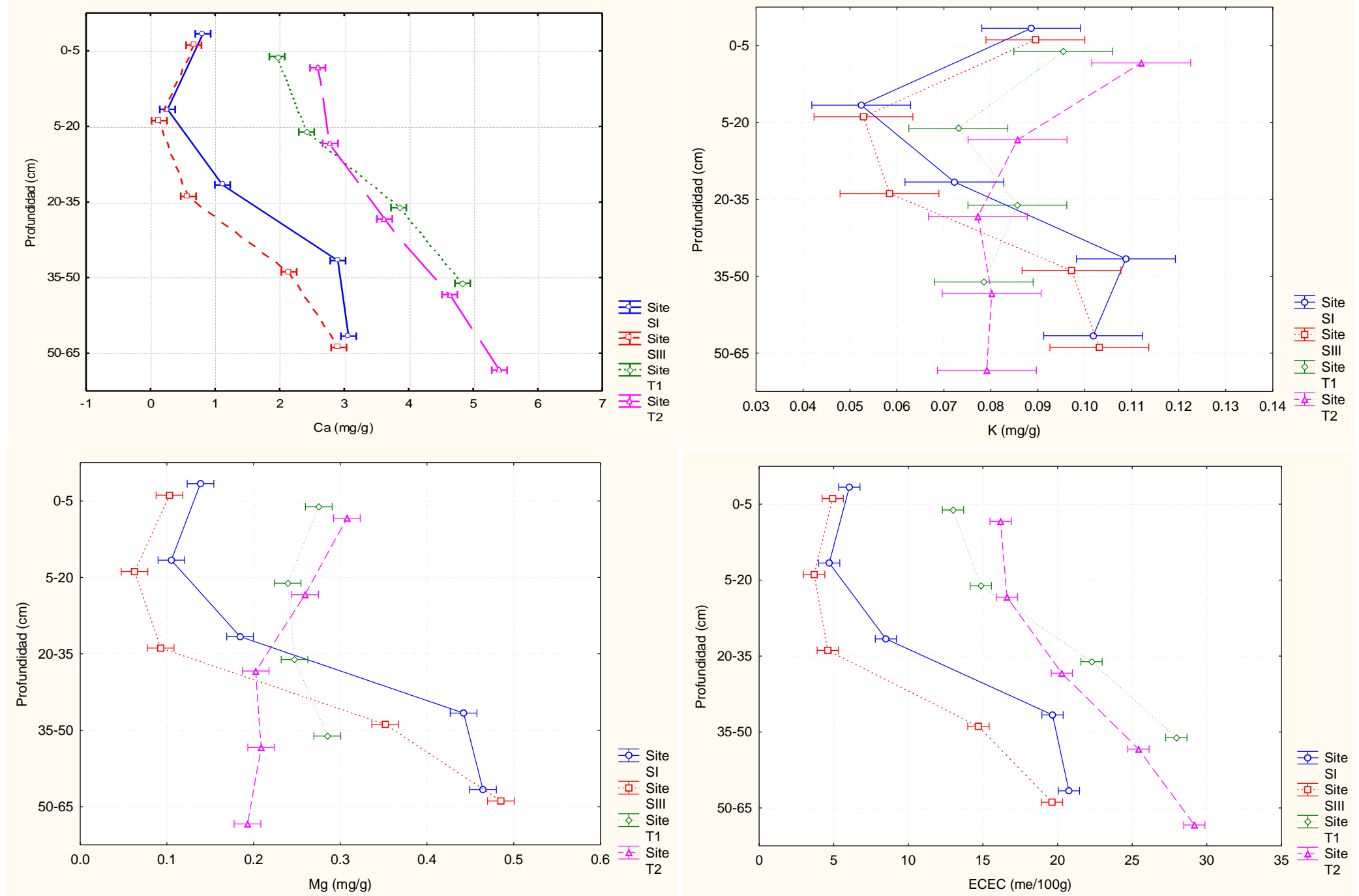

Figura 3.1.16 a: Concentraciones de calcio (Ca), potasio (K), magnesio (Mg) y capacidad de intercambio catiónico efectiva (ECEC) ien los Sitios forestados (SI y SIII) y Testigos (T1 y T2). 

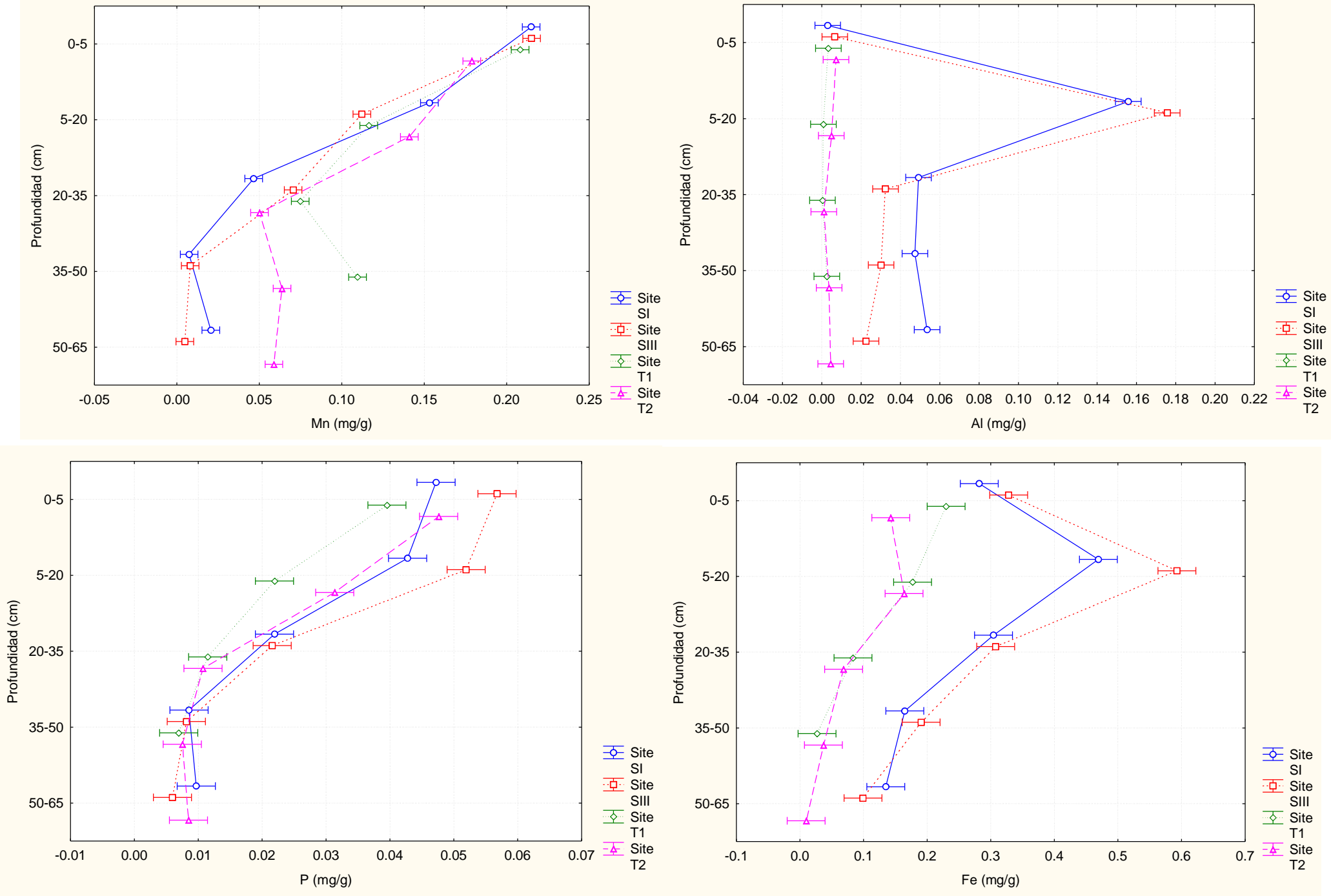

Figura 3.1.16 b: Concentraciones de fósforo (P) disponible, manganeso (Mn) y hierro (Fe) intercambiables, y Capacidad de Intercambio Catiónico (ECEC) en los Sitios forestados (SI y SIII) y Testigos (T1 y T2) 


\section{$\begin{array}{lllllll}\mathbf{P} & \mathrm{K} & \mathrm{Ca} & \mathrm{Mg} & \mathrm{Mn} & \mathrm{Fe} & \mathrm{Al}\end{array}$}

\section{Testigo 1}

Stock total $(\mathrm{kg} / \mathrm{ha})$

$\begin{array}{rrrrrrr}776 & 4484 & 39050 & 9963 & 3770 & 58236 & 81462 \\ 148 & 835 & 41101 & 2528 & 904 & 1013 & 11 \\ 19 & 19 & 105 & 25 & 24 & 2 & 0\end{array}$

Nutriente disponible o intercambiable $(\mathrm{kg} / \mathrm{ha})$

Disponible/stock (\%)

19

\section{Testigo 2}

Stock total $(\mathrm{kg} / \mathrm{ha})$

Nutrientes disponible o intercambiable $(\mathrm{kg} / \mathrm{ha})$

$\begin{array}{rrrrrrr}822 & 4505 & 46808 & 9533 & 2814 & 54379 & 81039 \\ 176 & 860 & 41451 & 2312 & 783 & 889 & 39 \\ 21 & 19 & 89 & 24 & 28 & 2 & 0\end{array}$

Disponible/stock (\%)

\section{SI}

Stock total (kg/ha)

Nutrientes disponible o intercambiable ( $\mathrm{kg} / \mathrm{ha})$

$\begin{array}{rrrrrrr}765 & 4438 & 17214 & 6451 & 1286 & 75011 & 84451 \\ 239 & 876 & 18146 & 2963 & 718 & 2853 & 749 \\ 31 & 20 & 105 & 46 & 56 & 4 & 1\end{array}$

\section{SIII}

Stock total (kg/ha)

Nutrientes disponibles $(\mathrm{kg} / \mathrm{ha})$

Disponible/ stock (\%)

\begin{tabular}{rrrrrrr}
731 & 3828 & 13892 & 5637 & 985 & 81211 & 84379 \\
258 & 816 & 14194 & 2426 & 647 & 3171 & 638 \\
35 & 21 & 102 & 43 & 66 & 4 & 1 \\
& & & & & & \\
47 & 3 & -56 & 22 & -15 & 200 & 2907 \\
7 & -7 & -28 & -22 & -11 & 10 & -17 \\
\hline
\end{tabular}

\begin{tabular}{lrrrrrrr} 
Diferencia forest. de 3 años-pastizal (\%) & 47 & 3 & -56 & 22 & -15 & 200 & 2907 \\
Diferencia forest. de 3 años-forest. 11 años (\%) & 7 & -7 & -28 & -22 & -11 & 10 & -17 \\
\hline
\end{tabular}

Tabla 3.1.9: Contenido de nutrientes totales y disponibles en los sitios testigos y en las parcelas forestadas, e índices que los relacionan.

En el pastizal el P, K, Mg y Mn de fácil disponibilidad representan un 19-28\% del stock total; casi todo o todo el Ca está intercambiable. Asimismo, el Fe y Al intercambiable son una fracción mínima del total (Tabla 3.1.9).

La fracción disponible en el suelo forestal, respecto de los nutrientes totales en él, es del 21, 35 y $43 \%$ para el $\mathrm{P}, \mathrm{K}$, y $\mathrm{Mg}$, respectivamente. El $66 \%$ del $\mathrm{Mn}$ y todo el Ca se encuentra en forma intercambiable, en cambio, solo el $4 \%$ del Fe y el $1 \%$ del Al lo están en esa forma. En el caso del $\mathrm{Mn}$, el aumento de la fracción disponible, esperado con menor $\mathrm{pH}$, determina que la disminución del Mn total con la conversión, no resulte en cambios notorios en su disponibilidad. 
En la plantación forestal de 3 años, los stocks de nutrientes intercambiables son, respecto de los pastizales, similares en $\mathrm{K}$, cerca $50 \%$ superiores en $\mathrm{P}$, un $22 \%$ mayor en $\mathrm{Mg}$, un $200 \%$ superior en Fe y un $2900 \%$ mayor en Al; pero un 15\% menor en Mn y un 56\% inferior en Ca.

Por otra parte en el intervalo de 8 años de plantación, entre la de 3 y 11 años de edad, los cambios registrados en el $\mathrm{P}$ disponible $\mathrm{y}$ las bases del complejo de intercambio fueron menores a los ocurridos en el periodo previo de 3 años de preparación del terrenocrecimiento inicial de la plantación. En los ocho años mencionados los mayores cambios se produjeron en la disminución de $\mathrm{Ca}$ y $\mathrm{Mg}$, la tendencia decreciente fue menor en $\mathrm{Mn}$ y $\mathrm{K}$ (11 y $7 \%$ respectivamente). Asimismo, se observó un menor aumento en $\mathrm{P}(7 \%)$ y Fe (10\%) y un decrecimiento del $17 \%$ del $\mathrm{Al}$, en ambos casos respecto de los grandes incrementos del periodo anterior. En general los suelos bajo la plantación y el pastizal poseen una fracción de nutrientes, disponible e intercambiables, similar respecto de los totales en el suelo.

Además, prácticamente todo el Ca de éstos suelos estuvo como Ca intercambiable lo que tal vez explique las rápidas pérdidas totales al convertir a plantación y el gran papel conservador de éstos nutrientes que cumplen los pastizales. Las fracciones de Fe y Al intercambiables son pequeñas tanto en el pastizal como en la plantación forestal; sin embargo el enorme incremento de Fe y Al intercambiables en el suelo bajo la plantación muestra que la reserva de éstos elementos en el suelo es muy alta. Eso se suma a la relación inversa entre el $\mathrm{pH}$ y las concentraciones-masa de Fe y Al (Figura 3.1.17), lo que permite entrever el mantenimiento de un gran potencial de acidificación de los suelos. 


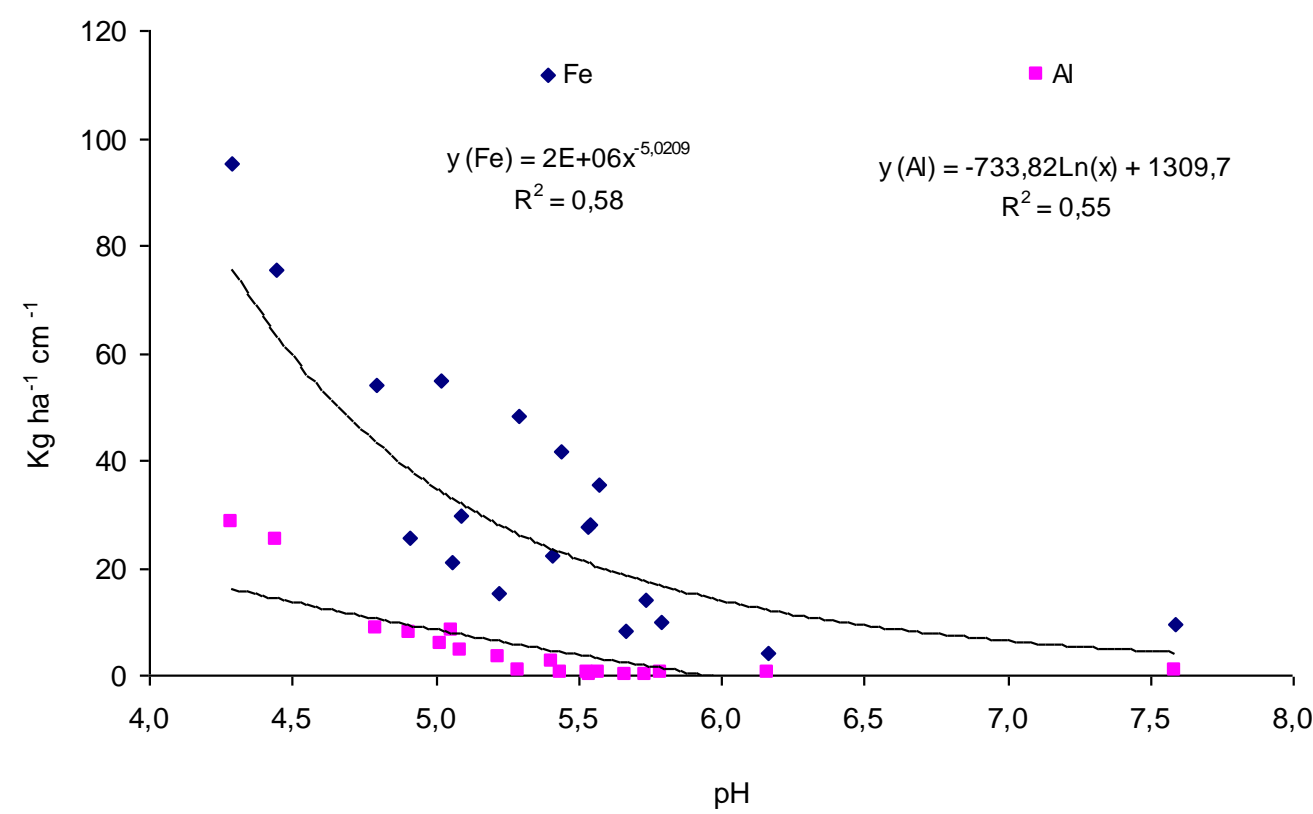

Figura 3.1.17: Relación entre el pH y el contenido de Al y Fe intercambiables del suelo.

\subsubsection{Densidad aparente de los suelos}

Los valores de la densidad aparente determinada hasta los $60 \mathrm{~cm}$ se presentan en la Tabla 3.1.10.

\begin{tabular}{ccccc}
\hline \multicolumn{5}{c}{ Densidad aparente (g/cm3) } \\
\hline & Sitio III & Testigo pastizal \\
Prof. $(\mathbf{c m})$ & Promedio & DS & Promedio & DS \\
$0-10$ & 1.47 & 0.07 & 1.54 & 0.08 \\
$10-20$ & 1.68 & 0.01 & 1.62 & 0.07 \\
$20-30$ & 1.8 & 0.05 & 1.71 & 0.05 \\
$30-40$ & 1.73 & 0.07 & 1.61 & 0.04 \\
$40-50$ & 1.47 & 0.06 & 1.52 & 0.05 \\
$50-60$ & 1.55 & 0.05 & 1.59 & 0.08 \\
\hline
\end{tabular}

Tabla 3.1.10: Valores de densidad aparente $\left(\mathrm{g} / \mathrm{cm}^{3}\right)$ del suelo en el sitio III.

La densidad aparente a las distintas profundidades no se diferenció significativamente entre el sitio forestado y el pastizal. En ambos se observó un aumento de la misma con el aumento de la profundidad hasta los $30 \mathrm{~cm}$ para luego disminuir su valor. El incremento se correspondió con la presencia de un horizonte de alto contenido de arcilla 
característico de los suelos Inceptisoles que presentan dos clases texturales fuertemente contrastantes entre los $25 \mathrm{~cm}$ y el metro de profundidad con presencia de materiales gleyzados muy densos y poco permeables (Tasi, 1993).

\subsubsection{Agua edáfica}

La disponibilidad de agua del suelo para las plantas depende, entre otros factores, de las propiedades edáficas entre las cuales la textura, la estructura, la profundidad y el contenido de materia orgánica del suelo son sumamente importantes (Conti, 2000). Los suelos de textura más gruesa (arenosos) poseen tamaños de poro mayores con baja capacidad de retención de agua, aun así, la baja energía de retención hace que el agua, encontrándose en porcentajes bajos, se halle disponible a las plantas. Asimismo el drenaje es rápido. Los suelos con elevado contenido de arcilla, en cambio, retienen mucha agua en sus poros pequeños pero exigen elevados contenidos de agua para que ésta se encuentre disponible debido a las elevadas fuerzas de retención ejercidas por los coloides. Un elevado contenido de MO ayuda a la retención del agua. Con aportes de agua mayores a los que puede retener el suelo, éste puede saturarse o aún anegarse. Un suelo tiene un contenido de Agua a Saturación cuando está con todos sus poros llenos de la misma. Los suelos de textura arenosa poseen un alto contenido de agua a saturación. Parte de ésta agua se pierde bajo la fuerza de la gravedad. El agua disponible para las plantas se encuentra entre la Capacidad de Campo (CC) y el Punto de Marchitez Permanente (PMP). La Capacidad de Campo se define como la cantidad de agua que es retenida en el suelo después que ha drenado el agua gravitacional; su equivalente medido en laboratorio es denominado Humedad Equivalente (HE) (Ratto, 2000). El PMP es la cantidad de agua retenida bajo una presión, que por convención, se establece en -1.5 MPa; las plantas de interés agronómico se estima que entran en un proceso de marchitez irreversible si el agua del suelo es retenida con esa fuerza. Los árboles y muchas otras plantas adaptadas a zonas áridas o de elevado contenido salino pueden obtener agua del suelo que es retenida con fuerzas muy superiores a las del PMP convencional. Para estimar el potencial hídrico del suelo puede medirse el potencial hídrico pre-alba asumiendo que en ausencia de transpiración el potencial hídrico está en equilibrio con el del suelo. Como se mencionó en la introducción, en Concordia se 
midieron valores de potencial hídrico pre-alba de -3.3 (+/- 0.14) MPa para Eucalyptus grandis, lo cual indicaría que puede mantener la turgencia de los tejidos por debajo del PMP estipulada para los cultivos. Como se indicó en la Introducción, otros resultados indican que existen varias especies de Eucalyptus con este comportamiento: $E$. beheriana, $-4.7 \mathrm{MPa}, E$. macrocarpa -4.2 MPa (Mears \& Neales, 1984 en Bell \& Williams, 1997).

Como se ha destacado los suelos forestados de Concordia, considerados en este estudio, tienen textura arenosa y escaso contenido de MO (Tabla 3.1.6), lo cual afecta a la retención de agua. También, la profundidad efectiva en donde los árboles pueden penetrar con sus raíces y extraer agua es, en éstos casos, limitada, ya que aproximadamente entre los 20 y los $40 \mathrm{~cm}$ de profundidad se encuentra un horizonte con mayor contenido de arcilla $\left(B_{2} t\right)$ que dificulta la entrada de las raíces y el drenaje profundo. La CC en el sitio estudiado fue de $149.63 \mathrm{~mm}$. El agua útil, diferencia entre la CC y el PMP del suelo arenoso forestal, es muy baja (Figura 3.1.18). Considerando los valores de los índices hídricos para el sitio III, el agua útil hasta los $60 \mathrm{~cm}$ resultó de $35.6 \mathrm{~mm}$ (Tabla 3.1.8). Estos suelos arenosos mestizos tienen una rápida pérdida del agua gravitacional y baja retención en los primeros $30 \mathrm{~cm}$; a más profundidad, en el horizonte arcilloso, la pérdida del agua gravitacional es menor, hay una mayor cantidad de agua útil, pero retenida por el suelo con mayor fuerza. Asimismo, ese horizonte arcilloso que dificulta el drenaje profundo, ayuda a que durante eventos de lluvia intensos, los horizontes arenosos superficiales puedan saturarse y en casos anegarse.

El suelo mestizo saturado del Sitio III posee tres veces más agua que el que contiene a Capacidad de Campo (comparar Tabla 3.1.11 y 3.1.12), y teniendo en cuenta su drenaje profundo lento, es de esperar que parte del agua de saturación sea absorbida por los vegetales; por ende el suelo mestizo tendría una mayor disponibilidad de agua que un suelo arenoso profundo de mayor drenaje. El anegamiento de los suelos mestizos, en los relieves suaves estudiados, es infrecuente, y de escasa expresión espacial y temporal ya que el agua en exceso que no drena fácilmente en profundidad tiende a escurrir lateralmente. Como se ha señalado anteriormente, en éstos suelos la autora de ésta tesis ha medido potenciales hídricos de -3.3 MPa en E. grandis, lo que muestra la capacidad de la especie para extraer agua del suelo en condiciones de escasez, cuando la fuerza de retención es elevada; en esta situación el agua disponible para E. grandis sería mayor, ya que una parte de los $91 \mathrm{~mm}$ 
indicados para el PMP convencional medido en los laboratorios de suelos, podría ser absorbida por los árboles. En los primeros 20 - $30 \mathrm{~cm}$ de suelo el porcentaje de agua en el PMP convencional resultó de ca. 9\% (Figura 3.1.18; Tabla 3.1.11). Considerando que los suelos arenosos ya no ceden agua cuando su contenido es de aproximadamente el $2 \%$ y que Eucalyptus grandis es capaz de desarrollar potenciales hídricos más bajos que el del PMP convencional, es posible pensar que estas plantas pueden extraer agua cerca de ese límite lo que implica mayor cantidad de agua útil. Sintetizando, la disponibilidad global de agua en estos suelos mestizos parece ser mayor a lo esperado; a lo que contribuiría, en periodos de mucha lluvia, el agua de saturación, favorecida por las características físicas del perfil, y, en periodos secos, a la capacidad fisiológica de E. grandis para extraer agua.

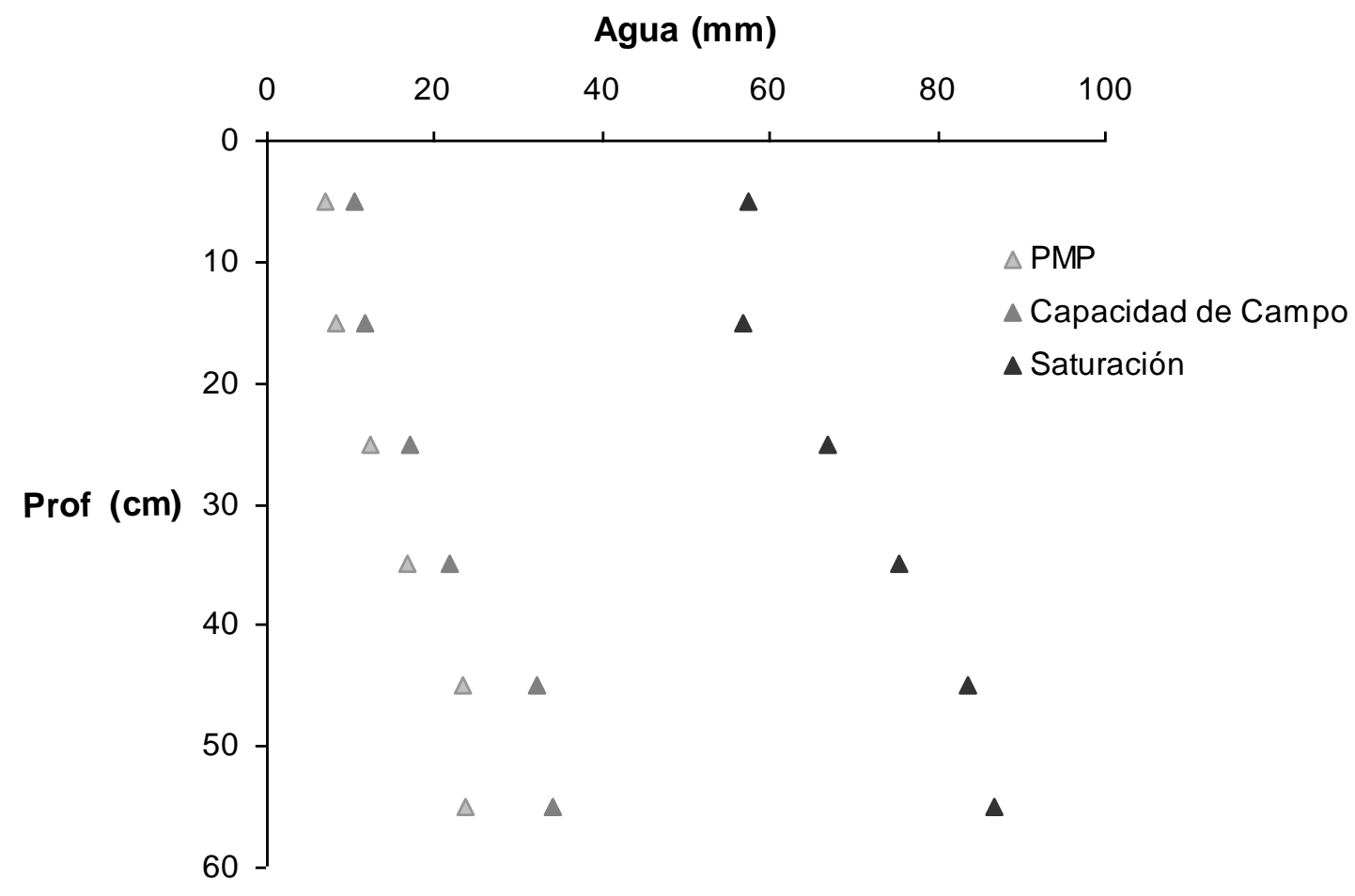

Figura 3.1.18: Perfil del contenido de agua en el suelo $(\mathrm{mm})$ en el Punto de Marchitez Permanente (PMP) convencional, la Capacidad de Campo (CC) y a Saturación (Sat) hasta los $60 \mathrm{~cm}$ de profundidad. 


\begin{tabular}{|c|c|c|c|c|c|c|}
\hline \multirow{3}{*}{ Profundidad $(\mathrm{cm})$} & \multicolumn{6}{|c|}{ Lámina de agua $(\mathrm{mm})$} \\
\hline & \multicolumn{2}{|c|}{ PMP } & \multicolumn{2}{|c|}{$\mathrm{HE}$} & \multicolumn{2}{|c|}{ Sat } \\
\hline & Promedio & Desv Std & Promedio & Desv Std & Promedio & $\begin{array}{l}\text { Desv } \\
\text { Std }\end{array}$ \\
\hline $0-10$ & 6.8 & 0.6 & 10.3 & 0.5 & 57.3 & 3.5 \\
\hline $10-20$ & 8.2 & 0.6 & 11.7 & 1.1 & 56.6 & 8.1 \\
\hline $20-30$ & 12.2 & 1.3 & 16.9 & 2.3 & 66.9 & 10.3 \\
\hline $30-40$ & 16.7 & 5.8 & 21.8 & 7.3 & 75.3 & 14.5 \\
\hline $40-50$ & 23.4 & 1.5 & 32.0 & 3.0 & 83.6 & 8.2 \\
\hline $50-60$ & 23.6 & 0.5 & 33.9 & 0.5 & 86.9 & 9.4 \\
\hline Total & 91.1 & & 126.7 & & 426.6 & \\
\hline
\end{tabular}

Tabla 3.1.11: Valores de los índices hídricos del suelo para el Sitio III: Punto de marchitez permanente (PMP a -1,5 MPa), Humedad equivalente (HE) y Saturación (Sat) determinados en laboratorio.

\begin{tabular}{cccccc}
\hline & \multicolumn{5}{c}{ Lámina de agua a capacidad de campo $(\mathbf{m m})$} \\
\hline Profundidad $(\mathbf{c m})$ & Perfil 1 & Perfil 2 & Perfil 3 & Promedio & Desviación \\
$0-10$ & 17.1 & 16.9 & 19.6 & 17.86 & 1.22 \\
$10-20$ & 20.7 & 21.2 & 20.3 & 20.72 & 0.35 \\
$20-30$ & 23.3 & 23.1 & 21.6 & 22.65 & 0.74 \\
$30-40$ & 29.2 & 27.1 & 28.1 & 28.13 & 0.86 \\
$40-50$ & 31.6 & 31.8 & 28.8 & 30.70 & 1.38 \\
$50-60$ & 30.3 & 29.9 & 28.6 & 29.57 & 0.70 \\
Total & & & & 149,63 & \\
\hline
\end{tabular}

Tabla 3.1.12: Valores del contenido hídrico en el perfil de suelo $(\mathrm{mm})$ a Capacidad de Campo en el Sitio III.

\subsection{Flujos de Agua y Balance Hidrológico}

\subsubsection{Precipitación bruta}

Durante los dos periodos del balance hidrológico estudiados (abril 2003-marzo 2004 y abril 2004-marzo 2005) la precipitación anual fue de 1417 mm y 1264 mm respectivamente. Considerando el valor anual promedio de las precipitaciones de la serie histórica 1967-2005, que fue de $1345.3 \pm 287.7 \mathrm{~mm}$, los valores anuales de los dos períodos analizados quedaron comprendidos en el rango del valor medio más/menos un desvío estándar. No obstante, hubo variaciones mensuales en ambos períodos que por exceso o por defecto se alejaron de la media histórica (Figura 3.2.1). 


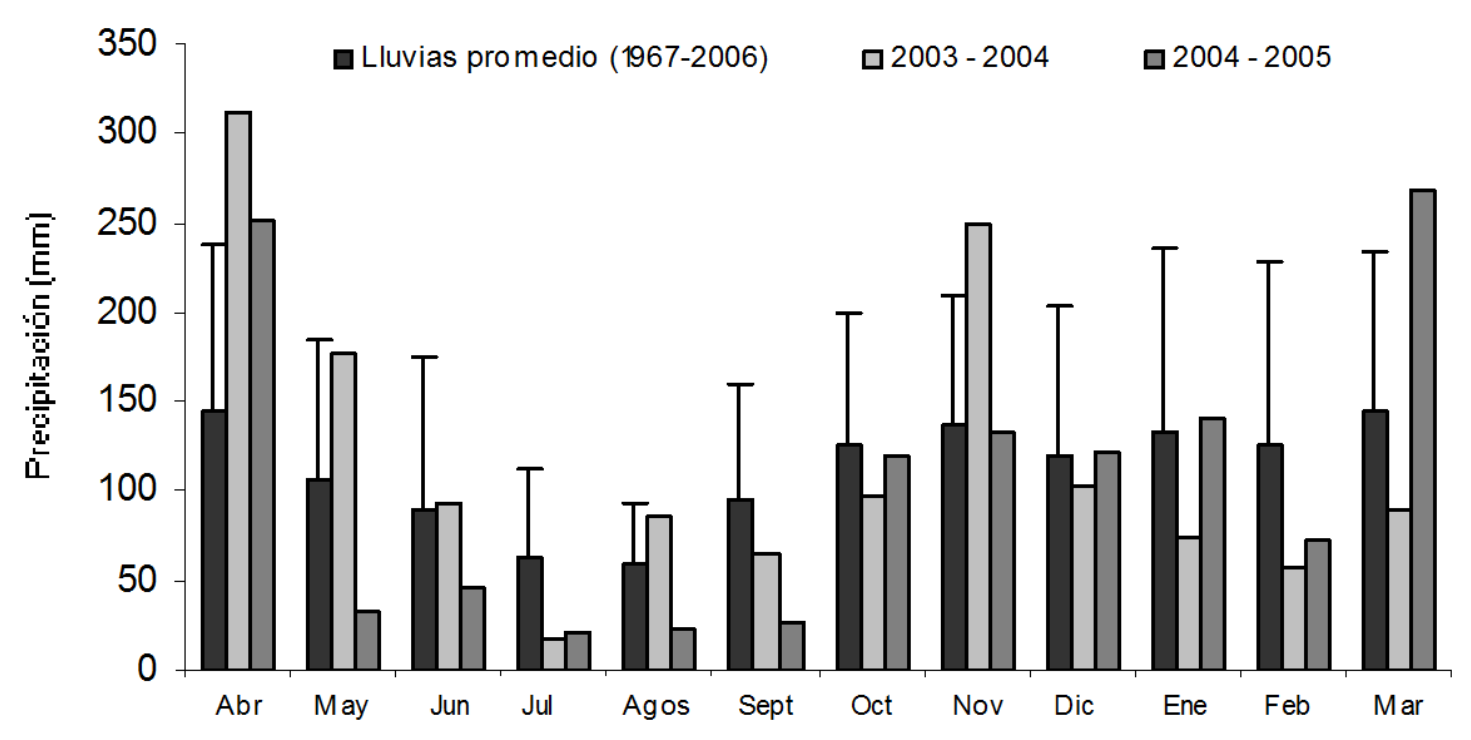

Figura 3.2.1: Precipitaciones mensuales durante los dos períodos estudiados y el promedio para el período $1967-2005$.

La distribución de las precipitaciones presentó menores precipitaciones en el invierno, como es característico al clima de Concordia.

\subsubsection{Trascolación}

Para el Sitio I (3 - 4 años) los valores de trascolación (T) fueron $1193 \pm 18 \mathrm{~mm}$ para el primer período y de $1023 \pm 25 \mathrm{~mm}$ para el segundo. La regresión entre los valores de precipitación bruta (PB) versus los de trascolación se representa en la Figura 3.2.2. La relación entre variables resultó significativa.

La regresión entre los valores de precipitación bruta (PB) versus los de trascolación para el Sitio III se representa en la Figura 3.2.3. La relación entre variables resultó significativa ( $p<0.01 ; n=97)$. Para el Sitio III los valores anuales de trascolación fueron $1195 \pm 56$ mm para el primer período y de $1069 \pm 36 \mathrm{~mm}$ para el segundo. 


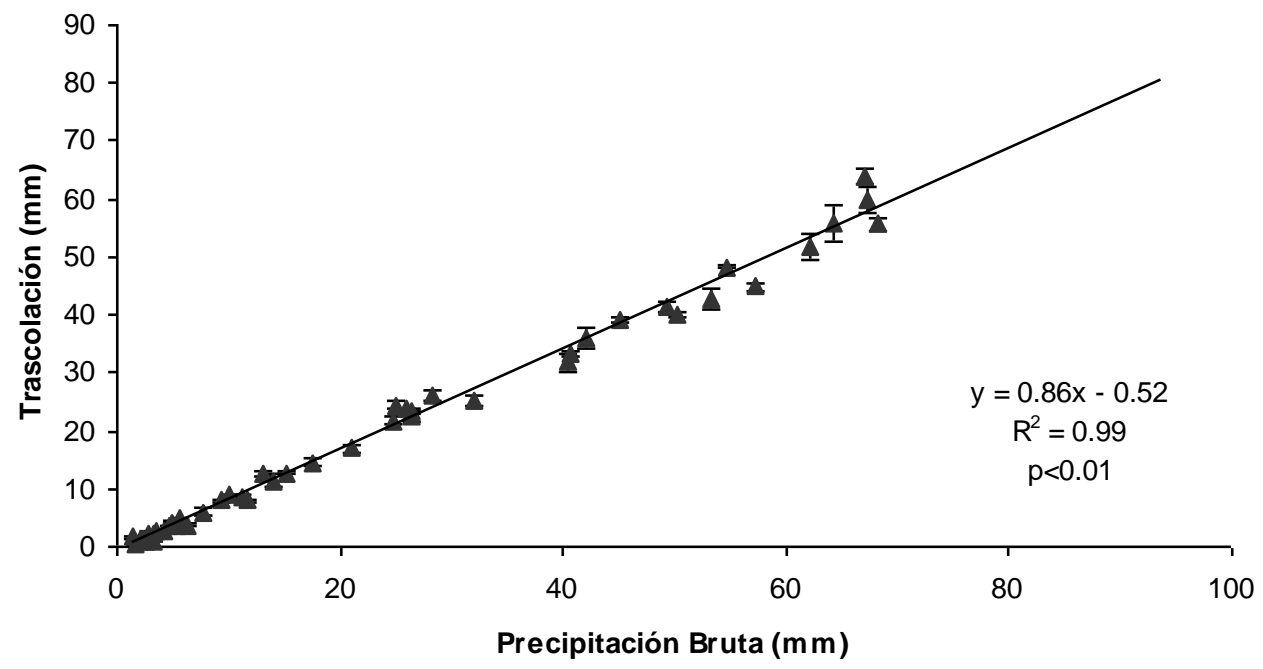

Figura 3.2.2: Regresión entre la trascolación y la precipitación bruta a los $3-4$ años de edad (n=97).

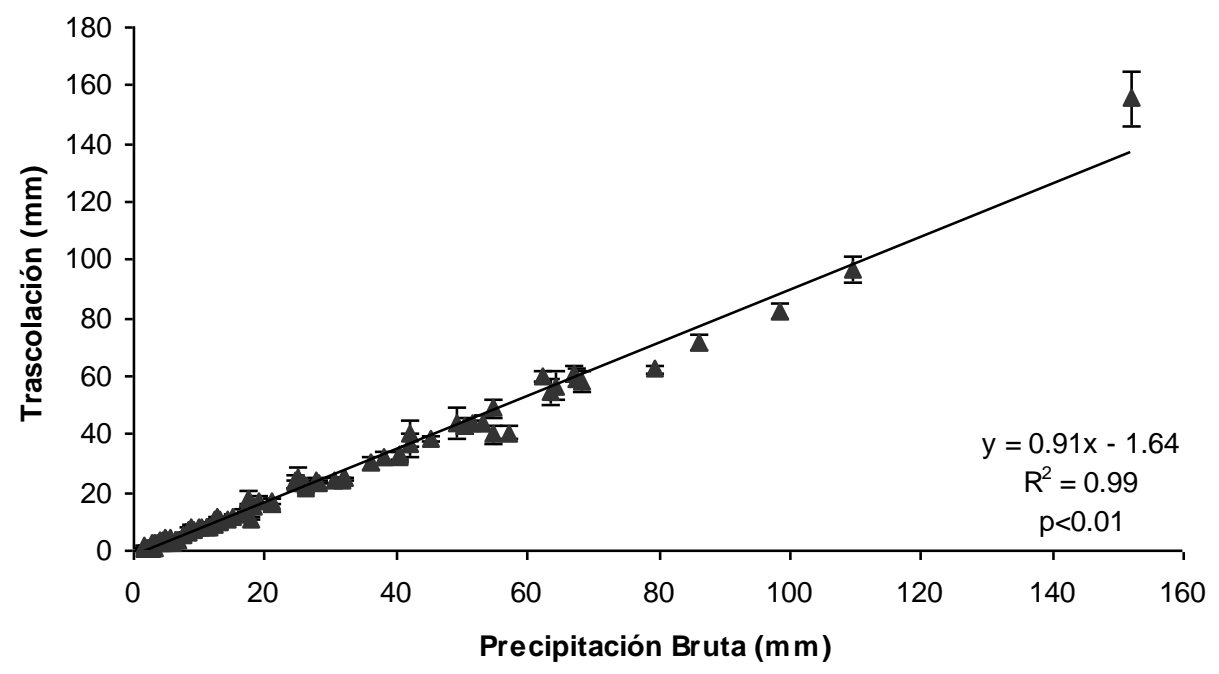

Figura 3.2.3: Regresión entre la trascolación y la precipitación bruta a los 11 - 12 años de edad ( $n=97)$.

El resultado de comparar los parámetros de las regresiones de las dos edades, indica que los modelos comparados no difieren en la ordenada al origen pero sí en la pendiente, para los sitios de 3 y 12 años (Tabla 3.2.1). 


\begin{tabular}{lllllll}
\hline & Beta & Error Std & B & Error std B & T (443) & P \\
\hline Intercep & & & -0.61472 & 0.414616 & -1.48261 & 0.140007 \\
$\mathrm{~T}$ & 0.955842 & 0.015344 & 0.85914 & 0.013792 & 62.29375 & 0.000000 \\
$\mathrm{I}$ & -0.023363 & 0.012780 & -1.02863 & 0.562675 & -1.82810 & 0.069267 \\
$\mathrm{~T} * \mathrm{I}$ & 0.053977 & 0.018337 & 0.05014 & 0.017034 & 2.94357 & 0.003693 \\
\hline
\end{tabular}

Tabla 3.2.1: Comparación de los parámetros de las dos regresiones entre la Precipitación y la Trascolación (T) en los sitios I y III. Variable indicadora (I), su significancia indica si la ordenada al origen de los modelos de regresión difieren entre si. T* I, su significancia indica si las pendientes de los modelos de regresión difieren entre sí.

La mayor trascolación en el Sitio III puede deberse a diferencias en la arquitectura de las copas de los árboles y a la estructura de la plantación. Si bien se trata de individuos de una misma especie y similar genética, la edad y la densidad de la plantación son factores que afectan la morfología de los organismos modulares. (Halle et al., 1978; Kimmins, 1997). Lo que ocasiona diferencias en la profundidad de la copa, las ramificaciones, la disposición foliar, el área foliar, etc.

Si bien el área foliar ha sido reconocida como de gran importancia en la intercepción de agua y por lo tanto afecta a la trascolación, en este caso un similar índice de área foliar en ambas plantaciones no parece explicar las diferencias significativas en la intercepción, lo cual sugiere que los otros elementos de la arquitectura vinculados con la posición espacial de las hojas en la copa y las características de estas últimas puedan estar involucradas en las diferencias observadas. Posiblemente las diferencias estructurales expliquen también las diferencias en la capacidad de almacenaje de agua de las copas; para la edad más joven el valor del almacenaje de la copa fue de $0.60 \mathrm{~mm}$ mientras que en la edad adulta el valor ascendió a $1.8 \mathrm{~mm}$.

\section{2.3 Flujo caulinar}

Para los dos períodos anuales estudiados el volumen de agua registrado como flujo caulinar (FC) en el sitio III fue de $73 \pm 6 \mathrm{~mm}$ y $48 \pm 2 \mathrm{~mm}$ respectivamente.

La regresión entre los eventos de PB y del flujo caulinar correspondiente ( $n=91)$ mostró una relación significativa ( $p<0.01)$ (Figura 3.2.4). 
Los ángulos de inserción de ramas en el tronco, la poca rugosidad de la corteza de E. grandis y la ausencia de epifitas determinaron que, con escasa precipitación ya se produjera flujo caulinar. Para el sitio estudiado, el valor mínimo de precipitación bruta a partir del cual se observó flujo caulinar fue de $0.6 \mathrm{~mm}$.

Se encontró una relación directa de tipo exponencial entre el diámetro de los árboles y el flujo caulinar (Figura 3.2.5). Así los árboles más grandes (mayor DAP y área basal/individuo) condujeron más agua que los más pequeños, favoreciendo que un mayor volumen de agua llegara al suelo en las inmediaciones de la base de los troncos. Este comportamiento fue observado por diversos autores. Johnson \& Lehmann (2006) realizaron una revisión en varias especies sobre como impacta la magnitud y el aporte de nutrientes con el flujo caulinar, mencionando la importancia de la arquitectura de la canopia para la captación de recursos. Asimismo Herwitz (1986) con la finalidad de resaltar la importancia del flujo caulinar como aporte de agua y nutrientes en las inmediaciones de la base del tronco calculó un cociente de encausamiento (funneling ratio). A su vez, Laclau et al. (2009), para Eucalyptus, destaca que el flujo caulinar incrementa la variabilidad espacial de raíces finas y nutrientes en la solución del suelo de los horizontes superficiales, cerca de la base del tronco. Los árboles dominantes y co-dominantes son entonces capaces de captar mayor cantidad y calidad de recursos retroalimentando su posición jerárquica en el rodal. Estos enfoques destacan la importancia de este flujo para las plantas en especial en zonas y períodos con déficit hídricos. 


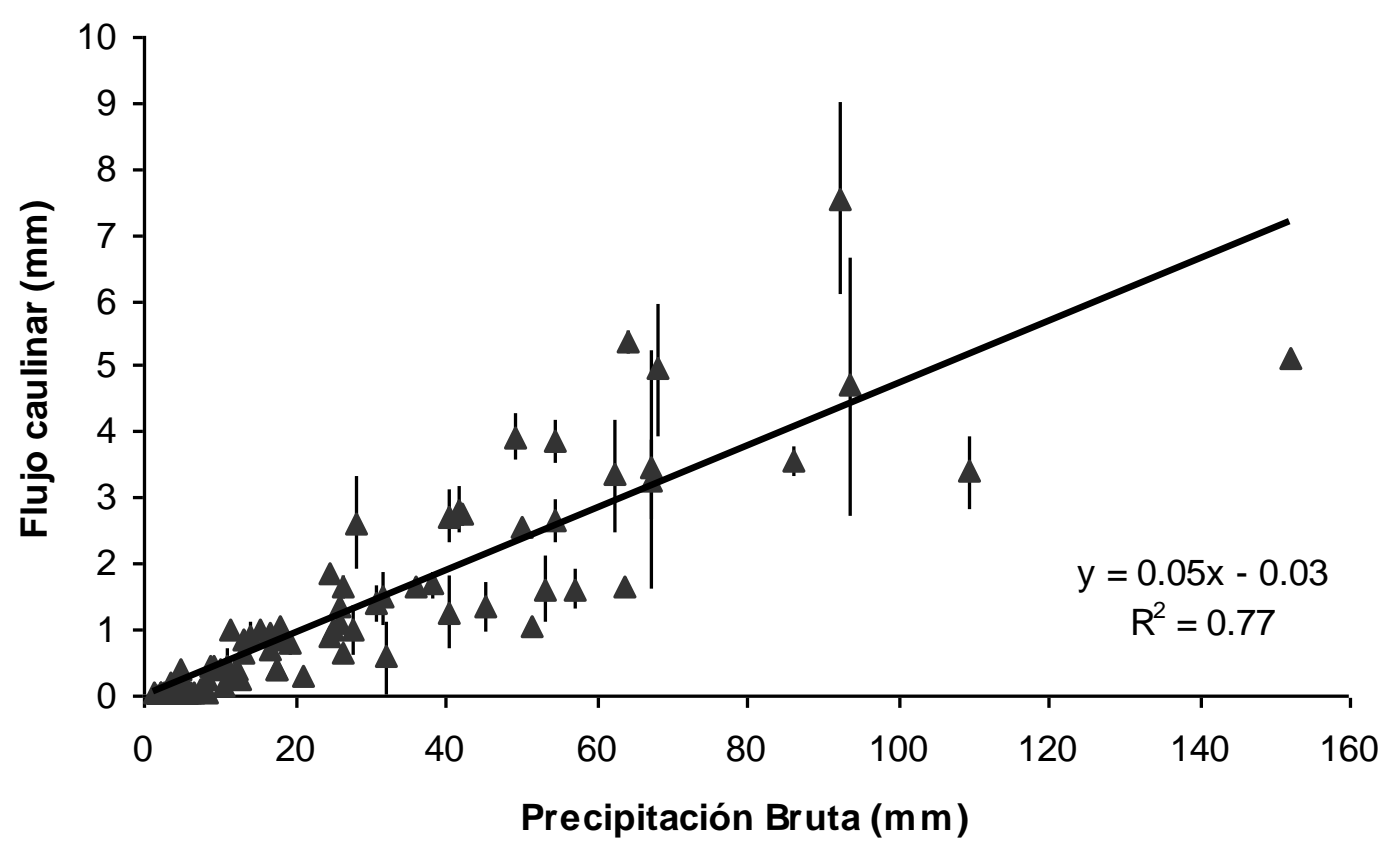

Figura 3. 2.4: Relación entre el flujo caulinar $(\mathrm{mm})$ y la precipitación bruta $(\mathrm{mm})$.

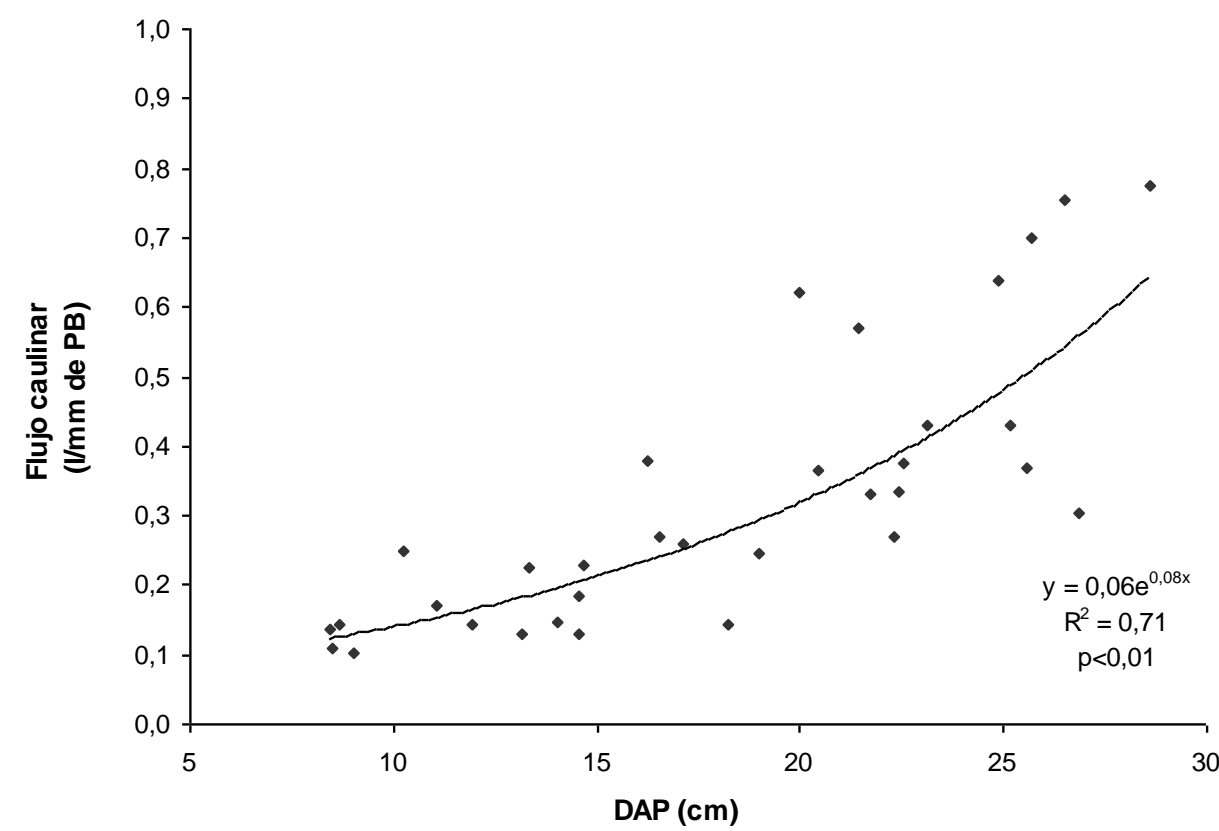

Figura 3.2.5: Relación entre el flujo caulinar (litros de FC/mm de PB) y el diámetro de los árboles (DAP). 


\subsubsection{Precipitación Neta e Intercepción}

La precipitación neta $(\mathrm{PN}=\mathrm{T}+\mathrm{FC})$ en los dos períodos evaluados fue de 1265 y 1112 $\mathrm{mm}$ respectivamente.

La intercepción del dosel $(I=P B-(T+F C))$ resultó ser el 10.7 y el $12.0 \%$ de la precipitación bruta. Según Kellinger \& Scotter (en Waring \& Running, 1998) la intercepción en ecosistemas forestales se sitúa en valores comprendidos entre el $10 \%$ y el $50 \%$, alcanzando este valor para ecosistemas de vuelo muy espesos. Soares \& Almeida (2001) obtuvieron valores de intercepción similares a los obtenidos en este estudio, en una plantación de $E$. grandis de 9 años. Otros valores de intercepción para plantaciones de $E$. grandis se presentaron en la Tabla 1.1.

En comparación con la intercepción de los Eucalyptus, las copas con más área foliar de las coníferas y por lo tanto mayor capacidad de almacenamiento de agua, pueden conducir a mayores pérdidas por intercepción (con valores típicos entre $15 \%$ y $24 \%$ de la precipitación) en algunos casos alcanzando el 60 \% de la precipitación (Le Maitre et al., 1999).

En la Figura 3.2.6 se indican los valores mensuales de la precipitación bruta, como de la precipitación neta y sus componentes (trascolación y flujo caulinar). Debido a que la distribución de las lluvias no es homogénea a lo largo del año, la evaporación podrá verse afectada por la disponibilidad de lluvias. En general en los meses de mayor demanda atmosférica se advierte una mayor pérdida por evaporación. La evaporación desde los vuelos aumenta exponencialmente con la temperatura, debido a los efectos de esta sobre el déficit de presión de vapor junto con la turbulencia que genera la rugosidad de la cubierta vegetal (Mc Naughton, 1976; Kellinher \& Jackson, 2001 en Savé et al., 2005), por lo cual las pérdidas evaporativas son mayores en los meses cálidos.

\subsubsection{Intercepción del mantillo}

La cantidad de precipitación retenida y evaporada por el mantillo $(\mathrm{Im}=\mathrm{PN}-\mathrm{Tm})$ ha sido demostrado que es un componente significativo del proceso de intercepción. 
Generalmente la cantidad perdida se incrementa con el incremento de la profundidad del mantillo (Sopper \& Lull, 1965). Debido a la baja tasa de descomposición que tienen los detritos finos estos se acumulan sobre el suelo.

En éste estudio se encontró una relación lineal significativa entre el volumen de la trascolación del mantillo (Tm = la fracción que atraviesa el mantillo) y la precipitación bruta

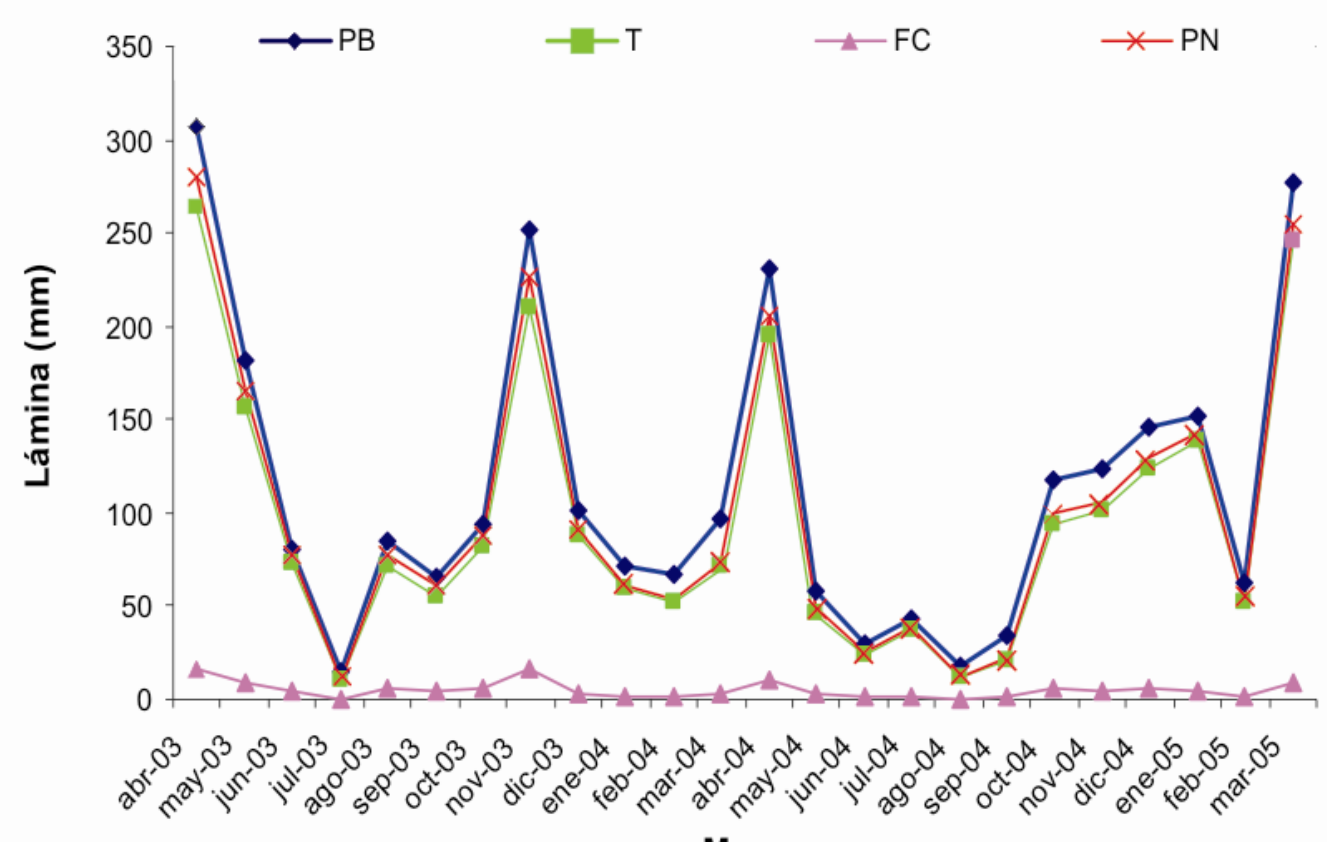

\section{Meses}

Figura 3.2.6: Precipitación Bruta (PB), Trascolación (T), Flujo Caulinar (FC) y Precipitación Neta (PN). Valores mensuales (mm).

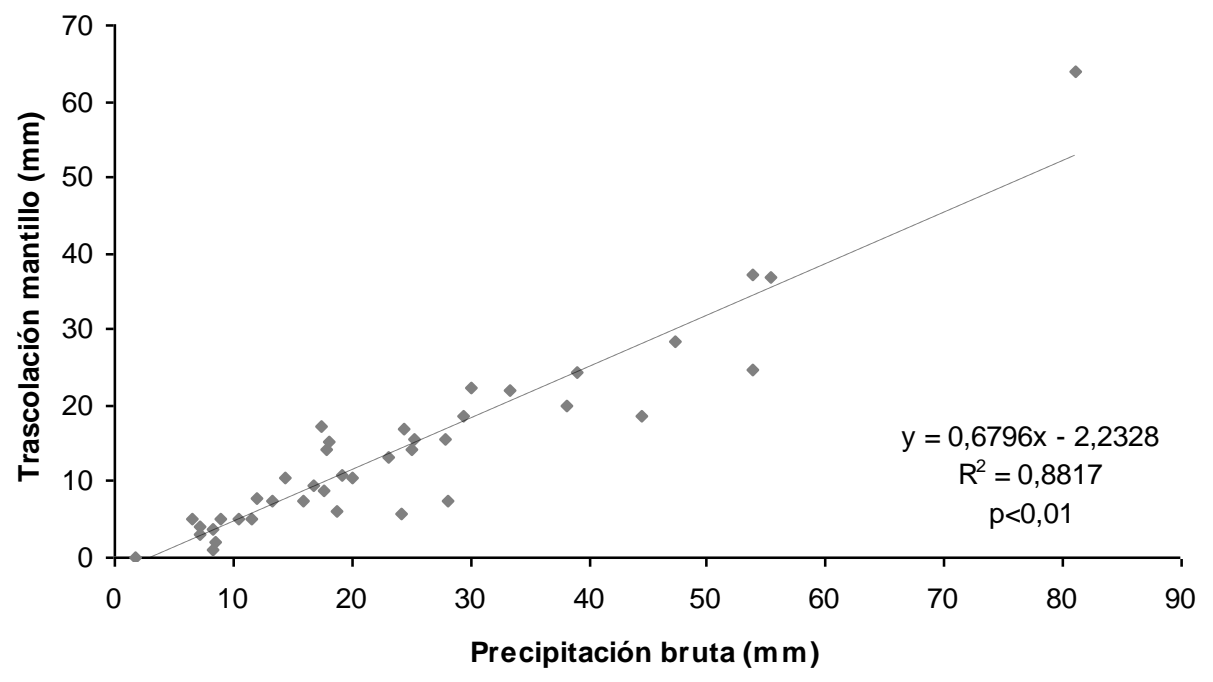

Figura 3. 2. 7: Relación entre la trascolación del mantillo $(\mathrm{mm})$ y la precipitación bruta $(\mathrm{mm})$ 
(Figura 3.2.7). Consecuentemente, los valores anuales de intercepción del mantillo medidos para cada período anual resultaron de $232 \pm 8 \mathrm{~mm}$ y $152 \pm 9$ respectivamente.

La alta intercepción del mantillo sugiere que sería conveniente realizar prácticas de manejo tendientes a disminuir las pérdidas por evaporación. Esto implicaría trabajar sobre el mantillo para reducir la cantidad que se acumula, en la superficie del terreno que aumenta la superficie interceptora; esta tarea debe compatibilizarse con la conservación ecosistémica de los nutrientes en la necromasa y, si es posible, aumentar la calidad del mantillo y el suministro de elementos minerales al suelo. Para cumplir con esos objetivos, las medidas a tomar podrían apuntar a aumentar la calidad química del mantillo disminuyendo la relación $\mathrm{C} / \mathrm{N}$ (y C/nutrientes en general), como asimismo su calidad física, de manera de favorecer un aumento de la tasa de descomposición. El establecimiento de plantaciones mixtas con especies de leguminosas, la incorporación de leguminosas herbáceas en el sotobosque (Alcaraz, L.; com. pers., 2011) son posibilidades a tener en cuenta en investigaciones que tengan dicho propósito. La fertilización nitrogenada puede ser otro camino, pero debería evaluarse cuidadosamente el posible impacto del aporte de este tipo de fertilización en el suelo. Otras vías a explorar podrían vincularse con el manejo del mantillo de eucalipto propiamente dicho; esto conllevaría la posibilidad de reducción del espesor de mantillo, y su redistribución horizontal, sea incorporándolo al suelo, cambiando el arreglo espacial del mismo o fraccionarlo para disminuir el tamaño de los componentes, y otras medidas que tiendan a reducir espesores de mantillo, facilitar áreas de ingreso del agua al suelo, acelerar la incorporación de la materia orgánica al suelo y aumentar la velocidad de descomposición por aumento de la relación área/volumen que favorece el ataque de los microorganismos.

\subsubsection{Nivel freático}

La medición del nivel freático en la EEA Concordia no ha sido continua. Con los datos disponibles se trató de verificar si existió alguna tendencia de cambio en el nivel freático con el transcurso de los años registrados. Asimismo con los datos del pozo bajo la plantación se 
pretendió efectuar una primera aproximación al posible efecto del cambio de uso de la tierra.

Los resultados indicaron que el nivel freático medio registrado entre enero de 1968 y julio de 1999 en la Estación Meteorológica de la EEA Concordia fue de $19.8 \pm 0.73 \mathrm{~m}$ bajo el nivel del terreno (47 msnm) el promedio del nivel freático registrado entre marzo de 2005 y febrero de 2006 fue de $18.8 \pm 0.32 \mathrm{~m}$. Las fluctuaciones del nivel de la napa freática en la Estación Meteorológica EEA Concordia parecen explicarse parcialmente por la variación de las precipitaciones (Fig. 3.2.8). Asimismo la variación del nivel freático en dicha estación meteorológica, no manifiesta una marcada tendencia de cambio en el largo plazo.

En el período de la medición, inmediatamente posterior al estudio hidrológico de la plantación, la profundidad de la napa freática en los dos sitios bajo pastizales y el sitio bajo la plantación (Fig.3.2.9) mostraron rasgos diferentes. En los sitios EM y claro la variación estacional de la napa freática fue mayor que bajo la plantación, y el nivel de la freática corregido por la altitud del sitio bajo la plantación fue menor en los sitios sin plantaciones que bajo el forestado.

La diferencia entre los valores máximos y mínimos del nivel de la napa en cada pozo, corregido por un coeficiente de porosidad, (yield capacity ratio) de 0.12, mostró valores positivos en el período 2005 - 2006. El valor de los sitios ubicados en claros reflejaron un incremento de la lámina del orden de 112 y $140 \mathrm{~mm}$ que representaron del $6.6 \%$ al $8.3 \%$ de la PB del período (1681,7 mm) mientras que bajo la plantación este incremento alcanzó un valor inferior, $70 \mathrm{~mm}$, que representó el $4.2 \%$ de la PB. 


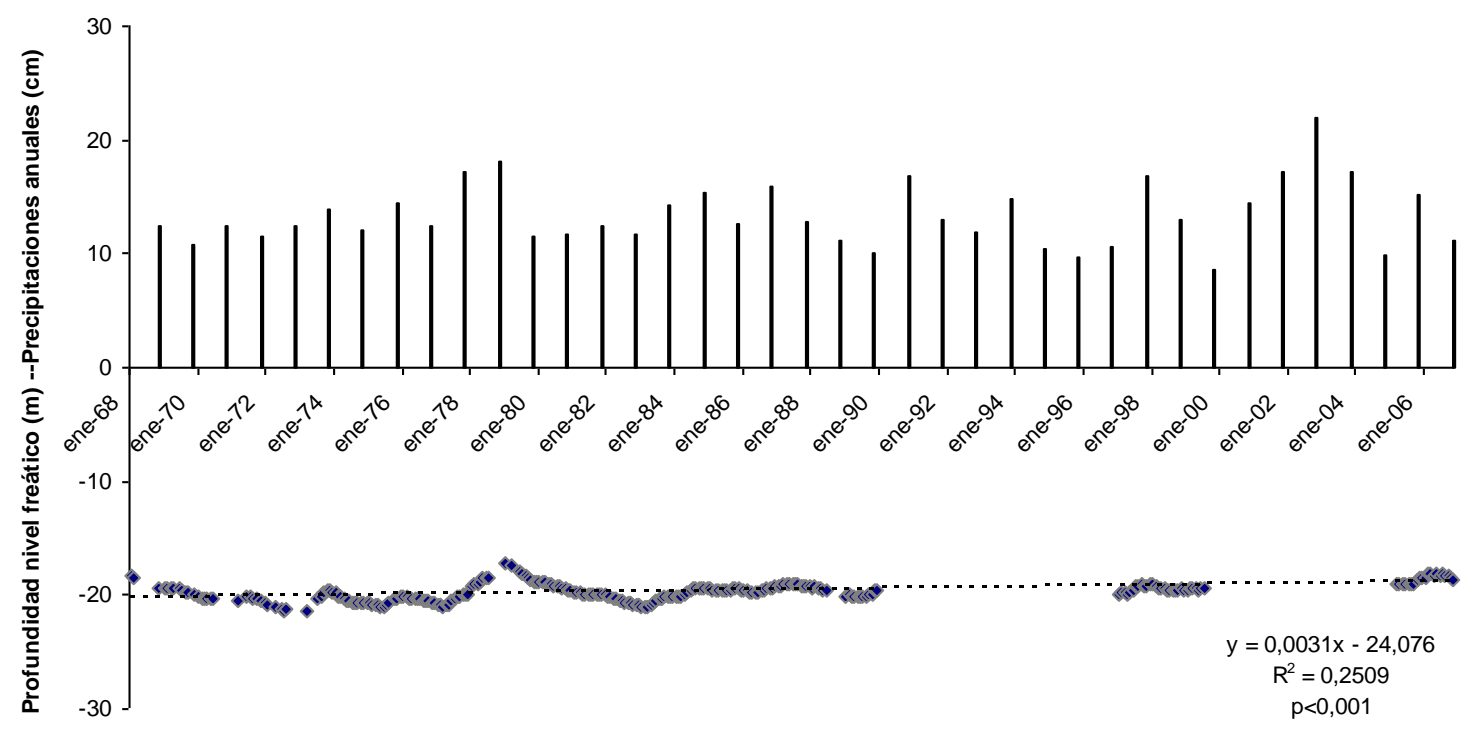

Figura 3.2.8: Precipitaciones $(\mathrm{cm})$ y nivel freático $(\mathrm{m})$. Período $1968-2006$

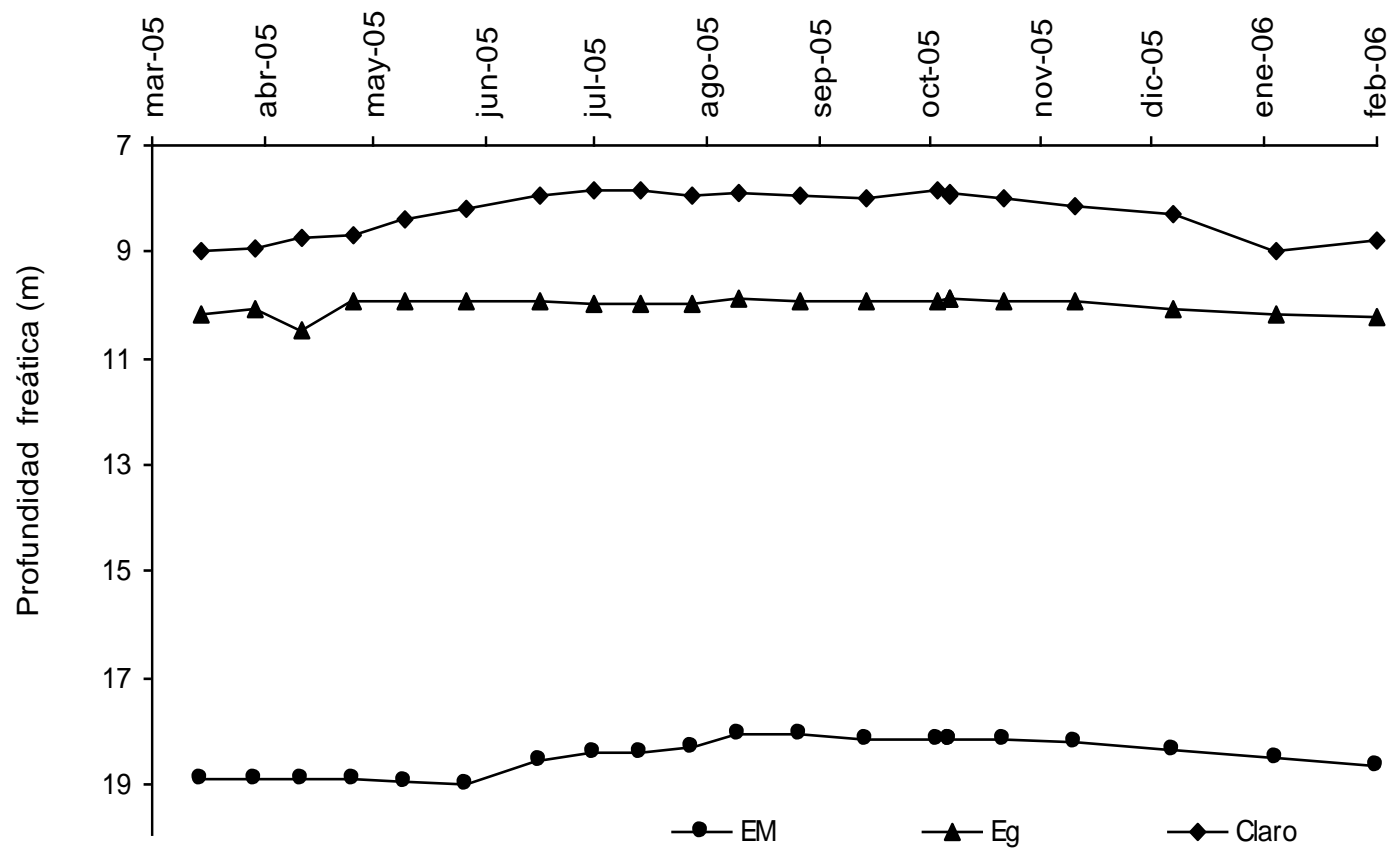

Figura 3.2.9: Nivel freático mensual medidos en pozos encamisados en la Estación meteorológica EEA INTA Concordia (EM), en la plantación estudiada (Eg) y en un claro ubicado a 2000 m de la plantación.

Estos resultados concuerdan con los de Walker et al. (1999) quienes estudiaron la percolación en el SE de Australia bajo diferentes tipos de vegetación (anuales, perennes y árboles; Figura 3.2.16) en un gradiente de precipitaciones (entre 600 y 1200 mm) concluyendo que los menores valores se encontraban bajo los árboles y que con el incremento de las precipitaciones las diferencias en el drenaje profundo entre distintas cubiertas de vegetación aumentan. Asimismo los valores de fuga profunda de agua (leakage) 
bajo las cubiertas arbóreas a lo largo de todo el rango de precipitaciones analizado se mantienen prácticamente constantes lo cual sugiere un aumento de la evapotranspiración y una reducción de la fracción de agua de lluvia que percola el suelo.

\subsubsection{Escurrimiento superficial en la plantación y en el pastizal}

El año de mediciones del escurrimiento superficial en el pastizal y plantación forestal, permitió ajustar una regresión que vincula los valores del escurrimiento superficial en relación a la precipitación bruta de los eventos de lluvia para cada ecosistema (Fig. 3.2.10)

En el pastizal aledaño la pendiente de la regresión ajustada fue de 0.24 mientras que para la plantación la misma fue de 0.05 . El volumen de escurrimiento superficial en la plantación resultó un 80 \% menor que el registrado para el pastizal. Esta diferencia podría ayudar a interpretar lo indicado en la sección correspondiente a agua del suelo, en que se expresó que parte del agua de saturación, que potencialmente escurriría, podría estar siendo absorbida por los árboles.

La disminución del escurrimiento superficial en plantaciones forestales respecto a situaciones anteriores de pastizal fue informado por muchos investigadores (Calder, 1998; Farley et al., 2005; Gao et al., 2009) y es uno de los principales aspectos cuestionados debido a que el rendimiento de las cuencas forestadas se ve reducido así como la recarga de los acuíferos. El impacto mayor ocurre para los sitios con menores precipitaciones medias anuales. 


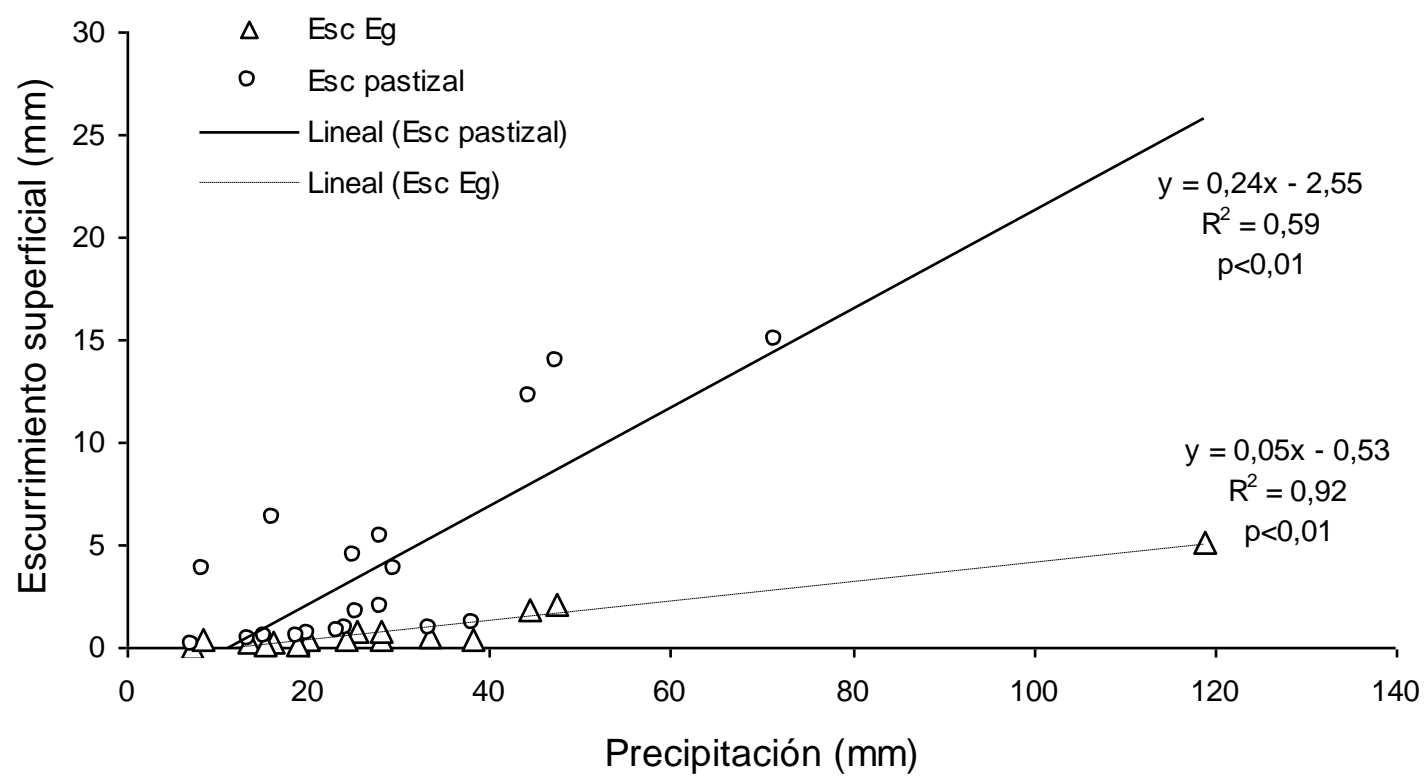

Figura 3.2.10: Relación entre el escurrimiento superficial en la plantación (Eg) y la precipitación bruta y entre el escurrimiento en el pastizal y la PB.

\subsubsection{Transpiración}

La transpiración se ve afectada por una importante cantidad de factores abióticos como las temperaturas altas y bajas, la salinidad, el estrés hídrico, el déficit de saturación del aire, la contaminación atmosférica, etc. y por factores bióticos como la forma y distribución de las hojas en la cubierta, la conductancia estomática, la conductancia de la capa límite, la del mesófilo y la cuticular (Save et al., 2005).

Con los datos obtenidos de xilema activo y diámetro de los árboles se ajustó la regresión presentada en la Figura 3.2.11.

La transpiración estimada a partir de una ecuación de regresión múltiple empleando el flujo diario medio ( $\mu, \mathrm{n}=98$ días) como variable dependiente y variables atmosféricas y edáficas como variables independientes (Tabla 3.2.2) permitió concluir que la heliofanía (HEL), y el déficit de saturación de vapor (DSV) influyeron significativamente en la transpiración, y, en cambio, no fueron significativas la acción del viento y el API para el período evaluado. 


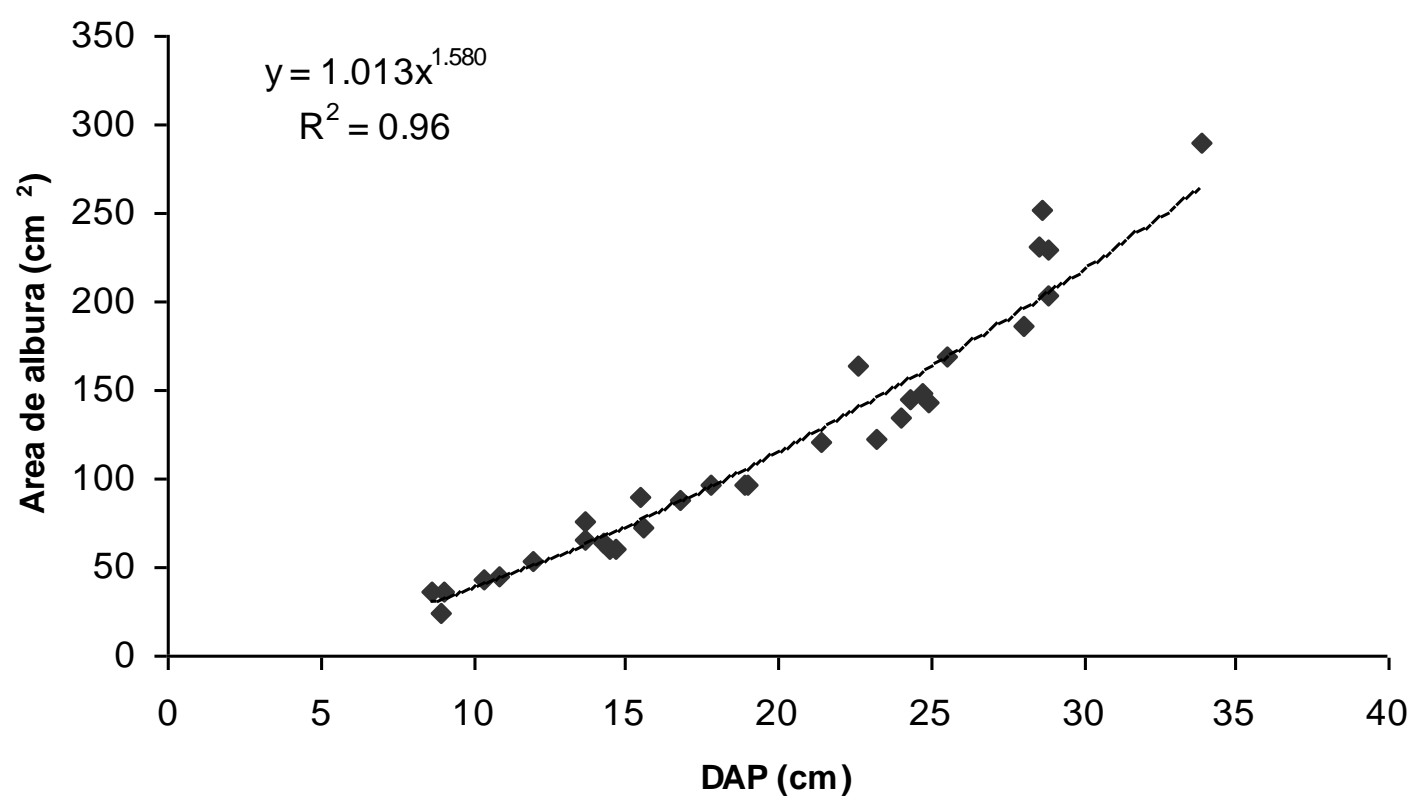

Figura 3.2.11: Relación entre la albura y el DAP (diámetro del árbol a 1,3 m)

Resumen de la Regresión múltiple para la variable independiente U

$R=0.89 \quad R^{2}=0.79 \quad R^{2}$ ajustado $=0.77$

$F(5.55)=41.54 p<.00000$ Error típico de la estimación: 0.002

$\begin{array}{cccccc}\begin{array}{c}\text { Coeficiente } \\ \text { estandarizado } \\ \text { BETA }\end{array} & \begin{array}{c}\text { Error típico } \\ \text { de BETA }\end{array} & \begin{array}{c}\text { Coeficiente no } \\ \text { estandarizado } \\ \text { B }\end{array} & \begin{array}{c}\text { Error típico } \\ \text { de B }\end{array} & \text { T } & \text { Significancia } \\ 2.865 & 0.660 & -0.000 & 0.001 & -0.209 & 0.835 \\ 1.545 & 0.244 & 0,002 & 0.010 & 4.338 & 0.000 \\ -5.544 & 1.509 & -0.067 & 0.000 & 6.328 & 0.000 \\ 2.830 & 0.928 & 0.028 & 0.018 & -3.673 & 0.000 \\ -1.072 & 0.229 & -0.000 & 0.009 & 3.049 & 0.004 \\ \end{array}$

Tabla 3.2.2: Regresión múltiple entre el flujo de savia $(\mu)$ y variables climáticas y edáficas.

La fórmula para el cálculo de $\mu\left(\mathrm{Kg}_{\text {н20 }} \cdot \mathrm{m}^{-2} \mathrm{~s}^{-1}\right)$, resultó:

$\mu\left(\mathrm{Kg}_{\mathrm{H} 2 \mathrm{O}} \mathrm{m}^{-2} \mathrm{~s}^{-1}\right)=-0.0002+0.0452 \mathrm{DSV}+0.0024 \mathrm{HEL}^{2}-0.0674(\mathrm{DSV})^{2}+0.02806(\mathrm{DSV})^{3} \mathrm{~V}-0.0002 \mathrm{HEL}^{2}$ 
La superficie del xilema activo medido en los árboles de las parcelas fue de $12.15+/-0.69 \mathrm{~m}^{2}$ /ha. El valor diario de la lámina transpirada, calculado a partir del flujo de savia y de la superficie del xilema activo, permitió calcular el valor anual de transpiración para el período 2003 - 2004 que resultó ser de 980.7 mm y para el 2004-2005 que fue de 943.6 mm. Estos valores representaron el 69 y el 75 \% de la precipitación bruta para los dos años analizados, aumentando la proporción en el año con menores precipitaciones.

Almeida et al. (2007) analizando el balance hidrológico durante 6 años en una plantación obtuvo un promedio de agua transpirada del $77 \%$ del agua precipitada, con la misma tendencia observada para los años secos. Stape (2004) obtuvo, en un gradiente de precipitaciones en plantaciones clonales de Eucalyptus grandis, valores anuales extremos de $592 \mathrm{~mm}$ y $999 \mathrm{~mm}$, observando una relación positiva entre el aumento de las precipitaciones y el aumento de la transpiración.

A pesar de que durante el estudio la humedad del suelo no fue una variable significativa en la regresión múltiple posiblemente debido a que los valores de los dos períodos analizados fueron altos, en un estudio posterior, desarrollado en el año 2008 (año en que las precipitaciones fueron la mitad de la media), se observaron importantes reducciones en la densidad de flujo de savia. En la Fig. 3.2.12 se muestra a modo de ejemplo los cambios en el flujo de savia comparando dos días con igual demanda atmosférica $(E T P=4.1)$ pero distintas condiciones en la humedad del suelo. El flujo medio diario del día con el suelo húmedo fue 3 veces el del día con el suelo seco. Esto reforzaría la idea de que las plantaciones con Eucalyptus grandis están utilizando principalmente el agua de las precipitaciones.

\subsubsection{Balance de agua de la plantación forestal}

En la Tabla 3.2.3 y las Figuras 3.2.12 y 3.2.13, se observan los valores anuales de los componentes del balance hídrico para los dos años analizados. Los ingresos corresponden a los valores de la precipitación bruta que se ha mencionado fueron de 1417 y 1265 mm, respectivamente para cada periodo anual estudiado. Las copas de los eucaliptos interceptaron entre un 11 y $12 \%$ de la PB, por lo cual la precipitación neta que llega a la 
superficie del terreno fue de 89 y $88 \%$. La mayor contribución a la PN la hizo la trascolación (94 y $96 \%$ de la PN), el resto (6 y 4\%) descendió externamente por los tallos como flujo caulinar. Las salidas gaseosas correspondieron a la suma de las intercepciones de las copas (11 y $12 \%$ de la PB) y del mantillo ( 16 y $12 \%$ de la PB), y a la transpiración, que fue la componente más importante de los egresos gaseosos ( 69 y $75 \%$ de la PB). De esos números se advierte que la evaporación desde el mantillo puede ser similar o mayor a las pérdidas desde las copas de los árboles, lo cual constituye una reducción importante del agua que puede ingresar por infiltración al suelo mineral. La fracción interceptada por el mantillo como se ha mencionado, se ha considerado que finalmente es evaporada; no obstante es posible que la fracción evaporada sea la retenida en la capa $\mathrm{F}$ del mantillo, capa del mantillo donde la materia orgánica no está descompuesta y los materiales son identificables, mientras que una fracción del agua pueda ser absorbida por raíces y micelios, y otra utilizada por organismos que habitan los materiales en estado más avanzado de descomposición de los capas más profundas del mantillo; que corresponden a la capa $\mathrm{H}$ del mantillo caracterizada por la materia orgánica parcialmente descompuesta y la capa $\mathrm{F}$ del mantillo, con la materia orgánica totalmente descompuesta y no identificable (Fig. 3.2.13).

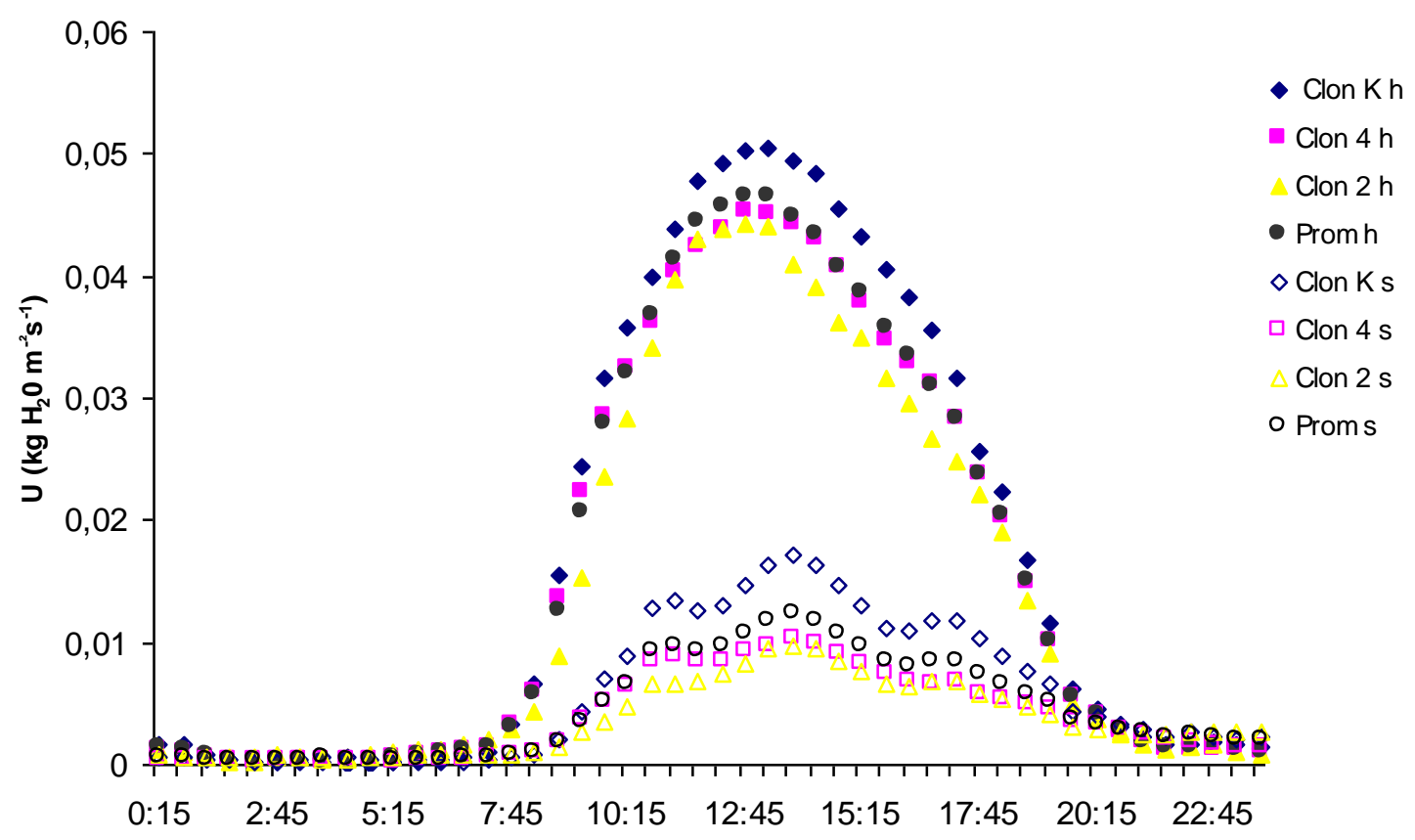

Figura 3.2.12: Valores de densidad de flujo de savia medidos en dos fechas con igual ETP ( $4.1 \mathrm{~mm} /$ día), una con suelo húmedo (h) y, otra, en condiciones de sequía (s) en los clones $\mathrm{K}, 4$ y 2 de Eucalyptus grandis. Corresponde a los días $18 / 10 / 2008$ y $22 / 12 / 2008$, respectivamente. 


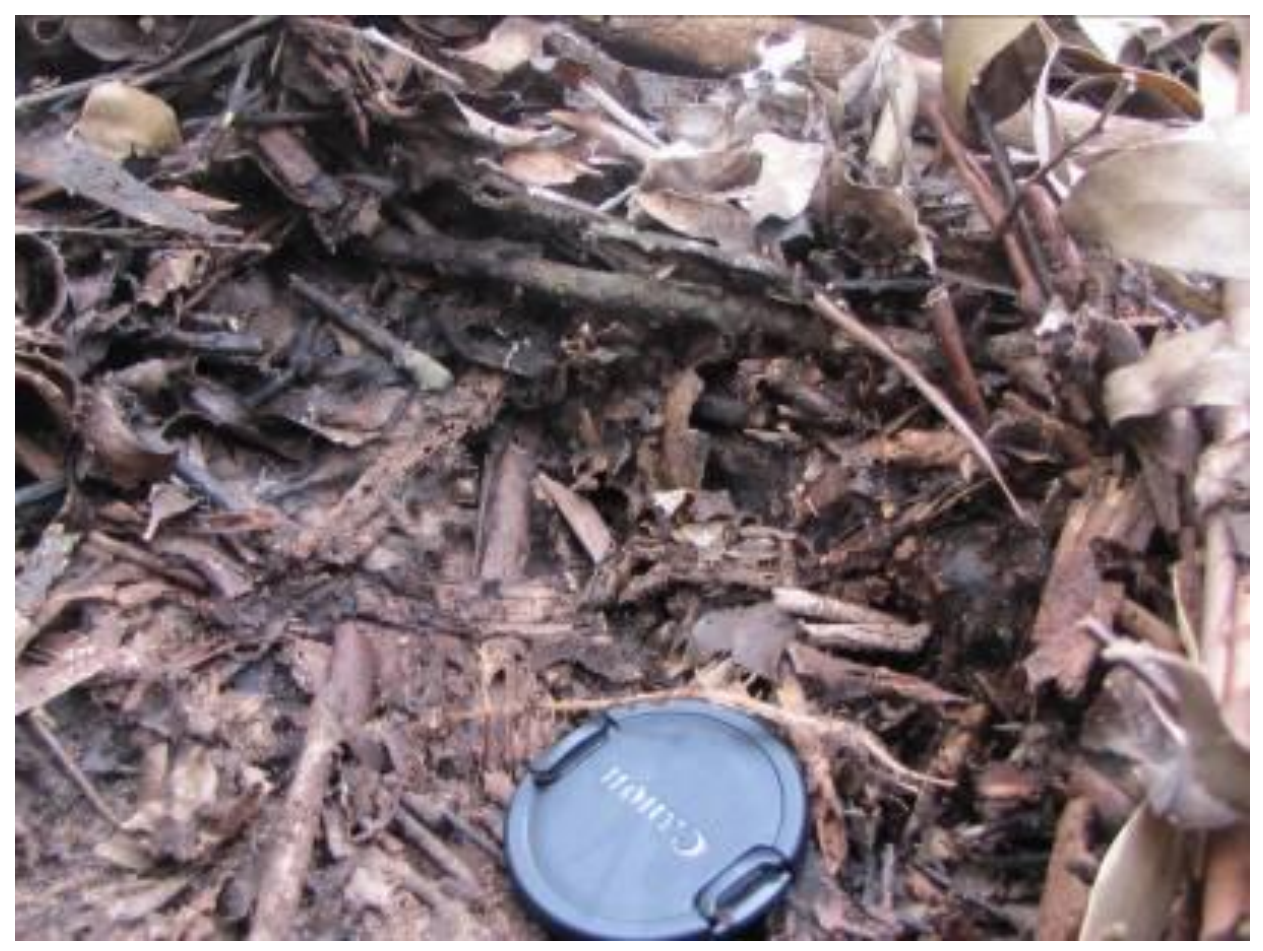

Figura 3.2.13: Hifas y raíces finas de los árboles presentes en condiciones de alta humedad desarrollándose en el mantillo.

Como resultado de éstas vías de flujo del agua en el mantillo, es posible que parte del agua interceptada en el mantillo sirva a procesos biológicos previo a evaporarse y también sea trasladada al interior de las plantas vía raíces y micorrizas participando de distintos procesos incluido el transpiratorio. El resultado final de esto es que el agua que ingresa infiltrando la superficie superior del suelo mineral es inferior a la precipitación neta. Asimismo la absorción de agua desde el suelo para satisfacer la demanda transpiratoria de los árboles fue la mayor proporción (95 y 98\%) del agua infiltrada, lo que determinó que finalmente el agua de percolación que se pudo aportar al subsuelo y las napas subterráneas resultara muy limitada (4 y $1 \%$ de la PB). En el cálculo del balance hídrico, el escurrimiento superficial, se ha considerado que representa tanto una entrada como una salida de agua líquida, dado que debido al relieve con suave pendiente del sitio puede esperarse que eso ocurra el terreno, lo que determina, en éstos periodos, un efecto neutro sobre el balance de agua. 


\begin{tabular}{lrrrr}
\hline & \multicolumn{3}{c}{ Lámina (mm) } & \multicolumn{2}{c}{ \% de PB } \\
\cline { 2 - 5 } Flujos & $2003-2004$ & $2004-2005$ & $2003-2004$ & 2004-2005 \\
\hline Precipitación Bruta & 1417 & 1265 & & \\
Flujo caulinar & 73 & 48 & 5.2 & 3.8 \\
Trascolación & 1192 & 1065 & 84.1 & 84.2 \\
Precipitación Neta & 1265 & 1113 & 89.3 & 88.0 \\
Intercepción copas & 152 & 153 & 10.7 & 12.1 \\
Transpiración & 981 & 944 & 69.2 & 74.6 \\
Intercepción mantillo & 232 & 152 & 16.4 & 12.0 \\
Evapotranspiración & 1365 & 1249 & 96.3 & 98.8 \\
Percolación & 52 & 16 & 3.7 & 1.2 \\
\hline
\end{tabular}

Tabla 3.2.3: Valores anuales de los componentes del balance hídrico para los dos años analizados

En síntesis el balance hidrológico fue positivo en los dos años, muy ajustado a las precipitaciones, ya que el cociente ET/PB fue 0.96 y 0.99 para los años evaluados. Almeida et al. (2007), para el estudio mencionado anteriormente en el punto 3.2.8, reportan un valor promedio para este cociente de 0.95 con valores extremos de 0.77 y 1.21 , correspondiendo los valores extremos mayores a los años secos. Para Concordia, esto sugiere que en años de menores precipitaciones que las registradas en los periodos estudiados, es de esperar, dado el comportamiento fisiológico de la especie, que pueda haber un balance hidrológico negativo ( $\mathrm{PB}<$ (Evapotranspiración + Rendimiento de agua)) donde la plantación puede sostener su crecimiento en base a su alta capacidad de obtención de agua del suelo y, en casos de sequía extrema, con reducción drástica de la transpiración y del crecimiento de la especie forestal ya que la misma no parece poder aprovechar una fracción significativa del agua profunda. 


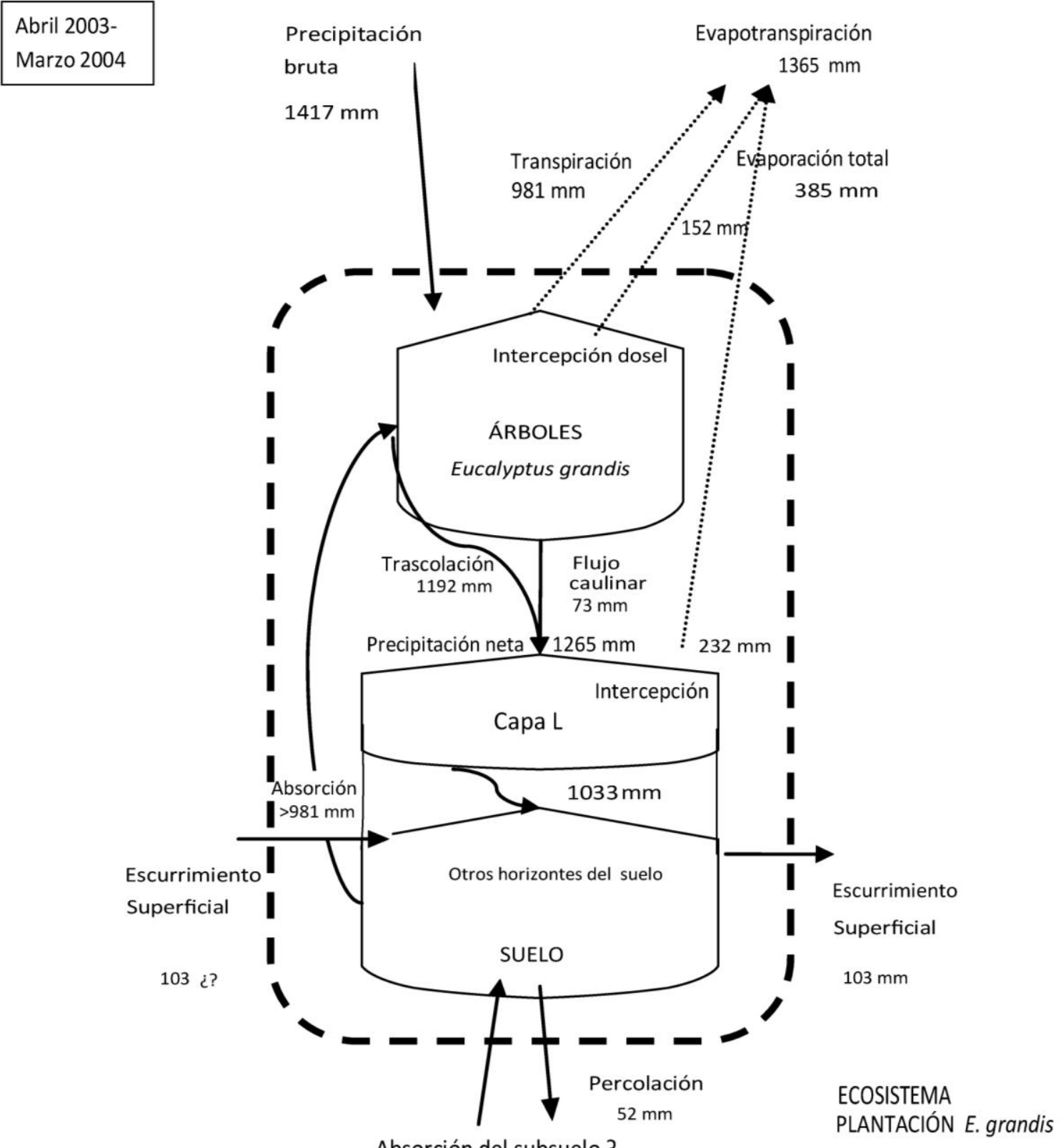

Absorción del subsuelo ?

Figura 3.2.14: Flujos hídricos período abril 2003 - marzo 2004. 


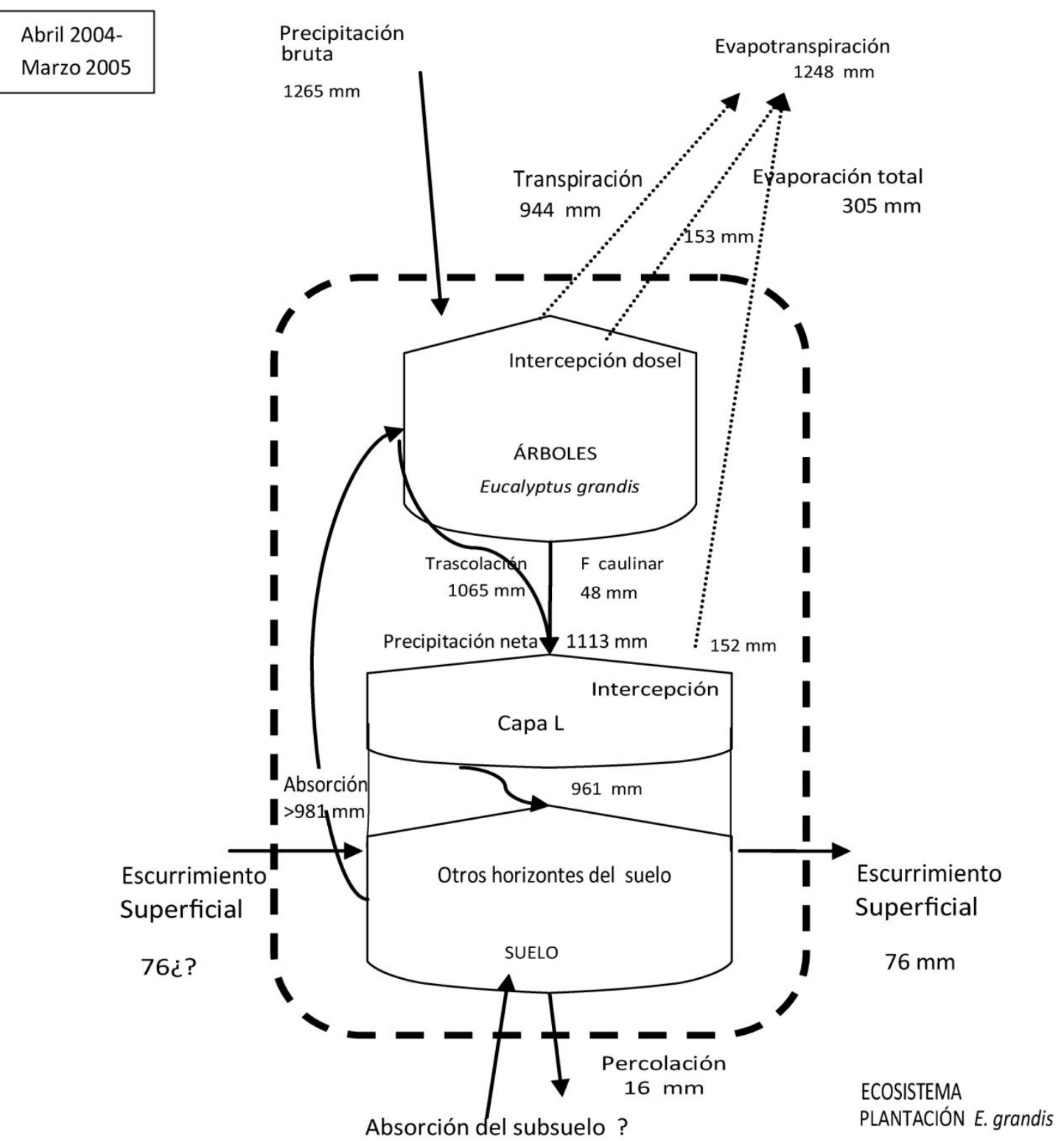

Figura 3.2.15: Flujos hídricos período abril 2004 - marzo 2005 


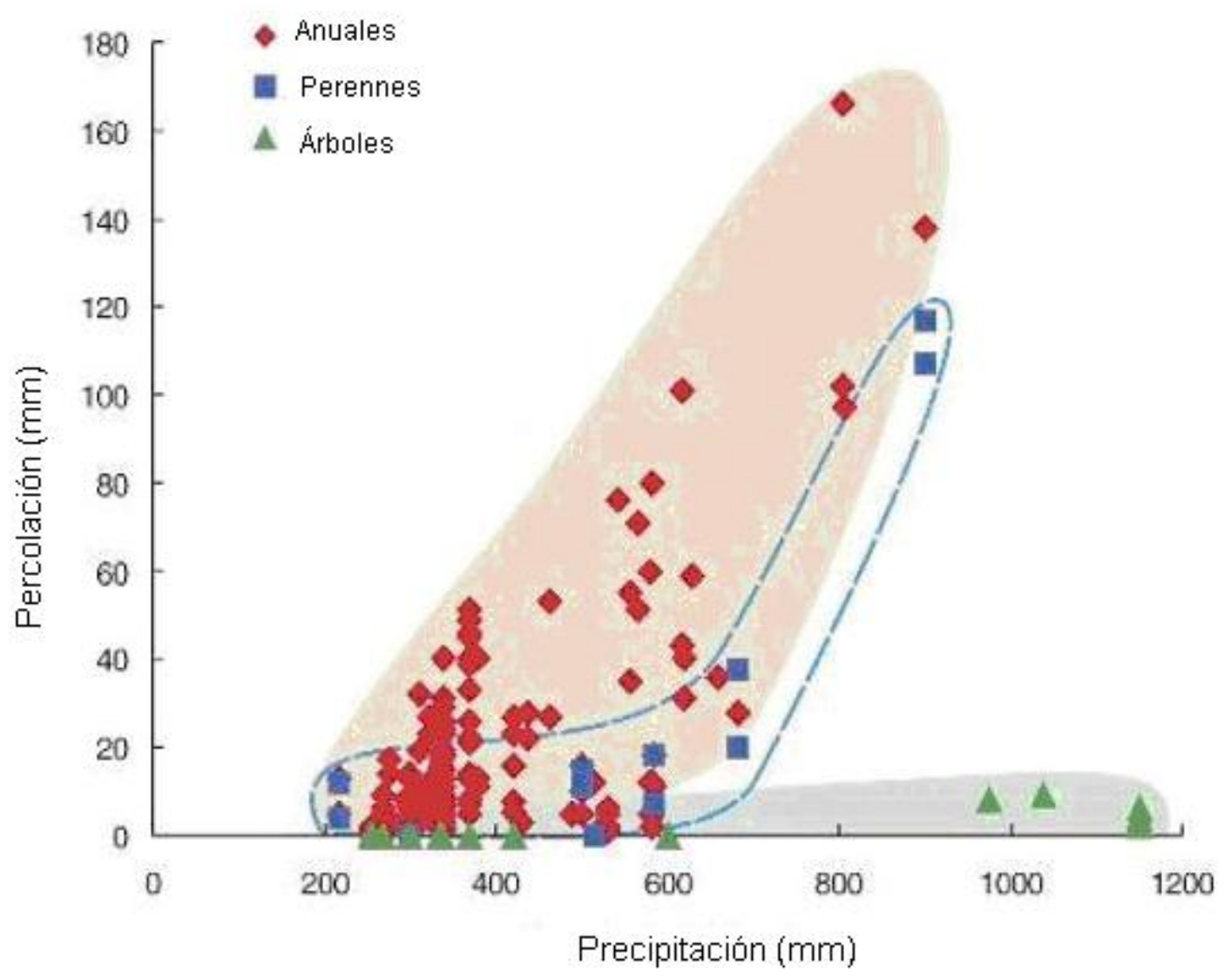

Figura 3.2.16: Comparación de fuga profunda de agua (leakage) bajo diferentes tipos de vegetación. Generalmente el leakage es mayor bajo vegetación anual, intermedio bajo vegetación perenne y más bajo debajo de los árboles. La diferencia aumenta cuando se incrementan las precipitaciones. Fuente Walter et al. (1999).

\subsection{Producción y Eficiencia Hídrica}

\subsubsection{Crecimiento, producción, eficiencia en el uso y la captura de agua de la plantación}

Los resultados obtenidos de producción primaria aérea neta (ANPP), eficiencia en el uso de agua (WUE) y eficiencia en la captación de agua de este estudio se presentan en la Tabla 3.3.1.

La eficiencia en el uso de agua (WUE) fue mayor, 3.4 vs $3.1 \mathrm{Kg} \mathrm{MS} \mathrm{m}^{-3}$ en el año con mayores precipitaciones de los dos estudiados. Mientras que la eficiencia en la captura de agua aumentó con la reducción de las precipitaciones. 
Stape et al. (2004) ajustaron una regresión que vincula la WUE y la transpiración para un gradiente geográfico en el noreste de Brasil para plantaciones al turno, la misma se presenta en la Figura 3.3.1.

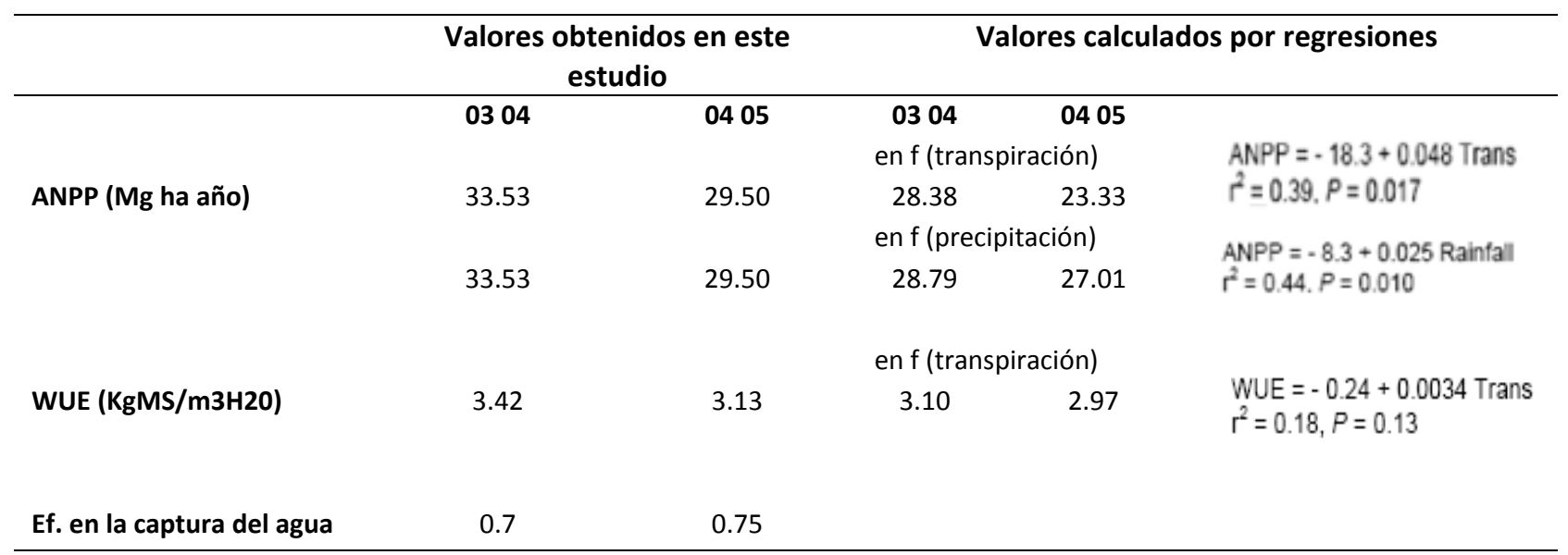

Tabla 3.3.1: Valores de Producción Primaria Neta Aérea (ANPP; Tn/ha), eficiencia en el uso del agua (WUE; Kg MS $\mathrm{m}^{-3}$ ) y eficiencia en la captura, medidas y estimados, para los dos períodos estudiados.

A fines comparativos se utilizaron las regresiones obtenidas por dichos autores en Brasil para plantaciones de Eucalyptus grandis X E. urophylla para estimar la ANPP y la WUE en función de las precipitaciones y la transpiración (Tabla 3.3.1).

Comparando los valores obtenidos de este estudio con la regresión desarrollada por Stape et al. (2004), los valores de eficiencia en el uso de agua anuales vs transpiración anual se hallan en el intervalo de confianza del 95 por ciento (Figura 3.3.1). 


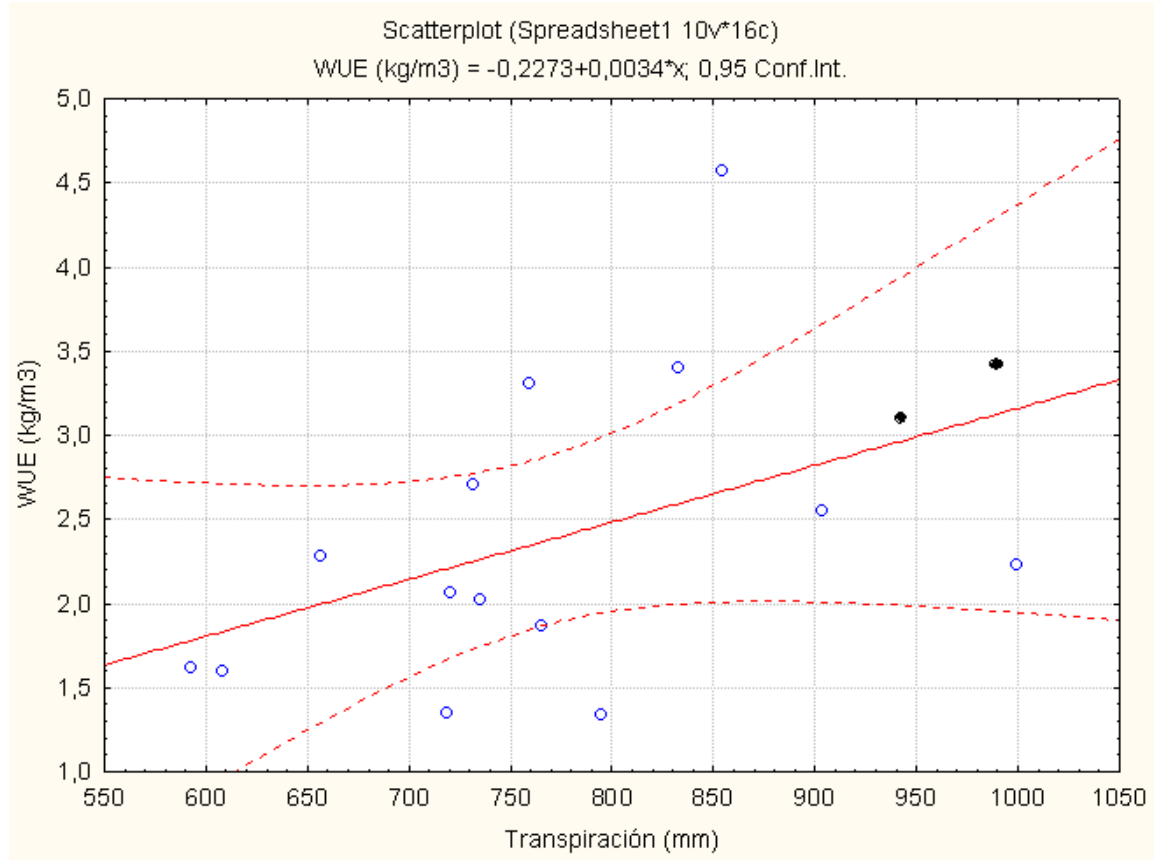

Figura 3.3.1: Regresión e intervalos de confianza del $95 \%$ entre la transpiración y la eficiencia en el uso del agua. Realizada con los datos de la tesis doctoral de Stape, 2001 y los resultados de este estudio (puntos rellenos).

Cabe destacar que no se ha medido la eficiencia instantánea en el uso del agua y que el cálculo de la WUE, tanto en el presente estudio como en los trabajos de Stape (2002, 2004), se realizó considerando la producción primaria neta y no sobre la producción primaria total.

En su estudio Stape (2002) propone que el incremento en la WUE se debió al incremento en la asimilación de carbono mediante la fotosíntesis y a cambios en la partición de carbono, en la relación biomasa subterránea/ biomasa aérea en los distintos sitios. A lo largo de la transecta estudiada, Stape (2002) encontró que la PB y el DSV estaban inversamente correlacionados, con los valores más bajos de DSV en los sitios más productivos y húmedos; también observó una relación inversa entre DSV promedio y la WUE. Esta relación también fue observada por otros autores como Lindroth y Cienciala (1996; en Stape, 2002) a nivel de hoja, árbol y plantación. El incremento en la conductancia estomática, por la disminución del déficit de agua en el suelo y el DSV, y las tasas más altas de fijación de $\mathrm{CO}_{2}$ en los sitios más productivos condujo a incrementar no solo la WUE, sino también la eficiencia en el uso de la luz y la eficiencia en el uso del nitrógeno. Respecto a la partición biomasa subterránea/biomasa aérea en su estudio esta relación bajaba significativamente en los sitios más productivos. 
Stape (2002) calculó además la eficiencia de respuesta del agua y para aumentar el rango del alcance de sus estudios incluyó una parcela de la zona de Amazonia donde las precipitaciones eran de $2500 \mathrm{~mm}$ anuales. Encontrando que la lluvia de máxima eficiencia de respuesta era de $1360 \mathrm{~mm}$ anuales.

En otro estudio realizado por Dye et al. (2001) en plantaciones de Eucalyptus grandis y Pinus patula, en Sudáfrica, cubriendo un amplio rango de condiciones edáficas y climáticas, encontraron una amplia variabilidad de la WUE, (calculada como la relación entre la biomasa del tronco y el agua transpirada). Los sitios con sequía mostraban menores valores de WUE, atribuyendo esta reducción a la alteración del patrón de partición de carbono en los árboles estresados, resultando en una mayor proporción de asimilados hacia las raíces a expensas del tronco.

En otro estudio realizado por Stape et al. (2004b) en una plantación de Eucalyptus grandis $x$ urophylla en el que se evaluó la eficiencia en el uso de agua durante dos años con y sin irrigación encontraron aumentos de la eficiencia con el aumento del uso del agua, en los lotes irrigados en los dos años.

En cuanto a la independencia del crecimiento y las precipitaciones, en contraste con lo planteado por Stape (2004), Dye (1995) en un estudio realizado en Sudáfrica en el que impedía la recarga de agua del suelo con una cubierta plástica colocada en la superficie, no encontró disminución en el uso de agua del E. grandis, ni en el crecimiento en volumen, ni en el área foliar, como respuesta a la menor disponibilidad de agua en el suelo. Concluyendo que el déficit de agua en el suelo no causó estrés severo en los sitios estudiados y que la falta de respuesta de los árboles al estrés impuesto podía ser atribuida a que los árboles son capaces de extraer el agua a profundidades superiores al menos de $8 \mathrm{~m}$. Encontrando, en el sitio de 10 años, raíces a una profundidad de $28 \mathrm{~m}$. Esta conclusión independizaría el crecimiento de las plantaciones de la precipitación. Sin embargo, esta conclusión no concuerda con lo demostrado por Stape (2002) quién encuentra una relación directa entre el uso de agua de las plantaciones, las precipitaciones y el crecimiento. Coincidentemente con Stape (I.c.) existen antecedentes locales de relaciones entre la precipitación y el crecimiento obtenidas por Dalla Tea (2008). Coincidentemente con lo observado por Stape (2002) y Dalla Tea (2008), en mediciones posteriores realizadas en el Sitio III de este estudio, para un período de sequía y un período húmedo, se observó una relación estrecha entre el 
crecimiento y las precipitaciones y la humedad en el suelo (Figuras 3.3.2 a 3.3.4). Esto sugiere que para nuestro sitio de estudio, el agua es una limitante para el crecimiento y que su principal fuente de abastecimiento serían las precipitaciones, no observándose independencia entre las precipitaciones y el crecimiento, como lo observado en el sitio estudiado por Dye (1995).

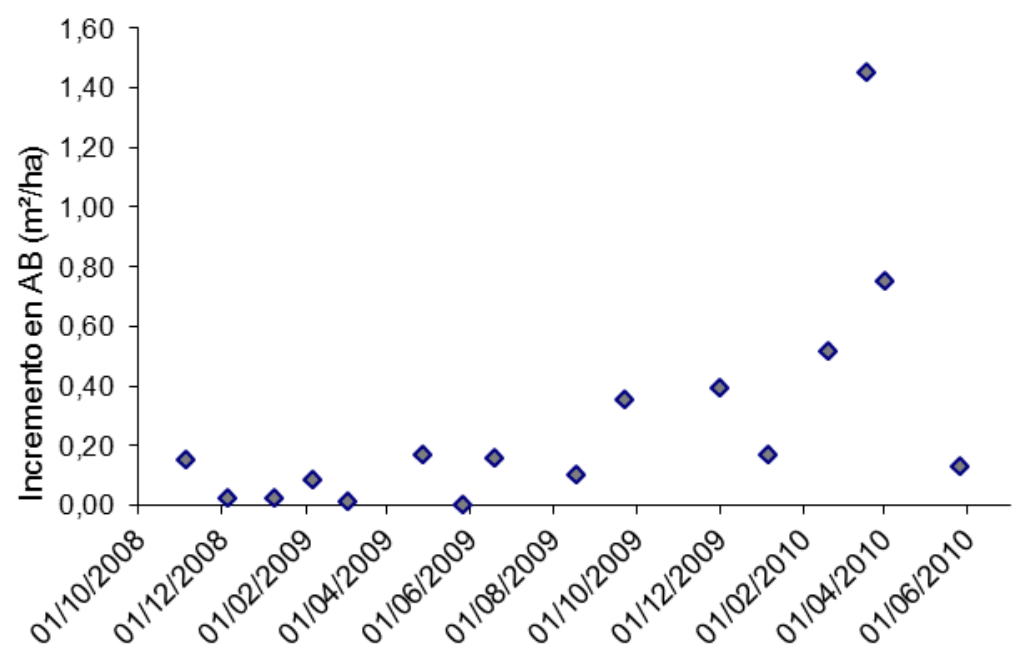

Figura 3.3.2: Crecimiento en Área basal ( $\left.\mathrm{m}^{2} / \mathrm{ha}\right)$ del Sitio III.

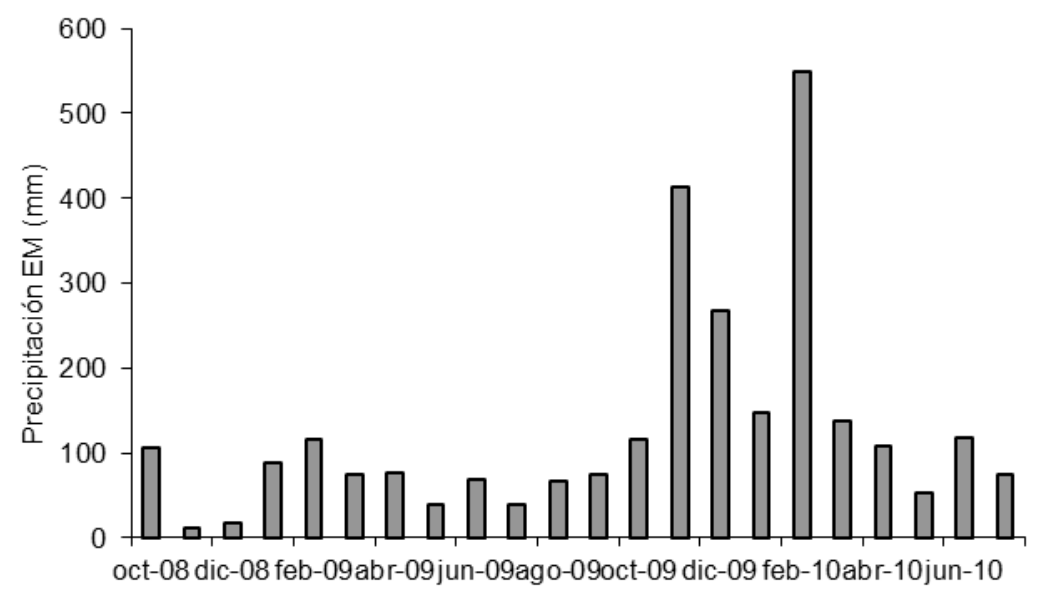

Figura 3.3.3: Precipitaciones mensuales Estación Meteorológica Concordia (EM). 


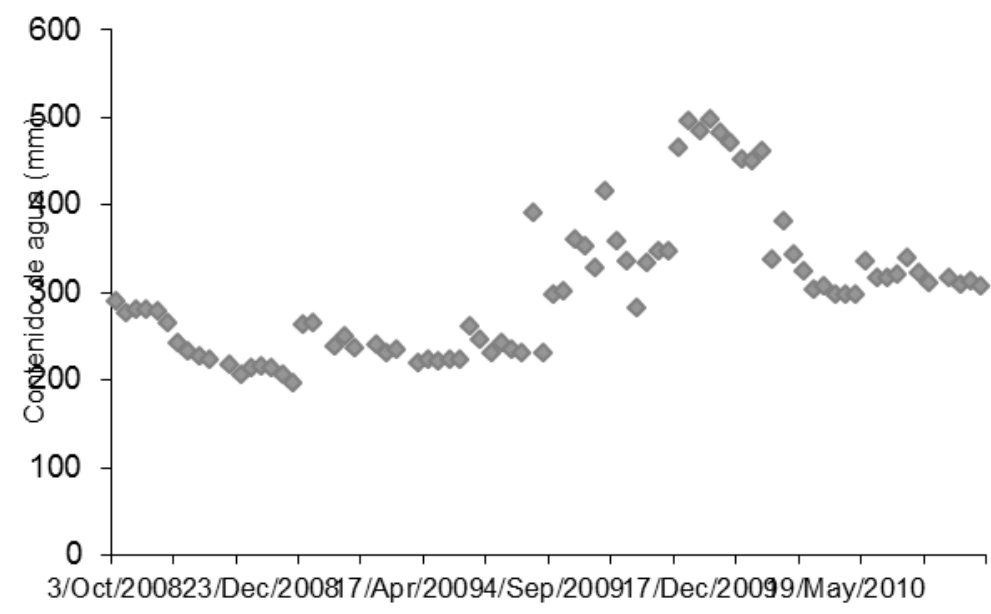

Figura 3.3.4: Contenido de agua en el suelo hasta los $160 \mathrm{~cm}$ de profundidad

Considerando que la WUE aumentó con la disponibilidad de agua (ANPP/T), es posible plantearse otros esquemas de manejo de las plantaciones que sean más eficientes en el uso de este recurso. Entre ellos, el manejo de la densidad de plantación o la planificación de raleos podrían contribuir a una mayor eficiencia al disponer los árboles individualmente de más agua. Por otra parte, podría existir menos competencia por el recurso postergándose el inicio del estrés hídrico. 


\section{4 Ciclos de Nutrientes}

Como se destacara en la Introducción, los ciclos de nutrientes en bosques y plantaciones forestales requieren tener en cuenta la concentración y contenido de elementos químicos en la biomasa, la necromasa y el suelo pero también su concentración y circulación en flujos de los ciclos bioquímicos, biogeoquímicos y geoquímicos. A continuación se informan los resultados correspondientes al periodo abril de 2004 a marzo de 2005, los que incluyen las concentraciones y los contenidos de nutrientes en las vías de agua de ingreso, circulación interna y salida de los ecosistemas forestales en el Sitio III que forman parte de los ciclos biogeoquímicos y geoquímicos.

\subsubsection{Concentración de nutrientes en los flujos hídricos y su relación con la magnitud de los eventos de precipitación bruta}

Un análisis de las concentraciones de nutrientes en los flujos hídricos a nivel del dosel arbóreo o aéreos (precipitación bruta -PB-, trascolación -T- y flujo caulinar -FC-) en relación a eventos de precipitación bruta individuales, o de eventos muy próximos ocurridos en intervalos breves de distinta intensidad, permitió advertir un conjunto de detalles (Fig. 3.3.1 a 3.3.8). Se verificó que, en general, los valores extremos más altos de concentraciones en los flujos de agua correspondieron a eventos de PB de baja magnitud; asimismo, el conjunto de eventos de baja magnitud presentó el mayor rango de variabilidad en las concentraciones de nutrientes en la PB, T y FC. En la mayoría de los casos, la concentración de los nutrientes considerados se mantuvo más o menos constante por encima de cierta intensidad de flujo de agua (>30 mm en la precipitación bruta, > $40 \mathrm{~mm}$ en la trascolación, y $>1.5 \mathrm{~mm}$ en el flujo caulinar)

A pesar de que las figuras 3.4 .1 a 3.4 .8 sugieren cierta tendencia a la disminución de las concentraciones con el aumento de la magnitud de los eventos de la PB, y en consecuencia de los eventos de los flujos hídricos dependientes ( $T, F C$ ), solo algunas de esas relaciones 
fueron significativas. En la precipitación bruta, solo el decrecimiento de la concentración del Ca, COD y las formas de $N$, en relación con el incremento de la $P B$, fue significativo $(p<0,05)$. En el FC y $\mathrm{T}$, solo las concentraciones de $\mathrm{K}$ y COD decrecieron significativamente con el aumento de la magnitud de los eventos de PB. Considerando cada nutriente, solo el COD mostró una tendencia significativa decreciente de concentración vs flujo de agua para los tres flujos aéreos ( $\mathrm{PB}, \mathrm{FC}$ y $\mathrm{T}$ ); en tanto el $\mathrm{P}$ y el $\mathrm{Mg}$ no mostraron relación significativa para ninguno de los tres flujos hídricos mencionados.

Las amplias variaciones de concentración de nutrientes observadas durante los eventos hídricos de escasa magnitud en la PB, el FC y la T, se deberían en parte a la duración y características atmosféricas del periodo sin lluvias previo a cada evento de precipitación que afectan la disponibilidad y acumulación de materiales en la atmósfera y sobre los vegetales, como al estado de las superficies de éstos, pasibles de ser arrastrados en solución por el agua de la lluvia posterior; como también a las condiciones atmosféricas (temperatura, déficit de saturación, viento) durante eventos de escasa magnitud que afecten su concentración.

Para la forma nitrito, la concentración media en los flujos aéreos (PB, T y FC) estuvo por debajo del límite de detección del método (5 ug/l), por lo cual esta forma fue asumida como nula considerando que esta decisión no afecta los objetivos de este estudio.

Los resultados de analizar los cambios de concentración de nutrientes en el escurrimiento superficial (ES) y en el lixiviado del mantillo (LM) en relación a la magnitud de la PB muestran que como en las relaciones entre los flujos aéreos los valores extremos más altos de concentración ocurren en eventos de lluvias de baja magnitud, de igual manera durante eventos de lluvia de baja magnitud se observó el mayor rango de variabilidad en el ES y en el LM. 


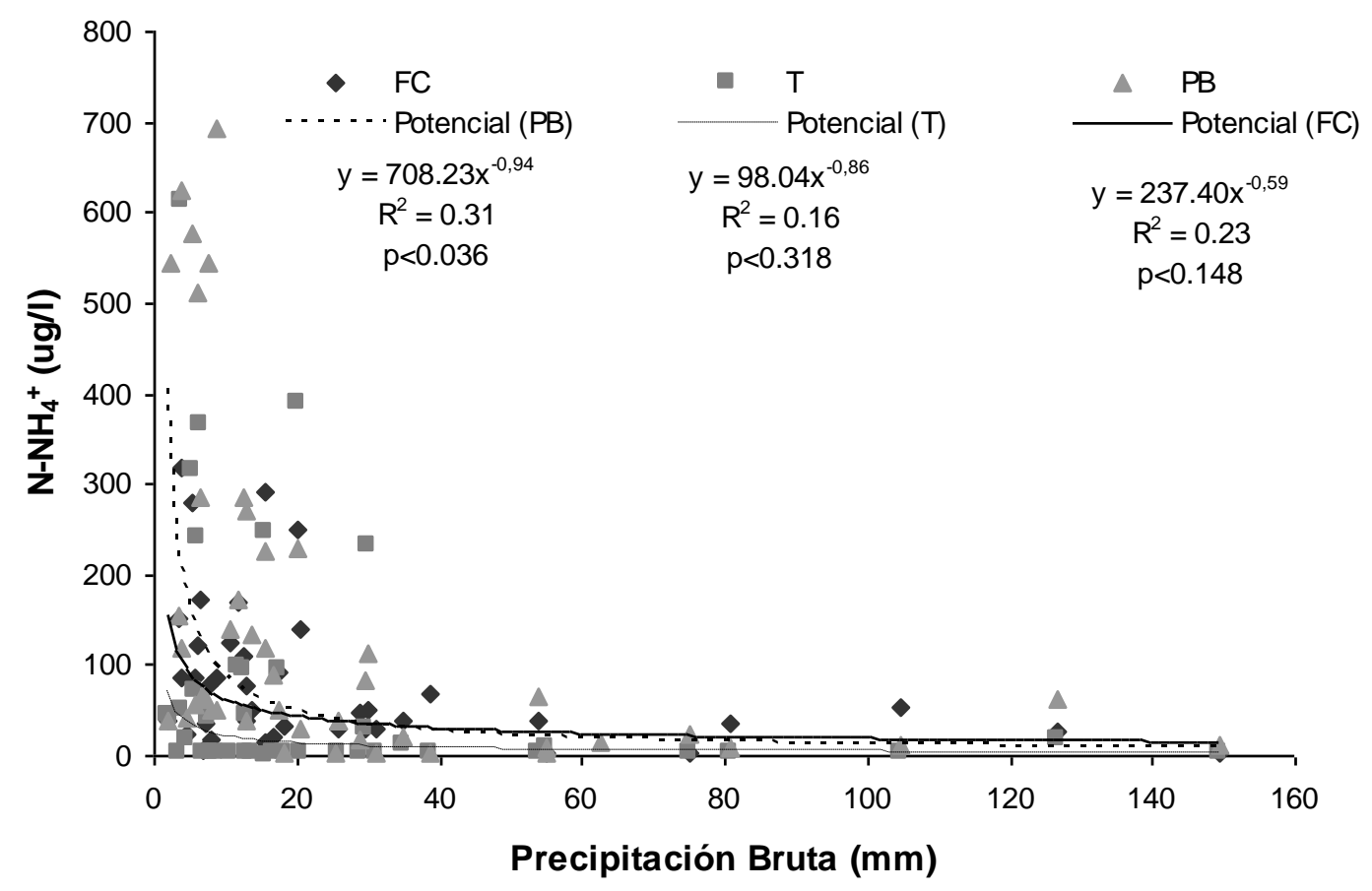

Figura 3.4.1: Concentración de amonio en los flujos hídricos aéreos ( $F C=$ flujo caulinar; $T=$ trascolación; $P B=$ precipitación bruta) en relación a la precipitación bruta.

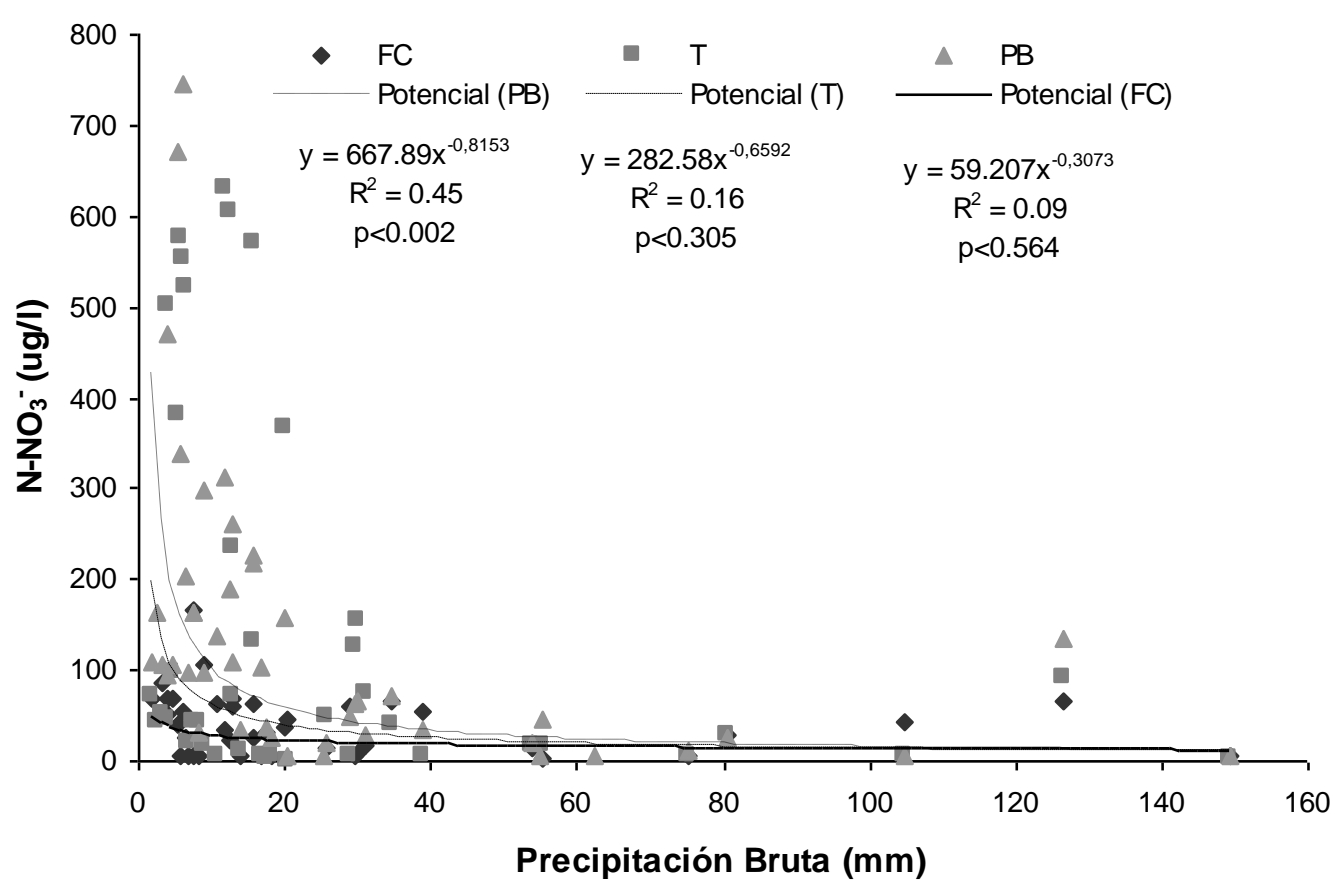

Figura 3.4.2: Concentración de nitrato en los flujos hídricos aéreos $(\mathrm{FC}=$ flujo caulinar; $\mathrm{T}=$ trascolación; $\mathrm{PB}=$ precipitación bruta) en relación a la precipitación bruta (mm). 


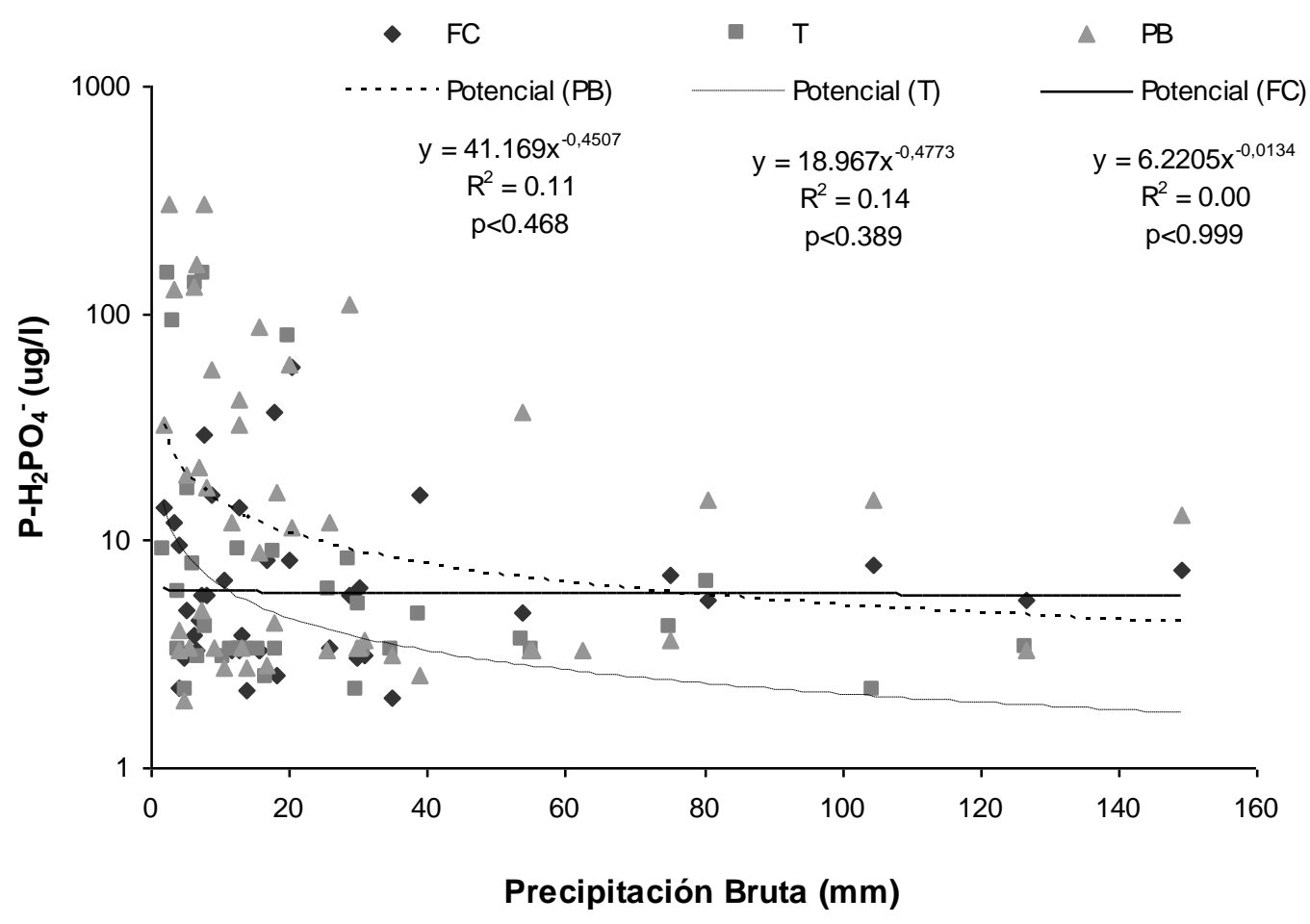

Figura 3.4.3: Concentración de fósforo en los flujos hídricos aéreos ( $F C=$ flujo caulinar; $T=$ trascolación; $P B=$ precipitación bruta) en relación a la precipitación bruta $(\mathrm{mm})$.

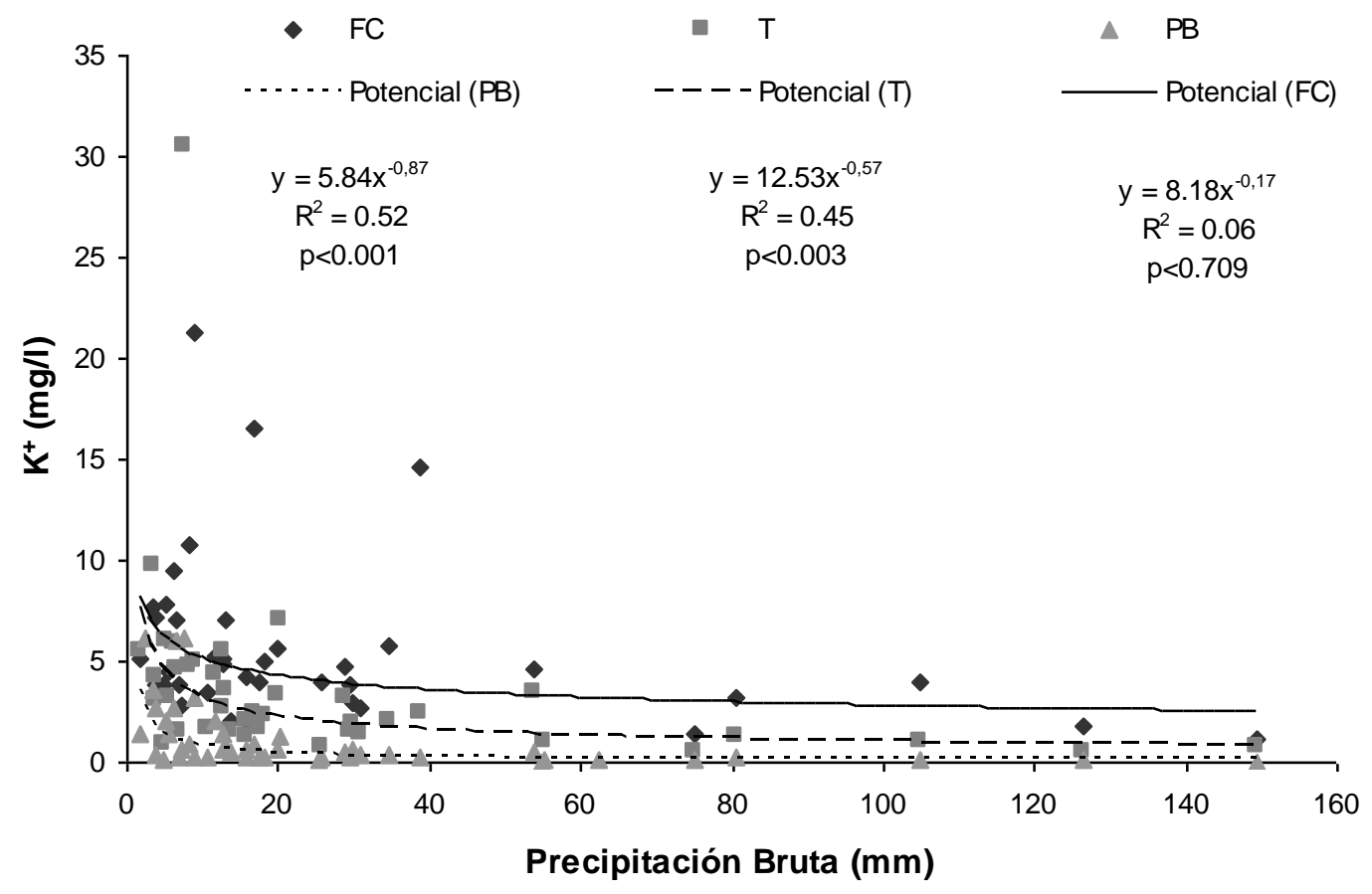

Figura 3.4.4: Concentración de potasio en los flujos hídricos aéreos ( $F C=$ flujo caulinar; $T=$ trascolación; $P B=$ precipitación bruta) en relación a la precipitación bruta $(\mathrm{mm})$. 


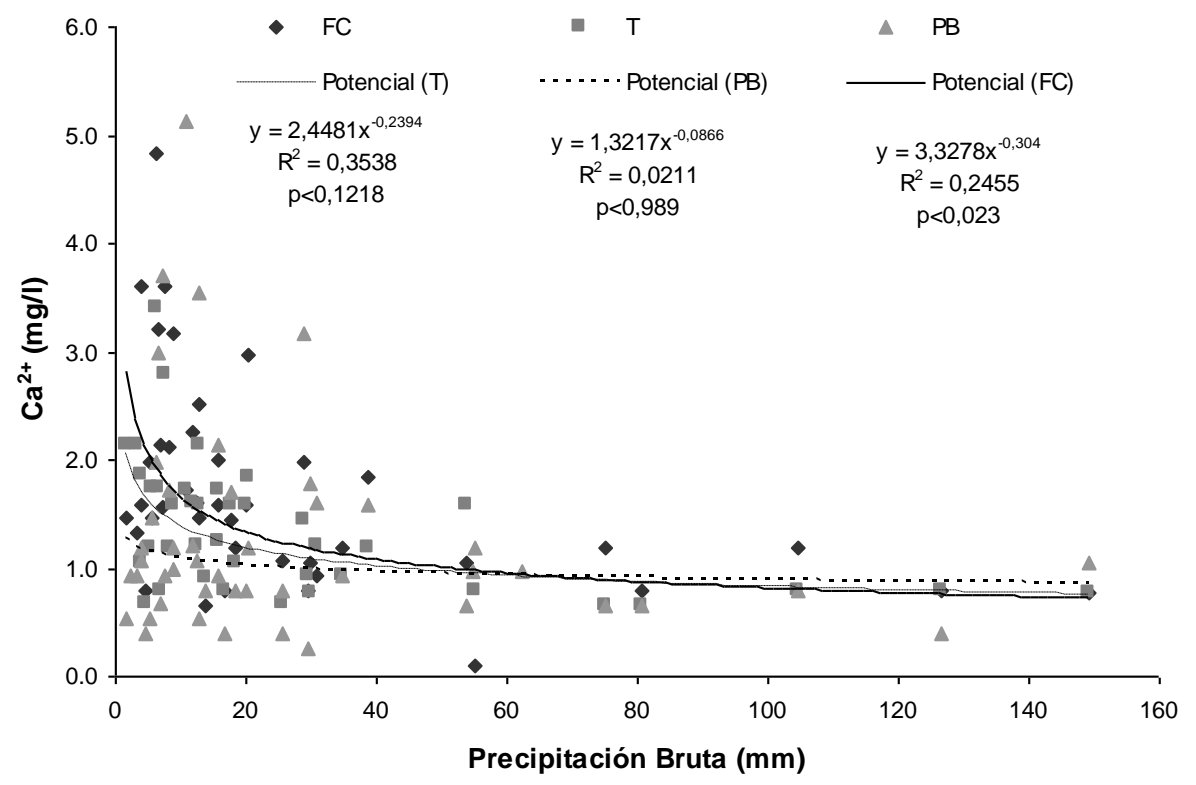

Figura 3.4.5: Concentración de calcio en los flujos hídricos aéreos ( $\mathrm{FC}=$ flujo caulinar; $\mathrm{T}=$ trascolación; $\mathrm{PB}=$ precipitación bruta) en relación a la precipitación bruta $(\mathrm{mm})$.

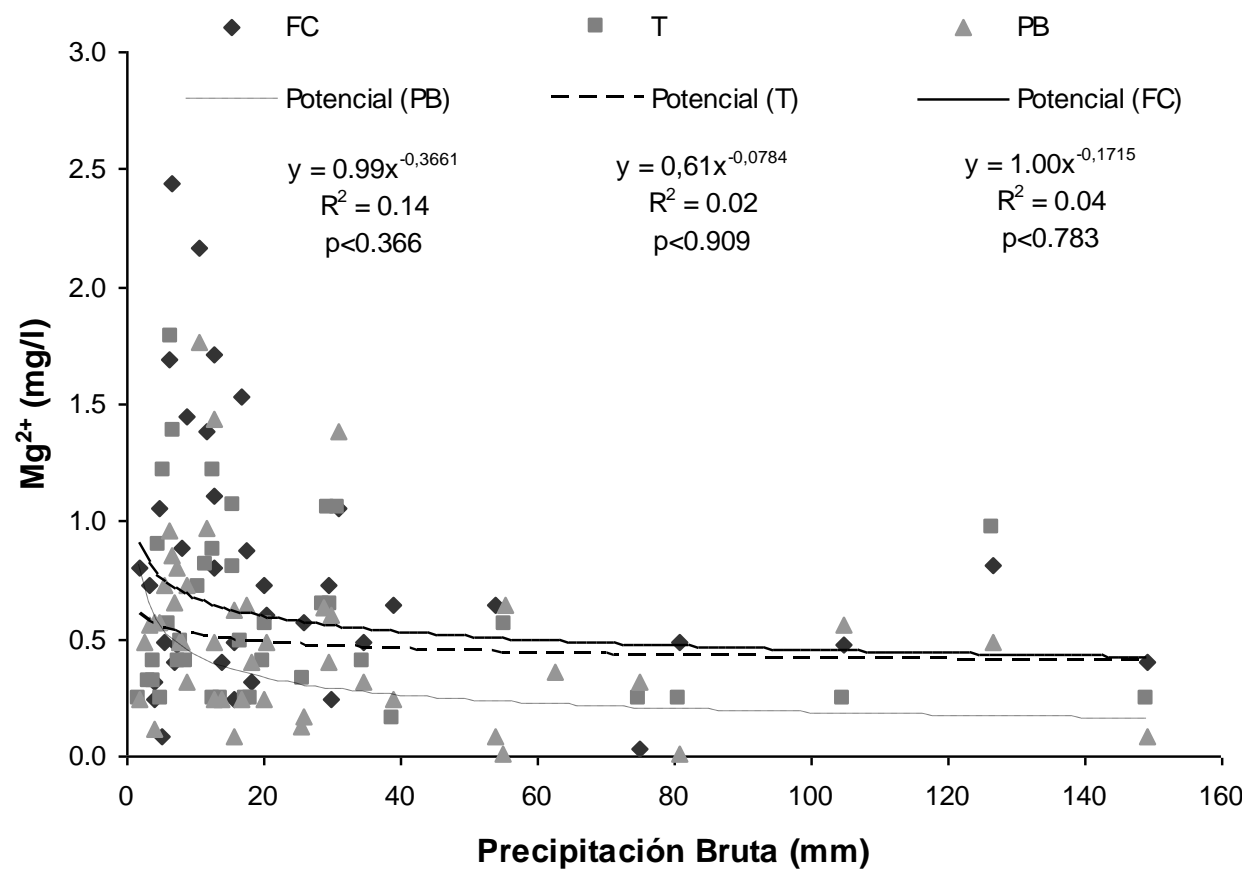

Figura 3.4.6: Concentración de magnesio en los flujos hídricos aéreos ( $F C=$ flujo caulinar; $\mathrm{T}=$ trascolación; $\mathrm{PB}=$ precipitación bruta) en relación a la precipitación bruta $(\mathrm{mm})$. 


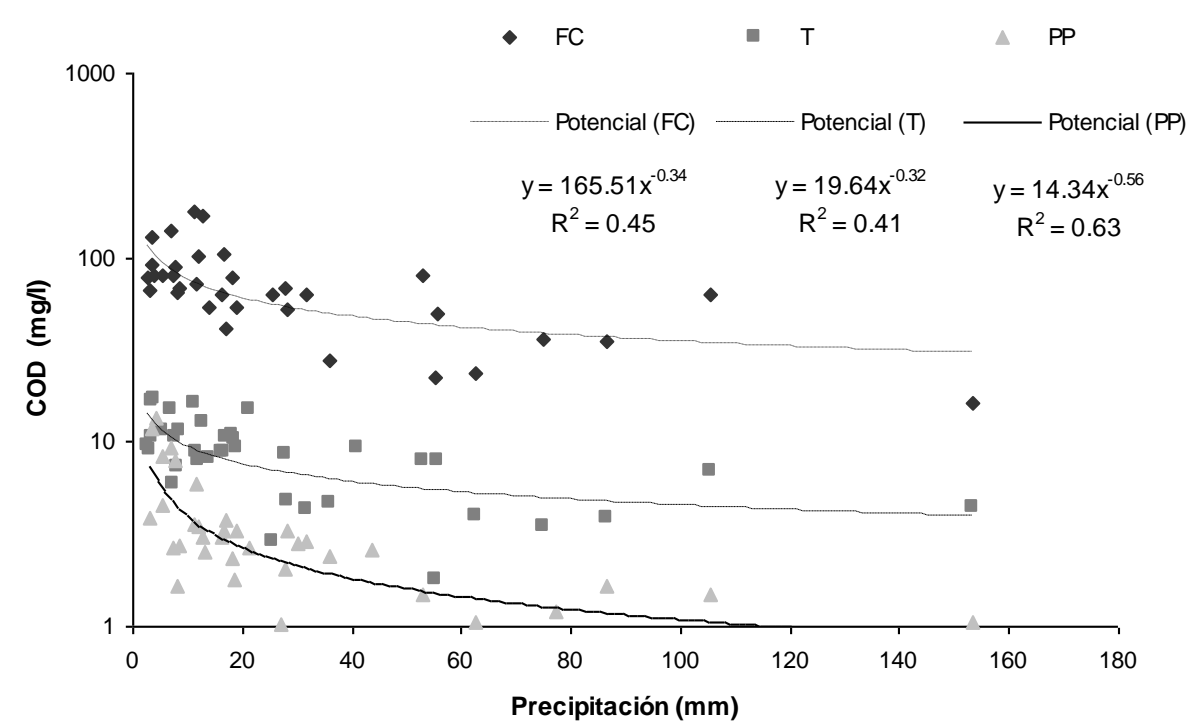

Figura 3.4.7: Concentración de carbono orgánico disuelto en los flujos hídricos aéreos (FC= flujo caulinar; $T=$ trascolación; $\mathrm{PB}=$ precipitación bruta) en relación a I la precipitación bruta $(\mathrm{mm})$. 

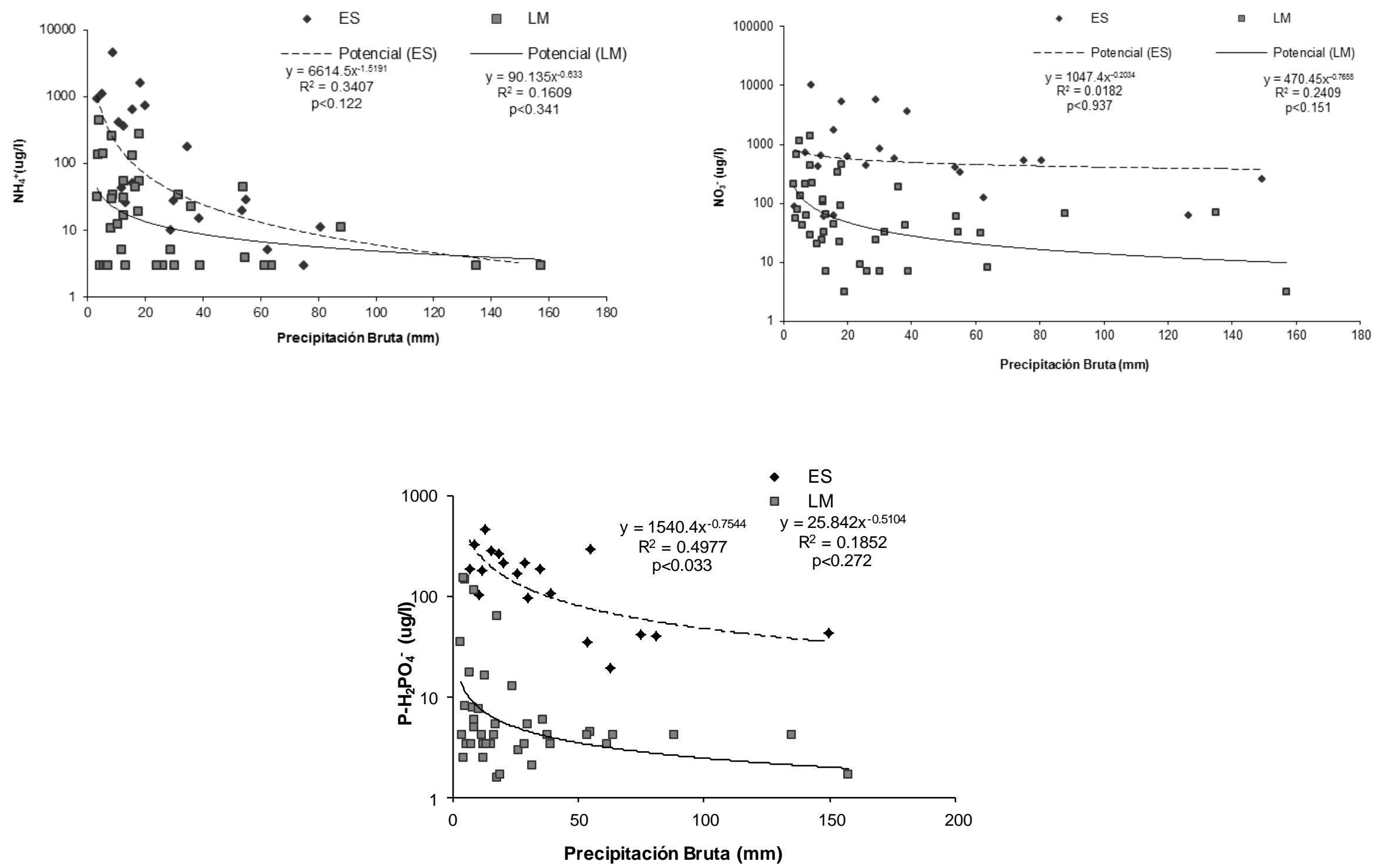

Figura 3.4.8: Concentraciones de amonio, nitrato y fosfato vs. Precipitación Bruta (PB) en el escurrimiento superficial y en el lixiviado del mantillo. 

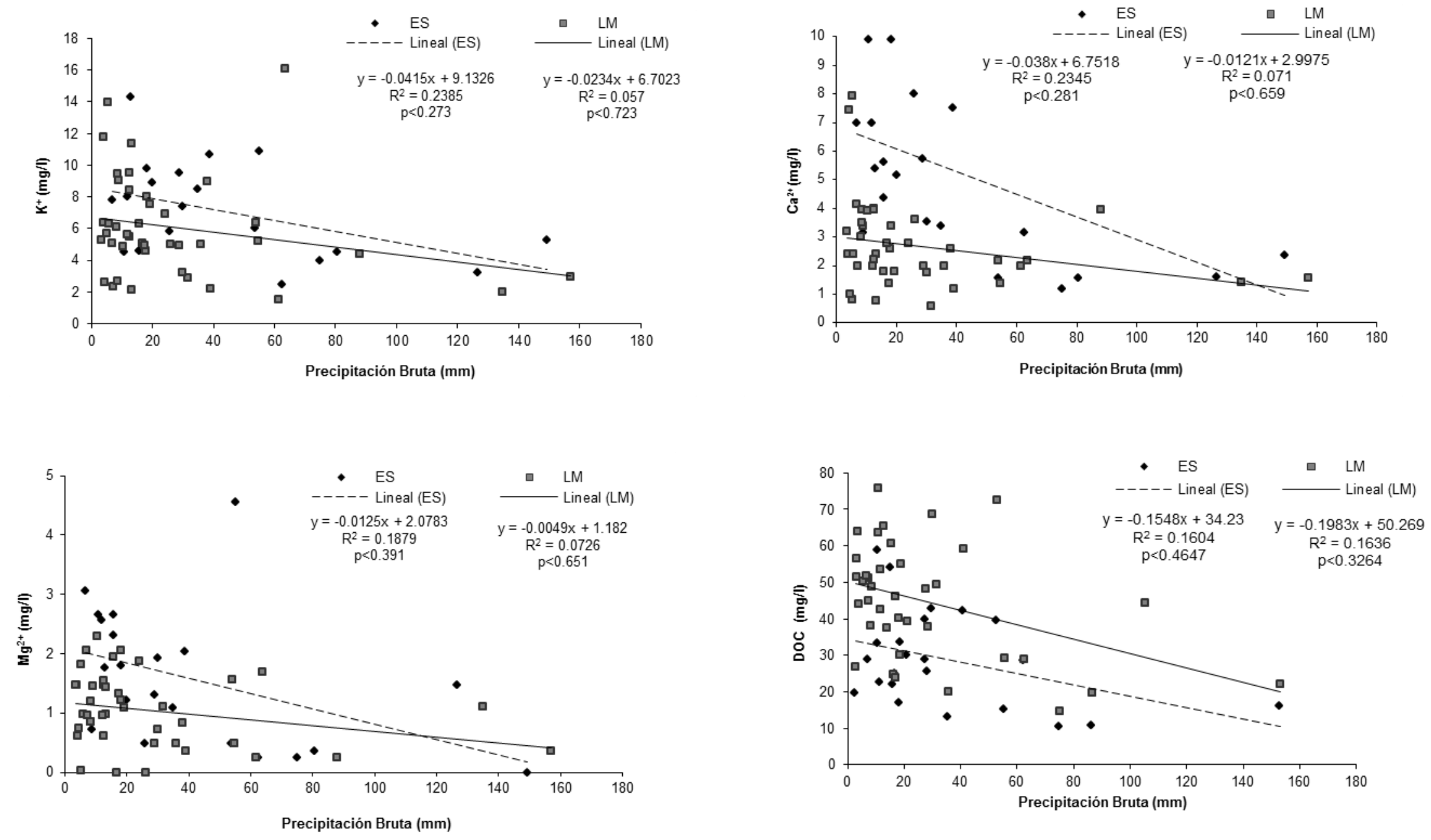

Figura 3.4.9: Concentraciones de potasio, calcio, magnesio y DOC vs. Precipitación Bruta (PB) en el escurrimiento superficial y en el lixiviado del mantillo. 
En general para eventos de similar magnitud de PB las concentraciones y su variabilidad fueron mayor en el ES que en el LM (Fig. 3.4.9). Esta relación se invierte con las concentraciones de COD en ambos flujos.

En general las regresiones muestran tendencias de relaciones negativas no significativas para todos los nutrientes y especies químicas consideradas. Solo la regresión entre la concentración de fósforo y la PB en el escurrimiento superficial fue significativa.

\subsubsection{Concentraciones promedio de nutrientes en los flujos de agua}

Los distintos eventos de precipitación, como hemos visto en la segunda parte de éste capítulo, dan lugar a la manifestación de diferentes flujos hídricos de entrada, salida y circulación en el interior de la plantación, de los cuales se analizaron químicamente muestras que permitieron la obtención de las concentraciones ponderadas de nutrientes, incluido el carbono orgánico disuelto (COD), en ellos (Tabla 3.4.1a). 


\begin{tabular}{|c|c|c|c|c|c|c|c|c|c|c|c|c|c|}
\hline \multirow{2}{*}{$\begin{array}{l}\text { Nutrientes } \\
\text { (mg/l) }\end{array}$} & \multicolumn{2}{|c|}{ Precipitación } & \multicolumn{2}{|c|}{ Trascolación } & \multicolumn{2}{|c|}{ Flujo caulinar } & \multicolumn{2}{|c|}{ Esc superficial } & \multicolumn{2}{|c|}{ Lix mantillo } & \multicolumn{2}{|c|}{ Napa freática } & \multirow{2}{*}{$\begin{array}{c}\text { Precip neta } \\
\text { Prom }\end{array}$} \\
\hline & Prom & Desv & Prom & Desv & Prom & Desv & Prom & Desv & Prom & Desv & Prom & Desv & \\
\hline $\mathrm{N}-\mathrm{NH}_{4}^{+}$ & 0.072 & 0.019 & 0.016 & 0.013 & 0.087 & 0.044 & 0.23 & 0.089 & 0.033 & 0.026 & 0.003 & 0,000 & 0.019 \\
\hline $\mathrm{N}-\mathrm{NO}_{2}^{-}$ & 0,000 & 0,000 & 0,000 & 0,000 & 0.001 & 0.001 & 0.007 & 0.003 & 0.002 & 0.001 & 0,000 & 0,000 & 0,000 \\
\hline $\mathrm{N}-\mathrm{NO}_{3}^{-}$ & 0.074 & 0.019 & 0.062 & 0.015 & 0.039 & 0.006 & 0.349 & 0.006 & 0.058 & 0.024 & 0.988 & 0.338 & 0.061 \\
\hline $\mathbf{N}$ total & 0.146 & 0.038 & 0.078 & 0.028 & 0.127 & 0.051 & 0.586 & 0.098 & 0.093 & 0.051 & 0.991 & 0.338 & 0.081 \\
\hline P- $\mathrm{H}_{2} \mathrm{PO}_{4}^{-}$ & 0.021 & 0.008 & 0.007 & 0.004 & 0.007 & 0.002 & 0.075 & 0.001 & 0.01 & 0.008 & 0.006 & 0.003 & 0.007 \\
\hline $\mathbf{K}^{+}$ & 0.608 & 0.137 & 1.856 & 0.64 & 4.402 & 0.926 & 3.556 & 0.887 & 4.361 & 0.507 & 0.892 & 0.388 & 1.968 \\
\hline $\mathrm{Ca}^{2+}$ & 0.692 & 0.304 & 0.975 & 0.103 & 1.002 & 0.146 & 2.451 & 1.393 & 1.97 & 0.319 & 4.804 & 1.604 & 0.977 \\
\hline $\mathrm{Mg}^{2+}$ & 0.269 & 0.135 & 0.442 & 0.037 & 0.528 & 0.086 & 0.407 & 0.026 & 0.827 & 0.007 & 1.967 & 1.238 & 0.446 \\
\hline DOC & 2.018 & 0.361 & 6.471 & 0.778 & 67.516 & 11.102 & 36.249 & 26.024 & 36.241 & 4.09 & 1.574 & 0.557 & 9.112 \\
\hline pH (unid) & 6.4 & 0.2 & 6.4 & 0 & 5.5 & 0.1 & 6.8 & 0.2 & 6.6 & 0 & 6.1 & 0.2 & I \\
\hline
\end{tabular}

Tabla 3.4.1a: Comparación entre las concentraciones de nutrientes $(\mathrm{mg} / \mathrm{l})$ y el pH de los flujos hídricos y la napa freática. 
En cuanto a los nutrientes para los flujos analizados el elemento que presentó mayor concentración fue el COD. Para los flujos aéreos, la concentración de COD del FC fue la más alta y se diferenció significativamente $(p<0,01)$ de las concentraciones de COD de la PB y de la T. La concentración de COD en la trascolación fue intermedia entre la precipitación y el flujo caulinar, como lo reportado por Moreno, Gallardo \& Bussotti, (2001) en Johnson \& Lehmann (2005) para la especie Quercus pyrenaica. Asimismo, Laclau (2001) determinó, como en este estudio, diferencias significativas entre las concentraciones de COD de la precipitación bruta, la trascolación y el flujo caulinar en una plantación de Eucalyptus en el Congo y obtuvo el mismo orden de concentraciones entre los flujos.

Los nutrientes que le siguieron al COD, en orden decreciente, fueron el potasio, el calcio y el magnesio. A continuación siguieron, el nitrógeno total y el fósforo, este último fue el elemento cuya concentración fue notoriamente más baja en todos los flujos.

Respecto al pH el promedio de la precipitación bruta fue 6.4 y el flujo con menor valor fue el flujo caulinar de pH 5.5. En los flujos en contacto con el mantillo y el suelo (lavado de mantillo y escurrimiento superficial), los valores de $\mathrm{pH}$ fueron más altos y alcanzaron un $\mathrm{pH}$ de 6.59 y 6.75 respectivamente. La mayor acidez del flujo caulinar, posiblemente producto de la presencia de compuestos de la degradación de la lignina (Tesón et al., 2009) es la posible causa de enriquecimiento con cationes de dicho flujo. No obstante debe tenerse en cuenta que el aumento de la concentración de nutrientes es asimismo favorecido por la evaporación que ocurre en los flujos de agua interiores a la plantación forestal.

Según Jobbagy \& Jackson (2003), analizando plantaciones de eucaliptos en la Pampa Húmeda el mecanismo de acidificación de los suelos por liberación de ácidos orgánicos desde el canopeo no sería la causa de acidificación ya que encuentra que los aportes aéreos son más alcalinos que la lluvia. En este estudio en Concordia, los valores de pH de la trascolación no se diferenciaron significativamente de la PB, cuyos valores no fueron alcalinos sino levemente ácidos ( $\mathrm{pH}$ 6.4), pero el FC fue significativamente 
más ácido, fuertemente ácido $(\mathrm{pH} 5,5)$. Si bien el flujo caulinar es una fracción menor del agua que alcanza el suelo su efecto de acidificación en las inmediaciones de la base del árbol no debe ser descartado.

Con respecto a las características del agua freática cabe destacar que sus propiedades químicas son el resultado de un proceso histórico regional de largo plazo. Por la tanto los valores reportados deben considerarse en ese contexto y como referencia a las condiciones del paisaje en que se encuentran las plantaciones estudiadas y no como parte del balance hidrológico y de nutrientes particular de éstas. En la Tabla 3.4.1b se presenta la composición química del agua subterránea del NE de Entre Ríos (Santi, M. et al., 2009). Los valores encontrados en la bajo la plantación son similares a los mínimos reportados por Santi et al. (2009) lo que sugiere que no existen cambios químicos importantes en la freática producto del cambio de uso de la tierra. Lamentablemente, no existen series de datos en la EEA Concordia, que permitan asegurar esto último y evaluar cambios en la composición química en el tiempo.

\begin{tabular}{|c|c|c|c|c|c|c|c|c|c|c|c|c|}
\hline & $\begin{array}{c}\text { C.E. } \\
\mu \mathrm{mho} / \mathrm{cm}\end{array}$ & $\begin{array}{l}\text { R.S. } \\
\mathrm{mg} / \mathrm{l}\end{array}$ & $\begin{array}{l}\text { Dur. } \\
\mathrm{mg} / \mathrm{l}\end{array}$ & $\begin{array}{c}\mathrm{CO}_{3} \mathrm{H}^{-} \\
\mathrm{mg} / \mathrm{l}\end{array}$ & $\begin{array}{c}\mathrm{Cl}^{-} \\
\mathrm{mg} / \mathrm{l}\end{array}$ & $\begin{array}{c}\mathrm{SO}^{2-} \\
\mathrm{mg} / \mathrm{l}\end{array}$ & $\begin{array}{r}\mathrm{NO}^{-} \\
\mathrm{mg} / \mathrm{l}\end{array}$ & $\begin{array}{l}\mathrm{Ca}^{2+} \\
\mathrm{mg} / \mathrm{l}\end{array}$ & $\begin{array}{c}\mathrm{Mg}^{2+} \\
\mathrm{mg} / \mathrm{l}\end{array}$ & $\begin{array}{l}\mathrm{Na}^{+} \\
\mathrm{mg} / \mathrm{l}\end{array}$ & $\begin{array}{c}\mathrm{K}^{+} \\
\mathrm{mg} / \mathrm{l}\end{array}$ & RAS \\
\hline Mín. & 69 & 48 & 35 & 13 & 3 & 4 & 0 & 4 & 2 & 1 & 0 & 0 \\
\hline Prom. & 511 & 350 & 129 & 323 & 16 & 15 & 15 & 36 & 9 & 83 & 2 & 4 \\
\hline Máx. & 2316 & 1500 & 289 & 670 & 450 & 180 & 100 & 102 & 42 & 470 & 5 & 18 \\
\hline
\end{tabular}

Tabla 3.4.1 b: Valores mínimos, promedios y máximos de las determinaciones químicas del agua subterránea en el NE de Entre Ríos (C.E: conductividad eléctrica; R.S: residuos sólidos; Dur: dureza;RAS: relación adsorción sodio). Fuente: Santi el al., 2009.

En cuanto a los resultados obtenidos sobre la composición química en este estudio el contenido de nitrógeno total corresponde solo a nitratos. Siendo ésta la forma más móvil del $\mathrm{N}$ y teniendo en cuenta su origen esencialmente biótico, puede asumirse que resulta del aporte debido a los procesos que acontecen en el suelo. La determinación precisa del origen de los nitratos en la napa requeriría la realización de otros análisis (por ej. la relación isotópica $\mathrm{N}-15 / \mathrm{N}-14)$ que están fuera del alcance de éste trabajo. La concentración de nitratos (ca. $1 \mathrm{mg} / \mathrm{l}$ ) se encuentra por debajo de los límites correspondientes a lo tolerado para aguas potables de consumo humano (Código Alimentario Argentino, concentración 
máxima de nitratos $=45 \mathrm{mg} / \mathrm{l})$. Asimismo la concentración de $\mathrm{P}$ y COD es baja, lo que es coincidente con la conocida escasez de éste elemento en los materiales arenosos y la poca movilidad del mismo; los valores del resto de los elementos químicos analizados son normales. Estos resultados sugieren que actualmente esta napa no está químicamente contaminada.

\subsection{Cocientes de concentraciones de nutrientes entre los flujos hídricos}

La comparación de las concentraciones de los nutrientes entre flujos (Tabla 3.4.1) y de los cocientes de enriquecimiento (Tabla 3.4.2) permite advertir distintos comportamientos de los elementos químicos considerados dentro de la plantación.

Vale la pena destacar que Laclau (2002) consideró sinónimos a las relaciones de concentraciones y los factores de enriquecimiento. Sin embargo el aumento de la concentración de un flujo puede ocurrir por la sola pérdida del solvente (agua) sin ganancia de nutrientes. De la misma forma que una reducción de concentración puede ocurrir por absorción o retención por los organismos con o sin pérdidas de agua. La denominación enriquecimiento conviene aplicarla solamente en los casos en que existe una auténtica ganancia de elementos químicos (aerosoles, elementos lixiviados y lavados, etc). Tanto las ganancias como las reducciones de nutrientes en los flujos pueden observarse en los balances de masas, como se verá posteriormente (Fig. 3.4.11 a Fig. 3.4.16). Por lo que en este punto solo se intenta explicar los cambios en la concentración de los flujos sin explicar el origen de las diferencias.

\begin{tabular}{ccccccccc}
\hline & $\mathbf{N}^{-\mathrm{NH}_{4}{ }^{+}}$ & $\mathbf{N}-\mathrm{NO}_{3}{ }^{-}$ & $\mathbf{N}$ total & $\begin{array}{c}\mathbf{P}- \\
\mathbf{H}_{2} \mathbf{P O}_{4}^{-}\end{array}$ & $\mathbf{C a}^{2+}$ & $\mathbf{M g}^{2+}$ & $\mathbf{K}^{+}$ & DOC \\
\hline T/P & 0.22 & 0.84 & 0.54 & 0.33 & 3.05 & 1.41 & 1.64 & 3.21 \\
$\mathbf{F C} / \mathbf{P}$ & 1.21 & 0.53 & 0.87 & 0.33 & 7.24 & 1.45 & 1.96 & 33.46 \\
$\mathbf{F C} / \mathbf{T}$ & 5.44 & 0.63 & 1.62 & 1.00 & 2.37 & 1.03 & 1.19 & 5.60 \\
ES/PN & 12.06 & 5.72 & 7.28 & 10.70 & 1.81 & 2.51 & 0.91 & 3.98 \\
LM/PN & 1.73 & 0.95 & 1.15 & 1.43 & 2.22 & 2.02 & 1.85 & 3.98 \\
\hline
\end{tabular}


Tabla 3.4.2: Relaciones de concentración trascolación/precipitación (T/P), flujo caulinar/precipitación (FC/P), flujo caulinar/trascolación (FC/T), escurrimiento superficial/precipitación neta (ESC/PN) y lixiviación del mantillo /precipitación neta (LM/PN).

Las concentraciones de $\mathrm{K}$ entre los flujos aéreos manifestaron diferencias significativas $(p<0.01)$. Mientras que para el Ca, si bien aumentó, el valor de la concentración de Ca en el FC no se diferenció significativamente del resto. La concentración de Mg aumentó en el flujo caulinar y, la misma, en este flujo, se diferenció significativamente de aquella de la precipitación bruta pero no de la obtenida en la trascolación. En resumen, se observó un incremento en las concentraciones de $\mathrm{DOC}, \mathrm{Ca}, \mathrm{Mg}$ y $\mathrm{K}$ a medida que el agua fluye desde la copa hacia el suelo manifestado en cocientes de concentraciones mayores a la unidad (Tabla 3.4.2).

Por otra parte, las concentraciones de $\mathrm{P}$ y $\mathrm{N}$ mostraron una tendencia decreciente a medida que el agua atraviesa el dosel arbóreo. Para el $\mathrm{N}$ total y las formas de $\mathrm{N}$ analizadas, si bien las concentraciones bajaron, las diferencias entre flujos no fueron significativas. Las concentraciones de $\mathrm{P}$, tanto en el flujo caulinar como en la trascolación, mostraron diferencias significativas con aquellas en la precipitación bruta $(p<0.05)$. En consecuencia, para estos dos últimos nutrientes, los cocientes de las concentraciones fueron valores menores a la unidad. La disminución en las concentraciones de estos dos elementos, a pesar de la evaporación de parte del agua precipitada que conduce a un incremento de las concentraciones sin que necesariamente haya ganancia de nutrientes, puede deberse a la absorción por el dosel arbóreo de estos elementos. La absorción foliar directa de $\mathrm{N}$ fue observada en muchos ecosistemas forestales donde los requerimientos de nitrógeno son altos (Lindberg et al., 1986; Adams \& Attiwill, 1991; Marques \& Ranger, 1997; todos en Laclau et al., 2005). Andrade et al. (1995) observó resultados similares para el nitrógeno y el fósforo en plantaciones de Eucalyptus grandis en Brasil. Mientras que Laclau et al. (2005) observaron absorción de nitrógeno por el dosel arbóreo pero no de fósforo. 
Respecto a los cocientes de concentraciones entre los flujos Laclau et al. (2005) encontraron valores entre 0 y 8.1 al comparar la concentración de N, K, Ca, Mg y COD en el flujo caulinar con la de la trascolación en una plantación de Eucalyptus evaluada en el Congo. En el presente estudio se obtuvieron cocientes entre estos flujos entre 1 y 5 . El clima más cálido en el Congo (temperatura media de $25 \stackrel{\circ}{\circ}$ vs $18 \stackrel{\circ}{\circ}$ en Concordia) determinaría mayor actividad microbiológica que podría expresarse en cocientes de COD más elevados como producto de la degradación de compuestos orgánicos.

Las mayores concentraciones principalmente de cationes y COD en el escurrimiento superficial y en la lixiviación del mantillo son consideradas consecuencia de ingresos con la precipitación neta al suelo, el incremento de la concentración debido a pérdidas de agua por evaporación desde el mantillo, y la disolución de compuestos orgánicos (lábiles provistos por detritos en descomposición y microorganismos, y compuestos húmicos coloreados). Posiblemente la mayor disponibilidad de bases este vinculada a los procesos de solubilización de cationes ocurridos en el suelo y mantillo que explicaría el incremento del pH en este flujo respecto a los de la precipitación neta.

Al observar las concentraciones en los análisis del agua de la napa freática (Tabla 3.4.1), los resultados muestran que respecto al agua de lixiviación del mantillo, que ingresa al suelo mineral, decrece la concentración de DOC y potasio y se enriquece en calcio y magnesio, mostrando que las aguas de percolación son afectadas por procesos bióticos y abióticos en el suelo y subsuelo que retienen, descomponen y/o liberan los distintos nutrientes. No obstante, como se mencionó anteriormente, debe considerarse que el contenido de nutrientes de la napa freática puede ser el efecto colectivo del mosaico de ecosistemas naturales, agrícolas y forestales en la cuenca. 


\subsubsection{Otros aspectos relativos al COD: contenido de COD y color de la materia orgánica} disuelta en los distintos flujos hídricos y estimación de la concentración de COD en flujos de agua en función del color.

Los flujos hídricos mostraron no solo distintas concentraciones promedio sino diferentes rangos de concentración de COD (Tabla 3.4.3) La concentración ponderada aumentó en la secuencia vertical de movimiento del agua, desde la precipitación, a la trascolación, hacia los horizontes orgánicos del suelo; en esa secuencia vertical se destacó el flujo caulinar que tuvo la más elevada concentración de COD. La baja concentración de COD $(=[C O D])$ en la napa freática, donde $[C O D]=1.57 \pm 0.56 \mathrm{mg} . \mathrm{l}^{-1}(\mathrm{n}=6)$, indicó un descenso notorio del COD en su transcurso por el suelo mineral y subsuelo. El aumento de la [COD] en los flujos de la precipitación neta puede atribuirse parcialmente a las pérdidas de agua por evaporación desde el dosel pero también a la incorporación de carbono orgánico desde superficies en contacto con el agua. El FC, un pequeño porcentaje de las lluvias, mostró un orden de magnitud mayor en la concentración de COD que la T, lo que puede adjudicarse al contacto, además de con el follaje, con la superficie de ramas y troncos. Como se indicara en el punto anterior, valores altos extremos de concentración de COD en el flujo caulinar ocurrieron en lluvias de baja intensidad y corta duración. 


\begin{tabular}{|c|c|c|c|c|c|c|c|}
\hline Flujos & $\mathbf{n}$ & Intercepción & Pendiente & $\mathbf{R}^{2}$ & $\begin{array}{l}\text { COD media } \\
\pm \mathrm{DS} \text { (ppm) }\end{array}$ & $\begin{array}{l}\text { COD } \\
\text { rango } \\
\text { (ppm) }\end{array}$ & $\begin{array}{l}\text { Color rango } \\
\text { (densidad } \\
\text { óptica)* }\end{array}$ \\
\hline Todos & 395 & $0.84+$ & 103.28 & 0.93 & & $\begin{array}{c}0.71- \\
242.60\end{array}$ & $0.003-1.921$ \\
\hline $\begin{array}{l}\text { Precipitación } \\
\text { bruta }\end{array}$ & 69 & $2.09 \mathrm{a}$ & $71.38 \mathrm{a}$ & 0.60 & $2.02 \pm 0.36$ & $\begin{array}{l}0.71- \\
13.67\end{array}$ & $0.003-0.123$ \\
\hline Trascolación & 109 & $1.35 \mathrm{a}$ & $75.82 \mathrm{a}$ & 0.80 & $6.47 \pm 0.78$ & $\begin{array}{l}1.67- \\
23.24\end{array}$ & $0.003-0.237$ \\
\hline Flujo caulinar & 100 & $15.67 \mathrm{~b}$ & $103.19 \mathrm{~b}$ & 0.83 & $\begin{array}{c}67.52 \pm \\
11.1\end{array}$ & $\begin{array}{c}4.69- \\
242.60\end{array}$ & $0.046-1.921$ \\
\hline $\begin{array}{l}\text { Lixiviación del } \\
\text { mantillo }\end{array}$ & 73 & $10.99 \mathrm{~b}$ & $68.39 \mathrm{a}$ & 0.67 & $\begin{array}{c}36.24 \pm \\
4.09\end{array}$ & $\begin{array}{l}2.55- \\
39.59\end{array}$ & $0.152-1.103$ \\
\hline $\begin{array}{l}\text { Escurrimiento } \\
\text { superficial }\end{array}$ & 44 & $12.09 \mathrm{~b}$ & $46.47 c$ & 0.62 & $\begin{array}{c}36.25 \pm \\
26.02\end{array}$ & $\begin{array}{l}9.01- \\
63.68\end{array}$ & $0.109-1.097$ \\
\hline
\end{tabular}

* logaritmo del porcentaje de transmitancia

Tabla 3.4.3: Valores de COD (ppm) y color en los flujos hídricos de la plantación de E. grandis

La comparación de la concentración de COD versus Color para cada flujo hídrico mostró diferencias en la intercepción sobre el eje y, y en la pendiente de la línea de regresión (Tabla 3.4.3, Figura 3.4.11).

El valor de la intercepción de la ecuación que incluye todos los flujos no difiere significativamente de 0 (Tabla 3.4.3), sugiriendo la ausencia de compuestos orgánicos incoloros. No obstante, el análisis de flujos individuales mostró 3 tipos de intercepciones. Primero, la precipitación y la trascolación presentaron un bajo valor de intercepción del eje y, que indicaría escasez o ausencia de compuestos incoloros de COD; junto a una diferencia no significativa en la pendiente de la línea de regresión de ambos, sugiere una similar composición y baja concentración de COD con compuestos coloreados de bajo peso molecular. Una PAR relativamente alta (PAR $=0.2$ del PAR exterior) debajo del dosel arbóreo, un IAF $=$ ca. 2.3 y una alta frecuencia de claros en el follaje, haría que parte de la precipitación bruta entre directamente como trascolación, y explicaría las similitudes de COD entre esos flujos. Segundo, el valor más alto de la intercepción del eje y correspondió al COD en el flujo caulinar, sugiriendo una alta concentración de metabolitos incoloros menos polimerizados de fácil descomposición. Este COD puede participar en procesos mediados por microorganismos a través del cometabolismo, que contribuye a la descomposición de compuestos refractarios como la lignina y 
sus derivados (Horvath, 1972; De Haan, 1974, 1977; Geller, 1985). Este mecanismo explicaría el suministro de COD de características aromáticas que, de manera similar que las sustancias húmicas en sistemas acuáticos, absorben luz visible. Tercero, el grupo compuesto por flujos asociados al mantillo. La alta intercepción del eje y, menor que la del flujo caulinar, se debería a sustancias orgánicas incoloras aportadas por la precipitación neta, la lixiviación y descomposición del mantillo fino (de origen foliar y los microorganismos), y la concentración debida a la evaporación edáfica.
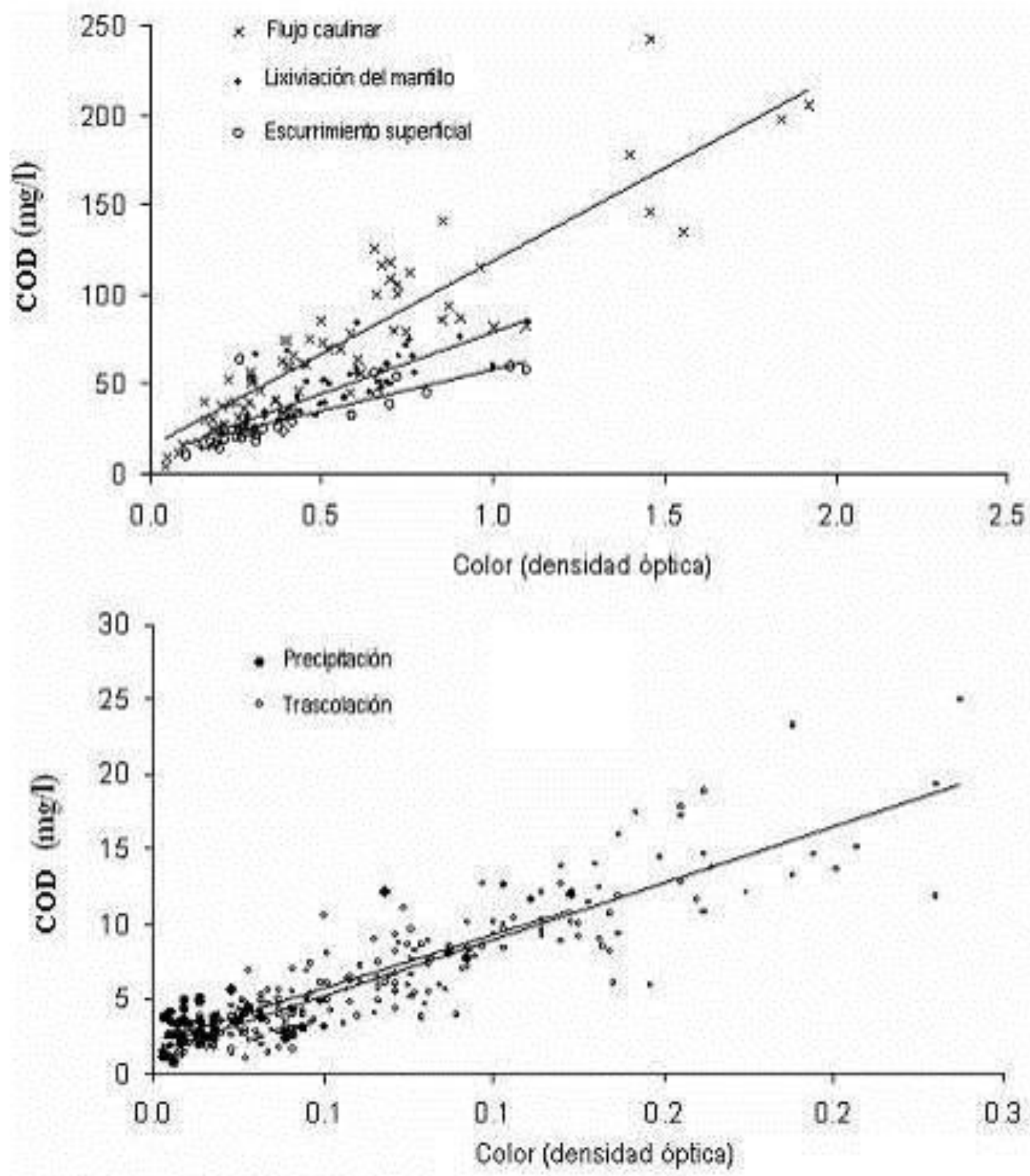
Figura 3.4.10. Relación entre la concentración de COD y el color por flujo hídrico. Se indican las líneas de regresión por cuadrados mínimos ordinarios

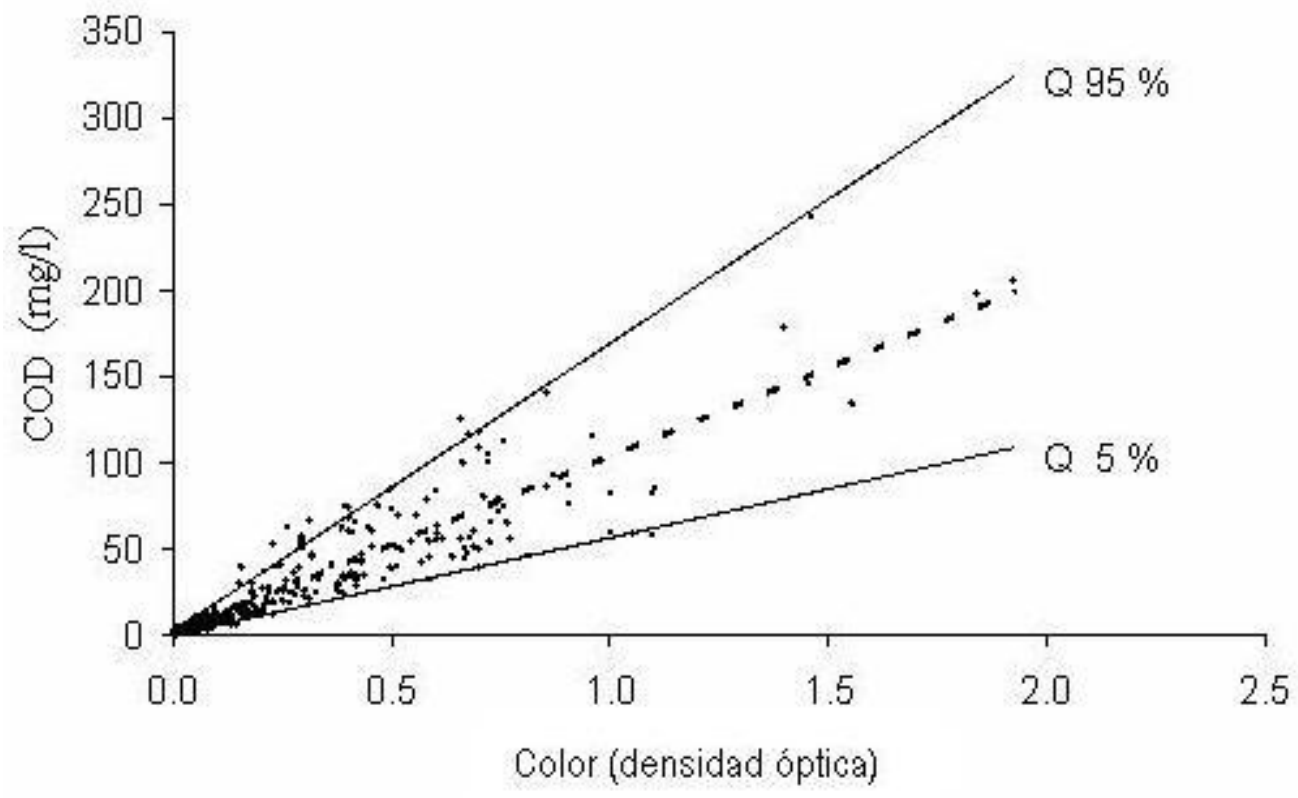

Figura 3.4.11. Relación entre la concentración de COD y el color para todos los flujos hídricos. Se indica la línea por mínimos cuadrados ordinarios (línea de puntos) y límites de confianza basado en la regresión de cuantiles. Q 5\%: intercepción= 0.25, pendiente= 56.56; Q 95\%: intercepción= 0.53, pendiente= 167.01 .

Las pendientes indicaron cambios en la [COD] por unidad de color, y mostraron que iguales [COD] tuvieron diferente capacidad de absorción de luz visible según el flujo, sugiriendo que los compuestos orgánicos coloreados difirieron en su estructura y/o peso molecular en diferentes conjuntos de flujos de agua (Figura 3.3.11).

La pendiente de las líneas de regresión de [COD] vs Color en el flujo caulinar y escurrimiento superficial difirieron significativamente entre sí, y de los otros flujos (sin diferencias significativas entre sí) (Tabla 3.4.3). 
Los menores rangos y valores de [COD] en la precipitación y trascolación, y las dificultades con la determinación espectrofotométrica de bajas concentraciones, hacen prudente evitar más comentarios y restringir el análisis de las pendientes de regresión a los flujos de mayor [COD] y amplio rango de superposición entre ellos (Figura 3.4.9).

Las líneas de regresión del flujo caulinar, la lixiviación de hojarasca y el escurrimiento superficial corresponden a una secuencia de flujos de movimiento vertical descendente del agua dentro de la plantación. En igual orden de esos flujos hay una disminución de la pendiente de sus líneas de regresión [COD] vs Color. La actividad microbiana heterotrófica sobre los troncos suministraría materia disuelta al flujo caulinar, notablemente sustancias coloreadas derivadas de la lignina favorecidas por los procesos de co-metabolismo. No obstante, los compuestos orgánicos proceden de la lignina en descomposición y recombinada y en cierta forma son químicamente análogos. Los resultados indicaron una decreciente [COD] por unidad de color en los tres flujos. La razón podría relacionarse al incremento del peso molecular del COD como consecuencia de la humificación en el suelo. Las moléculas grandes no solo absorben la luz, debido a las transiciones electrónicas, sino que también dispersan luz en mayor medida que las moléculas menores (Chen et al., 1977; Bloom \& Leenheer, 1989) y promueven una disminución de la transmisión de la radiación dentro de las celdas espectrofotométricas lo que se traduce en una mayor absorción. Por ello, la pendiente de COD por unidad de color, se hace menor con el incremento del tamaño molecular. Consecuentemente, el decrecimiento de las pendientes (Tabla 3.3.3) podría ser indicador del incremento del grado de polimerización de los compuestos de COD entre esos compartimentos.

En síntesis, las copas de los árboles hacen un menor aporte de COD a la trascolación por lavado y lixiviado; la actividad abiótica y biótica sobre los vegetales suministran productos al flujo caulinar; la descomposición de lignina es el origen de productos como los polifenoles, azúcares y quinonas que comienzan las reacciones de condensación con síntesis de compuestos coloreados de relativamente alto peso molecular. Luego, en otros compartimientos, las reacciones de condensación a través del proceso de humificación producen materiales húmicos coloreados de alto peso molecular. De manera general, la estructura de ellos contiene grupos 
de ácido carboxílico, quinonas, cetonas, fenoles, hidroxilos alcohólicos en un esqueleto de anillos aromáticos entrecruzados por grupos puente de oxígeno y nitrógeno (Stevenson, 1982).

La [COD] en una muestra, de densidad óptica conocida de cualquier vía de circulación del agua en la plantación de $E$. grandis al final de su rotación, puede ser estimada satisfactoriamente para propósitos generales mediante la ecuación de regresión total (Tabla 3.4.1, Figura 3.4.11). Sin embargo, los comentarios anteriores destacan las limitaciones de ésta aproximación.

\subsubsection{Comparación de concentración de nutrientes en el escurrimiento superficial de la plantación y del pastizal}

Durante parte del estudio se pudo analizar la concentración de nutrientes en el escurrimiento superficial dentro y fuera de la plantación para un conjunto de eventos $(n=21)$. Los resultados se presentan en la Tabla 3.4.4.

\begin{tabular}{|c|c|c|c|c|c|c|c|}
\hline & $\begin{array}{c}\mathrm{N}-\mathrm{NH}_{4}{ }^{+} \\
\mathrm{mg} / \mathrm{l}\end{array}$ & $\begin{array}{c}\mathrm{N}-\mathrm{NO}_{2}^{-} \\
\mathrm{mg} / \mathrm{l}\end{array}$ & $\begin{array}{c}\mathrm{N}-\mathrm{NO}_{3}^{-} \\
\mathrm{mg} / \mathrm{l}\end{array}$ & $\begin{array}{c}\mathrm{P}-\mathrm{H}_{2} \mathrm{PO}_{4}^{-} \\
\mathrm{mg} / \mathrm{l}\end{array}$ & $\begin{array}{l}\mathrm{Ca}^{2+} \\
\mathrm{mg} / \mathrm{l}\end{array}$ & $\begin{array}{l}\mathrm{Mg}^{2+} \\
\mathrm{mg} / \mathrm{l}\end{array}$ & $\begin{array}{c}\mathrm{K}^{+} \\
\mathrm{mg} / \mathrm{l}\end{array}$ \\
\hline ESF Prom & $0.07 \mathrm{a}$ & $0.02 a$ & $0.13 a$ & $0.04 \underline{a}$ & $3.32 \mathrm{a}$ & 0.30 a & $3.42^{a}$ \\
\hline Desv Est. & 0.02 & 0.01 & 0.02 & 0.01 & 0.25 & 0.12 & 0.76 \\
\hline ESP Prom & $0.17 \mathrm{~b}$ & $0.01 a$ & $0.23 a$ & $0.44 b$ & $2.85 a$ & 0.50 a & $4.21 \underline{a}$ \\
\hline Desv Est. & 0.021 & 0.003 & 0.076 & 0.042 & 0.110 & 0.088 & 0.913 \\
\hline
\end{tabular}

Tabla 3.4.4: Concentraciones de nutrientes en escurrimiento superficial de la plantación (ESF) y en el escurrimiento superficial del pastizal aledaño (ESP). Período Junio 2005 - junio 2006. Letras diferentes indican diferencias de concentración significativas $(p<0.01)$ entre sitios.

Al analizar las concentraciones mediante ANOVA se encontraron diferencias significativas (Tukey, $\mathrm{p}<0.01$ ) para la forma amonio del $\mathrm{N}$ y para el $\mathrm{P}$, con las concentraciones más elevadas en los flujos del pastizal. Para el resto de los nutrientes las diferencias de concentraciones no fueron significativas (Tukey, $p>0.05$ ).

Teniendo en cuenta que el volumen de agua de escurrimiento superficial es mayor en el pastizal, puede concluirse que la masa de nutrientes que se mueven mediante escurrimiento es mayor en el pastizal que en la plantación forestal. 


\subsubsection{Circulación de nutrientes en los flujos hídricos}

3.4.6.1. Nitrógeno. La cantidad de nitrógeno disuelto en los distintos flujos hídricos en el período analizado se presenta en la Figura 3.4.12. El ingreso anual de nitrógeno con la precipitación bruta fue de $1.83 \mathrm{~kg} \mathrm{ha}^{-1} \mathrm{año}^{-1}$. Según Hedin (1995) éste es un valor bajo que se encuentra en el rango de aquellos que se hallan en áreas libres de contaminación. Valores cercanos a $1 \mathrm{~kg} \mathrm{ha}^{-1}$ año $^{-1}$ se encontraron en bosques del sur de Chile y en bosques de Nothofagus de Tierra del Fuego $1-1.3 \mathrm{~kg} \mathrm{ha}^{-1} \mathrm{año}^{-1}$ (Frangi et al, 2004).
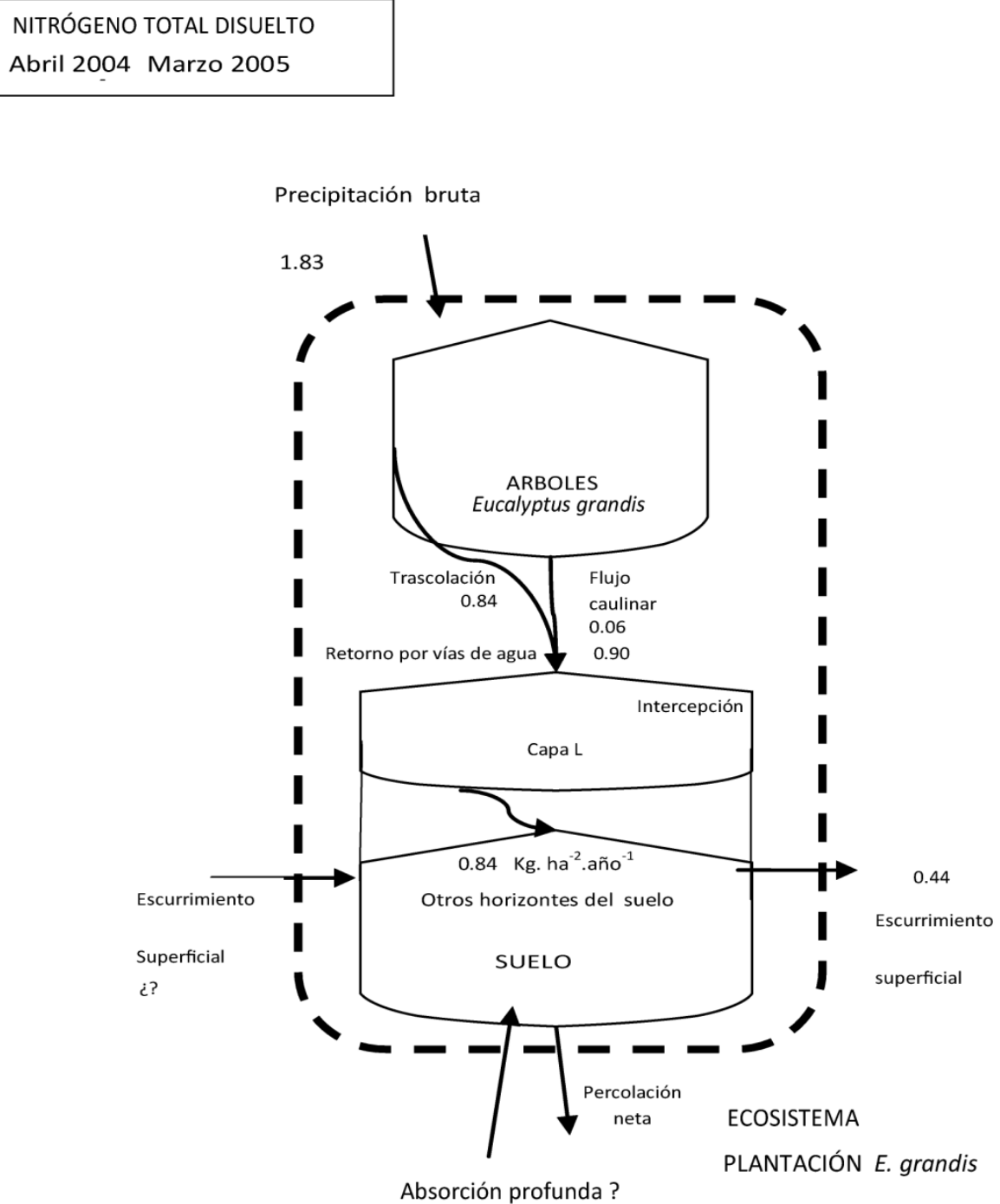

Figura 3.4.12: Nitrógeno disuelto ( $\mathrm{kg} \mathrm{ha}^{-1} \mathrm{año}^{-1}$ ) en los flujos hídricos en una plantación de E. grandis. Período abril 2004 marzo 2005. 
Por otra parte, el ingreso anual de $\mathrm{N}$ con la precipitación bruta fue mayor a los ingresos asociados a la precipitación neta, lo que indicaría como se observó cuando se analizaron las concentraciones que existiría absorción de nitrógeno a medida que el agua circula por la copa y los troncos de los árboles.

Una vez que el agua alcanzó el suelo y atravesó el mantillo la cantidad de nitrógeno contenida en el agua colectada por debajo de aquel también disminuyó. Según Terradas (2001) dado el uso intenso del N por los organismos, no es extraño que este nutriente sea eficazmente retenido en muchos ecosistemas. Durante la primera fase de descomposición de la hojarasca, en vez de liberarse $\mathrm{N}$ al medio la concentración de $\mathrm{N}$ en la hojarasca suele aumentar, ya que el $\mathrm{N}$, cuando es limitante para los microorganismos del suelo, es retenido por éstos. Goya et al. (2008) han constatado que el N y el P son inmovilizados durante la descomposición del mantillo de $E$ grandis en los tres tipos de suelos principales de la zona de Concordia. Frangi et al. (2000) analizó el contenido de nutrientes en el mantillo en distintas fases de desarrollo de las plantaciones encontrando valores en la relación $\mathrm{C} / \mathrm{N}$ de 71.5 en la fase IV, que corresponde a la edad de este estudio. Este valor de la relación $\mathrm{C} / \mathrm{N}$ resulta ser muy elevado respecto a la misma relación en los tejidos de los microorganismos. Kaye \& Hart (1997) han propuesto que C:N 30 es un cociente teórico crítico por encima del cual los microorganismos heterotróficos están limitados por $\mathrm{N}$ y debajo de los cuales ellos están limitados por C. Consecuentemente, en la descomposición del mantillo fino de $E$. grandis en Concordia los descomponedores privilegian la respiración de compuestos carbonados, con liberación de C, y la inmovilización de $\mathrm{N}$, reduciendo de esa manera la relación $\mathrm{C} / \mathrm{N}$ del complejo detrito-microorganismos.

La cantidad de $\mathrm{N}$ en el agua de escurrimiento superficial también fue baja, $0.44 \mathrm{~kg} \mathrm{ha}^{-1} \mathrm{año}^{-1}$, lo que indicaría la mencionada inmovilización de $\mathrm{N}$ en el mantillo, facilitada por la gran superficie de contacto entre el agua y las capas inferiores mas descompuestas del mantillo (capas F y H). 
3.4.6.2. Fósforo. La cantidad ( $\mathrm{kg} \mathrm{ha}^{-1} \mathrm{año}{ }^{-1}$ ) de fósforo disuelto en los flujos hídricos en el período analizado se presenta en la Figura 3.4.13. El ingreso de este nutriente con la precipitación bruta fue bajo, $0.26 \mathrm{~kg} \mathrm{ha}^{-1} \mathrm{año}^{-1}$, aunque dentro del rango de los antecedentes para este nutriente citados en la Tabla 1.3 que oscilaba entre los $0.1-1.2 \mathrm{~kg} \mathrm{ha}^{-1} \mathrm{año}^{-1}$
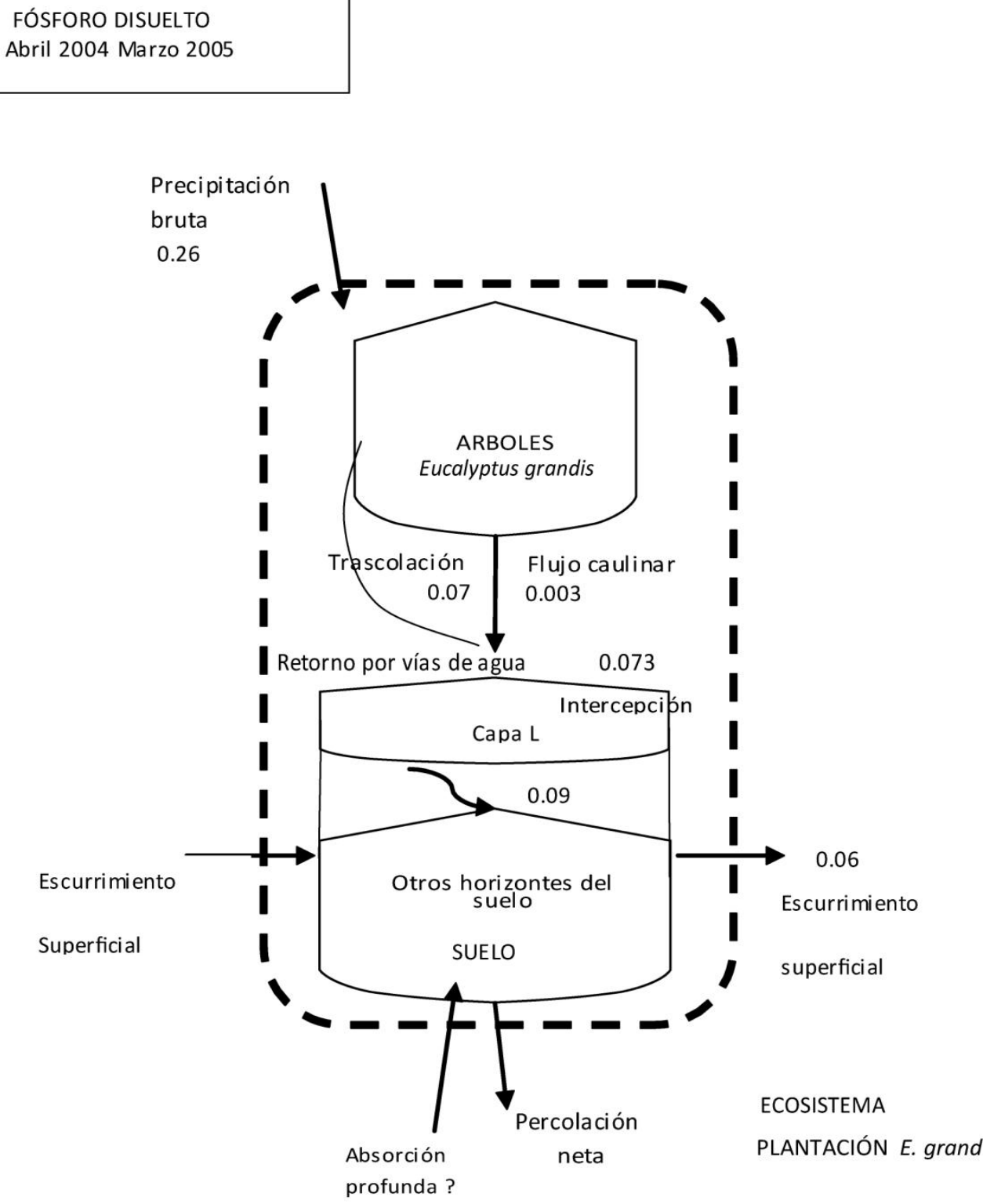

Figura 3.4.13: Fósforo disuelto $\left(\mathrm{kg} \mathrm{ha}^{-1} \mathrm{ano}^{-1}\right)$ en los flujos hídricos en una plantación de E. grandis. Período abril 2004 - marzo 2005. 
A pesar del bajo ingreso de $\mathrm{P}$ disuelto con la precipitación bruta $\left(0.26 \mathrm{~kg} \mathrm{ha}^{-1} \mathrm{año}^{-1}\right)$ se observa que la cantidad de $\mathrm{P}$ que ingresa con la precipitación neta se reduce a menos de un tercio de aquel valor $\left(0.07 \mathrm{~kg} \mathrm{ha}^{-1} \mathrm{año}^{-1}\right)$. Particularmente el ingreso con el FC es muy bajo, lo que expresa una importante captura de $\mathrm{P}$ al fluir el agua por el tronco. Los resultados también evidencian que ocurre inmovilización de $\mathrm{P}$ en el mantillo y la superficie del suelo, ya que el lixiviado del mantillo y el escurrimiento superficial transportan anualmente poco $\mathrm{P}$ por unidad de área.

3.4.6.3. Potasio. La cantidad de potasio disuelto en los flujos hídricos en el período analizado se presenta en la Figura 3.4.14. Hubo un incremento en la cantidad de este nutriente a medida que el agua atravesó el dosel arbóreo. La masa de K que ingresa con la precipitación neta es la segunda en magnitud entre los elementos estudiados. Este aporte al suelo se debe a su estado en forma de ión y su alta solubilidad en el agua, lo que favorece la lixiviación de las distintas superficies en contacto con la misma, como menciona Chapin (1996). La cantidad de $\mathrm{K}$ aportada por la precipitación neta a la superficie del terreno fue tres veces superior al aporte de la precipitación bruta. También se produjo un incremento en el contenido de $\mathrm{K}$ luego que el agua atravesó el mantillo.

El potasio usualmente es fuertemente lixiviado desde las copas, este comportamiento se observó en muchos ecosistemas forestales alrededor del mundo y particularmente en las forestaciones de Eucalyptus spp (Laclau et al., 2005). Sin embrago, Andrade et al. (1995) encuentran menor aporte de potasio en la precipitación neta en un ensayo de Eucalyptus grandis indicando que probablemente la absorción por las copas de este nutriente está relacionado a la baja disponibilidad del mismo en el sitio de estudio; ésta absorción de $\mathrm{K}$ por las copas no se observó en este estudio.

3.4.6.4. Calcio. El aporte de este elemento con la precipitación fue el tercero en importancia. El agua se enriqueció con calcio a medida que atravesaba el dosel arbóreo y el mantillo (Figura 3.4.15). 
Este elemento es considerado crítico, ya que como se verá en el punto 3.4 .7 el calcio presenta una tasa de retención muy importante en la biomasa y baja retraslocación dentro de la planta. El calcio es altamente inmóvil dentro de las plantas ya que se encuentra en las paredes celulares de los tejidos vegetales. Su concentración es muy alta en el mantillo y en la corteza.

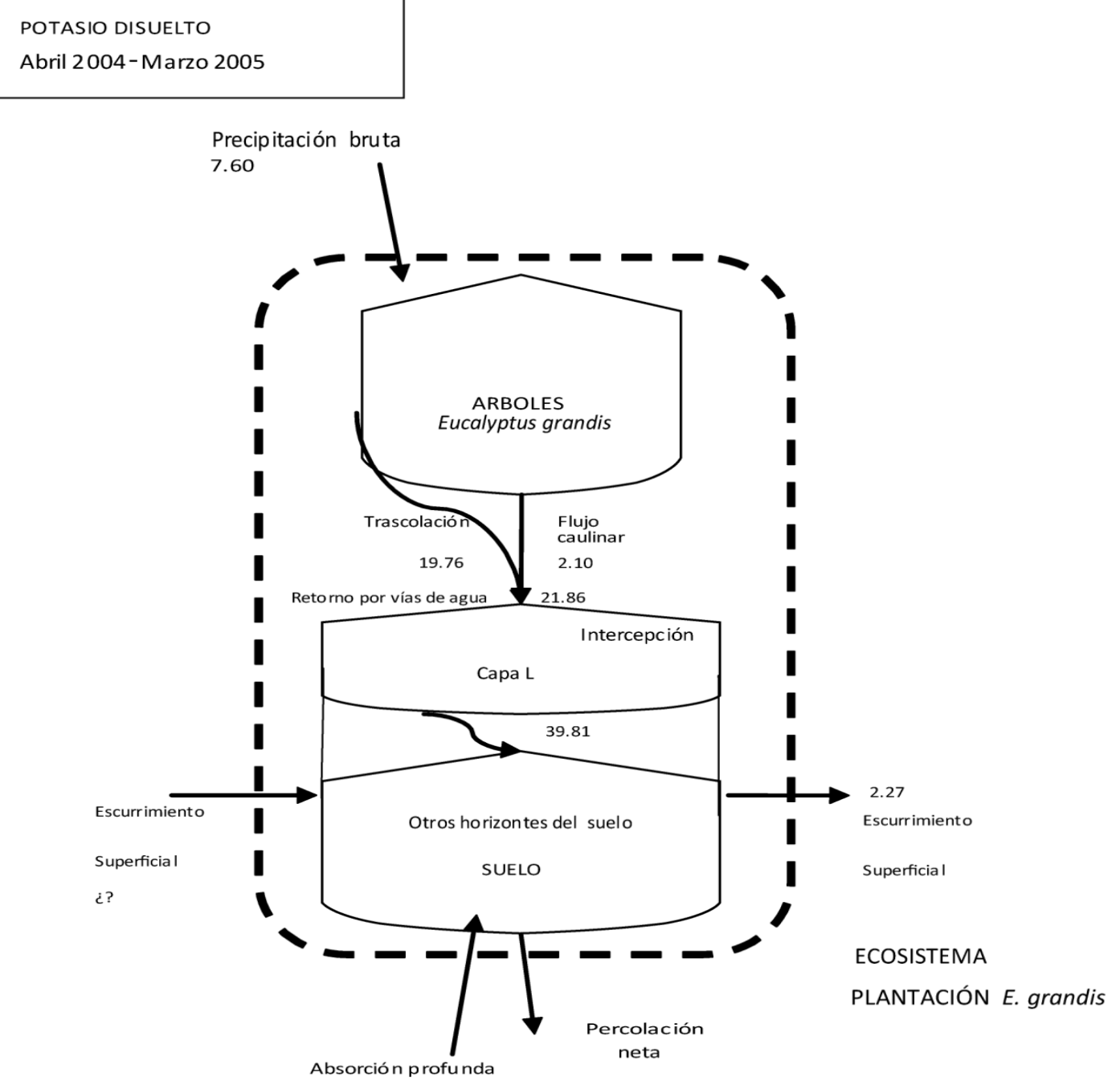

Figura 3.4.14: Potasio disuelto $\left(\mathrm{kg} \mathrm{ha}^{-1} \mathrm{año}^{-1}\right)$ en los flujos hídricos en una plantación de $E$. grandis. Período abril 2004 - marzo 2005. 


CALCIO DISUELTO
Abril 2004-Marzo 2005

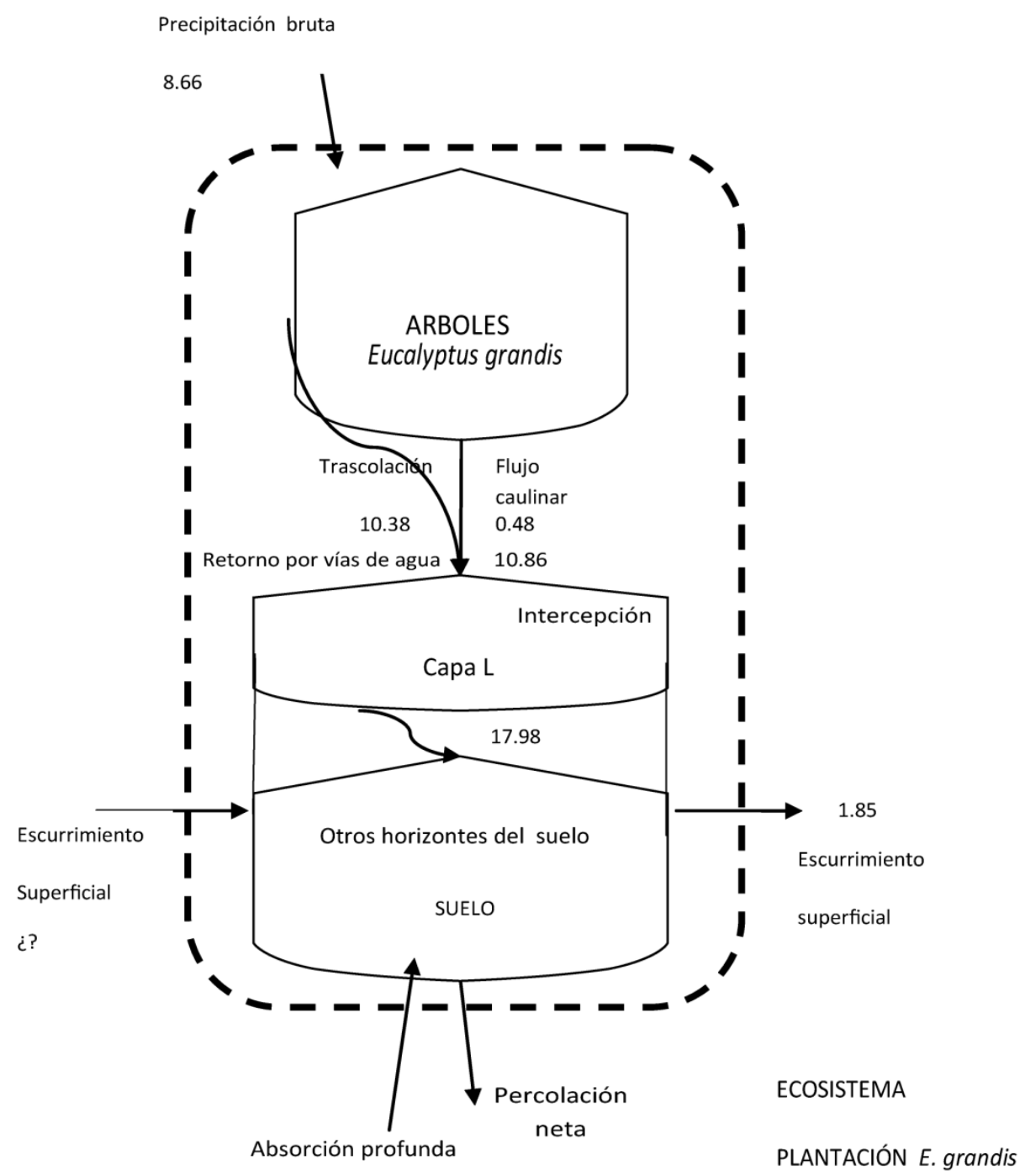

Figura 3.4.15: Calcio disuelto ( $\mathrm{kg} \mathrm{ha}^{-1}$ año ${ }^{-1}$ en los flujos hídricos en una plantación de E. grandis. Período abril 2004 - marzo 2005.

Los resultados de los análisis de suelo mostraron una reducción muy importante de este nutriente en las plantaciones que se incremento con la edad de la plantación. Jobbagy (2006) considera a la redistribución vertical del Ca como la principal causa de acidificación de los suelos en plantaciones de Eucalyptus en la pampa húmeda. 
3.4.6.5. Magnesio. El magnesio fue el cuarto nutriente en orden de magnitud en los flujos hídricos. Las cantidades presentes en los distintos flujos se presentan en la Figura 3.4.16. El aporte de la precipitación neta fue mayor respecto del aporte de la precipitación bruta, existiendo por lo tanto un enriquecimiento en los flujos relacionados con la precipitación neta debido al lavado del dosel arbóreo. Asimismo se observó un aumento del Mg en los flujos de agua al atravesar el mantillo lo que explica que éste se comporta como un contribuyente neto del mismo. El magnesio es moderadamente móvil dentro de la planta
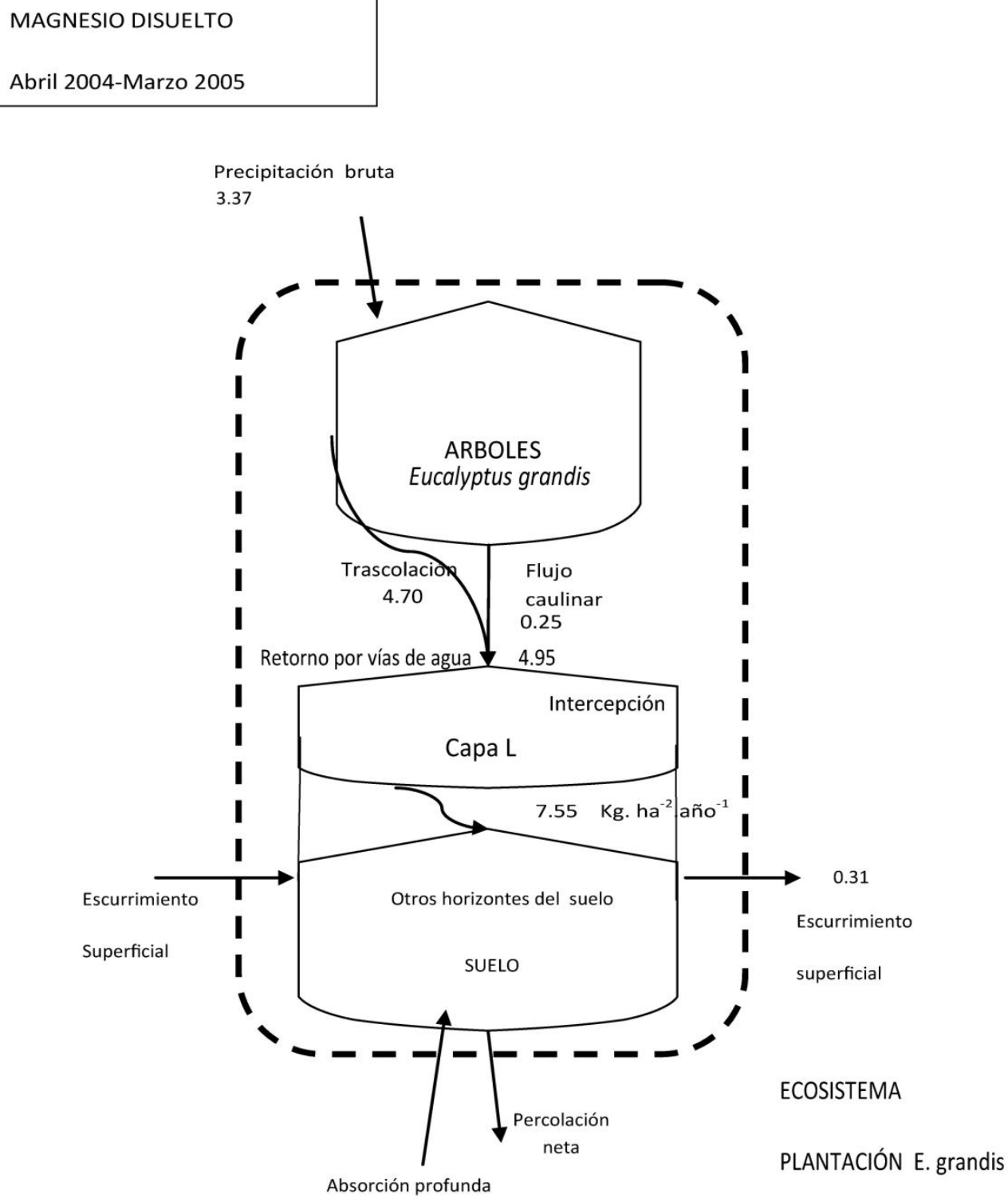

Figura 3.4.16: Magnesio disuelto $\left(\mathrm{kg} \mathrm{ha}^{-1} \mathrm{año}{ }^{-1}\right)$ en los flujos hídricos en una plantación de E. grandis. Período abril 2004 - marzo 2005. 
3.4.6.6. Carbono orgánico disuelto. El Carbono orgánico disuelto (DOC), en los sistemas naturales, se origina de actividades metabólicas autotróficas y heterotróficas y de la lisis de material muerto. Como resultado, compuestos extra-celulares lábiles, como péptidos, carbohidratos, ácidos grasos y sus derivados, de peso molecular relativamente bajo, son incorporados en la fase líquida. Por otra parte, la degradación de la lignina presente en las plantas vasculares lleva a la formación de compuestos disueltos de alto peso molecular, refractarios, de carácter aromático tales como las sustancias húmicas como ocurre en la humificación. Las cargas negativas, asociadas con grupos carboxílicos y fenólicos presentes en éstas sustancias integrantes del DOC, juegan un papel en el balance iónico de las soluciones, como Laclau et al. (2005) encontraron en sabanas y plantaciones de Eucalyptus.

COD

Abril 2004-Marzo 2005

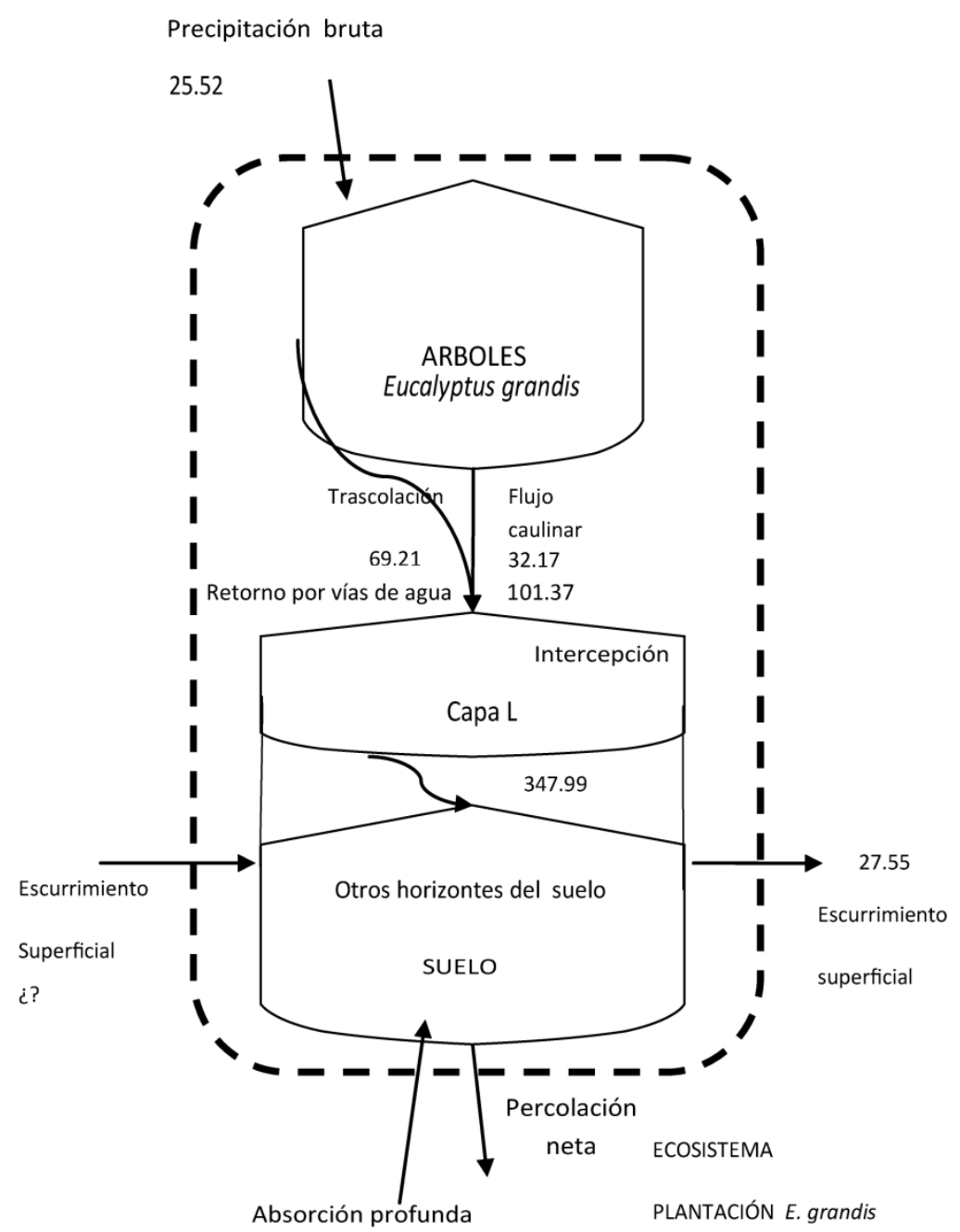


De manera que, la importancia del DOC está relacionada con la magnitud del flujo de carbono y se extiende, a causa de ésta propiedad de los aniones orgánicos, al transporte y distribución de cationes en éstos sistemas.

La cantidad de COD presente en los flujos hídricos se presenta en la Fig. 3.3.17 El carbono fue el nutriente que se encontró en mayor magnitud disuelto en los flujos hídricos de la plantación. Se observó un enriquecimiento en el contenido de COD en la precipitación neta y en el agua de lavado del mantillo producto de los procesos mencionados con anterioridad.

\subsubsection{Ciclo de nutrientes}

Barrera et al (2005) realizaron un estudio del ciclo de nutrientes en plantaciones de Eucalyptus grandis en Concordia sobre un suelo mestizo a la edad de rotación y calcularon los flujos de nutrientes utilizando las fórmulas de Cole \& Rapp (1981). Consideraron que el retorno de nutrientes es la cantidad anual de nutrientes presentes en la caída de hojarasca. La retención es el contenido de nutrientes en la producción anual de madera. El requerimiento la suma de la retención más el contenido de nutrientes en la producción de estructuras anuales (hojas, ramas finas y frutos). La absorción, se calculó como el retorno más la retención. La retraslocación o reciclado se estimó como los requerimientos menos la absorción. En la Tabla 3.4 .5 se presentan los resultados obtenidos por Barrera et al. (I.c.), la los ingresos de nutrientes por vía atmosférica y los aportes de la precipitación neta que se obtuvieron en ésta Tesis; habiéndose asimismo calculado índices producto de las relaciones entre los flujos. 


\begin{tabular}{|c|c|c|c|c|c|}
\hline & \multicolumn{5}{|c|}{$\begin{array}{c}\text { Nutriente } \\
\text { s }\end{array}$} \\
\hline & $\mathbf{N}$ & $\mathbf{P}$ & $\mathbf{K}$ & $\mathrm{Ca}$ & Mg \\
\hline - Balance & \multicolumn{5}{|c|}{ (kg ha $\left.{ }^{-1} a_{n ̃ o} o^{-1}\right)$} \\
\hline Retorno & 45.20 & 1.70 & 36.66 & 74.80 & 14.95 \\
\hline Retención & 19.30 & 1.95 & 9.00 & 39.60 & 3.00 \\
\hline Requerimientos & 116.80 & 9.25 & 80.80 & 116.90 & 30.40 \\
\hline Absorción & 64.50 & 3.68 & 45.70 & 114.40 & 18.00 \\
\hline Reciclado & 52.30 & 5.57 & 35.10 & 2.50 & 12.40 \\
\hline - Aportes & \multicolumn{5}{|c|}{$\left(k_{g ~ h a}{ }^{-1} a^{n} o^{-1}\right)$} \\
\hline Precipitación Bruta & 1.83 & 0.26 & 7.60 & 8.66 & 3.37 \\
\hline $\begin{array}{l}\text { Precipitación Neta } \\
\text { - Índices }\end{array}$ & 0.90 & 0.07 & $\begin{array}{r}21.86 \\
(\%)\end{array}$ & 10.86 & 4.95 \\
\hline Retorno/Absorción & 70 & 46 & 80 & 65 & 83 \\
\hline Retención/Absorción & 30 & 53 & 20 & 35 & 17 \\
\hline Reciclado/Requerimientos & 45 & 60 & 43 & 2 & 41 \\
\hline Absorción/Requerimientos & 55 & 40 & 57 & 98 & 59 \\
\hline Precip. Bruta/Absorción & 3 & 7 & 17 & 8 & 19 \\
\hline $\begin{array}{l}\text { Absorción directa de } \\
\text { copas }\end{array}$ & 50 & 73 & & & \\
\hline
\end{tabular}

Tabla 3.4.5: Balance de nutrientes (Barrera et al., 2005) y los aportes de nutrientes en los flujos hídricos obtenidos en ésta Tesis.

Los aportes geoquímicos en solución por las lluvias resultaron más importantes, en orden decreciente, para el $\mathrm{K}, \mathrm{Mg}$ y $\mathrm{Ca}$. Los aportes de $\mathrm{N}$ y $\mathrm{P}$ resultaron bajos, lo que es de esperar en precipitaciones procedentes de atmósferas no contaminadas.

El retorno aéreo representa un porcentaje muy importante en relación a la absorción, pero la mayor parte del mismo tiende a acumularse en el mantillo y algunos de los nutrientes a inmovilizarse en él debido a la baja tasa de descomposición por la acción microbiana. Por lo cual, al reducirse el ingreso en solución al suelo mineral de nutrientes críticos como el $\mathrm{N}$ y $\mathrm{P}$, mucho de éstos nutrientes se obtienen de los horizontes minerales a partir del legado de los pastizales sabánicos y bosques xerófilos preexistentes. La escasez de nutrientes como el $\mathrm{N}$ se manifiesta además en la captura tanto de la copa de los árboles como de los microorganismos ligados al mantillo. Las reducciones de nutrientes y el descenso del pH observados en los perfiles de suelo (Figuras 3.1 .5 y 3.1.6), que acompañan el crecimiento de 
la plantación, muestran como estas plantaciones provocan cambios profundos en el estado nutricional de los suelos arenosos evolucionados bajo pastizales y árboles nativos.

Para el caso del P y del Ca la retención es muy elevada, 53\% y $35 \%$ de la absorción respectivamente. En valores absolutos $2 \mathrm{~kg}$ de fósforo y $39 \mathrm{~kg}$ de calcio quedan retenidos anualmente en la biomasa de la plantación. Jobaggy et al. (2006) señala a la extracción de Ca como una de las principales causas de acidificación de los suelos en la pampa húmeda. En coincidencia, los resultados de los análisis de suelo de este estudio muestran reducción de Ca y disminución del pH en los sitios evaluados.

Barrera et al. (2005) calcularon la proficiencia de reabsorción para $\mathrm{N}$ y $\mathrm{P}$ en hojas senescentes recién caídas durante el período de máxima caída. La proficiencia es completa cuando los valores de concentración son menores al $0.7 \%$ de $\mathrm{N}$ y $0.05 \%$ de $\mathrm{P}$ (Killingbeck, 1996). Dichos autores encontraron una proficiencia completa de $\mathrm{N}$ y más notoriamente de $\mathrm{P}$ para plantaciones de Eucalyptus grandis sobre suelos mestizos. En el mismo estudio encontraron el cociente N/P fue de 15.5, de acuerdo a este indicador de abundancia relativa de nutrientes, el $\mathrm{P}$ sería el principal factor limitante con un desbalance manifiesto para el sitio mestizo. El estudio concluye que las plantaciones poseen muy buenos mecanismos de recuperación de nutrientes a través de la retraslocación siendo más marcado en el caso del $P$, para el cual la eficiencia de uso es mayor.

La capacidad de captar nutrientes limitantes a través del dosel y de usar eficientemente los mismos le permite mantener altas tasas de producción aún en sitios con bajas tasas de descomposición y en suelos de baja o mediana fertilidad. 


\section{CONCLUSIONES}

Del análisis de los resultados de este estudio, surgen un conjunto de conclusiones de interés e importancia silvícola y ambiental. Las mismas se ordenan en dos grupos de acuerdo a los aspectos considerados en la Tesis: 1- Las variables meteorológicas y edáficas y 2Flujos hídricos. Balance hidrológico y eficiencias. Nutrientes disueltos en los flujos.

Asimismo, esos aspectos responden a los objetivos planteados (CAPÍTULO 1), los cuales se indican entre paréntesis.

\subsection{Aspectos microclimáticos y edáficos}

(Objetivo 1: Determinar las características endoclimáticas térmicas de la plantación y compararlas con los claros circundantes. Vincular éstas características con los flujos de agua del rodal. Objetivo 2: Identificar cambios en los suelos como resultado de la conversión de pastizales a plantaciones forestales de Eucalyptus grandis. Objetivo 7: Realizar un modelo de ciclo de nutrientes de la plantación al turno integrando la información obtenida en éste estudio con la existente en la bibliografía para las mismas plantaciones.)

- La plantación al turno no creó condiciones térmicas interiores muy diferentes a las del exterior de aquella. Asimismo, los valores menores de humedad relativa a $1.5 \mathrm{~m}$ bajo la plantación parecen ser consecuencia de la falta de sotobosque. Las condiciones de humedad y temperatura sugieren que la evaporación en el piso forestal es tan elevada como en el exterior de la misma.

- Los suelos de los sitios forestados, mostraron cambios destacables que incluyeron el incremento de la acidez, y la disminución de las concentraciones totales de $\mathrm{C}, \mathrm{N}, \mathrm{Mg}$, Ca y $\mathrm{Mn}$; el aumento de la relación $\mathrm{C} / \mathrm{N}$, y de las concentraciones de Fe y $\mathrm{Al}$ a partir de los $35 \mathrm{~cm}$ de profundidad. Los cambios no son explicados totalmente por la reubicación mineral en la fracción aérea de la plantación, debida a la retención en la biomasa y necromasa forestal que conlleva la conversión de la vegetación natural a plantación forestal. Estos resultados que indican el empobrecimiento nutritivo de los suelos plantean la necesidad de investigaciones que atiendan a procesos bióticos y 
abióticos, sobre la evolución de los suelos bajo plantaciones de Eucalyptus y los factores directos (absorción) e indirectos (ej. acidificación del suelo, cambio en la calidad química y física de la materia orgánica) que influyen en los cambios. , pero también a las consecuencias de las distintas etapas del manejo de las plantaciones.

- Los cambios en las concentraciones de nutrientes disponibles e intercambiables en el primer periodo (preparación del terreno-3 años de crecimiento) serían mayores que durante los años posteriores de la rotación, a pesar de que este periodo es de una duración superior al doble del previo. La preparación del terreno, seguramente sumada a una mayor absorción para satisfacer la mayor demanda de nutrientes por unidad de masa de materia seca vegetal, emergen como procesos claves para explicar las pérdidas de nutrientes.

- Los efectos del actual manejo de cada etapa de una rotación deberían ser evaluados exhaustivamente para identificar y ponderar con precisión las etapas y procedimientos más críticos. Esto debería servir al desarrollo de buenas prácticas, que puedan ser optimizadas para evitar o mitigar los impactos negativos. Un manejo de la plantación acorde con criterios e indicadores de sustentabilidad en un contexto de referencia ecológico integrado (suelo- hidrología-nutrientes-biodiversidad), debería incluir al menos pautas claras y específicas para la preparación del terreno, la duración de las rotaciones, los tipos de cosecha, el tratamiento de los residuos de cosecha, entre otros aspectos. 


\subsection{Flujos hídricos. Balance hidrológico y eficiencias. Nutrientes disueltos en los flujos.}

(Objetivo 2: Cuantificar los flujos aéreos del ciclo hidrológico en una plantación de Eucalyptus grandis de edad al turno (11 años). Comparar la trascolación en plantaciones de 3 y 11 años. Objetivo 3: Establecer, en base a datos de eventos de lluvia individuales, modelos de regresión entre la precipitación bruta y otras vías de flujo propias del bosque con el fin de evaluar herramientas predictivas de comportamiento hidrológico de la plantación. Objetivo 4: Estimar la demanda evapotranspiratoria en una plantación de Eucalyptus grandis y las consecuencias de las pérdidas gaseosas en el balance de agua bajo el régimen de precipitaciones de la zona). (Objetivo 5: Estimar la circulación -aportes, movimientos internos y salidas- de macronutrientes por flujos de agua y ponderar su magnitud en relación a datos disponibles de nutrientes asociados a flujos de la materia seca (biomasa y necromasa).

- En la plantación las salidas gaseosas (transpiración, intercepción del dosel y del mantillo) fueron similares a los ingresos aportados por la precipitación bruta (PB). Se destaca el valor de la intercepción del mantillo, que resultó 1.26 veces el volumen de agua interceptada por las copas que alcanzó el $11 \%$ de la PB, y el valor de la transpiración, 72 \% de la PB. En base a los ingresos y egresos, la contribución a la recarga de las napas mediante la percolación sería entonces muy baja (ca. 2 \% de la $\mathrm{PB})$.

- La trascolación de las copas y del mantillo, el flujo caulinar y el escurrimiento superficial estuvieron positivamente relacionados con la PB. El flujo caulinar aumentó exponencialmente con el diámetro del árbol, por lo cual los árboles de mayor diámetro concentran mayor calidad y cantidad de recursos en la base del tronco lo que retroalimentaría su posición jerárquica en el rodal. El escurrimiento superficial inferior en la plantación respecto del pastizal aledaño, concuerda con los antecedentes y sugiere que se debe evaluar el impacto de distintas proporciones de la superficie de terreno dedicadas a esta actividad a nivel de cuenca, dentro de un régimen climático dado, para establecer umbrales críticos que puedan comprometer la disponibilidad de agua para otros sistemas del mosaico de la cuenca. 
- La plantación forestal depende principalmente del suministro de agua de las precipitaciones, sin manifiesta dependencia hídrica del agua freática, como lo demuestra la disminución del crecimiento y la reducción notoria de la transpiración en periodos secos. Este comportamiento se corresponde con el esperado para las especies del subgénero Symphyomyrtus al que pertenece E. grandis. Esta cuestión deberá tenerse en cuenta para establecer posibles limitaciones a la producción forestal de acuerdo con la variación temporal y espacial de la magnitud y régimen de las precipitaciones, como también para el desarrollo de modelos de impacto hidrológico de las plantaciones.

- La tendencia al aumento de la eficiencia en el uso de agua (ANPP/T) encontrada por Stape et al. (2004) en un gradiente de precipitaciones se observó en este estudio para un mismo sitio en dos años distintos con distintas precipitaciones. Lo que permite concluir que la eficiencia de uso del agua cambia en una misma plantación dependiendo de la disponibilidad de agua. La eficiencia en la captura aumentó con la disminución de la PB, lo que sugiere una mayor proporción asignada a la transpiración en años secos, y la consecuente reducción en los otros flujos de salida.

- El aporte de nutrientes desde la atmósfera fue bajo para los nutrientes más críticos como el nitrógeno (3\% de la absorción anual) y el fósforo (7\% de la absorción anual). Sin embargo, el menor aporte de la precipitación neta respecto de la precipitación bruta en el balance anual manifiesta que el dosel arbóreo de E. grandis absorbe estos nutrientes. Esto asimismo sugiere que esta especie posee adaptaciones múltiples para resolver limitaciones nutritivas.

- La precipitación bruta constituyó un aporte importante de potasio y magnesio (17\% y 19\%, respectivamente, de la absorción anual). El enriquecimiento en $\mathrm{K}, \mathrm{Ca}$ y $\mathrm{Mg}$ aumentó en la secuencia precipitación, trascolación y flujo caulinar. También hubo un aumento de estos nutrientes en la solución que ingresa al suelo mineral producto de la lixiviación del mantillo, respecto de la precipitación neta. Sin embargo al analizar el contenido de estos nutrientes en el suelo se observa una importante disminución de los mismos, lo que sugiere que el retorno no compensa las salidas por absorción, lavado, y otros. Este es un aspecto importante a considerar en 
investigaciones futuras, que involucran tanto efectos directos como indirectos de la plantación de eucaliptos sobre los suelos. Asimismo, puede ser un elemento a tener en cuenta en la selección de cultígenos forestales más eficientes en el uso de los recursos edáficos con el fin de reducir el impacto de la silvicultura.

- Al comparar los egresos de nutrientes disueltos en el agua de escurrimiento, respecto a los ingresos de los mismos con la precipitación neta se observó un ingreso neto positivo por vía hídrica al subsistema suelo para todos los nutrientes evaluados excepto para el COD. Esto muestra que también en los horizontes superficiales existen mecanismos de retención de nutrientes

- El C fue el nutriente de mayor magnitud disuelto en los flujos hídricos. Las cargas negativas, asociadas con grupos carboxílicos y fenólicos presentes en las sustancias integrantes del COD, juegan un papel en el balance iónico de las soluciones participando en el transporte y distribución de cationes en éstos sistemas. Los ácidos orgánicos podrían ser en parte responsables de la disminución del pH en el suelo en los horizontes superiores.

- En los suelos mestizos, las plantaciones de E. grandis crecen más que en los suelos arenosos y arcillosos de la zona, a pesar de esto, manifiestan una proficiencia completa de reabsorción de $\mathrm{N}$ y $\mathrm{P}$ que indica que estos nutrientes están limitando el crecimiento (Barrera et al., 2005). Asimismo esta tesis muestra que E. grandis tiene otros mecanismos que, en conjunto, se complementan en el uso eficiente de los nutrientes críticos mencionados: la incorporación de nutrientes por vía foliar, una gran absorción de los nutrientes del suelo, y un eficiente uso del agua en la producción, especialmente en condiciones húmedas.

- Por último, se ha destacado en el texto que varias de las mejoras en el manejo deberían tener en cuenta simultáneamente las cuestiones hidrológicas como nutritivas. Las soluciones no parecen ser necesariamente simples y requerirán creatividad y experimentación para elegir buenas prácticas. 
En síntesis, en relación con las hipótesis planteadas puede destacarse que:

Hipótesis 1: A consecuencia del cambio del tipo de vegetación, en los sitios forestados se produce un endoclima particular y procesos en los suelos que conducen a la acidificación y pérdida de nutrientes. Este trabajo mostró que existen particularidades consistentes en una escasa modificación del perfil térmico del aire dentro de la vegetación y aumentos en la temperatura en el suelo superficial que conducen a que las condiciones de variables meteorológicas que influyen en la evapotranspiración (temperatura, déficit de saturación de vapor de agua, entre ellas) determinen una considerable pérdida gaseosa de agua tanto desde el dosel como del mantillo. En cuanto a los suelos los sitios forestados en relación a los pastizales mostraron disminución del pH e importantes cambios en los contenidos de nutrientes totales y disponibles.

Hipótesis 2: Las magnitudes de los flujos hídricos en la plantación están directamente relacionados con la magnitud de la precipitación bruta y con la estructura de la plantación. En especial, en base a las mediciones de los flujos hídricos resultantes de numerosos eventos de precipitación se constató una fuerte correlación entre los distintos flujos con la precipitación bruta, lo que permite disponer de modelos que, tomados en conjunto, permiten calcular, con un conjunto mínimo de variables meteorológicas, los balances de agua anuales de plantaciones al turno de E. grandis. Pudo verificarse también que algunos flujos hídricos (por ej., la transpiración de los individuos arbóreos) dependen de variables vegetacionales (por ej. el diámetro del árbol asociado a distinta área de albura). Asimismo, en comparación con pastizales pudo constatarse que la plantación al turno de $E$ grandis, de obvia diferente estructura, tiene un distinto comportamiento de escurrimiento. Más aún, teniendo en cuenta las estimaciones de pérdidas evapotranspiratorias para pastizales y plantaciones forestales de $E$. grandis realizadas por otros autores pudo corroborarse una mayor evapotranspiración en las plantaciones forestales.

Hipótesis 3. Como consecuencia de la intercepción de agua por el dosel, del lavado y lixiviado del follaje y del mantillo, la concentración de nutrientes y la abundancia de sustancias orgánicas cromóforas aumenta en la secuencia de eventos de precipitaciones, trascolación, 
flujo caulinar, escurrimiento. Asimismo la concentración de nutrientes disminuirá con la magnitud de los eventos. En general a medida que el agua atravesó el dosel arbóreo aumentó la concentración de nutrientes en solución. Esto no ocurrió al comparar las concentraciones de $\mathrm{P}$ y $\mathrm{N}$ de la precipitación bruta con las de la precipitación neta, contrariamente a lo observado para los cationes, existió absorción por el dosel arbóreo de estos nutrientes críticos.

Hipótesis 4. Debido a los procesos de descomposición del mantillo hay un aporte de nutrientes en solución que ingresan en el suelo mineral. Esto se demostró para los cationes evaluados ( $\mathrm{Ca}, \mathrm{K}$ y $\mathrm{Mg}$ ) y el COD, mientras que para el $\mathrm{N}$ y el $\mathrm{P}$, los aportes no fueron muy diferentes que los de la precipitación neta. Debido a la alta relación entre las concentraciones de $\mathrm{C} / \mathrm{N}$ y de $\mathrm{C} / \mathrm{P}$ del mantillo posiblemente parte de los aportes de estos nutrientes con la precipitación neta quedan inmovilizados en el mismo.

Hipótesis 5. La magnitud de la pérdida de nutrientes por escurrimiento es proporcional a la magnitud del evento de Iluvia. El escurrimiento es un flujo de salida de nutrientes pero la tendencia de las relaciones observadas mostró una disminución de las concentraciones con la magnitud del evento, esta tendencia fue significativa para el COD y para el P.

Hipótesis 6. En condiciones ecológicas comparables la eficiencia de uso de agua en la producción de madera de esta especie es similar a la encontrada en otras regiones de cultivo. La eficiencia en el uso de agua está relacionada con la cantidad de agua precipitada para el rango de valores de las precipitaciones locales y fue comparable a la eficiencia encontrada en otras regiones. 


\subsection{Líneas de investigación futura}

Esta tesis ha permitido visualizar algunas líneas de investigación que parecen prioritarias al efecto de un mejor conocimiento de las consecuencias ambientales de plantar E. grandis y de contribuir a una silvicultura más acorde con los principios de la sustentabilidad. Varias de las mismas se han indicado en párrafos anteriores de éstas conclusiones y están vinculadas al uso de resultados de ésta tesis como insumos de los nuevos estudios.

- Desarrollar modelos hidrológicos integrales, y modelos hidrológicos productivos empleando como insumos las regresiones y otra información de ésta tesis, la existente en la bibliografía y otra a obtener, con la finalidad de tener una mayor capacidad de predicción de la respuesta de las plantaciones y su ambiente a los cambios en las condiciones meteorológicas, y también de los efectos de las forestaciones sobre el paisaje.

- Identificación y ponderación de los procesos vinculados con la acidificación y la pérdida de nutrientes en el suelo en los sitios forestados, y la determinación de la importancia relativa de los distintos procesos. Esto tiene por finalidad entender los mecanismos bióticos y abióticos que puedan estar provocando efectos sobre los suelos que comprometan la producción forestal.

- Valoración del impacto de las tareas tradicionales y de propuestas alternativas de manejo de las distintas fases (preparatorias del terreno para la plantación, cosecha, postcosecha, etc) sobre los suelos, el agua y los nutrientes.

- Ensayar alternativas de manejo que favorezcan el aumento de la calidad e incremento de la tasa de descomposición del mantillo forestal y, consecuentemente, una mayor disponibilidad de nutrientes críticos. La incorporación de especies de leguminosas, herbáceas y/o perennes, sea con fines de usarlas como abonos orgánicos o bien asimismo sumarlas a la producción 
forestal, es un camino de importancia para ayudar a resolver cuestiones de nutrición nitrogenada y evitar el uso de fertilizantes nitrogenados que pudieran incrementar el efecto de la acidez sobre los suelos incluido sus bases.

- Evaluación de especies y/o clones teniendo como criterio fundamental la eficiencia en el uso del agua y los nutrientes. Emplear dichos criterios para la selección en los programas de mejoramiento genético. 
Ing. Agr. Natalia Tesón

\section{Bibliografía}




\section{BIBLIOGRAFÍA}

- ALMEIDA, A. C., SOARES, J. V., LANDSBERG, J. J., REZENDE, G. D. 2007. Growth and water balance of Eucalyptus grandis hybrids plantations in Brazil during a rotation for pulp production. Forest Ecology and Management, 251: 10-21.

- ALLISON, G. B., HUGHES, M. W. 1983. The use of natural tracers as indicators of soil-water movement in a temperate semi-arid region. Journal of Hydrology, 60:157-173.

- ANDERSON, J.M., INGRAM J.S.I.1993. Tropical Soil Biology and Fertility: a Handbook of Methods, $2^{\text {nd }}$ edition. C.A.B. International. Wallingford, UK. 221 p.

- ANDRADE, G de C., DA SILVA H.D., FERREIRA, C.A., BELLOTE, A.F.J., MORO, L. 1995. Contribución del agua de lluvia en la oferta de nutrientes minerales para Eucalyptus grandis. Bosque, 16(1): 47 -51 .

- APHA.1985. Standard Methods for the Examination of Water and Wastewater. American Public Health Association. Washington DC.

- ATTIWILL, P. M., LEPPER, G. W. 1987. Forest soils and nutrient cycles: Fire and Forest. Melbourne University Press.

- ATTIWILL, P. M., WESTON, C. J. 2001. Chapter 7: Forest soils. Pp. 157 - 187. En Evans, J. (Ed.), Forest Handbook. Blackwell Science Ltd.

- BAKER, T. G., ATTIWILL, P. M. 1987. Fluxes of elements in rain passing through forest canopies in south-eastern Australia. Biogeochemistry 4: 27-39.

- BARRerA, M. D., GOYA, J. F., FRANGI, J. L. 2005. Ciclo y eficiencia en el uso de $N$ y $P$ en plantaciones de Eucalyptus grandis (Hill ex Maiden) sobre diferentes tipos de suelos en Entre Ríos, Argentina. Actas Tercer Congreso Forestal Argentino y Latinoamericano. Corrientes, Argentina.

- BARROS, N. F.1990. Relaçao solo-eucalipto. Editora Folha de Viçosa, Viçosa, Brasil. 330 p.

- BENYON, R. G. 1999. NighTtime water use in an irrigated Eucalyptus grandis plantation. Tree Physiology, 19: 853-859.

- BELL, D. T., WILLIAMS, J. E. 1997. Eucalypt ecophysiology. Pp. 168 -195. En: Williams, J. Woirnarski, J. (Eds), Eucalypts ecology. Individuals to ecosystems. Cambridge University Press, UK.

- BINKLEY, D., STAPE, J. L., RYAN, M.G. 2004. Thinking about efficiency of resource use in forest. Forest Ecology and Management, 193:5 -16.

- BLOOM PR \& LEENHEER JA. 1989. Vibrational, electronic, and high-energy spectroscopic methods for characterizing humic substances. Cap.14, p 409-446. En: Hayes, M.H.B, MacCarthy P., Malcolm R.L., Swift, R.S. (eds). Humic substances II. In search of structure. John Wiley \& Sons. 
- BOOTH, T. H., PRIOR, L. D. 1991. Climatic requirements of some commercially important eucalypt species. Forest Ecology and Management, 43: 26-31.

- BRAIER, G. 2004. Estudio de tendencias y perspectivas del sector forestal en América Latina. Informe Nacional Argentina. Secretaría de Ambiente y Desarrollo Sustentable de la Nación Argentina (SAD y S). Secretaría de Agricultura, Ganadería, Pesca y Alimentos de la Nación Argentina (SAGP y A). Organización de las Naciones Unidas para la Agricultura y la Alimentación (FAO). $67 \mathrm{p}$.

- BRAIER, G. 2004. Tendencias y perspectivas del sector forestal al año 2020. SAGPyA. FAO. 220 p.

- BRUIJNZEEL, L. A. 1997. Hydrology of forest plantations in the tropics. Pp. 125 - 168. En: Nambiar, E.K.S., Brown, A. (eds), Management of soil, nutrients and water in tropical plantation Forests. CSIRO. $571 \mathrm{p}$.

- CALDER, I.R., HALL, R.L., PRASANNA, K.T. 1993. Hydrological impact of Eucalyptus plantation in India. Journal of Hydrology, 150: 635-648.

- CALDER, I. A. 1998. Water use by forests, limits and controls. Tree Physiology, 18: 625-631.

- CANADELL, J., JACKSON, R.B., EHLERINGER, J.R., MOONEY, H.A., SALA, O.E., SCHULZE, E.D. 1996. Maximum rooting depth of vegetation types at the global scale. Oecologia, 108: 583-595.

- CARRASCO - LETELIER, L. EgUREN, G., CASTIÑEIRA, C. PARRA, O., PANARIO, D. 2004. Preliminary study of prairies forested with Eucalyptus sp. at the northwestern uruguayan soils. Environmental Pollution, 127: 49-55.

- CARPINETTI, L. A. DALLA TEA, F. GLADE, J., MARCO, M.A. Ed. 1995. Manual para productores de eucaliptos de la Mesopotamia argentina. SAGPyA - INTA. Argentina.162 p.

- CARVAlHo BALIEIRO, F., fRANCO, A. A., FERREIRA FONTES, R. L., DIAS, L. E., CARNEIRO CAMPELLO, E. F., FARIA, S. M. 2007. Evaluation of the throufall and stemflow nutrient contents in mixed and pure plantations of Acacia mangium, Pseudisamenea guachapele and Eucalyptus grandis. Revista Árvore, Viçosa - MG, 31 (2): 339-346.

- CHAPIN, F. S., MATSON, P.A. MOONEY, H.A. 2002. Principles of terrestrial ecosystem ecology. Ed. Springer-Verlag. $426 \mathrm{p}$.

- CHEN, C.R., CONDRON, L.M., DAVIS, M.R., SHERLOCK, R.R. 2003. Seasonal changes in soil phosphorus and associated microbial properties under adjacent grassland and forest in New Zealand. Forest Ecology and Management, 177: 539-557.

- CHEN, Y., SENESI N., SCHNITZER, M. 1977. Information provided on humic substances by E4/E6 ratios. Soil Science Society America Journal, 41: 352-358.

- CONTI, M. E. 2000. Principios de Edafología. Ed. Facultad de Agronomía UBA. 430 p. 
- DALLA TEA, F. 2008. Riesgos climáticos que afectan las plantaciones forestales de la región. Rev. COPAER, Entre Ríos 23: 12-15.

- DAWSON, T. E. 1996. Determining water use by trees and forests from isotopic, energy balance and transpiration analyses: the roles of tree size and hidraulic lift. Tree Physiology, 16: 263-272.

- DE HAAN, H. 1974. Effect of a fulvic acid fraction on the growth of a Pseudomonas from Tjeukemeer (The Netherlands). Freshwater Biology, 4:301-310.

- DE HAAN, H. 1977. Effect of benzoate on microbial decomposition of fulvic acids in Tjeukemeer (The Netherlands). Limnology and Oceanography, 22:38-44.

- DE HAAN, H., DE BOER, T., KRAMER, H.A ., VOERMAN, J. 1982. Applicability of light absorbance as a measure of organic carbon in humic lake water. Water Research, 16:1047-1050.

- DELFS, J. 1967. Interception and stemflow in stands of Norway spruce and beech in West Germany. Pp 179 -185. En: Sopper, W.E., Lull, H. W. (Eds), Forest Hidrology. Pergamon Press, Gran Bretaña.

- Delgado, S., Alliaume, F., García PrÉChAC, F., hernándeZ, J. 2006. Efecto de las plantaciones de Eucalyptus sp. sobre el recurso suelo en Uruguay. Agrociencia, 10 ( 2): 95 - 107.

- DURÁN, A., GARCíA-PRÉChAC, F., PÉREZ BIDEgain, M., FRIONI, L., SICARDI, M., MOLTENI, C., BOZzO, A. 2001. Propiedades físicas, químicas y biológicas. Cap. 2.5. Suelos y Vegetación. In: Informe Final, Proyecto Monitoreo ambiental de plantaciones forestales en Uruguay, Convenio UDELAR-División Forestal MGAP-Banco Mundial.

- DYE, P. J. 1987. Estimating water use by Eucalyptus grandis with the Penman Monteith equation. Forest Hydrology and Watersbed Management - Hydrologie Forestiere et Amenagement des Bassins Hydrologiques, Proceedings of the Vancouver Symposium August 1987, Actes du Colloque de Vancouver, 167: 329 - 337.

- DYE, P. J. 1996. Response of Eucalyptus grandis trees to soil water deficits. Tree Physiology, 16: 233-238.

- DYE, P., Vilakasi, P., Gush, M., Ndlela, R., Royappen, M. 2001 Investigation of the feasibility of using trunk growth increments to estimate water use of Eucalyptus grandis and Pinus patula plantations. WRC Report No.:809/01/01. 43 pp.

- ELDRIDGE, K, DAVIDSON, J., HARWOOD, C, VAN WIK, G. 1994. Eucalypt Domestication and Breeding. Clarendon Press, Oxford. 288 p.

- FAO. 2002. Bibliografía anotada sobre los efectos ambientales, sociales y económicos de los eucaliptos (versión en español), Documentos de Trabajo: Plantaciones forestales. Documento de Trabajo FP/17S. Palmberg - Lerche, C. Servicio de Desarrollo de Recursos Forestales. Dirección de Recursos Forestales, FAO. Roma (inédito). 
- FAO. 2006. Evapotranspiración del cultivo. Guías para la determinación de los requerimientos de agua de los cultivos. Estudio FAO Riego y Drenaje 56. 322 p.

- FARLEY, K. A., JOBBAGY, E.G., JACKSON, R. B. 2005. Effects of afforestation on water yield: a global synthesis with implications for policy. Global Change Biology, 11, 1565-1576.

- FEDERER, C.A., HORNBECK, J.W., TRITTON, L.M., MARTIN, C.W., PIERCE, R.S. 1989. Long-term depletion of calcium and other nutrients in eastern US forests. Environmental Management, 13: 593-601.

- FLORENCE, R.G. 1996. Ecology and silviculture of eucalyptus forests. CSIRO. Australia. 413 p.

- FRANGI, J. L, RICHTER, L. L.1994. Balances hídricos de bosques de Nothofagus de Tierra del Fuego, Argentina. Revista de la Facultad de Agronomía (UNLP), 70: 65-79.

- FRANGI, J. L., BARRERA M. D., PUIGDEFÁBREGAS, J., YAPURA, P., ARAMBARRI, A., RICHTER, L. 2004. Ecología de los bosques de Tierra del Fuego Capítulo 18: 1 - 88. En: ARTURI, M.F., FRANGI, J.L., GOYA, J.F. (eds). 2004. Ecología y Manejo de los Bosques de Argentina. EDULP (Editorial Universidad Nacional de La Plata). ISBN 950-34-0307

- FRANGI, J.L., GOYA, J.F., BIANCHINI, F., LUY, A.M., LAROCCA, F., MARCÓ, M.A. 2000. Ciclo de Nutrientes en Plantaciones de Eucalyptus grandis en la provincia de Entre Ríos. Informe Final PIA 11/96. Proyecto Forestal de Desarrollo. SAGPyA-BIRF. LISEA/UNLP-INTA/EEA Concordia (manuscrito). $65 \mathrm{p}$.

- GAO, Z., ZHANG, Z., ZHANG, X. 2009. Responses of water yield to changes in vegetation at a temporal scale. Front. For. China 2009, 4(1): 53-59.

- GARRAN, S. M. 2007. El clima de la Región de Concordia y sus heladas. XXII Jornadas Forestales de Entre Ríos. Concordia, Argentina. III 1- III 3.

- GELLER, A. 1985. Degradation and formation of refractory DOM by bacteria during simultaneous growth on labile substrates and persistent lake water constituents. Schweizerische Zeitschrift fur Hydrologie, 47:27-44.

- GLADE, J. FRIEDL, R. 1988. Ecuaciones de volumen para Eucalyptus grandis Hill ex MAIDEN en el noreste de Entre Ríos. VI Congreso Forestal Argentino, Santiago del Estero. II: 416 - 420.

- GOYA, J.F. 2004. Análisis del ciclo de nutrientes en Eucalyptus grandis de dos edades de plantación en el NE de Entre Ríos. Trabajo Presentado en el XIX Congreso Argentino de la Ciencia del Suelo. Paraná, Argentina.

- GOYA, J.F., FRANGI, J.L., DALLA TEA, F. 1997. Relación entre biomasa aérea, área foliar y tipos de suelos en plantaciones de Eucalyptus grandis del NE de Entre Ríos, Argentina. Revista de la Facultad de Agronomía de La Plata, 102: 1 - 20. 
- GOYA, J.F., FRANGI, J.L., DENEGRI, G., LAROCCA, F. 2009. Simulación del impacto de diferentes regímenes de cosecha sobre el capital de nutrientes e indicadores económicos en plantaciones de Eucalyptus grandis del NE de Entre Ríos, Argentina. AUGMDOMUS, 1:1-17.

- GOYA, J.F., FRANGI, J.L., PÉREZ, C., DALLA TEA, F. 2008. Decomposition and nutrient release from leaf litter in Eucalyptus grandis plantations on three different soils in Entre Ríos, Argentina. BOSQUE 29 (3): 217-226,

- GRANIER, A. 1985. Une nouvelle méthode pour la mesure du flux de sève brute dans le tronc des arbres. Annals of Forest Science, 42 (2) : 193 - 200.

- GRANIER, A. 1996. Sap flow measurement using the radial flowmeter technique. Unité $d^{\prime}$ Écophysiologie Forestiere. INRA France.

- HALLE, F., OLDEMAN, R.A., TOMLINSON, P.B. 1978. Tropical trees and forests an architectural analysis. Springer verlag, Berlín. $441 \mathrm{p}$.

- HERNANDEZ, M.A., GONZALEZ, M., TROVATTO, M. 2001. La zona no saturada en áreas de llanura. Estimación de la evapotranspiración real por medio del balance hidrológico en la ZNS. Congreso en memoria de Germán Galarza. La ZNS y las aguas subterráneas. IGME, Barcelona. Pp 241-247.

- HERNANDEZ, M.A., GONZALEZ, M., TROVATTO, M 2001. La zona no saturada en áreas de llanura. Estimación de velocidad de infiltración por correlación diaria aportes-freatigrafía. Congreso en memoria de Germán Galarza. La zona no saturada y las aguas subterráneas IGME, Barcelona. Pp 241-247.

- HEDIN, L.O., ARMESTO, J.J., JOHNSON, A.H. 1995. Patterns of nutrients loss from unpolluted, oldgrowth temperate forests: evaluation of biogeochemical theory. Ecology 76: 493-509.

- HELVEY, J. D., PATRIC, J.H. 1965. Canopy and litter interception of rainfall by hardwoods of eastern United States. Water resource Res., 1:193-206.

- HEWLETT, J.D., NUTTER, W.L. 1996. An Outline of Forest Hidrology. University Of Georgia. 137p.

- HOPMANS, P., STEWART, H.T.L., FLINN, D.W. 1993. Impacts of harvesting on nutrients in a eucalypt ecosystem in southeastern Australia. Forest Ecology and Management, 59: 29-57.

- HORVATH, R.S. 1972. Microbial co-metabolism and the degradation of organic compounds in nature. Bacteriological Review, 36:146-155

- HUBBARD, R.M., RYAN, M.G., GIARDINA, C.P., BARNARD, H. 2004. The effect of fertilization on sap flux and canopy conductance in a Eucalyptus saligna experimental forest. Global Change Biology, 10: 427-436.

- ICANTÚ SILVA, I. GONZALEZ RODRÍGUEZ, H. 2001. Interception loss, troughfall and stemflow chemystry in pine and oak forests in northeastern Mexico. Tree Physiology, 21: 1009-1013. 
- IGLESIAS-TRABADO, G., WILSTERMANN, D. 2008. Eucalyptus universalis. Global cultivated eucalypt forest map. Version 1.0.1. En: GIT Forestry Consulting. www.git-forestry.com

- JACKSON, R.B.1999. The importance of root distributions for hydrology, biogeochemistry, and ecosystem functioning. Pp. 219-240. En: Tenhunen, J.D., Kabat, P. (eds.), Integrating hydrology, ecosystem dynamics and biogeochemistry in complex landscapes. John Wiley \& Sons Ltd., Chichester, UK.

- JIMENEZ, E., VEGA, J.A., PEREZ-GOROSTIAGA, P., FONTURBEL, T., CUIÑAS, P., FERNANDEZ, C. 2007. Evaluación de la transpiración de Eucalyptus globulus mediante la densidad de flujo de savia y su relación con variables meteorológicas y dendrométricas. Boletín del CIDEU, 3:119-138.

- JOBBAGY, E. G., JACKSON, R. B. 2003. Patterns and mechanisms of soil acidification in the conversión of grassland to forests. Biochemistry 64: $205-229$.

- JOBBAGY, E., JACKSON, R.B. 2004a. Groundwater use and salinization with grassland afforestation. Global Change Biology, 10 (8): 1299 - 1312.

- JOBBAGY, E., JACKSON, R.B. 2004b. The uplift of soil nutrients by plants: biogeochemical consequences across scales. Ecology, 85 (9): 2380-2389.

- JOBBAGY, E.G., VASAllo, M., FARLEY, K.A., PIÑEIRO, G., GARBULSKY, M.F., NOSETTO, M.D., JACKSON, R.B., PARUELO, J.M. 2006. Forestación en pastizales hacia una visión integral de sus oportunidades y costos ecológicos. Agrociencia (Uruguay), 10 (2): 109 - 124.

- JOHNSON, M. S., LEHMANN, J. 2006. Double-funneling of trees: stemflow and root-induced preferencial flow. Ecoscience, 13 (3):324 - 333.

- JUDD, T.S. 1996. Simulated nutrient losses due to timber harvesting in highly productive eucalypt forests and plantations. Pp. 249-58. En: Attiwill, P.M., Adams, M.A. (eds), Nutrition of Eucalypts, CSIRO, Melbourne.

- KALLARACKAL, J., SOMEN, C.K. 1995. Water use by Eucalyptus tereticornis stands of differing density in southern India. Tree Physiology, 17: 195-203.

- KAUFMANN, M.R., KELLIHER, F.M. 1991. Measuring transpiration rates. Pp 117-140.En: Lassoie, J.P., Hinckley T.M. (eds), Techniques and Approaches in Forest Tree Ecophysiology. CRC Press, Boca Raton.

- KAYE, J.P., HART, S.C. 1997. La competencia por el nitrógeno entre plantas y microorganismos del suelo. Trends in Ecology and Evolution, 12:139-143

- KEITH, H. 1997. Nutrient cycling in eucalypt ecosystems. Pp 197-226. En: WILLIAMS, J.E., WOIRNARSKY, J. Z. (eds), Eucalypt Ecology, individuals to ecosystems. Cambridge University Press, Cambridge, UK. 
- KELLIHER, F.M., LEUNING, R., SCHULZE, E-D. 1993. Evaporation and canopy characteristics of coniferous forests and grasslands. Oecologia, 95: 153-163.

- KIEKENS, J.P. 1997. Certification and its implications for Eucalyptus production and trade. IUFRO Conference in Silviculture and Improvement of Eucalypts, Salvador, Brasil, 4: 1-11.

- KILLINBECK, K. T. 1996. Nutrients in senesced leaves: keys to the search for potential resorption and resorption proficiency. Ecology, 77(6) : 1716-1727.

- $\quad$ KIMMINS, J.P. 1997. Forest Ecology. Prentice Hall. NJ, EEUU.

- KOROL, R.L., KIRSCHBAUM, U.F., MYERS, B.J. 2000. Carbon isotope discrimination of irrigated and fertilised Eucalyptus grandis grown in different climates. CSIRO. Technical Report No. 120. 9 p..

- LACLAU, J.P. 2001. Dynamique du functionnement mineral d'une plantation d'Eucalyptus. Institut National Agronomique Paris- Grignon. Thèse pour obtenir le grade de Docteur de I'Institute National Agronomique Paris- Grignon: 1-164.

- LACLAU, J.P., RANGER, J., BOUILLET, J.P., NZILA, J. D., DELEPORTE, P. 2005. Nutrient cycling in a clonal stand of Eucalyptus and an adjacent savanna ecosystem in Congo.1.Chemical composition of rainfall, troughfall and stemflow solutions. Forest Ecology and Management 176:105 - 119.

- $\quad$ LACLAU, J.P., RANGER, J., MORAES GONÇALVES, J. L., MAQUERE, V., KRUSCHE, A.V., M'BOU, A. T., NOUVELLON, Y., SAINT-ANDRE, L., BOUILLET, J.P., CASSIA PICCOLO, M., DELEPORTE, P. 2009. Biogeochemical cycles of nutrients in tropical Eucalyptus plantations. Main features shown by intensive monitoring in Congo and Brazil. Forest Ecology and Management: 259, 1771-1785.

- LANDSBERG, J.J., GOWER, S.T. 1997 Applications of physiological ecology to forest management. Academic Press, USA. 354 p.

- LARCHER, W. 1977. Ecofisiología vegetal. Ed. Omega. Barcelona, España.

- $\quad$ LAROCCA, F., DALLA TEA, F., SCHULZ, G. 2009. Manejo intensivo de rebrotes de Eucalyptus grandis en el NE de Entre Ríos. Actas del XIII World Forestry Congress. Buenos Aires, Argentina. Pp: 1-9.

- LECO CORPORATION. 2005. Carbon and Nitrogen in Soil and Sediment. Organic Application Note TruSpec CN, Form No. 203-821-275, St. Joseph, MI.

- LECO CORPORATION. 2009. Modification of method Moisture and Ash Determination in Flour. Organic Application Note TGA701, Form No. 203-821-359, St. Joseph, MI, USA.

- LE MAITRE, D.C., SCOTT, D.F., COLVIN, C. 1999. A review of information on interactions between vegetation and groundwater. Water SA 25: 137-152.

- LEONARD, R. 1967. Matemathical theory of interception. Pp 131-136. En: Sopper, W.E., Lull H.W. (eds), Forest Hidrology. Pergamon Press, Gran Bretaña. 
- LEYTON, L., REYNOLDS, E.R.C., THOMPSON, F.B.. 1967. Rainfall Interception in forest and moorland. Pp 163-178. En: Sopper, W.E., Lull H.W, (eds), Forest Hidrology. Pergamon Press, Gran Bretaña.

- LUH HUANG, C-Y. , SCHULTE, E.E. 1985. Digestion of plant tissue for analysis by ICP Emission Spectrometry. Communications in Soil Science and Plant Analysis, 16: 943-958.

- MACKERETH, F.J.H., HERON, J., TALLING, J.F.. 1989. Water Analysis: some Revised Methods for Limnologists. Fresh Water Biological Association. Scientific Publication $\mathrm{N}^{\circ} 36$. Windermere. Inglaterra. $120 \mathrm{p}$.

- MARCO, M.A. 1998. Incidencia del origen de la semilla y el sitio en el crecimiento de Eucalyptus grandis en el NE de Entre Ríos. Actas de las III Jornadas Forestales de Entre Ríos. Pp: 4.1 - 4.15.

- MARCO, M. A., SHIELD, E. 2005. Eucalyptus de rápido crecimiento para usos sólidos. IDIA XXI Forestales, 5 (8):184 -185.

- MARCO, M. A., HARRAND, L., OBERSHELP, J., GARRAN, S. 2007. Especies e híbridos de eucaliptos para sitios fríos de Entre Ríos. Día de campo forestal. EEA Concordia. Pp. 5-20.

- MC CUNE, D.C., BOYCE, R.L. 1992. Precipitation and the transfer of water, nutrients and pollutants in tree canopies. Tree, 7: 4-7.

- MC LEAN, E.O. 1982. Soil pH and Lime requirement. Pp. 199 - 209. En: PAGE, A.L., MILLER, R.H. , Keeney, D.R. (Eds.), Methods of Soil Analysis, Part 2. Chemical and Microbiological Properties, American Society of Agronomy, Madison, WI, USA.

- MC NAUGHTON, K.G. 1976. Evaporation and advection II: evaporation downwind of a boundary separating regions having different surface resistances and available energies. Quarterly Journal of the Royal Meteorological Society, 102: 193-202.

- MEINZER, F.C., CLEARWATER, M.J., GOLDSTEIN, G.. 2001. Water transport in trees: current perspectives, new insights and some controversies. Environmental and Experimental Botany, 45: 239-262.

- MENGEL, K., KIRBY, E. 2000. Principios de nutrición vegetal. Ed. International Potash Institute, Basel. $692 \mathrm{p}$.

- MESKIMEN, G.; FRANCIS, J. K. 2000. Eucalyptus grandis. Pp. 211-217. En: FRANCIS, J.K., Lowe, C.A. (Eds). Bioecología de árboles nativos y exóticos de Puerto Rico y las Indias Occidentales. USDA Forest Service. Reporte Técnico General IITF-15. 582 p.

- MURPHY, J., RILEY, J.P.1962. A modified single solution method for the determination of phosphate in natural waters. Anal. Chem. Acta 27: 31-36. 
- MYERS, B.J., THEIVEYANATHAN, N.D., O'BRIEN, N.D., BOND, W.J. 1996. Growth and water use of Eucalyptus grandis and Pinus radiata plantations irrigated with effluent. Tree Physiology: 16: $211-$ 219.

- NOSETTO, D.M., JOBBAGY, E.G., PARUELO, J.M. 2005. Land use change and water losses: the case of grassland afforestation accross a soil textural gradient in central Argentina. Global Change Biology, 11: $1101-1117$.

- ODUM, H.T. 1971. Environment, Power and Society. Wiley, Nueva York, NY. $331 \mathrm{p}$

- OLBRICH, B.W.1991. The verification of the heat pulse technique for estimating sap flow in Eucalyptus grandis. Canadian Journal Forestry, 21: 836 - 841.

- O' LAUGHLIN, E., NAMBIAR, E.K.S. 2001. Plantations, Farm Forestry and Water. A discussion paper. Water and salinity. Issues in Agroforestry No. 8. RIRDC Publication No. 01/137. 26 p.

- OYARZUN, C.E., HUBER, A .W., VASQUEZ, S. G. 1985. Balance hídrico en tres plantaciones de Pinus radiata. I: Redistribución de las precipitaciones. Bosque, 6 (1): 3-14.

- PARKER, G.G. 1983. Throughfall and stemflow in the forest nutrient cycle. Adv. Ecol. Res., 13: 57-133.

- PEREZ BIDEgain, M., GARCIA-PRECHAC, F., DURAN, A., 2001a. Soil use change effect from pastures to Eucalyptus spp., on some soil physical and chemical properties in Uruguay. In: Proceedings of the 3rd International Conference on Land Degradation, Rio de Janeiro, in CD-ROM.

- POORE, M.E.D., FRIES, C.1985. The ecological effects of Eucalyptus. FAO Forestry Paper No. 59. FAO, Rome. 87 p.

- REBORI, M.G, DIAZ, R. A. 2002. Análisis de la intercepción de la lluvia en un monte de Eucalyptus dunnii. IX Reunión Argentina de Agrometeorología. Pp: 89-90.

- RÉBORI, M.G. 2007. Sensibilidad de ecuaciones de evapotranspiración en la estimación de los consumos de agua de Eucalyptus dunnii. Anais I Seminario de Recursos Hídricos da Bacia Hidrográfica do Paraíba do Sul: o Eucalipto e o Ciclo hidrológico. Taubaté, Brasil. Pp 237 - 244.

- ROBERTS, S., VERTESSY, R. 2001. Transpiration from Eucalyptus sieberi (L. Johnson) forests of different age. Forest Ecology and Management, 143: 153-161.

- SANTI, M., BIANCHI G., REZZÓNICO G., 2009. Agua subterránea en el noreste de Entre Ríos. Actas VI Congreso Argentino de Hidrogeología. Planificación y gestión de aguas subterráneas. Santa Rosa, La Pampa. Pp. 63-72.

- SALISBURY, F.B., ROSS, C.W. 1994. Fisiología Vegetal. Ed. Iberoamérica S.A. de C.V. 759 p. 
- SAVÉ, R., HERRALDE, F. DE, BIEL, C. 2005. Aproximación al ciclo del agua en ecosistemas forestales. Investigación Agraria: Sist. Recur. For. 14(3): 497 - 512.

- SCHENK H.J., JACKSON, R.B. 2002. The global biogeography of roots. Ecological Monographs, 72: 311-328.

- SICARDI, M., GARCÍA-PRÉCHAC, F., FRIONI, L. 2004. Soil microbial indicators sensitive to land use conversion from pastures to conmercial Eucalyptus grandis (Hill ex Maiden) plantations in Uruguay. Applied Soil Ecology, 27: 125-133.

- SMN (Servicio Meteorológico Nacional). 1992. Estadísticas Climatológicas 1981-1990. Fuerza Aérea Argentina, Comando de Regiones Aéreas. Buenos Aires, Argentina. SMN. (Serie B NE 37).

- SOARES, J.V., ALMEIDA, A.C. 2001.Modeling the water balance and soil water fluxes in a fast growing Eucalyptus plantation in Brazil. Journal of Hydrology, 253: 130-147.

- $\quad$ SPURR, S.H., BARNES, B.V. 1980. Forest Ecology. John Wiles \& Sons. USA. 687 pp.

- STAPE, J. L. 2002. Production ecology of clonal Eucalyptus plantations in northeastern Brazil. Dissertation for the degree of Doctor of Philosophy. Department of Forest Science. Colorado State University. 226 pp.

- STAPE, J.L., BINKLEY, D., RYAN, M.G. 2004a. Eucalyptus production and the supply, use and efficiency of use of water, light and nitrogen across a geographic gradient in Brazil. Forest Ecology and Management , 193: 17- 31.

- STAPE, J.L., BINKLEY, D., RYAN, M.G., DO NASCIMIENTO GOMES, A. 2004b. Water use, and the water efficiency in a Eucalyptus plantation. Bosque, 25 (2): 35-41.

- STAPE, J. L., MORAES GONÇALVES, J. L., GONÇALVES, A. N. 2001. Relationships between nursery practices and field performance for Eucalyptus plantations in Brazil. New Forests 22: 19-41.

- STEVENSON, F.J. 1982.Humus chemistry: genesis, composition, reactions. Wiley, New York. 443pp.

- SWITZER, G.L., NELSON, L.E. 1972. Nutrient accumulation and cycling in loblolly pine (Pinus taeda L.) plantation ecosystems: the first 20 years. Soil Sci. Soc Amer. Proc., 36: 143-147.

- TASI, H.1993. Carta de Suelos de la República Argentina. Departamento Concordia. Provincia de Entre Ríos. Convenio INTA - Gobierno de Entre Ríos.

- TEIXEIRA DIAS, H.C. 2004. Precipitação efetiva e aporte de nutrientes pelas chuvas em florestas plantadas. Anais do Seminário sobre silvicultura em florestas plantadas. Vitoria. Espíritu Santo. Brasil. 196- 211.

- TERRADAS, J. 2001. Ecología de la vegetación. De la ecofisiología de las plantas a la dinámica de comunidades y paisajes (1a Ed). . Ed. Omega. 703 p. 
- TESON, N., CONZONNO, V.H., ARTURI, M.F., FRANGI, J.L. 2009. Carbono orgánico disuelto en flujos hídricos de plantaciones de Eucalyptus grandis del NE Entre Ríos, Argentina. VI Congreso da Meio Ambiente AUGM- San Carlos, Brasil, on-line.

- TESON, N., LICATA, J.A., MONTEOLIVA, S. 2010. Informe final proyecto nacional. Determinación de las bases ecofisiológicas de la silvicultura para la producción de madera de calidad. EEA Concordia, INTA. $48 \mathrm{p}$.

- VÁZQUEZ, M.E. 2007. Calcio y Magnesio del suelo. Encalado y enyesado. Fertilidad de suelos y fertilización de cultivos.Cap. 8: 161-185. En: Echeverría, H., García F. (eds.). Encalado y enyesado. Fertilidad de suelos y fertilización de cultivos INTA. , 1을 Edición, 1을 Reimpresión. 525 p.

- VÁzQUEZ, M.E. 2010. Calcio y Magnesio, su dinámica. Diagnóstico y requerimientos de fertilización. Cap. 4: 371-394. En: RUBIO G., ÁLVAREZ R., ÁLVAREZ C., LAVADO , R. (eds). Fertilidad del suelo. Diagnóstico y manejo en la Región Pampeana. Ed. FAUBA. Buenos Aires. 423 p.

- VON CAEMMERER, S. BAKER, N. 2007. The Biology of Transpiration. From Guard Cells to Globe. Plant Physiology 143(1): 3.

- WALKER, G., GILFEDDER, M., WILLIAMS, J. 1999. Effectiveness of current farming systems in the control of dryland salinity. CSIRO Land and water. Australia. $16 \mathrm{p}$.

- WARING, R.H., RUNNING, S.W. 1998. Forest ecosystems. Analysis at multiple scales. Academic Press. USA. $370 \mathrm{p}$.

- WARING, R.H., SCHLESINGER, W.H. 1985. Forest ecosystems. Concepts and management. Academic Press Inc. USA. 340 p.

- WILLIAMS, J.E., WOINARSKI, J.C.Z. 1997. Eucalypt ecology. Individuals to ecosystems. Cambridge University Press. Gran Bretaña.

- ZHANG, L., DAWES, W.R., WALKER, G.R. 2001. Response of mean annual evapotranspiration to vegetation changes at catchment scale. Water Resources Research, 37: 701-708.

- ZINKE, P.S. 1967. Forest interception studies in the United Status. In: Internacional Symposium on Hydrology, 137 - 162. En: Sopper, W.E., Lull, H. W. (Eds), Forest Hidrology. Pergamon Press, Gran Bretaña.

Ing. Agr. Natalia Tesón

Tesista
Dr. Jorge L. Frangi

Director
Dr. Mario Hernández

Co Direct 
Ing. Agr. Natalia Tesón 